\title{
WestVirginiaUniversity
}

THE RESEARCH REPOSITORY @ WVU

Graduate Theses, Dissertations, and Problem Reports

2005

\section{Risk and resilience in youth: An examination of moderating factors}

Beverly L. Fortson

West Virginia University

Follow this and additional works at: https://researchrepository.wvu.edu/etd

\section{Recommended Citation}

Fortson, Beverly L., "Risk and resilience in youth: An examination of moderating factors" (2005). Graduate Theses, Dissertations, and Problem Reports. 2312.

https://researchrepository.wvu.edu/etd/2312

This Dissertation is protected by copyright and/or related rights. It has been brought to you by the The Research Repository @ WVU with permission from the rights-holder(s). You are free to use this Dissertation in any way that is permitted by the copyright and related rights legislation that applies to your use. For other uses you must obtain permission from the rights-holder(s) directly, unless additional rights are indicated by a Creative Commons license in the record and/ or on the work itself. This Dissertation has been accepted for inclusion in WVU Graduate Theses, Dissertations, and Problem Reports collection by an authorized administrator of The Research Repository @ WVU.

For more information, please contact researchrepository@mail.wvu.edu. 
Risk and Resilience in Youth: An Examination of Moderating Factors

Beverly L. Fortson, M.A.

\begin{abstract}
Dissertation submitted to the Eberly College of Arts and Sciences

at West Virginia University in partial fulfillment of the requirements

for the degree of
\end{abstract}
Doctor of Philosophy
in
Psychology

\author{
Tracy L. Morris, Ph.D., Chair \\ Karen G. Anderson, Ph.D. \\ Martin L. Boone, Ph.D. \\ Katherine H. Karraker, Ph.D. \\ Cheryl B. McNeil, Ph.D. \\ Department of Psychology
}
Morgantown, West Virginia 2005

Keywords: child maltreatment, resilience, moderator 


\begin{abstract}
Risk and Resilience in Youth: An Examination of Moderating Factors
\end{abstract}

Beverly L. Fortson

Child maltreatment (i.e., emotional abuse, physical abuse, sexual abuse, emotional neglect, physical neglect) poses a significant risk for psychological difficulties to millions of children annually. Some children develop posttraumatic stress disorder (PTSD) or other anxiety disorders (e.g., generalized anxiety disorder, panic disorder, social anxiety disorder), depressive disorders (e.g., major depressive disorder), and substance abuse/dependence as a result of maltreatment. Fortunately, many other children, who have been termed "resilient," escape such incidents relatively unscathed. This study explored the unique associations between child maltreatment and several outcome variables (e.g., substance use, sexualized behavior, depression, generalized anxiety, and social anxiety) as well as the role in which factors purported to promote resiliency (i.e., level of social support, parentification, attachment style, and locus of control) moderate the relation between child maltreatment and outcome. A large sample of undergraduate students $(N=$ 502) were used in examining these relations. Results from data analyses suggested that the subtypes of maltreatment were not, in all cases, significant predictors of each of the different outcomes. Likewise, the resiliency factors examined in the current study did not consistently emerge as moderators of the maltreatment-outcome relation. Implications of these findings and future directions for research are discussed. 


\section{Acknowledgements}

I would like to extend my greatest appreciation to my committee chair, Dr. Tracy Morris, for "coming to the rescue" and providing the support and encouragement necessary to complete this project. I also would like to thank my other committee members, Drs. Karen Anderson, Martin Boone, Katherine Karraker, and Cheryl McNeil, who each contributed valuable time, support, and thoughtful comments to ensure a scholarly outcome. Of course, this project would not have been possible without the help of Lisa Ware and Jennifer Tiano, with whom I worked for the last four years in envisioning and executing the project. I am indebted to the two of you for agreeing to allow me to use this for my dissertation project. Other graduate and undergraduate students devoted valuable time and assistance in collecting and entering data. A special thanks is extended to Kelly Bailey, Yi-Chuen Chen, Jennifer Chrystan, Lisa Greene, and Michelle Mantooth for the time they devoted to this project. This project was funded, in part, by the Department of Psychology Alumni Fund at West Virginia University, which is gratefully acknowledged. Finally, I would like thank my advisor, Dr. Joseph Scotti, for four years of guidance and encouragement—-I wish you the best, and I look forward to collaborating with you in the future. 


\section{Table of Contents}

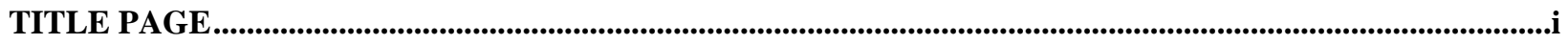

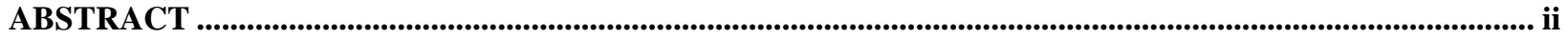

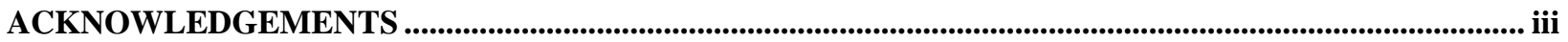

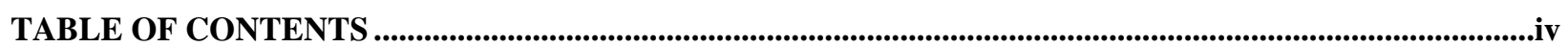

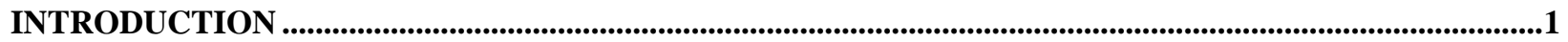

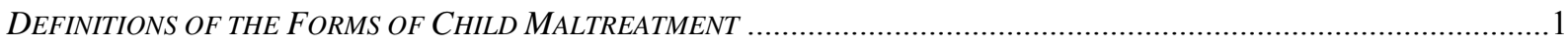

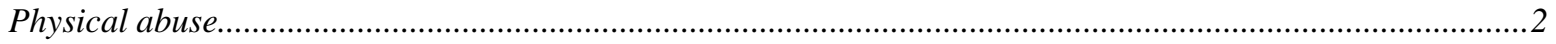

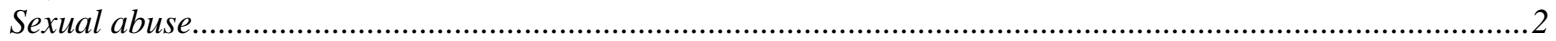

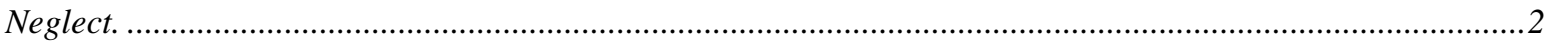

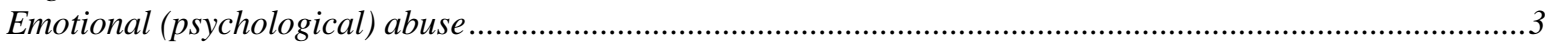

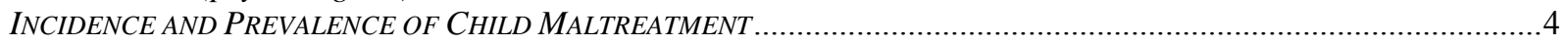

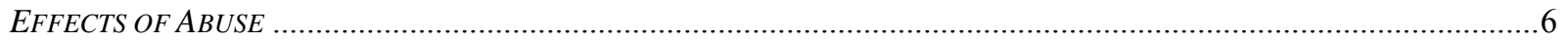

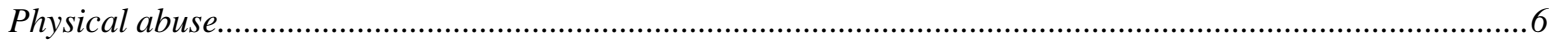

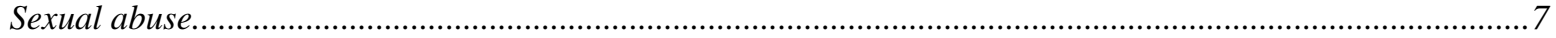

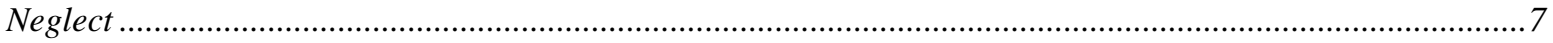

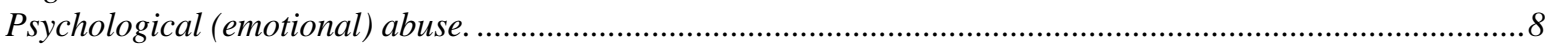

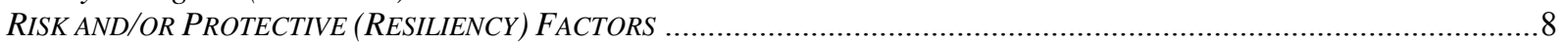

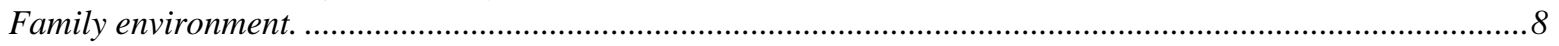

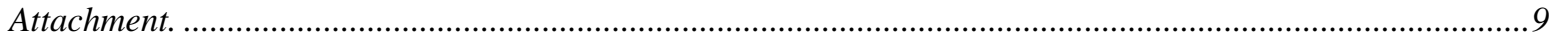

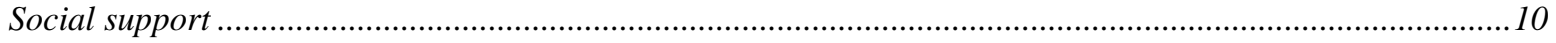

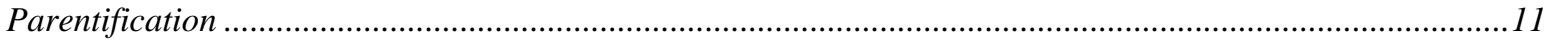

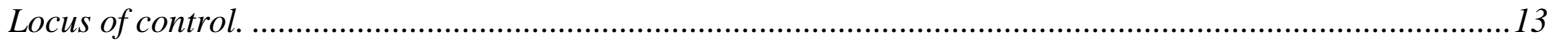

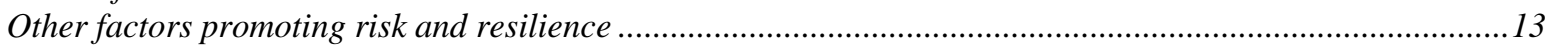

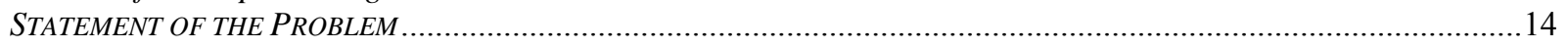

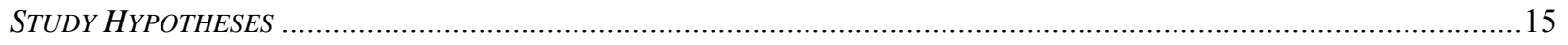

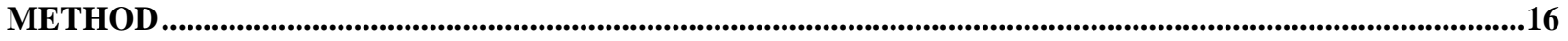

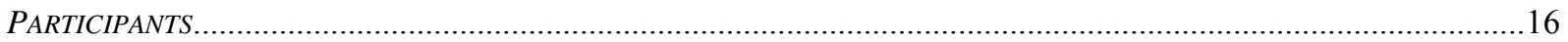

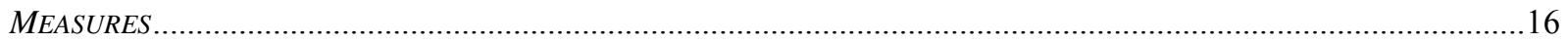

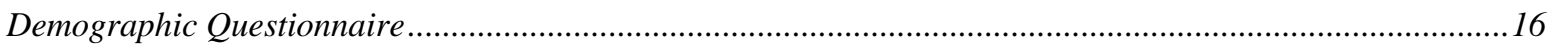

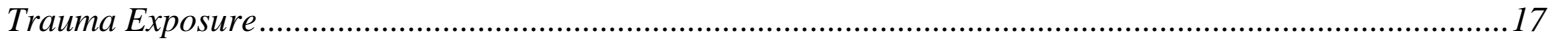

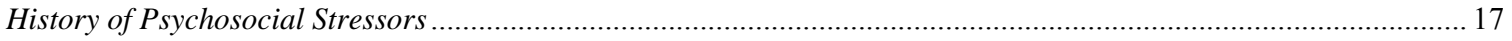

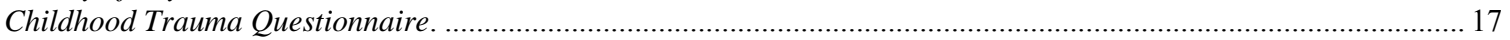

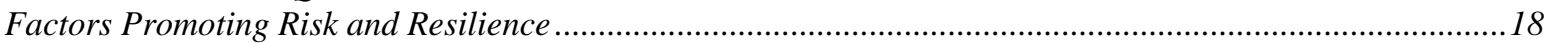

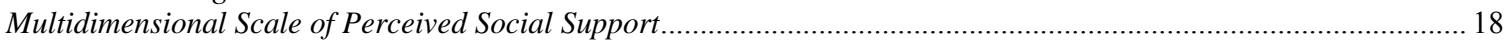

Perceived Social Support - Friend Scale and Family Scale ............................................................................... 19

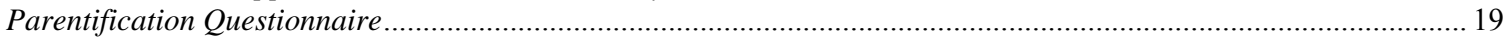

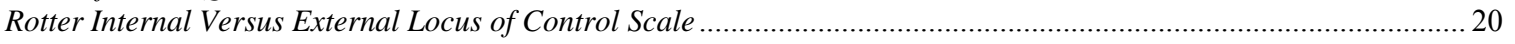

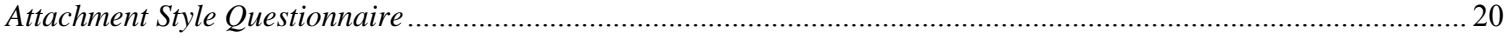

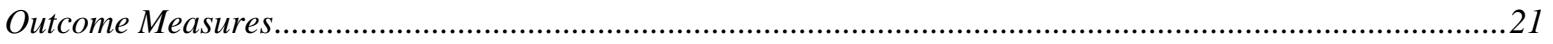

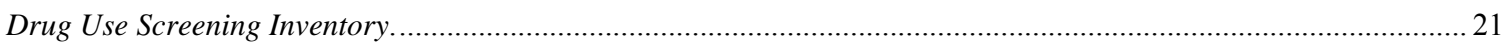

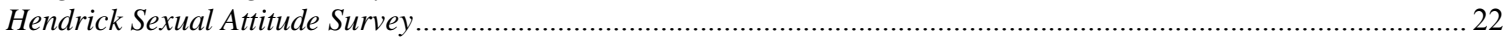

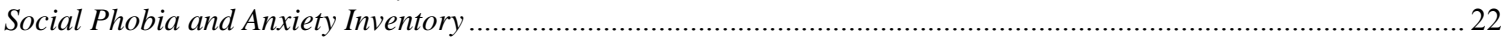

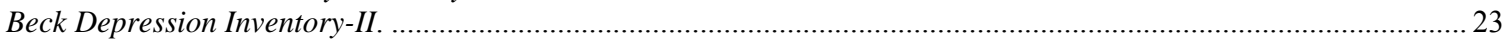

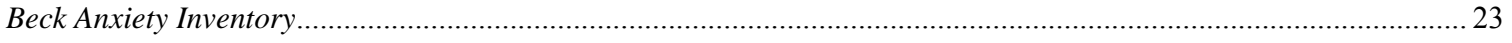

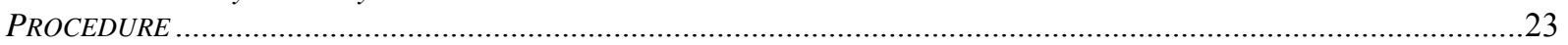

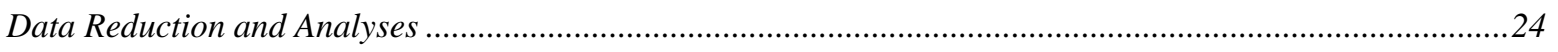

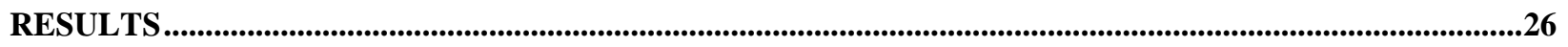

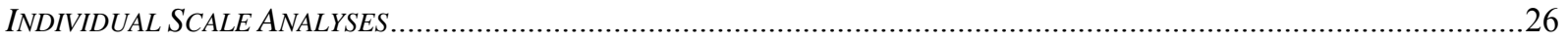

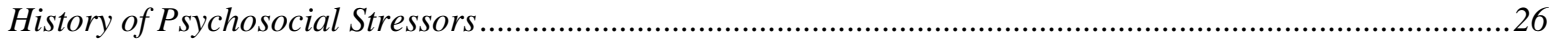




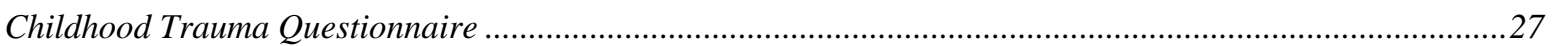

Multidimensional Scale of Perceived Social Support. .....................................................................................27

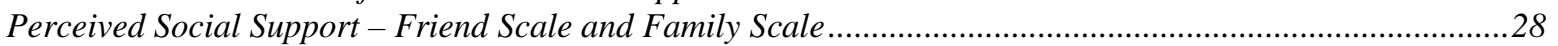

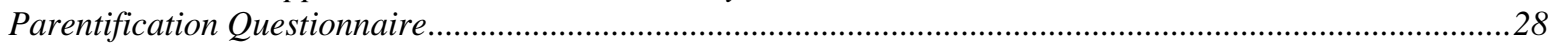

Rotter Internal Versus External Locus of Control Scale ................................................................................29

Attachment Style Questionnaire ................................................................................................................29

Drug Use Screening Inventory …………..........................................................................................29

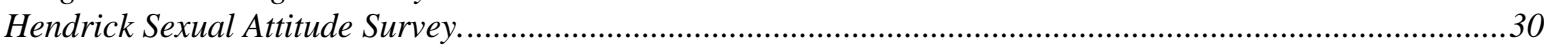

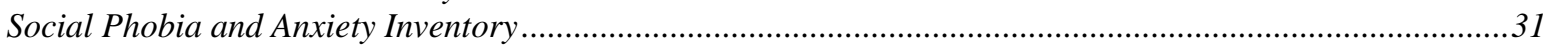

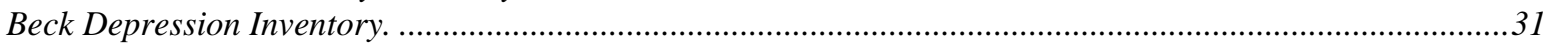

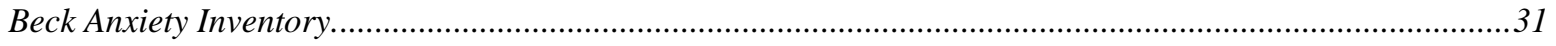

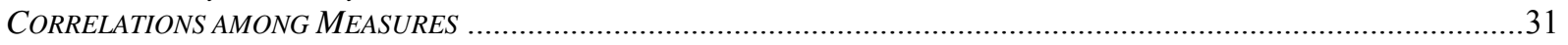

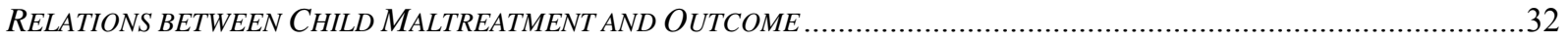

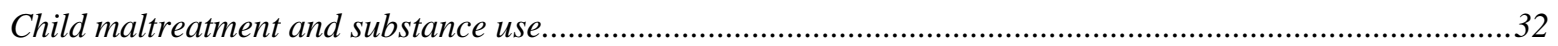

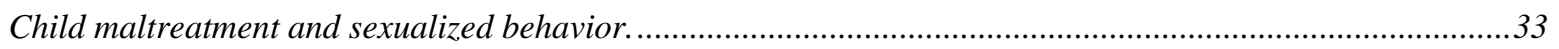

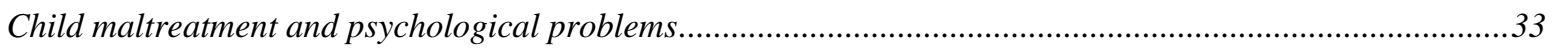

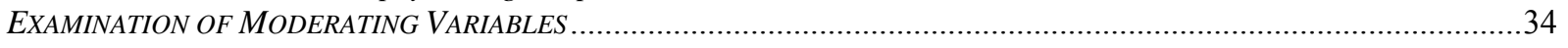

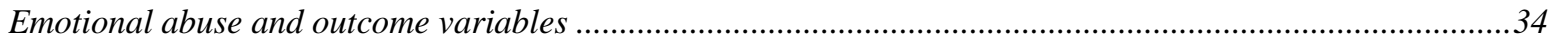

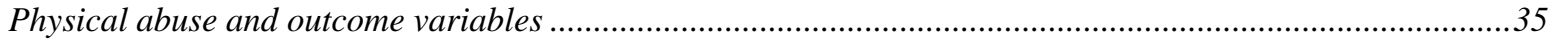

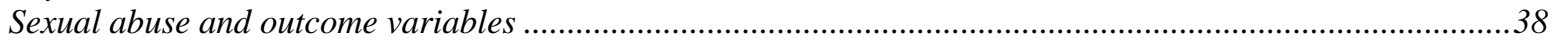

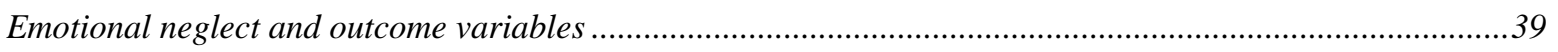

Physical neglect and outcome variables .............................................................................................

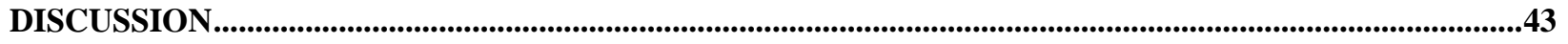

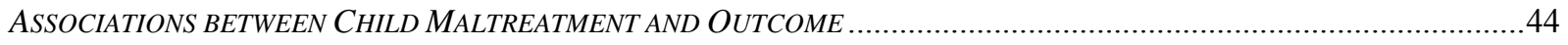

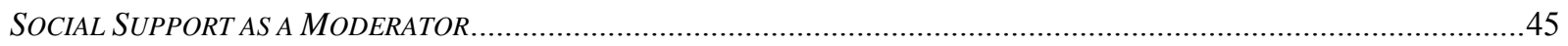

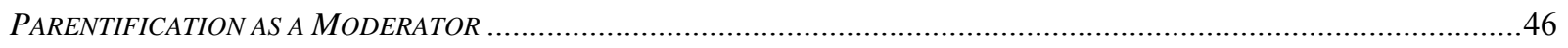

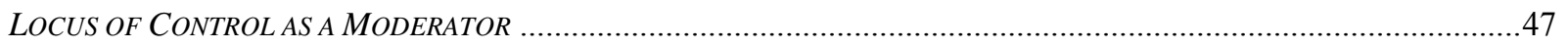

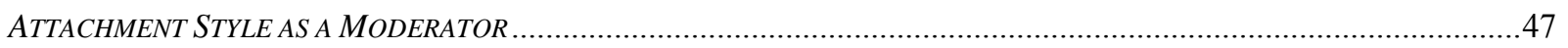

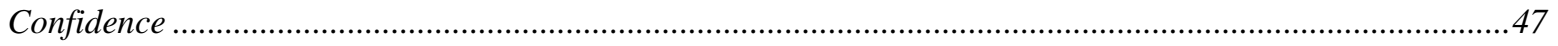

Need for approval. ...............................................................................................................................

Discomfort with closeness...................................................................................................................

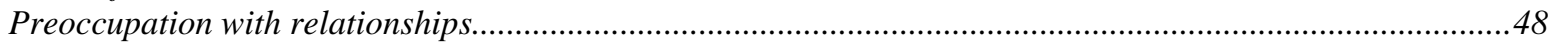

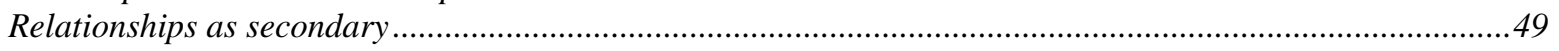

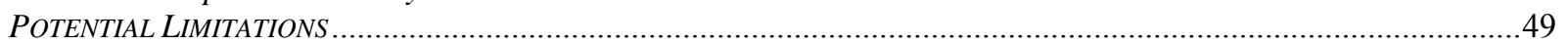

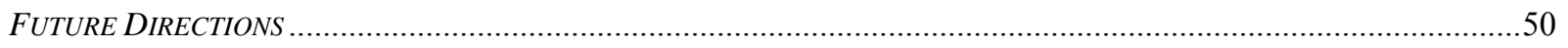

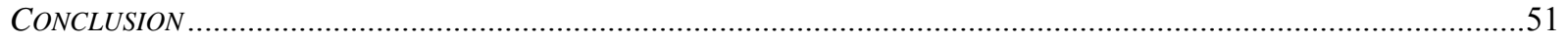

REFERENCES .....................................................................................................................................................52 
Risk and Resilience in Youth: An Examination of Moderating Factors

Research on the impact of child abuse and neglect has proliferated in recent years (e.g., Beitchman et al., 1992; Boney-McCoy \& Finkelhor, 1995; Kendall-Tackett, Williams, \& Finkelhor, 1993). The negative consequences of the various types of victimization have been documented extensively (see reviews by Arellano, 1996; Browne \& Finkelhor, 1986; MalinoskyRummell \& Hansen, 1993; Read, 1997) whereas other research has suggested that some children experience little or no symptomatology (Cicchetti, Rogosch, Lynch \& Holt, 1993; Conte \& Schuerman, 1987; Kaufman \& Zigler, 1987; Kruttschnitt, Ward, \& Sheble, 1987; McCord, 1983; Sirles, Smith, \& Kusama, 1989; Tong, Oates, \& McDowell, 1987; Widom, 1994). The children who experience good outcomes despite high risk and stressful circumstances have been termed “resilient” (Fraser, Richman, \& Galinski, 1999; Masten, 1994; Masten, Best, \& Garmezy, 1990). This paper will review several factors that have been purported to promote risk and resilience and provide data from an investigation in which the relations among five types of child maltreatment (i.e., emotional abuse, physical abuse, sexual abuse, emotional neglect, physical neglect) and a variety of risk and protective factors (i.e., level of social support, parentification, attachment style, and locus of control) were investigated. The paper will begin with a brief description of each of the types of maltreatment and the associated negative effects.

\section{Definitions of the Forms of Child Maltreatment}

The definitions of the various forms of child maltreatment typically vary depending on whether the definition is for legal or research purposes. In addition, the definitions differ among jurisdictions and researchers. The definitions provided herein are those from the Third National Incidence Study of Child Abuse and Neglect (NIS-3; Sedlak \& Broadhurst, 1996), which is a congressionally mandated report and one of the most comprehensive sources of information on 
the incidence of child abuse and neglect in the United States. Two sets of definitional standards were used in the NIS-3 in identifying cases of abuse and neglect: the Harm Standard and the Endangerment Standard. The Harm Standard required that an act of commission or omission result in demonstrable harm whereas the Endangerment Standard allowed children who were not yet harmed by maltreatment to be counted in the abused and neglected estimates if they were considered to be endangered by maltreatment or if their maltreatment was substantiated or indicated in a Child Protective Services (CPS) investigation (Sedlak \& Broadhurst).

Physical abuse. According to the NIS-3 (Sedlak \& Broadhurst, 1996), physical abuse is present when a child (i.e., an individual younger than 18 years of age) has been injured (harm standard) or is at risk of being injured (endangerment standard) by a parent or parent surrogate. Acts that constitute physical abuse include hitting with a hand or other object, kicking, shaking, throwing, burning, stabbing, or choking a child.

Sexual abuse. Sexual abuse has been defined as any sexual activity where consent is not or cannot be given (Finkelhor, 1979). The NIS-3 (Sedlak \& Broadhurst, 1996), on the other hand, divides sexual abuse into three forms: intrusion, molestation with genital contact, and other or unknown sexual abuse. The intrusion form of sexual abuse is described as a sexual act in which there is evidence of oral, anal, or genital penile penetration or anal or genital digital or other penetration. Molestation with genital contact was described as an act in which there was some form of actual genital contact with no specific indication of intrusion. Unspecified acts not known to have involved actual genital contact (e.g., fondling of breasts or buttocks and exposure) were classified as "other or unknown sexual abuse."

Neglect. Neglect is typically defined as an act of omission rather than commission. Thus, neglect occurs when there is a "deficiency in appropriate parenting behavior, rather than when an 
inappropriate parenting behavior occurs" (Schumacher, Slep, \& Heyman, 2001, p. 232). The NIS-3 (Sedlak \& Broadhurst, 1996) divided neglect into several categories: physical neglect, educational neglect, and emotional neglect. The category of physical neglect is subdivided into seven specific varieties, including refusal of health care, delay in health care, abandonment, expulsion (i.e., permanent or indefinite expulsion of the child from home without adequate arrangement for care by others), other custody issues (e.g., repeated shuffling of a child from one household to another due to apparent unwillingness to maintain custody), inadequate supervision, and other physical neglect (e.g., inadequate nutrition, clothing, or hygiene, reckless disregard of the child's safety and welfare). Educational neglect is divided into three specific forms: permitted chronic truancy, failure to enroll/other truancy, and inattention to special education need. Emotional neglect has seven forms: inadequate nurturance/affection, chronic/extreme spouse abuse in the child's presence, permitted drug/alcohol abuse, permitted other maladaptive behavior (e.g., delinquency), refusal of psychological care, delay in psychological care, and other emotional neglect (e.g., markedly overprotective restrictions that foster immaturity or emotional overdependence).

Emotional (psychological) abuse. Three forms of emotional abuse were identified in the NIS-3 (Sedlak \& Broadhurst, 1996): close confinement, verbal or emotional assault, and other or unknown abuse. The close confinement form of emotional abuse includes tying or binding or other forms of torturous restriction of movement. In this type of abuse, the child's arms or legs are tied together, the child is bound to a bed, chair, or other object, or the child is confined to an enclosed area (such as a closet) as a means of punishment. Verbal or emotional assault occurs when there is a habitual pattern of belittling, denigrating, scapegoating, or other nonphysical forms of overtly hostile or rejecting treatment as well as threat of other forms of maltreatment. 
The final form of emotional abuse, other or unknown abuse, includes other overtly punitive, exploitative, or abusive treatment other than those specified under other forms of abuse, or unspecified abusive treatment.

\section{Incidence and Prevalence of Child Maltreatment}

As noted earlier, defining the different types of maltreatment is an arduous task, which, in turn, makes estimating the incidence and prevalence of child maltreatment even more difficult. In 2002, approximately 2.6 million referrals were made to Child Protective Services (CPS) agencies throughout the United States for suspicions of child abuse and neglect (U. S. Department of Health \& Human Services, DHHS, 2004). Many of these referrals were not investigated; however, of those that were investigated (i.e., two-thirds), an estimated 896,000 children were determined to be victims of child abuse or neglect ( $20 \%$ were physically abused, $10 \%$ sexually abused, $60 \%$ neglected, $7 \%$ psychologically maltreated, and an additional $20 \%$ were victims of "other" types of maltreatment). Thus, the rate of victimization in the national population is 12.3 per 1,000 children (DHHS).

In contrast to official estimates, national prevalence studies, which are based on selfreport perpetration and victimization surveys, capture a sample of the general population and may detect abuse that was never reported to an official agency. Prevalence studies of sexual abuse suggest that at least $20 \%$ to $25 \%$ of women and from $5 \%$ to $15 \%$ of men have experienced some form of sexual abuse (i.e., non-contact and contact sexual abuse; Finkelhor, 1994). Straus, Hamby, Finkelhor, Moore, and Runyan (1998) found that nearly three fourths of parents reported some method of physical assault during the rearing of their children. Of note, however, is the fact that the majority of these physical assaults were in the "minor assault category" (i.e., corporal punishment), but nearly half of all parents engaged in behaviors from the severe physical assault 
subscale (e.g., hitting the child with an object such as a stick or belt, slapping the child on the face, hitting the child with a fist) at some point during their parenting. Rates of physical abuse were slightly different among psychiatric patients: Bryer, Nelson, Miller, and Krol (1987) found that $15 \%$ of the sample was physically abused before the age of 16 . Similarly, Read (1998) found that $12 \%$ of participants were physically abused as children. One potential reason for the difference in these estimates is that the former are reports from parents (i.e., perpetrators) whereas the latter estimates are based on reports from potential victims. Self-report surveys, by nature, also have their own problems: memory lapses may occur because of the retrospective reports and the respondents might not be truthful (Miller-Perrin \& Perrin, 1999).

According to official estimates, psychological maltreatment is the least often occurring form of maltreatment; however, self-report surveys suggest otherwise. In a survey conducted by Binggeli, Hart, and Brassard (2001), it was estimated that approximately one-third of the U. S. adult population has been psychologically maltreated. The rates of psychological maltreatment, as reported by official estimates, appear to be much lower. This likely occurs because psychological abuse is much more difficult to substantiate than the other forms of abuse as there are not usually any physical signs that the abuse has occurred. Self-report rates of neglect, on the other hand, are much lower than the rates found in official estimates. Twenty-seven percent of parents in a survey conducted by Straus et al. (1998) reported that they had engaged in some form of neglect at least once in the past year. These estimates do not take into account the number of children in each of these homes, and the survey was a self-report perpetration survey of neglectful behavior that had occurred in the past year. Research on neglect also has been sparse, which makes it difficult to gauge the prevalence in the general population. Given that neglect is substantiated more often than the other types of abuse, we would expect the prevalence 
to be much higher. In considering neglect, one also has to consider the ages of the children who most often are victims - many of the children are young, and they may not remember the neglectful behaviors that occurred when they were younger (although for many families, the problem persists over time).

Effects of Abuse

The negative consequences associated with child maltreatment affect some individuals well into adulthood. Individuals maltreated as children may exhibit posttraumatic stress disorder (PTSD) or other anxiety disorders (e.g., generalized anxiety disorder, panic disorder, social anxiety disorder), depressive disorders (e.g., major depressive disorder), and substance abuse/dependence (Kilpatrick et al., 2000; Kilpatrick et al., 2003; Merry \& Andrews, 1994; Perrin, Smith, \& Yule, 2000; Sack et al., 1993; Vernberg \& Varela, 2001). Research also has shown increased aggression, increased attention problems, and decreased academic or vocational performance among individuals exposed to traumatic events such as abuse and neglect (Kelley, Thornberry, \& Smith, 1997; McLeer, Callaghan, Henry, \& Wallen, 1994, McLeer \& Ruggiero, 2000; Rust \& Troupe, 1991; Stern, Lynch, Oates, O’Toole, \& Cooney, 1995). Negative selfperceptions (e.g., guilt and self-blame) and an impoverished sense of self (e.g., attachment difficulties and boundary confusion) have been documented among those maltreated as children (Briere, 1992). In a long-term study of young adults who had been abused, as many as $80 \%$ met diagnostic criteria for at least one psychiatric disorder (e.g., depression, anxiety, eating disorders) at age 21 (Silverman, Reinherz, \& Giaconia, 1996). The next section provides more detailed information on some of the long-term effects associated with each of the different types of maltreatment.

Physical abuse. Many of the psychological and social difficulties that emerge in 
childhood as a result of physical abuse persist into adulthood. For example, physically abused children often develop aggressive tendencies which may turn into criminal and violent behaviors as the child develops into adulthood. Widom and Maxfield (2001) found that being abused or neglected increased the likelihood of adult criminal behavior by $28 \%$ and violent crime by $30 \%$. Substance use, including alcohol and other substances, also is a common long-term effect associated with physical abuse (Malinosky-Rummell \& Hansen, 1993; National Institute on Drug Abuse, 2000).

Sexual abuse. A history of sexual abuse has been found to be associated with earlier engagement in sexual activity and more sexual partners (Perkins, Luster, Villarruel, \& Small, 1998; Wyatt, 1988). Other consequences of sexual abuse include depression and anxiety (Elliott \& Briere, 1992; Peters \& Range, 1995; Swett, Surrey, \& Cohen, 1990). A review of the literature found that depression is the most common symptom reported by adults sexually abused as children (Browne \& Finkelhor, 1986). Problems in interpersonal relationships as well as PTSD symptomatology also are long-term effects found in individuals sexually abused as children (Boyd, Guthrie, Pohl, Whitmarsh, \& Henderson, 1994; Thompson et al., 2003).

Neglect. Recent literature has suggested that the consequences of neglect may be more far-reaching than the effects of the other forms of maltreatment (Azar, Povilaitis, Lauretti, \& Pouquette, 1998). Important regions of the brain may fail to form properly as a result of neglect and, in turn, lead to impaired physical, mental, and emotional development (Perry, 2002; Shore, 1997). The intellectual functioning of individuals neglected as children may be impaired (Hoffman-Plotkin \& Twentyman, 1984; Wodarski, Kurtz, Gaudin, \& Howing, 1990). In addition, neglected children may have impaired attachment as infants (i.e., anxiously attached) and poorer social and emotional functioning from childhood into adulthood (Erickson \& 
Egeland, 1996; Youngblade \& Belsky, 1990).

Psychological (emotional) abuse. Newton (2001) noted that emotional abuse is at the core of all forms of abuse, and many of the long-term effects of child abuse and neglect stem largely from the emotional aspects of the abuse. Thus, as with the other types of maltreatment, emotional abuse may lead to psychological difficulties (e.g., anxiety, depression, interpersonal sensitivity, low self-esteem, and dissociation) later in life (Downs \& Miller, 1998; Hoglund \& Nicholas, 1995; Kent \& Waller, 1998).

\section{Risk and/or Protective (Resiliency) Factors}

As noted earlier, research and clinical evidence have demonstrated that not all children who are exposed to abuse and neglect develop negative consequences. Research has suggested that between one-quarter and one-third of individuals maltreated as children will not develop problems (Finkelhor, 1990; Lynskey \& Fergusson, 1997). Individual characteristics and environmental factors play a large role in whether one will experience negative consequences (McNally, 1999); however, the results are mixed as to specifically which variables serve as risk factors and which serve as protective factors. The next section provides a description of several factors that may promote risk and/or resilience in maltreated children.

Family environment. Family environment is typically characterized by parental/family and environmental factors that may have an effect on the maltreated child. Stress and poverty are two factors that researchers suggest may put one at risk for maltreatment (Cicchetti \& Toth, 1995, Crittenden \& Ainsworth, 1989; Schwab-Stone et al., 1995; Schumacher et al., 2001; Whipple \& Webster-Stratton, 1991) and for negative outcomes related to maltreatment (Conroy \& Brown, 2004; Shields \& Cicchetti, 1998). In a sample of 123 mostly low-income abusive families, abusive mothers reported more stress due to frequent life events (Whipple \& Webster- 
Stratton). Sidebotham et al. (2000) suggested that the significant risk factors for maltreatment (by the mother or father) include young parental age (i.e., younger than 20 years of age), lower educational achievement, history of psychiatric illness, maternal history of sexual abuse, paternal absence (especially during childhood), and paternal legal problems. Brown, Cohen, Johnson, and Salzinger (1998) delineated different patterns of risk factors for physical and sexual abuse. Risk factors for physical abuse included early separation from mother, maternal dissatisfaction, maternal external locus of control, poor marital quality, serious maternal illness, low maternal and paternal involvement, and low parental warmth, while the risk factors for sexual abuse included harsh punishment, negative life events, presence of a stepfather, and unwanted pregnancy.

Stress and poverty also can be risk factors for negative outcomes related to child maltreatment. Shields and Cicchetti (1998) found that an inner-city sample of maltreated children were more likely to be aggressive, exhibit attention deficits, and demonstrate difficulty regulating their emotions than non-maltreated children from the same type of environment. Likewise, Bagley and Mallick (2000) found that maltreated adolescents had poorer outcomes when their families were characterized by poverty and disorganization than when their families were not characterized by such variables.

Attachment. According to Bowlby $(1969 / 1982,1972,1980)$, attachments are formed as a result of one's interactions with others. Research has demonstrated consistency in attachment styles throughout life (Waters, Posada, Crowell, \& Lay, 1993); however, meta-analyses of attachment style stability from childhood to adulthood and within adulthood show that change is possible (Fraley \& Brumbaugh, 2004). This is important given that research has documented a relation between certain attachment styles and adult psychopathology (e.g., depression; Cole- 
Dekte \& Kobak, 1996; Eng, Heimberg, Hart, Schneier, \& Liebowitz, 2001; Fonagy et al., 1996; Murphy \& Bates, 1997; Reinecke \& Rogers, 2001, Roberts, Gotlib, \& Kassel, 1996; Strodl \& Noller, 2003). One of the many factors that appear to exert a direct impact on children's attachment style and subsequent relationship skills is child maltreatment (Morrison, Frank, Holland, \& Kates, 1999; Wekerle \& Wolfe, 1996). Alexander (1992) speculated that sexual abuse involves the intergenerational transmission of an insecure attachment. In a study of 90 mother-infant dyads, child maltreatment was associated with disorganized patterns of attachment (Vondra, Hommerding, \& Shaw, 1999). Thus, abuse and neglect may affect the child's cognitive, emotional, and social development such that a disorganized or insecure attachment results, which, in turn, may exacerbate the effect of other negative experiences and thereby yield poorer outcomes.

Social support. Research has demonstrated that the negative consequences resulting from exposure to traumatic events such as abuse and neglect may be buffered if one has a supportive environment (Rabalais, Ruggiero, \& Scotti, 2002). Thus, a good relationship with at least one parental figure can protect against the risk associated with family discord (Blum, Beuhring, \& Rinehart, 2000; Perkins \& Jones, 2004; Rutter, 1979). On the other hand, a lack of perceived social support from family members has been linked to negative consequences (Litty, Kolwaski, \& Minor, 1996). Other research also has suggested that social support serves as a possible moderator of the relation between abuse and outcome (e.g., Everill \& Waller, 1994; Nagel, Putnam, Noll, \& Trickett, 1997). The supportive adult who serves to buffer the relation between abuse and outcome does not necessarily have to be a parent; research suggests that a supportive adult outside the family also can serve to help the abused individual feel a sense of coherence and optimism (Hawley \& DeHaan, 1996; Perkins \& Jones; Werner \& Smith, 1992). 
Parentification. Parentification refers to children's caretaking activities in familial settings (Jurkovic, 1997). According to Jurkovic, four major prototypes of children's caretaking activities are identifiable: destructive parentification, adaptive parentification, nonparentification, and infantilization. These caretaking activities fall along a continuum and at one end is destructive parentification in which the child essentially plays the role of the parent while infantilization, which is at the other end of the continuum, occurs when children are expected to engage in minimal, if any, caretaking. These children's parents excessively meet their needs and they, like the destructively parentified child, experience boundary violations.

Destructive parentification occurs when children assume responsibilities that are excessive and developmentally inappropriate. In addition, the role represents a major source of identity for the child. Appropriate personal and family boundaries are violated and the child is exploited by parental figures. For example, the child may take a job to help support his/her family. The child also may act as a co-parent and/or spouse and provide physical and/or emotional support to help one's parents feel better (e.g., a male child may hold his mother whenever she needs physical contact). The child also may worry whether his parents and siblings can make it without him/her. The child's contributions to the family (e.g., cooking, cleaning) often go unnoticed by the parents. Jurkovic identified several parameters of parentification including: (a) overtness; (b) type of role assignments; (c) extent of responsibility; (d) object of caretaking; (e) age appropriateness; (f) internalization; (g) family boundaries; (h) social legitimacy; and (i) ethicality.

Adaptive parentification occurs when children engage in caretaking activities that are excessive; however, the child is not captivated by his/her role, and he/she receives support and fair treatment from one's family and cultural community. This type of parentification may occur 
in large families, in single-parent households, after a parental illness, and in poverty stricken families. An older child may be expected to care for his/her siblings and to cook and clean but he/she also receives support from the family and is not expected to be in the caretaking role all the time. Non-parentification occurs when the child is expected to engage in a moderate level of caretaking relative to one's culture and developmental stage. The child's efforts are acknowledged, reciprocated, and supervised. For example, the child may babysit siblings on an occasional basis or be expected to clean part of the home. In many families, these activities are referred to as chores.

Research on parentification has suggested that whether parentification serves as a risk or protective factor depends on a number of factors, including the overtness of the parentification, the type of parentification, the extent of the parentification, and the object of parentified behaviors expected of the child (Jurkovic, 1997). Also important is the developmental, psychological, sociofamilial, and ethical context in which the parentified behaviors are embedded (Jurkovic). When the child's parental responsibilities are appropriate and fair (and sometimes even when they are not), the child's development may be facilitated. For example, the child may learn important social skills related to responsibility, independence, empathy, nurturance, and fair give-and-take in relationships (Jurkovic).

As with many of the other risk and protective factors described here, parentification also can serve as a risk factor for maltreatment and negative outcomes. For example, children who are pathologically parentified may be at risk of experiencing a variety of emotional, cognitive, and sociofamilial difficulties including loss of childhood, parents, and trust, anger and resentment, stress, guilt and shame, peer problems, school difficulties, disruption in identity development, conflicts about leaving home, occupational concerns, and personality dysfunction (Jurkovic). 
These children also may be at risk for physical and sexual abuse, especially given that many parent-child boundaries are lacking or are blurred.

Locus of control. Locus of control refers to whether an individual believes that events result primarily from one's own behavior. Individuals with an internal locus of control believe that events are the result of their actions whereas those with an external locus of control believe that powerful others, fate, and/or chance primarily determine events. Those with an internal locus of control typically have better control of their behavior and are more likely to assume that their efforts will be successful. They also are more active in seeking information and knowledge concerning their situation than are externals (Rotter, 1966). Bolger and Patterson (2001) found that children maltreated early in life were less likely to perceive internal control, which appeared to protect against the later development of internalizing problems. Specifically, neglected children reported higher levels of perceived external control while sexually abused children had higher levels of perceived external control but only among children who also had been neglected. Thus, if a child has an internal locus of control, resilience may be promoted as the child may believe that he or she has control over whether abuse recurs and/or what type of outcome will result from the abuse. On the other hand,

Other factors promoting risk and resilience. Research has demonstrated that there are numerous other factors that may serve to promote resilience in maltreated children. Several researchers have found that religiosity provides an individual with a sense of purpose and may moderate the relation between abuse and outcome (Hawkins, Jenson, Catalano, \& Lishner, 1988; Hawley \& DeHaan, 1996; Luthar \& Zigler, 1991; Perkins \& Jones, 2004; Perkins, Luster, \& Jank, 2002). Involvement in extracurricular activities also has been found to serve as a protective factor for individuals maltreated as children (Eccles \& Gootman, 2002; Perkins \& Jones, 2004). 
Researchers have suggested that the victim's subjective perception of the event plays a large role in determining outcome (Miller-Perrin \& Perrin, 1999). Other factors that may serve to promote resilience include a positive temperament and easygoing disposition, good intellectual ability, high self-efficacy, self-confidence, and self-esteem, and an achievement orientation with high expectations (Doll \& Lyon, 1998; Seifer, Sameroff, Baldwin, \& Baldwin, 1992). Seifer et al. found that by age 13, high risk children who were socially and cognitively competent were distinguished by their higher self-esteem, more internal locus of control, effective parental teaching, limited parental criticism, and low rates of maternal depression.

\section{Statement of the Problem}

Many children who experience abuse and neglect develop negative consequences and psychological problems (e.g., behavior problems, depression, anxiety disorders); however, a large number also overcome adversity and go on to become competent and productive adults. Rutter (1985) noted that "even with the most severe stressors and the most glaring adversities, it is unusual for more than half of children to succumb” (p. 598). The children who successfully cope or develop competence despite such great risk have been termed "resilient.” Unfortunately, the specific mechanisms and processes through which resilience occurs are not fully understood, especially in abused and neglected populations.

In a review of the resilience literature, Masten and Coatsworth (1998) identified individual (e.g., good intellectual functioning, positive temperament or easygoing disposition), family (e.g., supportive parent figure and family networks, authoritative parenting), and extrafamilial (e.g., involvement in extracurricular activities, supportive adults outside the family) factors that play a role in promoting resilience. As noted by the authors, these factors also are associated with competence in "normal" development. Thus, of particular concern is how these 
factors protect some children or counteract threats to development whereas this does not happen in other children. Recent research on resilience has shifted and the goal is not to continue with the compilation of lists of discrete attributes of the individual; instead, research is aimed at investigating the interconnectedness of contexts, characteristics, and processes that lead to overcoming adversity (Masten, 1994; Rutter, 1985, 1987). The literature, however, is far from reaching the point where the specific mechanisms and processes through which resilience occurs are understood.

\section{Study Hypotheses}

The purpose of this study was to investigate the relations among five types of child maltreatment and factors purported to promote resiliency (e.g., social support, parentification, locus of control, attachment) in an attempt to understand the mechanisms/ processes through which resilience may occur in a sample of undergraduate students. In addition, the unique associations between child maltreatment and several outcome variables (e.g., substance use, sexualized behavior, depression, generalized anxiety, social anxiety, and agoraphobia) were assessed. Based on prior research, the following hypotheses were proposed and tested:

1. Child maltreatment would be significantly associated with the measured outcomes (i.e., substance abuse, sexualized behavior, depression, general anxiety, social anxiety, and agoraphobia).

2. Social support, parentification, locus of control, and attachment would moderate the relation between child maltreatment and outcome. Specifically, it was hypothesized that higher levels of perceived social support from friends and family currently and in the past, moderate levels of parentification, internal locus of control, and secure attachment would moderate the relation between child maltreatment and outcome. 
In addition to testing these hypotheses, participants' scores on each of the measures were compared to established, published, and/or available norms for similar populations (e.g., college students, late adolescents, or young healthy adults), if they existed. It was hypothesized that the scores of participants in the current sample would be similar to the existing data for each of the measures.

\section{Method}

\section{Participants}

Five hundred and three undergraduate students (358 females, 143 males, 2 unknown gender) enrolled in psychology courses at West Virginia University participated in the data collection and received course extra credit for their participation. Participants ranged in age from 18 to 54 years $(M=19.9, S D=2.8)$, and most were Caucasian $(89.2 \%$; African American $=$ $4.2 \%$, Asian/Pacific Islander $=1.6 \%$; Hispanic $=1.0 \%$, and Other $=3.6 \%)$ and female $(71.1 \%$; male $=28.5 \%)$. In addition, most participants were freshmen $(36.7 \%)$ or sophomores $(29.7 \%$; juniors $=17.7 \%$; seniors $=15.1 \%)$, were single $(94 \%$; married $=2.8 \%$; cohabiting $=2.6 \%$; divorced $=.4 \%)$, did not have any children $(97.6 \% ; 2.2 \%=1$ or more children $)$, and were unemployed (53.4\%) or employed part-time (44\%). Only $2.2 \%$ of the sample was employed fulltime. Approximately half of the participants had mothers and fathers who had a college degree or who had taken some college courses. Table 1 provides the educational level of participants' mothers and fathers.

\section{Measures}

Demographic Questionnaire. Participants were asked to provide information on age, gender, race/ethnicity, current class standing (i.e., freshman, sophomore, junior, or senior), marital status, and employment status (i.e., unemployed, part-time, full time). Participants also 
were asked to indicate whether they had any children of their own and whether they were receiving financial support from their parents. Questions assessed parental marital status, educational level, and occupation. Participants indicated the number of siblings in their family of origin as well as their placement in the birth order (e.g., oldest, youngest, third born). The questionnaire ended with questions regarding participants' high school and college friends, spiritual beliefs, extracurricular group involvement, and the availability of a supportive person during childhood.

\section{Trauma Exposure}

History of Psychosocial Stressors (HPS; Scotti et al., 2000). The HPS was used as a measure of exposure to 15 different stressful life events (e.g., death of a loved one) and included ratings of whether the event happened personally and/or was witnessed by the participant. If participants had experienced the event (either directly or indirectly), they were asked to indicate when the exposure occurred (last month, one month to one year ago, or more than one year ago) and how much distress (none to extreme) the event had caused in the previous week. When developing the HPS, the 15 life stressors were selected because of their relation to trauma and their high rate of occurrence in college populations, as shown by prior research (Scotti et al.). Previous research with the HPS has shown that most college students have been exposed to at least one psychosocial stressor (Fortson, 2003; Scotti et al.). The HPS has demonstrated convergent validity with the Impact of Event Scale (IES; Horowitz, Wilner, \& Alvarez, 1979), $r$ $=.24, p<.001$. Reliability of the measure was supported by test-retest comparisons, with similar levels of HPS-endorsed events across administrations (Fortson).

Childhood Trauma Questionnaire (CTQ; Bernstein \& Fink, 1998). The CTQ is a selfreport retrospective measure of child abuse and neglect for individuals 12 years of age and older. 
The questionnaire is composed of 28 items that attempt to quantify five types of childhood trauma: physical abuse, emotional abuse, sexual abuse, physical neglect, and emotional neglect. A three-item minimization/denial scale also is included to detect false-negative trauma reports. Questions are answered on a 5-point Likert-type scale according to their frequency of occurrence. Response options are never true, rarely true, sometimes true, often true, and very often true. The measure has good internal consistency with alphas ranging from .66 (physical neglect subscale) to .92 (sexual abuse subscale). The measure also has demonstrated good testretest reliability over a 2 - to 6 -month interval (intraclass correlation $=0.86$ ), suggesting that patients' reports of child abuse and neglect based on the CTQ were highly stable over time. Guidelines have been established by the authors for classifying the different types of maltreatment (see Table 2).

Factors Promoting Risk and Resilience

Multidimensional Scale of Perceived Social Support (MSPSS; Zimet, Dahlem, Zimet, \& Farley, 1988). The MSPSS is a 12 -item self-report questionnaire designed to measure perceived social support from friends, family, and a significant other. The three subscales (i.e., friends, family, and significant other) reflect the perceived social support from each of these sources. Questions are answered on a 7-point Likert-type scale where $1=$ very strongly disagree, $2=$ strongly disagree, $3=$ mildly disagree, $4=$ neutral, $5=$ mildly agree, $6=$ strongly agree, and $7=$ very strongly agree. In addition to assessing current perceptions of social support, the items on the MSPSS were adapted to assess perceptions of past social support. The questions were changed minimally - the verbs were changed to past tense and the instructions were specific in asking participants to answer the questions about events that have occurred in the past or to indicate current feelings about each statement. Higher scores on this measure reflect higher 
perceived support. The MSPSS has demonstrated good internal consistency, with alphas of .88 for the total scale and alphas of $.85, .87$, and .91 for the friends, family, and significant other subscales, respectively. The measure also has demonstrated adequate stability over a 2- to 3month time period, with test-retest reliability estimates ranging from .72 (significant other) to .85 (family).

Perceived Social Support - Friend Scale and Family Scale. The Perceived Social Support - Friend Scale (PSS-Fr; Procidano \& Heller, 1983) and - Family Scale (PSS-Fa; Procidano \& Heller) are both 20-item instruments designed to measure the degree to which one perceives his or her needs for support are fulfilled by friends and family. Procidano and Heller developed separate scales for family and friends particularly because the social support between friends and family varies. For example, one's network of friends typically is less long-term than the family network, and they usually require more social competence to maintain than the family network. Items on the questionnaires are answered in a yes, no, and don't know format. Higher scores on the measure reflect higher perceived social support. The psychometric properties of both the PSS-Fr and PSS-Fa are acceptable. Alphas for the PSS-Fr scale range from .84 to .90 while the alphas for the PSS-Fa scale range from .88 to .91 . The test-retest coefficient of stability over a 1month period was .83 .

Parentification Questionnaire (PQ; Sessions \& Jurkovic, 1986). The PQ is a 42-item selfreport questionnaire used to assess the long-term effects of parentification in late adolescents and young adults. Items are in a true/false format and assess the degree of instrumental and emotional caregiving experienced during the childhood and adolescent years as well as the perceived fairness of such caregiving (e.g., level of reciprocity, acknowledgement, support). The measure has good internal consistency (coefficient alpha $=.84$ ) and reliability (split-half 
reliability $=.94)$. The test-retest reliability over a two-week period was .86 in a sample of undergraduates (Goglia, Jurkovic, Burt, \& Burge-Callaway, 1992). The higher the total score on this measure, the greater the degree of parentification. Low scores suggest an absence of parentification but may reflect overprotection or infantilization. Females typically score higher on this measure than males.

Rotter Internal Versus External Locus of Control Scale (I-E Scale; Rotter, 1966). The I-E Scale is a 29-item forced choice scale of generalized feelings of locus of control. Locus of control refers to whether one feels that he or she has control over external events. For each of the 29 items on the I-E Scale, respondents read two statements and are asked to choose the answer that they strongly believe to be true. As a result of answers on this measure, respondents are classified as having an internal or external locus of control. Scores range from 0 to 23 with high scores reflecting an external locus of control while low scores suggest an internal locus of control. The measure has acceptable internal consistency (range $=.65$ to .79 ) and 1-month testretest reliability (range $=.60$ to .83 ; Dixon, McKee, \& McRae, 1976).

Attachment Style Questionnaire (ASQ; Feeney, Noller, \& Hanrahan, 1994). The ASQ is a 40-item self-report measure of adult attachment in adolescents and adults who may or may not have had experiences with romantic relationships. Respondents rate on a 6-point scale the degree to which they agree with the items on the questionnaire. The ASQ yields scores that fall into one of the following five subscales: Confidence (C), Discomfort with Closeness (DC), Need for Approval (NA), Preoccupation with Relationships (PR), and Relationships as Secondary (RS). The five subscales cluster together to form one secure and three insecure attachment styles: Secure, Preoccupied, Dismissing, and Fearful. Secure individuals have high C, low DC, NA, PR, and RS. Preoccupied individuals have low to moderate C, high PR and NA, moderate DC, and 
low RS. Dismissing individuals have high RS, moderate to high DC, and moderate C, NA, and PR. Fearful individuals have low $\mathrm{C}$ and high DC, NA, PR, and RS. The ASQ has acceptable testretest reliabilities after a period of approximately 10 weeks as the coefficients ranged from .67 (RS) to .78 (NA). The validity of the scale has been established as demonstrated by the good correlations with previous measures of attachment style, predictable patterns of correlations with measures of family functioning and personality, and the lack of correlation with a Lie scale on a personality measure.

\section{Outcome Measures}

Drug Use Screening Inventory (DUSI; Tarter, 1990). The DUSI is a multidimensional scale that quantifies the severity of involvement with drugs and alcohol and commonly associated health, psychiatric, and psychosocial problems. The measure is composed of 149 items that are answered in a yes/no format. A problem severity score is obtained (by totaling the number of yes responses in each domain) for each of the 10 domains assessed. The domains are (1) substance use; (2) behavior pattern; (3) health status; (4) psychiatric disorder; (5) social competence; (6) family system; (7) school performance/adjustment; (8) work adjustment; (9) peer relationships; and (10) leisure and recreation. Problem density scores for each domain are calculated by dividing the problem severity score by the number of items in the particular domain and then multiplying by 100 . An overall problem density score is obtained by dividing the total number of DUSI items $(n=149)$ into the number of yes responses and then multiplying the quotient by 100 .

The measure has good psychometric properties as demonstrated by the internal reliability estimates of .74 and .78 for males and females, respectively (Tarter, Laird, Bukstein, \& Kaminer, 1992). Test-retest reliability estimates have averaged .95 for males and .88 for females (Tarter, 
Mezzich, Kirisci, \& Kaczynski, 1994).

Hendrick Sexual Attitude Survey (HSAS; Hendrick \& Hendrick, 1987). The HSAS is a 43-item questionnaire that measures four dimensions of sexuality: permissiveness (HSAS-P), sexual practices (HSAS-SP), communion in the relationship (HSAS-C), and instrumentality (HSAS-I). Respondents are asked to rate each item where $1=$ strongly agree, $2=$ moderately agree, 3 = neutral, $4=$ moderately disagree, and $5=$ strongly disagree. Gender differences have been noted on the HSAS-P and HSAS-I subscales while differences on all four subscales have been noted among diverse races and ethnicities. The authors provide gender-specific norms as well as norms specific to different races and ethnicities to use as a comparison in determining whether scores are meaningful. The psychometric properties of the measure are acceptable; the standardized alphas for the HSAS-P, HSAS-SP, HSAS-C, and HSAS-I subscales equal .94, .71, .80 , and .80 , respectively. Test-retest reliabilities over a 4-week period ranged from .66 (HSASI) to .88 (HSAS-P).

Social Phobia and Anxiety Inventory (SPAI; Turner, Beidel, Dancu, \& Stanley, 1989). The SPAI is a 32-item self-report questionnaire designed to assess the cognitive, physiological, and behavioral dimensions of social anxiety. Items of the SPAI require respondents to provide frequency ratings of distress associated with thoughts, situations, and somatic symptoms on a 7point scale. Items ask respondents to rate their distress around strangers, the opposite sex, authority figures, and people in general. Possible scores range from 0-576. Cutoff scores can be used to screen for social phobia where $0-33=$ unlikely social phobia, $34-59=$ possible mild social phobia, $60-79=$ possible social phobia, and $\geq 80=$ probable social phobia . The testretest reliability of the measure is .86 ; the coefficient alpha for the social phobia scale is .96 . The SPAI has demonstrated discriminative validity as it can discriminate social phobics from other 
groups with clinical levels of anxiety (e.g., obsessive-compulsives and panic disordered individuals; Turner et al.).

Beck Depression Inventory-II (BDI-II; Beck, Steer, \& Brown, 1996). The BDI-II is a 21item self-report measure used to screen for the presence and severity of depressive symptoms during the past two weeks in both normal and clinical populations. Items are answered by respondents aged 13 to 80 on a 4-point scale. Cutoff scores have been calculated where $0-9=$ none to mild depression, $10-18=$ mild to moderate, $19-29=$ moderate to severe, $30-63=$ severe. The BDI-II has excellent internal consistency (coefficient alpha $=.93$ among college students; Beck et al.) and test-retest reliability $(r=.93)$. The BDI-II also has adequate content and factorial validity and diagnostic discrimination (Beck et al.; Dozois, Dobson, \& Ahnberg, 1998).

Beck Anxiety Inventory. The Beck Anxiety Inventory (BAI; Beck, Epstein, Brown, \& Steer, 1988) is a 21-item self-report measure used to screen for symptoms of anxiety that occurred during the past week. Questions are comprised of subjective, somatic, or panic-related symptoms of anxiety. Respondents are asked to indicate whether they have been bothered by any of the symptoms over the past week on a 4-point scale ranging from 0 to 3. Cutoff scores have been established where $0-7=$ none to mild anxiety, $8-15=$ mild to moderate, $16-25=$ moderate to severe, $26-63=$ severe.

\section{Procedure}

Participants were recruited from introductory psychology courses for participation in the study. Participants attended a study session in which they completed an informed consent agreement as well as a questionnaire packet. All questionnaire packets were arranged in the same order: participants first completed a demographic questionnaire and then went on to complete the 
HPS, MSPSS, PSS-Fr, PSS-Fa, PQ, I-E Scale, ASQ, DUSI, CTQ, HSAS, SPAI, BDI, and BAI. An examiner was available to answer questions and to collect packets at the end of the study session. Participants were given course extra credit slips after returning their completed packets to the examiner. Participants also were provided with a list of local mental health providers in the event that completing the questionnaires resulted in elevated levels of distress. A list of individuals who had participated in the study was updated after each session to ensure that participants did not complete the study more than once.

\section{Data Reduction and Analyses}

A total of 503 undergraduate students enrolled to participate in the study. One participant's data was excluded from the dataset due to incomplete data on most measures. For the remaining participants, if less than $10 \%$ of the data was missing on any one questionnaire, the missing data was replaced with the group mean for that questionnaire item. If more than $10 \%$ of the data was missing for a measure, the participant's data was excluded in the individual scale analyses. The following is a list of the number of participants who had greater than $10 \%$ of their data missing on each measure: zero participants on the MSPSS-past, two on the MSPSS-present, three on the PSS-Fr, zero on the PSS-Fa, one on the PQ, five on the I-E Scale, zero on the ASQ, one on Domain II of the DUSI, zero for all of the remaining domains of the DUSI, one on the CTQ, four on the HSAS, four on the SPAI, two on the BDI, and three on the BAI.

Prior to beginning analyses, the relations among the variables were examined to determine which variables would be retained for subsequent analyses. To achieve this, Pearson product moment correlations were calculated for all variable combinations. To determine whether participants' scores on each of the measures were similar to the norms from the standardization samples, one sample $t$-tests and $z$-scores were calculated. 
To address the first hypothesis that child maltreatment would be significantly associated with the measured outcomes (i.e., substance abuse, sexualized behavior, depression, general anxiety, social anxiety, agoraphobia), multiple regression analyses were carried out. The five subscales of the CTQ (physical abuse, emotional abuse, sexual abuse, physical neglect, and emotional neglect) served as the independent (predictor) variables while scores on the DUSI, HSAS, BDI-II, BAI, and SPAI served as the dependent (outcome) variables. Separate analyses were conducted for each of the outcome variables. In many cases, several variables from each of the measures were treated as outcome variables (e.g., two subscales were used from the DUSI, two from the HSAS, and two from the SPAI).

To address the second hypothesis that social support, parentification, locus of control, and attachment would moderate the relation between child maltreatment and outcome, hierarchical multiple regression analyses were conducted. Separate analyses were conducted for each outcome variable. The analyses controlled for demographic variables, including age and gender. These variables were entered on Step 1 in the regression. The predictor and moderator variable total scores across participants were entered into the second step of the multiple regression analysis as a means of testing predictor and moderator main effects. As recommended by Aiken and West (1991), the variables were centered to prevent the negative impact of multicollinearity. This was accomplished by putting all scores into deviation score form, which entailed subtracting the sample mean from each individual scale score, thereby producing a revised sample mean of zero. The centered predictor and moderator variables also were entered on the second step. To create the interaction terms that were entered on the third step, the centered predictor was multiplied by the centered moderator variables. Significant interactions identified in the regression analyses were examined in follow-up simple slope analyses and plots. 
Post-hoc probing with t-tests of the significant interactions was conducted to determine which simple slopes were significantly different from zero and to verify the conditions of the moderator for which the interaction term was significant. Plots were created by solving the regression equation $(y=m x+b)$ at specific levels of the moderating variable (i.e., one standard deviation above and below the mean; Aiken \& West, 1991; Holmbeck, 2002; Tabachnick \& Fidell, 2001).

Results

\section{Individual Scale Analyses}

Total scores as well as means and standard deviations for each of the measures and/or subscales of the measures were calculated. If norms or data from prior studies were available, the scores (i.e., means and standard deviations) on the present measures were compared with prior data to yield a $t$ statistic and a $z$-score. Table 3 presents the means and standard deviations as well as the $t$ values and $z$-scores of the measures. These results are presented separately for males and females and are collapsed to create an overall mean and standard deviation.

History of Psychosocial Stressors. Of the items on the HPS, participants reported exposure (either witnessed or experienced personally) to an average of four events $(M=4.3, S D$ =2.6). Consistent with prior research (Fortson, 2003), participants reported having personally experienced an average of two events. Males $(M=4.3, S D=2.5)$ and females $(M=4.3, S D=$ 2.7) did not differ in their reports of exposure to events, $t(498)=-.178, p=.89$. Motor vehicle accidents were the most commonly occurring trauma experienced and/or witnessed as it was endorsed by $72.9 \%$ of participants. The second most commonly occurring trauma was death of a loved one or someone close, which was endorsed by $58 \%$ of participants. Table 4 contains the number and percentage of participants who reported having witnessed or experienced each of the traumas. 
Childhood Trauma Questionnaire. Total scores for each of the five subscales on the CTQ were calculated. Scores (range $=5-25$ ) on the emotional neglect and emotional abuse subscales were higher than for the other types of maltreatment. Table 5 presents the number of symptoms for each subscale that were endorsed by males and females at each of the different classification levels. An independent samples t-test revealed that males and females did not differ in their endorsement of items on the emotional abuse, physical abuse, sexual abuse, and emotional neglect subscales; however, males endorsed more of the items on the physical neglect subscale than did females, $t(498)=2.4, p<.05$. A large number of participants were classified as having moderate to extreme levels of exposure to each of the types of maltreatment (see Table 5): 72 had experienced emotional abuse, 48 experienced physical abuse, 29 experienced sexual abuse, 62 experienced emotional neglect, and 28 experienced physical neglect. When scores of the participants in the present sample were compared to a normative sample of undergraduates, all zscores fell within the average range (range $=.23-.44$ ). The mean for females on the emotional abuse subscale was significantly different from the normative data for females, $t(355)=-8.8, p<$ .001 , with females in the current sample endorsing, on average, fewer of the items on the emotional abuse subscale.

Multidimensional Scale of Perceived Social Support. Mean scores for each of the subscales of the MSPSS suggested that individuals in the current sample perceive(d) high levels of social support from friends, family, and significant others. Mean scores ranged from 5.7 to 6.1. When scores were compared with results from other studies with college students, $z$-scores were average (range $=-.37-.50)$; however, independent samples $t$ tests suggested that most of the means were significantly different from those found in other studies (see Table 3 for $t$ values). Interestingly, however, these differences occurred for females and for the overall score 
on each subscale (which took into account the scores of females); the perceived social support of males in the current sample did not differ from that seen in prior research. Males and females differed on the MSPSS-Past friends subscale, $t(498)=-4.8, p<.001$, MSPSS-Past significant other subscale, $t(498)=-4.2, p<.001$, MSPSS-Past total score, $t(498)=-4.8, p<.001$, MSPSSPresent friends subscale, $t(496)=-6.1, p<.001$, MSPSS-Present significant other subscale, $t(496)=-6.8, p<.001$, and MSPSS-Present total score, $t(496)=-5.1, p<.001$. In each case, females reported higher levels of perceived social support than did males. Males and females did not differ in their rates of perceived familial support.

Perceived Social Support - Friend Scale and Family Scale. Total scores for the PSS-Fr and PSS-Fa were 0 to 20 . As with the MSPSS, higher scores on the measure reflect more perceived social support. The mean score on the PSS-Fr scale was $15.7(S D=4.2)$ while the mean score on the PSS-Fa scale was $14.9(S D=5.7)$. Again, participants appear to perceive high levels of social support from friends and family. $z$-scores were average, but, again, the means were significantly higher than those obtained in prior research, $t(498)=2.6, p<.05$ for the friend scale and $t(496)=5.9, p<.001$ for the family scale. Females also perceived more social support from friends than did males, $t(495)=-4.5, p<.001$. Males and females did not differ in their perceived support from family.

Parentification Questionnaire. Scores on the PQ ranged from 4 to 39 out of a total of 42 . Most participants' scores fell in the range that likely suggests adaptive parentification and nonparentification. Although females typically score higher on the measure than males, there was no significant difference in the scores of males and females in the present sample, $t(497)=1.6, p=$ .11. Overall, the scores of participants in the present sample were significantly higher than those found in other research, $t(500)=14.5, p<.001$. 
Rotter Internal Versus External Locus of Control Scale. Total scores on the I-E Scale ranged from 4 to 23. Lower scores are typically indicative of an internal locus of control whereas higher scores reflect an external locus of control. Approximately $80 \%$ of the sample scored below 15 on the measures, suggesting that most have more of an internal than an external locus of control. Males and females differed in their responses on the measure as males endorsed more internal control than females, $t(493)=-3.3, p<.001$; however, males and females in the present sample were lower in internal locus of control than the comparison sample $[t(138)=9.9, p<$ .001 for males; $t(355)=20.4, p<.001$ for females; $t(496)=22.7, p<.001$ overall]. $z$-scores were in the average range.

Attachment Style Questionnaire. Scores on each subscale of the ASQ were computed and used in $t$-test analyses. Males and females differed only on the Relationships as Secondary, $t(498)=4.5, p<.001$, and the Preoccupation with Relationships, $t(498)=-3.2, p<.001$, subscales. Males in the current study scored higher on the Relationships as Secondary subscale than females, which may suggest that they are more likely to emphasize achievement and independence in an attempt to protect themselves against hurt and vulnerability (Feeney et al., 1994). Females scored higher on the Preoccupation with Relationships subscale, which may suggest that they are more likely than males to reach out to others to fulfill dependency needs (Feeney et al.). Mean scores for each subscale differed significantly from the data seen in other research (see Table 3 for $t$ statistics). Participants in the current sample endorsed fewer items for the subscales than did participants in comparison samples, with the exceptions being in the Relationships as Secondary and Confidence subscales where participants endorsed more items.

Drug Use Screening Inventory. The DUSI classifies disturbance related to alcohol and drug use, in conjunction with nine other areas of disturbance. The means for males and females 
for all domains was less than 40 (range $=3.8$ to 38.5 ; individual means are listed in Table 3 ), suggesting an absence of significant problems in the domains assessed. The means on each of the subscales differed significantly from those found in other research with "normal" populations (see Table 3 for $t$ statistics), with the current sample endorsing more items from most of the domains (except the substance use domain) than the comparison samples. Males and females did not differ in the overall problem density domain, $t(497)=.80, p=.40$. Males did, however, endorse significantly more problems than females in the substance use, $t(498)=2.3, p<.05$, school performance, $t(498)=2.4, p<.05$, work adjustment, $t(498)=6.0, p<.001$, and peer relationships, $t(498)=2.9, p<.01$, domains; females endorsed significantly more problems in the health status, $t(498)=-3.4, p<.01$, psychiatric disorder, $t(498)=-2.1, p<.05$, and social competency, $t(498)=-2.9, p<.01$, domains. $z$-scores for all of the subscales were in the average range (range $=-.10$ to .69 ).

Hendrick Sexual Attitude Survey. After computing scores on each of the subscales of the HSAS, means and standard deviations were compared to those found in other research. The only non-significant score, $t(353)=.10, p=.89$, occurred for females on the Instrumentality subscale; the rest of the scores were significantly different from those in the comparison sample (see Table 3 for $t$ statistics). In most cases (except on the Sexual Practices subscale), participants in the current sample were less agreeable than participants in the comparison sample. Consistent with prior research (Hendrick \& Hendrick, 1987), gender differences were observed on the Permissiveness, $t(494)=-12.0, p<.001$, and Instrumentality, $t(494)=-2.3, p<.05$, subscales. Males were neutral about permissiveness while females disagreed with it, and although both males and females were neutral with Instrumentality, men were less neutral (and, as such, disagreed less). 
Social Phobia and Anxiety Inventory. Approximately $21 \%(n=106)$ of participants in the current sample answered questions in such a way as to suggest possible to probable social phobia. The mean scores and standard deviations for each subscale are listed in Table 3. Females scored significantly higher than males on the agoraphobia subscale, $t(495)=-3.8, p<.001$. Most of the scores differed from those seen in prior research (see Table 3 for $t$ statistics), with the exception having occurred for males on the Difference subscale, $t(141)=-1.3, p=.20$. In all cases, participants in the current sample endorsed fewer symptoms than participants in the comparison samples. $z$-scores for each subscale fell in the average range (range $=-.41$ to -.16 )

Beck Depression Inventory. Total scores on the BDI ranged from 0 to 45 . Seventy-one participants (14\%) endorsed symptoms such that scores resulted in moderate to severe levels of depressive symptoms. Females endorsed significantly more depressive symptoms than males, $t(496)=-3.3, p<.001$, and were more likely to be classified as moderately to severely depressed, $t(496)=-2.9, p<.01$. Females scores' were similar to those obtained in prior research, $t(354)=-$ $1.3, p=.21$; however, males' scores were significantly lower than the males' scores in the comparison sample, $t(142)=-7.5, p<.001 . z$-scores fell in the average range for each gender and overall (range $=-.49$ to -.08$)$.

Beck Anxiety Inventory. Ninety-four participants (18.7\%) had scores on the BAI that placed them in the moderate to severe anxiety categories. Scores ranged from 0 to 42 , with females scoring significantly higher than males, $t(495)=-4.0, p<.001$. In addition, females were more likely than males to be classified as moderately to severely anxious, $t(494)=-3.1, p<.01$. Scores on the measure in the current sample were significantly lower than those obtained in other research, $t(498)=-5.4, p<.001$, while the $z$-score $(-.22)$ was in the average range. 
Before beginning the regression analyses, correlations were conducted for the trauma variables, the variables hypothesized to promote resilience, and the outcome variables. The correlation matrix is depicted in Table 6 . Although the correlations were not very high, most of the variables were significantly correlated, either at the .05 or .01 level. Three variables, which were subscales of the HSAS, the Sexual Practices, Communion in the Relationship, and Instrumentality subscales, yielded insignificant correlations with most of the other measures and with the types of maltreatment; thus, these subscales were not used in subsequent analyses. Emotional abuse and emotional neglect were significantly correlated with everything except these variables. In addition to the three subscales on the HSAS, physical abuse was not significantly correlated with perceived social support from friends $(r=-.07)$, locus of control ( $r=$ $-.008)$, preoccupation with relationships attachment style $(r=-.02)$, need for approval attachment style $(r=-.01)$, confidence attachment style $(r=-.05)$, substance use $(r=.03)$, agoraphobia $(r=$ $.08)$, or social anxiety $(r=.05)$. Sexual abuse was not significantly correlated with most of the variables but was correlated with past perceived social support $(r=-.18, p<.01)$, parentification $(r=-.16, p<.01)$, confidence attachment style $(r=-.09, p<.05)$, DUSI overall problems $(r=$ $.12, p<.01)$, social anxiety $(r=.10, p<.05)$, and depression $(r=.11, p<.05)$. In addition to the subscales on the HSAS, physical neglect was not significantly correlated with locus of control $(r$ $=.07)$ and the preoccupation with relationships attachment style $(r=.07)$.

\section{Relations between Child Maltreatment and Outcome}

Child maltreatment and substance use. A regression analysis was conducted to examine the relation between child maltreatment and substance use. The total score on the Substance Use Domain and the Overall Problem Density Score served as dependent variables (in separate analyses) and the subscales on the CTQ were the independent (predictor) variables. The results 
of the regression demonstrated that the Emotional Abuse subscale of the CTQ was significant in predicting substance use, $t(495)=2.13, p<.05$. The Emotional Abuse, $t(494)=5.57, p<.05$, and Emotional Neglect, $t(494)=4.56, p<.05$, subscales were significant in predicting the DUSI Overall Problem Density Score.

Child maltreatment and sexualized behavior. To examine the relation between child maltreatment and sexualized behavior, the Permissiveness subscale of the HSAS served as a dependent variable and the subscales on the CTQ were the independent (predictor) variables. Emotional neglect was significant in predicting permissive attitudes as assessed by the HSAS, $t(491)=-3.27, p<.001$.

Child maltreatment and psychological problems. The relation of child maltreatment and depression, general anxiety, social anxiety, and agoraphobia were examined in five different regression analyses, with the BDI-II total score, the BAI total score, the SPAI Social Phobia, and the SPAI Agoraphobia subscales serving as the dependent variables. Several subscales of the CTQ were significant in predicting depression: Emotional Abuse, $t(493)=5.12, p<.001$, Physical Abuse, $t(493)=-2.87, p<.01$, and Emotional Neglect, $t(493)=3.77, p<.001$. The Emotional Abuse subscale also was significant in predicting general anxiety, $t(492)=3.88, p<$ .001 ; however, none of the other subscales were uniquely associated with general anxiety. Similar results were obtained in predicting social anxiety and agoraphobia: the Emotional Neglect subscale was significant in predicting social anxiety, $t(491)=3.37, p<.001$, while the Emotional Abuse subscale was significant in predicting agoraphobia, $t(491)=2.34, p<.05$.

As is evident in the preceding analyses, the first hypothesis that maltreatment would be related to each of the outcomes was not supported. The subscales that most consistently predicted outcome were Emotional Abuse and Emotional Neglect, but even they were not 
significant in all the regressions. The Sexual Abuse and Physical Neglect subscales did not serve as a significant predictor for any of the outcome variables.

\section{Examination of Moderating Variables}

Emotional abuse and outcome variables. The hierarchical multiple regression analyses that were conducted to examine whether social support, parentification, locus of control, and attachment style served to buffer the effects of emotional abuse (see Tables 7-13) yielded the following results: no variables emerged as moderators in the relation between emotional abuse and substance use, sexualized behavior, general anxiety, and social anxiety; parentification and locus of control were moderators for overall problem severity as assessed by the DUSI [F (11, $455)=1.25, p=.25$; final model not significant overall] while locus of control served as the only moderator for depression $[F(11,454)=1.84, p<.05]$ and agoraphobia $[F(11,453) p=.11$; final model not significant overall]. Follow-up simple slope analyses of the significant interactions resulted in the following observations:

1. The interaction between parentification and emotional abuse was significant at both high, $t(498)=7.04, p<.001$, and low levels of parentification, $t(498)=8.62, p<.001$, suggesting that individuals who reported high and low levels of parentification reported more overall problem behaviors as levels of emotional abuse increased. This is illustrated in Figure 1.

2. The interaction between locus of control and emotional abuse was not significant at high levels of locus of control, $t(494)=.14, p=.88$, but was significant at low levels, $t(494)=$ $10.599, p<.001$. Thus, individuals who reported lower levels of locus of control reported more overall problems as levels of emotional abuse increased. This is illustrated in Figure 2. 
3. Similar results were found in the interaction of locus of control and emotional abuse when depression was the dependent variable. The interaction between locus of control and emotional abuse was not significant at high levels of locus of control, $t(493)=-1.25$, $p=.21$, but was significant at lower levels , $t(493)=7.94, p<.001$, suggesting that individuals reporting lower levels of locus of control experienced increased depressive symptomatology as levels of emotional abuse increased. This is illustrated in Figure 3.

4. The interaction between locus of control and emotional abuse when agoraphobia was the dependent variable was significant at both high, $t(491)=-2.0, p<.05$, and low, $t(491)=$ $3.48, p<.001$, levels of locus of control, suggesting that individuals who reported high and low levels of locus of control reported more agoraphobic symptoms as levels of emotional abuse increased. This is illustrated in Figure 4.

Physical abuse and outcome variables. To examine whether social support, parentification, locus of control, and attachment style served to buffer the effects of physical abuse, seven regression analyses (see Tables 14-20) were conducted. No moderators emerged in the relation between physical abuse and social anxiety or agoraphobia. Support from a friend was a moderator in the relation between physical abuse and substance use $[F(11,456)=.90, p=.54$; final model not significant overall] as well as between physical abuse and overall problem severity as assessed on the DUSI $[F(11,456)=2.03, p<.05]$. Locus of control also served as a moderator between physical abuse and overall problem severity as assessed on the DUSI. Preoccupation with relationships served as a moderator for sexualized behavior $[F(11,453)=$ $.76, p=.69$; final model not significant overall], need for approval and discomfort with closeness were moderators for depression $[F(11,454)=1.72, p=.067$; final model not significant overall], and support from a friend, need for approval, and relationships as secondary were 
moderators for general anxiety $[F(11,453)=1.64, p=.084$; final model not significant overall] . Follow-up simple slope analyses of the significant interactions resulted in the following observations:

1. The interaction between support from a friend and physical abuse when substance use was the dependent variable was not significant at high, $t(497)=1.39, p=.165$, or low, $t(497)=-.59, p=.56$, levels of friend support. The plot revealed that individuals who reported higher levels of perceived social support from friends endorsed more substance use when levels of physical abuse increased (although this relation was not significant). Individuals who reported lower levels of perceived social support from friends appeared to experience a decrease in reported substance use as levels of physical abuse increased (although this relation also was not significant). This is illustrated in Figure 5.

2. The interaction between support from a friend and physical abuse was significant at high levels of perceived social support from friends, $t(496)=5.25, p<.001$, but was not significant at low levels, $t(496)=1.59, p=.11$. Thus, individuals who reported higher levels of perceived support from friends reported more overall problems as levels of physical abuse increased. This is illustrated in Figure 6.

3. The interaction between locus of control and physical abuse was not significant at high levels of locus of control, $t(494)=-1.78, p=.76$, but was significant at low levels, $t(494)$ $=4.99, p<.001$. Thus, individuals who reported lower levels of locus of control reported more overall problems as levels of physical abuse increased. This is illustrated in Figure 7.

4. The interaction between preoccupation with relationships and physical abuse was significant at both high, $t(496)=-2.36, p<.05$, and low, $t(496)=-2.63, p<.01$, levels of 
this attachment style. Individuals who reported higher and lower levels of preoccupation with relationships disagreed less often with more permissive statements as levels of physical abuse increased. This is illustrated in Figure 8.

5. The interaction between need for approval and physical abuse was significant at both high, $t(498)=2.09, p<.05$, and low, $t(498)=2.50, p<.05$, levels of this attachment style. Individuals who reported higher and lower levels of the need for approval attachment style reported more depressive symptoms as levels of physical abuse increased. This is illustrated in Figure 9.

6. The interaction between the discomfort with closeness attachment style and physical abuse was significant only at low levels of this attachment style, $t(498)=2.61, p<.01$. Individuals who reported lower levels of discomfort with closeness reported more depressive symptoms as levels of physical abuse increased. This is illustrated in Figure 10.

7. The interaction between perceived support from a friend and physical abuse when anxiety was the dependent variable was significant only when individuals perceived high levels of friend social support, $t(494)=3.99, p<.001$. Individuals who reported higher levels of perceived social support from friends reported more anxiety symptoms as levels of physical abuse increased. This is illustrated in Figure 11.

8. The interaction between the need for approval attachment style and physical abuse when anxiety was the dependent variable was significant at both high, $t(497)=2.22, p<.05$, and low, $t(497)=2.79, p<.01$, levels of this attachment style. Individuals who reported more and less of a need for approval reported more anxiety symptoms as levels of physical abuse increased. This is illustrated in Figure 12. 
9. The interaction between the relationships as secondary attachment style and physical abuse when anxiety was the dependent variable was significant at both high, $t(497)=$ $1.98, p<.05$, and low, $t(497)=2.86, p<.01$, levels of this attachment style. Individuals who endorsed higher and lower levels of the relationships as secondary attachment style reported more anxiety symptoms as levels of physical abuse increased. This is illustrated in Figure 13.

Sexual abuse and outcome variables. Few moderators emerged as significant in the relation between sexual abuse and outcome (i.e., few of the variables in the present study served to buffer the effects of sexual abuse). Confidence was a moderator for sexualized behavior [ $F$ $(11,453)=1.19, p=.29$; final model not significant overall] while the presence of current social support emerged as a moderator for both social anxiety $[F(11,453)=.62, p=.81$; final model not significant overall $]$ and agoraphobia $[F(11,453)=.99, p=.45$; final model not significant overall]. No other moderators emerged in the analyses. Tables 21-27 provide the results from the regression analyses. Follow-up simple slope analyses of the significant interactions resulted in the following observations:

1. The interaction between the confidence attachment style and sexual abuse when permissiveness was the dependent variable was not significant at high, $t(496)=-.89, p=$ .37 , or low, $t(496)=-.35, p=.73$, levels of this attachment style. Although not significant, the plot revealed that individuals who reported higher and lower levels of the confidence attachment style agreed with more permissive statements as levels of sexual abuse increased. This is illustrated in Figure 14.

2. The interaction between current perceived social support and sexual abuse when social anxiety was the dependent variable was only significant at high, $t(494)=3.02, p<.01$, 
levels of current perceived social support. Individuals who reported high levels of current perceived social support endorsed more symptoms of social anxiety as levels of sexual abuse increased. This is illustrated in Figure 15.

3. The interaction between current perceived social support and sexual abuse when agoraphobia was the dependent variable was only significant at high, $t(494)=2.96, p<$ .01 , levels of current perceived social support. Individuals who reported high levels of current perceived social support endorsed more symptoms of agoraphobia as levels of sexual abuse increased. This is illustrated in Figure 16.

Emotional neglect and outcome variables. Hierarchical regression analyses conducted to examine what variables served to moderate the relation between emotional neglect and outcomes resulted in the following: no moderators were found in predicting substance use, general anxiety, or social anxiety; locus of control served as a moderator for overall problems as assessed by the DUSI $[F(11,456)=1.17, p=.31$; final model not significant overall $]$ as well as for depression $[F(11,454)=1.62, p=.089$; final model not significant overall $]$ and agoraphobia $[F(11,453)=$ $1.03, p=.42$; final model not significant overall]; and past social support, need for approval, and discomfort with closeness emerged as moderators for sexualized behavior $[F(11,453)=2.27, p$ $<.05]$. Tables 28-34 provide results from the regression analyses. Follow-up simple slope analyses of the significant interactions resulted in the following observations:

1. The interaction between locus of control and emotional neglect when overall problems as assessed by the DUSI was the dependent variable was only significant at low levels of locus of control, $t(494)=9.7, p<.001$. The plot revealed that individuals who reported lower levels of locus of control endorsed more problematic behaviors as levels of emotional neglect increased. This is illustrated in Figure 17. 
2. The interaction between perceived social support in the past and emotional neglect when permissiveness was the dependent variable was significant at both high, $t(496)=-2.57, p$ $<.01$, and low, $t(496)=-4.33, p<.001$, levels of past perceived social support. The plot revealed that individuals who reported higher and lower levels of past perceived social support disagreed less with permissiveness statements as the level of emotional neglect increased. This is illustrated in Figure 18.

3. The interaction between the need for approval attachment style and emotional neglect when permissiveness was the dependent variable was not significant at high, $t(496)=.23$, $p=.82$, or low, $t(496)=-.62, p=.54$, levels of this attachment style. Although not significant the latter relation approached significance, suggesting that individuals who scored lower on the need for approval subscale of the ASQ disagreed less often with the permissive statements as levels of emotional neglect increased. This is illustrated in Figure 19.

4. The interaction between the discomfort with closeness attachment style and emotional neglect when permissiveness was the dependent variable was significant at both high, $t(496)=-3.03, p<.01$, and low, $t(496)=-2.61, p<.01$, levels of this attachment style. The plot revealed that individuals who reported higher and lower levels of the discomfort with closeness attachment style disagreed less with permissive statements as the level of emotional neglect increased. This is illustrated in Figure 20.

5. The interaction between locus of control and emotional neglect when depression was the dependent variable was significant only at low levels of locus of control, $t(493)=7.26, p$ $<.001$. The plot revealed that individuals who reported lower levels of locus of control endorsed more depressive symptoms as the level of emotional neglect increased. This is 
illustrated in Figure 21.

6. The interaction between locus of control and emotional neglect when agoraphobia was the dependent variable was significant only at low levels of locus of control, $t(491)=$ $2.68, p<.01$. The plot revealed that individuals who reported lower levels of locus of control endorsed more agoraphobic symptoms as the level of emotional neglect increased. This is illustrated in Figure 22.

Physical neglect and outcome variables. To examine whether social support, parentification, locus of control, and attachment style buffered the effects of physical neglect, a hierarchical regression analysis was conducted and yielded the following: no variables were found to moderate the relation between physical neglect and substance use, overall problem severity as assessed on the DUSI, general anxiety, or social anxiety; past social support, relationships as secondary, and discomfort with closeness were moderators for sexualized behavior $[F(11,456)=.94, p=.50$, final model not significant overall]; preoccupation with relationships was a moderator for depression $[F(11,454)=1.10, p=.36]$; and the presence of current social support and support from the family were moderators for social anxiety [ $F(11$, $453)=.99, p=.45]$. Tables $35-41$ provide the results from the regression analyses. Follow-up simple slope analyses of the significant interactions resulted in the following observations:

1. The interaction between perceived social support in the past and physical neglect when permissiveness was the dependent variable was significant at both high, $t(496)=-2.52, p$ $<.05$, and low, $t(496)=-4.0, p<.001$, levels of past perceived social support. The plot revealed that individuals who reported higher and lower levels of past perceived social support disagreed less with permissive statements as levels of physical neglect increased. This is illustrated in Figure 23. 
2. The interaction between the need for approval attachment style and physical neglect when permissiveness was the dependent variable was not significant at high, $t(496)=$ $2.52, p<.05$, or low, $t(496)=-4.0, p<.001$, levels of this attachment style. Although no significant relations were observed in those who had higher and lower levels of the need for approval attachment style, it appears that individuals disagreed more with permissive statements as the level of physical neglect increased. The opposite appears to be true for low levels of the attachment style (although it, too, is not significant). This is illustrated in Figure 24.

3. The interaction between the relationships as secondary attachment style and physical neglect when permissiveness was the dependent variable was significant at both high, $t(496)=-2.37, p<.05$, and low, $t(496)=-2.16, p<.05$, levels of this attachment style. The plot revealed that individuals who reported higher and lower levels of the relationships as secondary attachment style disagreed less with permissive statements as the level of physical neglect increased. This is illustrated in Figure 25.

4. The interaction between the discomfort with closeness attachment style and physical neglect when permissiveness was the dependent variable was significant only at low levels of this attachment style, $t(496)=-2.41, p<.05$. The plot revealed that individuals who reported lower levels of the discomfort with closeness attachment style disagreed less with permissive statements as levels of physical neglect increased. This is illustrated in Figure 26.

5. The interaction between the relationships as secondary attachment style and physical neglect when general anxiety was the dependent variable was significant at both high, $t(497)=2.21, p<.05$, and low, $t(497)=3.14, p<.01$, levels of this attachment style. The 
plot revealed that individuals who reported higher and lower levels of the relationships as secondary attachment style were more likely to report higher levels of anxiety as the level of physical neglect increased. This is illustrated in Figure 27.

6. The interaction between current perceived social support and physical neglect when social anxiety was the dependent variable was significant only at high levels of current perceived social support, $t(494)=2.13, p<.05$. Individuals who perceived high levels of social support currently reported more symptoms of social anxiety as the level of physical neglect increased. This is illustrated in Figure 28.

7. The interaction between perceived social support in one's family and physical neglect when social anxiety was the dependent variable was not significant at high, $t(496)=1.56$, $p<.12$, or low, $t(496)=.54, p=.59$, levels of perceived familial social support. Although not significant, the plot suggested that individuals who reported higher and lower levels of perceived familial social support appeared to report more symptoms of anxiety as levels of physical neglect increased. This is illustrated in Figure 29.

As was evident from these analyses, the second hypothesis that higher levels of perceived social support from friends and family currently and in the past, moderate levels of parentification, internal locus of control, and secure attachment would moderate the relation between child maltreatment and outcome was not totally supported. Internal locus of control appeared as a moderator more often than the others; however, none of the factors emerged as a consistent moderator in the relation between child maltreatment and outcome.

\section{Discussion}

This study explored the unique associations between child maltreatment and several outcome variables (e.g., substance use, sexualized behavior, depression, general anxiety, social 
anxiety, and agoraphobia) as well as the relations among five types of child maltreatment and factors purported to promote resiliency (e.g., social support, parentification, locus of control, attachment style) in a sample of undergraduate students. Several models were tested that incorporated the risk/resiliency factors as moderators of the relation between child maltreatment and outcome. Although the factors used in the current study were extrapolated from the existing literature, the variables did not consistently emerge as moderators of the maltreatment-outcome relation. In addition, the subtypes of maltreatment were not, in all cases, significant predictors of each of the different outcomes. The means and standard deviations of measures used in the current study also were compared to established norms, when available, to ensure that the current sample was answering in a manner similar to groups of the same consistency (e.g., college students, young healthy adults). All of the $z$-scores were in the average range; however, $t$-tests demonstrated that there were differences in the way individuals in the current sample answered when compared to normative samples. These differences likely are attributable to the fact that the standard deviations of the measures in both the current and established norm samples were highly variable. This variability was accounted for in the $z$-scores calculations but not in the $t$-test analyses. Several of the results warrant further discussion to examine the significant findings, explore why some hypotheses may not have been supported, and to identify ways future research may address questions raised by this research.

\section{Associations between Child Maltreatment and Outcome}

As can be seen in the correlation matrix, the child maltreatment subtypes were significantly correlated with most of the variables purported to moderate outcome and to the specific outcomes. The one exception to this was sexual abuse, which was only significantly correlated with a small number of the other variables. The lack of significant associations 
between sexual abuse and other variables in the study was unexpected but could have resulted because of the low rate of sexual abuse observed in the current study or the result of a skewed distribution, as most of the participants in the study were relatively healthy and had means on the outcome measures (e.g., social anxiety, general anxiety, depression) that were generally lower than those of the comparison samples.

In the regressions in which the associations between child maltreatment and the outcome variables (e.g., substance use, sexualized behavior, depression, general anxiety, social anxiety, and agoraphobia) were examined, several subscales more consistently predicted outcome than others: Emotional Abuse and Emotional Neglect predicted outcome more often than the other types, but even they were not significant in all the regressions. It is likely that the outcomes assessed in the current study are those commonly found in emotionally abused and neglected individuals, which is the reason they occur so frequently as significant predictors. The Sexual Abuse and Physical Neglect subscales, which also were the least commonly occurring types of maltreatment in the current sample, did not serve as a significant predictor for any of the outcome variables. It is likely that other outcomes are more common among these types of maltreatment (e.g., posttraumatic stress disorder). Thus, these variables may have served as significant predictors for other outcomes if they had been examined in the current study. One other reason that physical neglect may not have served as a predictor could have been due to the fact that it occurs when the child's basic needs are not met; thus, if the child is not the victim of any other type of maltreatment and his or her basic needs are eventually met (before failure-tothrive occurs), he or she may not experience negative long-term consequences.

\section{Social Support as a Moderator}

As noted earlier, research has demonstrated that the negative consequences resulting from 
exposure to traumatic events can be buffered if one perceives having had a good relationship with at least one parental figure (Blum et al., 2000; Perkins \& Jones, 2004; Rutter, 1979). On the other hand, lack of perceived social support from family members has been linked to negative consequences (Litty et al., 1996). Unlike other research which has suggested that social support serves as a moderator between abuse and outcome (e.g., Everill \& Waller, 1994; Nagel et al., 1997), the current study did not find this relation for all types of abuse and for all outcomes. The variable emerged as a moderator in the relations between physical abuse and substance use, physical abuse and overall problems as assessed by the DUSI, physical abuse and general anxiety, sexual abuse and social anxiety, sexual abuse and agoraphobia, emotional neglect and permissiveness, physical neglect and permissiveness, physical neglect and social anxiety, and physical neglect and agoraphobia. As was hypothesized, higher levels of perceived social support, in most cases, appeared to moderate the relation between child maltreatment and outcome and likely buffered the effects that might have been seen otherwise.

\section{Parentification as a Moderator}

Jurkovic (1997) suggested that parentification of a child can lead to a variety of emotional, cognitive, and sociofamilial difficulties. Of the child maltreatment types examined in the current study, parentification only emerged as a moderator in the relation between emotional abuse and overall problems as assessed by the DUSI. In this instance, individuals who reported high and low levels of parentification reported more overall problem behaviors as levels of emotional abuse increased. Thus, as Jurkovic hypothesizes, low and high levels of parentification may be problematic. Unfortunately, other outcome variables (e.g., trust, anger and resentment, stress, guilt and shame, peer problems, school difficulties, disruption in identity development, conflicts about leaving home, occupational concerns, and personality dysfunction), which 
Jurkovic stated could occur as a result of maltreatment, were not assessed in the current study. If present, parentification may have played more of a role in the maltreatment-outcome relation.

\section{Locus of Control as a Moderator}

Locus of control, which refers to whether an individual believes that events result primarily from one's own behavior, was a significant moderator in the emotional abuse-overall problem behavior relation, in the emotional abuse-depression relation, in the emotional abuseagoraphobia relation, in the physical abuse-overall problem behavior relation, in the emotional neglect-overall problem behavior relation, in the emotional neglect-depression relation, and in the emotional neglect-agoraphobia relation. In all cases in which locus of control emerged as a moderator, the significance only occurred at lower levels of locus of control (except two in which high and low levels of locus of control were significant). Thus, as hypothesized, internal locus of control appeared to moderate the relation between child maltreatment and the different outcomes. Although individuals with an internal locus of control in the current study appeared to have more problems as the levels of abuse increased, locus of control appeared to serve a moderating role and likely buffered the effects that might have been seen otherwise.

\section{Attachment Style as a Moderator}

Confidence. The confidence style of attachment based on scores on the ASQ served as a moderator in the relation between sexual abuse and permissiveness. Although individuals with high and low levels of the confidence attachment style did not differ significantly in their responding, they tended to disagree less with permissive statements as levels of sexual abuse increased. Of note, however, is the fact that the mean score on the measure of permissiveness was $4.2(S D=.70)$, suggesting that most individuals either moderately disagreed (score of 4$)$ or strongly disagreed (score of 5) with the statements or were neutral (score of 3). Therefore, these 
results do not necessarily suggest that these individuals were more permissive.

Need for approval. The need for approval style of attachment, based on scores on the ASQ, served as a moderator in the relation between physical abuse and depression, physical abuse and general anxiety, emotional neglect and permissiveness, and physical neglect and permissiveness. Feeney et al. (1994) suggest that the need for approval attachment style is reflective of an individual who needs others for acceptance and confirmation. Thus, individuals who reported higher and lower levels of the need for approval attachment style reported more depressive and anxiety symptoms as levels of physical abuse increased. Fewer disagreements with permissive attitudes were observed in those individuals who scored lower on the need for approval subscale of the ASQ; however, this result, as noted earlier, should be interpreted cautiously as scores on this measure do not necessarily reflect an individual's permissiveness, especially as the mean scores fall at the neutral range or above (i.e., in the range for disagreeing).

Discomfort with closeness. The discomfort with closeness style of attachment based on scores on the ASQ served as a moderator in the relation between physical abuse and depression, emotional neglect and permissiveness, and physical neglect and permissiveness. Feeney et al. (1994) suggest that the discomfort with closeness attachment style is akin to avoidant attachment. The individual may find it difficult to depend on others or to trust other people and may be uneasy about getting close to others. In each of the cases in the present study in which discomfort with closeness emerged as a moderator, the level of problematic behavior increased as levels of the predictor and moderator variables increased.

Preoccupation with relationships. The preoccupation with relationships style of attachment based on scores on the ASQ served as a moderator in the relation between physical abuse and permissiveness. The preoccupation with relationships attachment style involves an 
anxious reaching out to others in order to fulfill dependency needs. In the current study, if individuals were physically abused and had high or low levels of the preoccupation with relationships attachment style, they were more likely to disagree with permissive statements.

Relationships as secondary. Individuals who are characterized with the relationships as secondary style of attachment often attempt to protect themselves from hurt and vulnerability by emphasizing achievement and independence. In the current study, the relationships as secondary style of attachment served as a moderator in the relation between physical abuse and anxiety, physical neglect and permissiveness, and physical neglect and general anxiety. Individuals who reported higher and lower levels of the relationships as secondary attachment style were more likely to report higher levels of anxiety and to disagree less often with permissive statements.

As can be seen in these descriptions of the role of attachment style in moderating outcome, it appears that different attachment styles are instrumental in moderating or buffering the effects of different outcomes. Thus, the hypothesis that the confidence style of attachment would be the only attachment style that moderated effects was not supported. The nature of these attachment styles may play a role in these results. For example, the relationships as secondary style of attachment is characterized by a dependence on others for acceptance and confirmation. Thus, it is not surprising that this style of attachment moderates the relation between maltreatment and depression and anxiety.

\section{Potential Limitations}

While this study included an examination of a number of variables purported to promote resilience, the specific variables that may be more or less associated with specific types of abuse were not delineated. For example, research on sexual abuse has demonstrated that threats, force, and violence by the perpetrator are associated with greater negative outcome than when these 
things are not present (Beitchman et al., 1992; Browne \& Finkelhor, 1986). In addition, less serious forms of sexual contact (e.g., unwanted kissing and fondling of clothed body parts) are often less traumatic than more serious forms (e.g., vaginal or anal intercourse; Bagley \& Ramsay, 1986; Elwell \& Ephross, 1987; Mennen \& Meadow, 1995). These variables were not included in the present study, and, as such, the results from this study may not give the best estimate of variables that will buffer the effects of sexual abuse. In addition, one outcome that commonly occurs in response to traumatic events, posttraumatic stress disorder (PTSD), was not measured in the current study. If included, this outcome measure may have yielded a different set of moderator variables. Of the outcome variables that were measured (e.g., social anxiety, general anxiety, depression), participants, for the most part, appeared to be relatively healthy, often scoring lower than the comparison samples. Thus, the sample was composed of a skewed distribution in terms of outcomes, which may have affected the number of variables that emerged as moderators.

Another limitation of this sample is that it was composed primarily of Caucasian college students, which is not representative of the general population of abused and neglected individuals. In addition, questionnaires were completed in a self-report format, which may not have accurately captured all of the constructs measured. Participants also were asked to complete approximately 15 different questionnaires (some of which contained 70+ items); thus, participants may not have attended to each item on each questionnaire properly. Finally, the correlational nature of the study did not allow causal associations to be established.

\section{Future Directions}

Future research examining resilience and ways to promote resilience in abused and neglected children is warranted. Salter et al. (2003) demonstrated that $20-44 \%$ of victims of child 
sexual abuse experience no symptoms or mental health problems. Similar results have been established for the other types of maltreatment. The delineation of factors that potentiate outcome for each of the maltreatment subtypes is necessary, particularly in the development of preventive interventions. Also of importance is the frequency and severity of the abusive incidents. There are numerous biological, genetic, environmental, individual, and situational factors that can moderate outcome; thus, an ideal study will examine all of these factors in the same sample. There also is a dire need for longitudinal projects to explore new pathways between child maltreatment and outcome. Methodologically, research in this area could be improved by incorporating observational and interview data.

\section{Conclusion}

Results from the current study suggest that numerous variables emerge as moderators in the maltreatment-outcome relation (e.g., social support, locus of control). Of particular importance in the current study is the fact that a large number of individuals maltreated as children did not develop any significant problems. All of the individuals in the current study were enrolled in college courses and likely were not as severely affected by maltreatment as other individuals. This observation further highlights the need to attend to strengths within the individual. There is much to be learned from resilient individuals; if we can better understand the construction of resilience in victims, we will have new prospects for prevention efforts. 


\section{References}

Aiken, L. S., \& West, S. G. (1991). Multiple regression: Testing and interpreting interactions. Newbury Park, CA: Sage.

Alexander, P. C. (1992). Application of attachment theory to the study of sexual abuse. Journal of Consulting \& Clinical Psychology, 60, 185-195.

Arellano, C. M. (1996). Child maltreatment and substance use: A review of the literature. Substance Use and Misuse, 31, 927-935.

Azar, S. T., Povilaitis, T. Y., Lauretti, A. F., \& Pouquette, C. L. (1998). The current status of etiological theories of intrafamilial child maltreatment. In J. R. Lutzker (Ed.), Handbook of child abuse research and treatment (pp. 3-30). New York: Plenum.

Bagley, C., \& Mallick, K. (1998). Prediction of sexual, emotional, and physical maltreatment and mental health outcomes in a longitudinal cohort of 290 adolescent women. Child Maltreatment: Journal of the American Professional Society on the Abuse of Children, 5, 218-226.

Bagley, C., \& Ramsay, R. (1986). Sexual abuse in childhood: Psychological outcomes and implications for social work practice. Journal of Social Work and Human Sexuality, 4, $33-47$.

Beck, A. T., Epstein, N., Brown, G., \& Steer, R. A. (1988). An inventory for measuring clinical anxiety: Psychometric properties. Journal of Consulting \& Clinical Psychology, 56, 893897.

Beck, A.T., Steer, R. A., \& Brown, G. (1996). Manual for the Beck Depression Inventory-II. San Antonio, TX: Psychological Corporation.

Beitchman, J., Zucker, K., Hood, J., da Costa, G., Akman, D., \& Cassavia, E. (1992). A review 
of the long-term effects of child sexual abuse. Child Abuse \& Neglect, 16, 101-118.

Bernstein, D. P., \& Fink, L. (1998). Childhood Trauma Questionnaire: A retrospective selfreport. Manual. San Antonio, TX: Psychological Corporation.

Binggeli, N. J., Hart, S. N., \& Brassard, M. R. (2001). Psychological maltreatment: A study guide. Thousand Oaks, CA: Sage.

Blum, R. W., Beuhring, T., \& Rinehart, P. M. (2000). Protecting teens: Beyond race, income, and family structure. Minneapolis, MN: Center for Adolescent Health, University of Minnesota.

Bolger, K. E., \& Patterson, C. J. (2001). Pathways from child maltreatment to internalizing problems: Perceptions of control as mediators and moderators. Development \& Psychopathology, 13, 913-940.

Boney-McCoy, S., \& Finkelhor, D. (1995). Psychosocial sequelae of violent victimization in a national youth sample. Journal of Consulting and Clinical Psychology, 63, 726-736.

Bowlby, J. (1969/1982). Attachment and loss: Vol. 1. Attachment. (2 ${ }^{\text {nd }}$ ed.). New York: Basic Books.

Bowlby, J. (1972). Attachment and loss: Vol. 2. Separation, anxiety, and anger. New York: Basic Books.

Bowlby, J. (1980). Attachment and loss: Vol. 3. Loss, sadness, and depression. New York: Basic Books.

Boyd, C., Guthrie, B., Pohl, J., Whitmarsh, J., \& Henderson, D. (1994). African-American women who smoke crack cocaine: Sexual trauma and the mother-daughter relationship. Journal of Psychoactive Drugs, 26, 243-247.

Briere, J. N. (1992). Child abuse trauma: Theory and treatment of the lasting effects. Newbury 
Park, CA: Sage.

Brown, J., Cohen, P., Johnson, J. G., \& Salzinger, S. (1998). A longitudinal analysis of risk factors for child maltreatment: Findings of a 17-year prospective study of officially recorded and self-reported child abuse and neglect. Child Abuse \& Neglect, 22, 1065 1078.

Browne, A., \& Finkelhor, D. (1986). Impact of child sexual abuse: A review of the research. Psychological Bulletin, 99, 66-77.

Bryer, J. B., Nelson, B. A., Miller, J. B., \& Krol, P. A. (1987). Childhood sexual and physical abuse as factors in adult psychiatric illness. American Journal of Psychiatry, 144, 14261430.

Cicchetti, D., \& Lynch, M. (1993). Toward an ecological/transactional model of community violence and child maltreatment: Consequences for children's development. Psychiatry, 56, 96-118.

Cicchetti, D., Rogosch, F. A., Lynch, M., \& Holt, K. D. (1993). Resilience in maltreated children: Processes leading to adaptive outcome. Development \& Psychopathology, 5, $629-647$.

Cicchetti, D., \& Toth, S. L. (1995). Child maltreatment and attachment organization: Implications for intervention. In S. Goldberg, R. Muir, \& J. Kerr (Eds.), Attachment theory: Social developmental and clinical perspectives (pp. 279-308). Hillsdale, NJ: Analytic Press.

Cole-Detke, H., \& Kobak, R. (1996). Attachment processes in eating disorder and depression. Journal of Consulting \& Clinical Psychology, 64, 282-290.

Conroy, M. A., \& Brown, W. H. (2004). Early identification, prevention, and early intervention 
with young children at risk for emotional or behavioral disorders: Issues, trends, and a call for action. Behavioral Disorders, 29, 224-236.

Conte, J. R., \& Schuerman, J. R. (1987). Factors associated with an increased impact of child sexual abuse. Child Abuse \& Neglect, 11, 201-211.

Crittenden, P. M., \& Ainsworth, M. D. S. (1989). Child maltreatment and attachment theory. In D. Cicchetti \& V. Carlson (Eds.), Child maltreatment: Theory and research on the causes and consequences of child abuse and neglect (pp. 432-463). New York: Cambridge University Press.

Dixon, D. N., McKee, C. S., \& McRae, B. C. (1976). Dimensionality of three adult, objective locus of control scales. Journal of Personality Assessment, 40, 310-319.

Doll, B., \& Lyon, M. A. (1998). Risk and resilience: Implications for the delivery of educational and mental health services in schools. School Psychology Review, 27, 348-363.

Downs, W. R., \& Miller, B. A. (1998). Relationships between experiences of parental violence during childhood and women's psychiatric symptomatology. Journal of Interpersonal Violence, 13, 438-455.

Dozois, D. J., Dobson, K. S., \& Ahnberg, J. L. (1998). A psychometric evaluation of the Beck Depression Inventory-II. Psychological Assessment, 10, 83-89.

Eccles, J., \& Gootman, J. A. (Eds.). (2002). Community programs to promote youth development. Washington D.C.: National Academy Press.

Elliott, M., \& Briere, J. (1992). Sexual abuse trauma among professional women: Validating the Trauma Symptom Checklist-40 (TSC-40). Child Abuse \& Neglect, 16, 391-398.

Elwell, M. E., \& Ephross, P. H. (1987). Initial reactions of sexually abused children. Social Casework, 68, 109-116. 
Eng, W., Heimberg, R. G., Hart, T. A., Schneier, F. R., \& Liebowitz, M. R. (2001). Attachment in individuals with social anxiety disorder: The relationship among adult attachment styles, social anxiety, and depression. Emotion, 1, 365-380.

Erickson, M. F., \& Egeland, B. (1996). Child neglect. In J. Briere, L. Berliner, J. A. Bulkley, C. Jenny, \& T. Reid (Eds.), The APSAC handbook on child maltreatment (pp. 4-20). Thousand Oaks, CA: Sage.

Everill, J., \& Waller, G. (1994). Disclosure of sexual abuse and psychological adjustment in female undergraduates. Child Abuse \& Neglect, 19, 93-100.

Feeney, J. A., Noller, P., \& Hanrahan, M. (1994). Assessing adult attachment. In M. B. Sperling \& W. H. Berman (Eds.), Attachment in adults: Clinical and developmental perspectives (pp. 128-154). New York: Guilford.

Finkelhor, D. (1979). What's wrong with sex between adults and children? Ethics and the problem of sexual abuse. American Journal of Orthopsychiatry, 49, 692-697.

Finkelhor, D. (1990). Early and long-term effects of child sexual abuse: An update. Professional Psychology: Research and Practice, 21, 325-330.

Finkelhor, D. (1994). Current information on the scope and nature of child sexual abuse. Future of Children, 4, 31-53.

Fonagy, P., Leigh, T., Steele, M., Steele, H., Kennedy, R., Mattoon, G., Target, M., \& Gerber, A. (1996). The relation of attachment status, psychiatric classification, and response to psychotherapy. Journal of Consulting \& Clinical Psychology, 64, 22-31.

Fortson, B. L. (2003). Using the Internet to Collect Data on Psychological Symptoms: An Investigation of Psychometric Properties. Unpublished master's thesis, West Virginia University. 
Fraley, R. C., \& Brumbaugh, C. C. (2004). A dynamical systems approach to conceptualizing and studying stability and change in attachment security. In W. S. Rholes \& J. A. Simpson (Eds.). Adult attachment: Theory, research, and clinical implications (pp. 86132). NY: Guilford.

Fraser, M. W., Richman, J. M., \& Galinski, M. J. (1999). Risk, protection, and resilience: Toward a conceptual framework for social work practice. Social Work Research, 23, 131142.

Goglia, L. R., Jurkovic, G. J., Burt, A. M., \& Burge-Callaway, K. G. (1992). Generational boundary distortions by adult children of alcoholics: Child-as-parent and child-as-mate. American Journal of Family Therapy, 20, 291-299.

Hawkins, J. D., Jenson, J. M., Catalano, R. F., \& Lishner, D. M. (1988). Delinquency and drug abuse: Implications for social services. Social Service Review, 62, 258-284.

Hawley, D. R., \& DeHaan, L. (1996). Toward a definition of family resiliency: Integrating lifespan and family perspectives. Family Processes, 35, 283-298.

Hendrick, S., \& Hendrick, C. (1987). Multidimensionality of sexual attitudes. The Journal of Sex Research, 23, 502-526.

Hoffman-Plotkin, D., \& Twentyman, C. T. (1984). A multimodal assessment of behavioral and cognitive deficits in abused and neglected preschoolers. Child Development, 55, 794-802.

Hoglund, C. L., \& Nicholas, K. B. (1995). Shame, guilt, and anger in college students exposed to abusive family environments. Journal of Family Violence, 10, 141-157.

Holmbeck, G. (2002). Post-hoc probing of significant moderational and mediational effects in studies of pediatric populations. Journal of Pediatric Psychology, 27, 87-96.

Horowitz, M., Wilner, N., \& Alvarez, W. (1979). Impact of Event Scale: A measure of 
subjective distress. Psychosomatic Medicine, 41, 209-218.

Jurkovic, G. J. (1997). Lost childhoods: The flight of the parentified child. New York: Brunner/ Mazel.

Kaufman, J., \& Zigler, E. (1987). Do abused children become abusive parents? American Journal of Orthopsychiatry, 57, 186-192.

Kelley, B. T., Thornberry, T. P., \& Smith, C. A. (1997). In the wake of childhood maltreatment. Washington, DC: National Institute of Justice.

Kendall-Tackett, K., Williams, L., \& Finkelhor, D. (1993). Impact of sexual abuse on children: A review and synthesis of recent empirical studies. Psychological Bulletin, 113, 164-180.

Kent, A., \& Waller, G. (1998). The impact of childhood emotional abuse: An extension of the child abuse and trauma scale. Child Abuse \& Neglect, 22, 393-399.

Kilpatrick, D. G., Acierno, R., Saunders, B., Resnick, H. S., Best, C. L., \& Schnurr, P. P. (2000). Risk factors for adolescent substance abuse and dependence: Data from a national sample. Journal of Consulting and Clinical Psychology, 68, 19-30.

Kilpatrick, D. G., Ruggiero, K. J., Acierno, R. E., Saunders, B. E., Resnick, H. S., \& Best, C. L. (2003). Violence and risk of PTSD, major depression, substance abuse/dependence, and comorbidity: Results from the National Survey of Adolescents. Journal of Consulting and Clinical Psychology, 71, 692-700.

Kruttschnitt, C., Ward, D., \& Shele, M. A. (1987). Abuse-resistant youth: Some factors that may inhibit violent criminal behavior. Social Forces, 66, 501-519.

Litty, C. G., Kolwaski, R., \& Minor, S. (1996). Moderating effects of physical abuse and perceived social support on the potential to abuse. Child Abuse \& Neglect, 20, 305-314.

Luthar, S. S., \& Zigler, E. (1991). Vulnerability and competence: A review of research on 
resilience in childhood. American Journal of Orthopsychiatry, 61, 6-22.

Lynskey, M. T., \& Fergusson, D. M. (1997). Factors protecting against the development of adjustment difficulties in young adults exposed to childhood sexual abuse. Child Abuse and Neglect, 21, 1177-1190.

Malinosky-Rummell, R., \& Hansen, D. J. (1993). Long-term consequences of childhood physical abuse. Psychological Bulletin, 114, 68-79.

Marshall, L. L., \& Rose, P. (1990). Premarital violence: The impact of family of origin violence, stress, and reciprocity. Violence and Victims, 5, 51-64.

Masten, A. S. (1994). Resilience in individual development: Successful adaptation despite risk and adversity. In M. C. Wang \& E. W. Gordon (Eds.), Educational resilience in innercity America: Challenges and prospects (pp. 3-25). Hillsdale, NJ: Erlbaum.

Masten, A. S., Best, K. M., \& Garmezy, N. (1990). Resilience and development: Contributions from the study of children who overcome adversity. Development and Psychopathology, 2, 425-444.

Masten, A. S., \& Coatsworth, J. D. (1998). The development of competence in favorable and unfavorable environments: Lessons from research on successful children. American Psychologist, 53, 205-220.

McCord, J. (1983). A forty year perspective on effects of child abuse and neglect. Child Abuse \& Neglect, 7, 265-270.

McLeer, S. V., Callaghan, M., Henry, D., \& Wallen, J. (1994). Psychiatric disorders in sexually abused children. Journal of the American Academy of Child \& Adolescent Psychiatry, 33, 313-319.

McLeer, S. V., \& Ruggiero, K. (2000). Short-term correlates of child sexual abuse: Prevalence 
of psychiatric symptoms. Unpublished manuscript.

McNally, R. J. (1999). Posttraumatic stress disorder. In T. Millon \& P. H. Blaney (Eds.), Oxford textbook of psychopathology (pp. 144-165). New York: Oxford.

Mennen, F. E., \& Meadow, D. (1995). A preliminary study of the factors related to trauma in childhood sexual abuse. Journal of Family Violence, 9, 125-142.

Merry, S., \& Andrews, L. K. (1994). Psychiatric status of sexually abused children 12 months after disclosure of abuse. Journal of the American Academy of Child and Adolescent Psychiatry, 33, 939-944.

Miller-Perrin, C. L., \& Perrin, R. D. (1999). Child maltreatment: An introduction. Thousand Oaks, CA: Sage.

Morrison, J. A., Frank, S. J., Holland, C. C., \& Kates, W. R. (1999). Emotional development and disorders in young children in the child welfare system. In J. A. Silver, B. J. Amster, \& T. Haecker (Eds.), Young children and foster care: A guide for professionals (pp. 33-64). Baltimore, MD: Paul H. Brookes.

Murphy, B., \& Bates, G. W. (1997). Adult attachment style and vulnerability to depression. Personality and Individual Differences, 22, 835-844.

Nagel, D. E., Putnam, F. W. Noll, J. G., \& Trickett, P. K. (1997). Disclosure patterns of sexual abuse and psychological functioning at a 1-year follow-up. Child Abuse and Neglect, 21, $137-147$.

National Institute on Drug Abuse. (1998). Exploring the role of child abuse on later drug abuse. NIDA Notes, 13(2). Retrieved February 8, 2005, from www.nida.nih.gov/NIDA_Notes/ NNVol13N2/exploring.html

Newton, C. J. (2001). Child Abuse: An Overview. TherapistFinder.net Mental Health Journal. 
Retrieved February 5, 2005, from http://www.therapistfinder.net/Child-Abuse/.

Perkins, D. F., \& Jones, K. R. (2004). Risk behaviors and resiliency within physically abused adolescents. Child Abuse and Neglect, 28, 547-563.

Perkins, D. F., Luster, T., \& Jank, W. (2002). Protective factors that decrease the likelihood of purging for physically abused females. Journal of Adolescent Research, 17, 377-400.

Perkins, D. F., Luster, T., Villarruel, F. A., \& Small, S. (1998). An ecological, risk-factor examination of adolescents' sexual activity in three ethnic groups. Journal of Marriage and the Family, 60, 660-673.

Perrin, S., Smith, P., \& Yule, W. (2000). Practitioner review: The assessment and treatment of post-traumatic stress disorder in children and adolescents. Journal of Child Psychology and Psychiatry and Allied Disciplines, 41, 277-289.

Perry, B. D. (2002). Childhood experience and the expression of genetic potential: What childhood neglect tells us about nature and nurture. Brain and Mind, 3, 79-100.

Peters, D., \& Range, L. (1995). Childhood sexual abuse and current suicidality in college women and men. Child Abuse \& Neglect, 19, 335-341.

Procidano, M. E., \& Heller, K. (1983). Measures of perceived social support from friends and from family: Three validation studies. American Journal of Community Psychology, 11, $1-24$

Rabalais, A. E., Ruggiero, K. J., \& Scotti, J. R. (2002). Multicultural issues in the response of children to disasters. In A. M. La Greca, W. K. Silverman, E. M. Vernberg, \& M. C. Roberts (Eds.), Helping children cope with disasters and terrorism (pp. 73-99). Washington, DC: American Psychological Association.

Read, J. (1997). Child abuse and psychosis: A literature review and implications for professional 
practice. Professional Psychology: Research and Practice, 28, 448-456.

Read, J. (1998). Child abuse and severity of disturbance among adult psychiatric inpatients. Child Abuse and Neglect, 22, 359-368.

Reinecke, M. A., \& Rogers, G. M. (2001). Dysfunctional attitudes and attachment style among clinically depressed adults. Behavioural and Cognitive Psychotherapy, 29, 129-141.

Riggs, D. S., O'Leary, K. D., \& Breslin, F. C. (1990). Multiple correlates of physical aggression in dating couples. Journal of Interpersonal Violence, 5, 61-73.

Roberts, J. E., Gotlib, I. H., \& Kassel, J. D. (1996). Adult attachment security and symptoms of depression: The mediating roles of dysfunctional attitudes and low self-esteem. Journal of Personality \& Social Psychology, 70, 310-320.

Rust, J. O., \& Troupe, P. A. (1991). Relationships of treatment of child sexual abuse with school achievement and self-concept. Journal of Early Adolescence, 11, 420-429.

Rotter, J. B. (1966). Generalized expectancies for internal versus external control of reinforcement. Psychological Monographs: General and Applied, 80, 1-28.

Rutter, M. (1979). Protective factors in children's response to stress and disadvantage. In M. W. Kent \& J. E. Rolf (Eds.), Primary prevention of psychopathology, Vol. 3: Social competence in children (pp. 49-74). Hanover, NH: University Press of New England.

Rutter, M. (1985). Resilience in the face of adversity: Protective factors and resistance to psychiatric disorder. British Journal of Psychiatry, 147, 598-611.

Rutter, M. (1987). Psychosocial resilience and protective mechanisms. American Journal of Orthopsychiatry, 37, 317-331.

Sack, W. H., Clarke, G., Him, C., Dickason, D., Goff, B., Lanham, K., \& Kinzie, J. D. (1993). A six-year follow-up of Cambodian adolescents. Journal of the American Academy of Child 
and Adolescent Psychiatry, 32, 3-15.

Saigh, P. A., Green, B. A., \& Korol, M. (1996). The history and prevalence of posttraumatic stress disorder with special reference to children and adolescents. Journal of School Psychology, 34, 107-131.

Salter, D., McMillan, D., Richards, M., Talbot, T., Hodges, J., Bentovim, A., Hastings, R., Stevenson, J., \& Skuse, D. (2003). Development of sexually abusive behaviour in sexually victimised males: A longitudinal study. Lancet, 361, 471-476.

Schumacher, J. A., Slep, A. M. S., \& Heyman, R. E. (2001). Risk factors for child neglect. Aggression and Violent Behavior, 6, 231-254.

Schwab-Stone, M., Ayers, T. S., Kasprow, W., Voyce, C., Barone, C., Shriver, T., et al. (1995). No safe haven: A study of violence exposure in an urban community. Journal of the American Academy of Child and Adolescent Psychiatry, 34, 1343-1352.

Scotti, J. R., Ruggiero, K. J., Rabalais, A., Parker, L., Smith, T., \& Del Ben, K. (2000, November). History of Psychosocial Stressors: Conceptualization, utilization, validity, and test-retest reliability. Paper presented at the 34th annual convention of the Association for Advancement of Behavior Therapy, New Orleans, LA.

Sedlak, A. J., \& Broadhurst, D. D. (1996). Executive summary of the Third National Incidence Study of Child Abuse and Neglect. Washington, D.C.: U.S. Department of Health and Human Services.

Seifer, R., Sameroff, A. J., Baldwin, A., \& Baldwin, C. (1992). Child and family factors that ameliorate risk between 4 and 13 years of age. Journal of the American Academy of Child and Adolescent Psychiatry, 31, 893-903.

Sessions, M., \& Jurkovic, G. J. (1986). The Parentification Questionnaire. (Available from 
Gregory J. Jurkovic, Department of Psychology, Georgia State University, University Plaza, Atlanta, GA 30303).

Shields, A., \& Cicchetti, D. (1998). Reactive aggression among maltreated children: The contributions of attention and emotion dysregulation. Journal of Clinical Child Psychology, 27, 381-395.

Shore, R. (1997). Rethinking the brain. New York: Families and Work Institute.

Sidebotham, P., Golding, J., and the ALSPAC Study Team. (2001). Child maltreatment in the "Children of the Nineties": A longitudinal study of parental risk factors. Child Abuse and Neglect, 25, 1177-1200.

Silverman, A. B., Reinherz, H. Z., \& Giaconia, R. M. (1996). The long-term sequelae of child and adolescent abuse: A longitudinal community study. Child Abuse and Neglect, 20, 709-723.

Sirles, E. A., Smith, J. A., \& Kusama, H. (1989). Psychiatric status of intrafamilial child sexual abuse victims. Journal of the American Academy of Child \& Adolescent Psychiatry, 28, 225-229.

Stern, A. E., Lynch, D. L., Oates, R. K., O’Toole, B. I., \& Cooney, G. (1995). Self esteem, depression, behaviour and family functioning in sexually abused children. Journal of Child Psychology and Psychiatry, 36, 1077-1089.

Straus, M. A., Hamby, S. L., Finkelhor, D., Moore, D. W., \& Runyan, D. (1998). Identification of child maltreatment with the parent-child Conflict Tactics Scales: Development and psychometric data for a national sample of American parents. Child Abuse and Neglect, 22, 249-270.

Strodl, E., \& Noller, P. (2003). The relationship of adult attachment dimensions to depression 
and agoraphobia. Personal Relationships, 10, 171-185.

Swett, C., Surrey, J., \& Cohen, C. (1990). Sexual and physical abuse histories and psychiatric symptoms among male psychiatric outpatients. American Journal of Psychiatry, 147, 632-636.

Tabachnick, B. G., \& Fidell, L. S. (2001). Using multivariate statistics. Boston: Allyn \& Bacon.

Tarter, R. (1990). Evaluation and treatment of adolescent substance abuse: A decision tree method. American Journal of Drug and Alcohol Abuse, 16, 1-46.

Tarter, R., Laird, S., Bukstein, O., \& Kaminer, Y. (1992). Validation of the Drug Use Screening Inventory: Preliminary findings. Psychology of Addictive Behaviors, 6, 233-236.

Tarter, R., Mezzich, A., Kirisci, L., \& Kaczynski, N. (1994). Reliability of the Drug Use Screening Inventory among adolescent alcoholics. Journal of Child and Adolescent Substance Abuse, 3, 25-36.

Thompson, K. M., Crosby, R. D., Wonderlich, S. A., Mitchell, J. E., Redlin, J., Demuth, G., Smyth, J., \& Haseltine, B. (2003). Psychopathology and sexual trauma in childhood and adulthood. Journal of Traumatic Stress, 16, 35-38.

Tong, L., Oates, K., \& McDowell, M. (1987). Personality development following sexual abuse. Child Abuse \& Neglect, 11, 371-383.

Turner, S. M., Beidel, D. C., Dancu, C. B, \& Stanley, M. A. (1989). An empirically derived inventory to measure social fears and anxiety: The Social Phobia and Anxiety Inventory. Psychological Assessment, 1, 35-40.

U. S. Department of Health and Human Services (DHHS), Administration for Children and Families. (2004). Child maltreatment 2002. Washington, DC: Government Printing Office. Retrieved February 2, 2005, from www.acf.hhs.gov/programs/cb/publications/ 
cmreports.htm.

Vernberg, E. M., \& Varela, R. E. (2001). Posttraumatic stress disorder: A developmental perspective. In M. W. Vasey \& M. R. Dadds (Eds.), The developmental psychopathology of anxiety (pp. 386-406). New York: Oxford University.

Vogeltanz, N. D., Wilsnack, S. C., Harris, T. R., Wilsnack, R. W., Wonderlich, S. A., \& Kristjanson, A. F. (1999). Prevalence and risk factors for childhood sexual abuse in women: National survey findings. Child Abuse and Neglect, 23, 579-592.

Vondra, J. I., Hommerding, K. D., \& Shaw, D. S. (1999). Stability and change in infant attachment style in a low-income sample. Monographs of the Society for Research in Child Development, 64, 119-144.

Waters, E., Posada, G., Crowell, J., \& Lay, K. (1993). Is attachment theory ready to contribute to our understanding of disruptive behavior problems? Development and Psychopathology, $5,215-224$.

Wekerle, C., \& Wolfe, D. A. (1996). Child maltreatment. In E. J. Mash \& R. A. Barkley (Eds.), Child psychopathology (pp. 492-540). New York: Guilford.

Werner, E., \& Smith, R. (1992). Overcoming the odds: High risk children from birth to adulthood. Ithaca, NY: Cornell University.

Whipple, E. E., \& Webster-Stratton, C. (1991). The role of parental stress in physically abusive families. Child Abuse \& Neglect, 15, 279-291.

Widom, C. S. (1994). Childhood victimization and risk for adolescent problem behaviors. In M. E. Lamb \& R. Ketterlinus (Eds.), Adolescent problem behaviors (pp. 127-164). Mahwah, NJ: Erlbaum.

Widom, C. S., \& Maxfield, M. G. (2001). An update on the 'cycle of violence.' Washington, DC: 
National Institute of Justice.

Wodarski, J. S., Kurtz, P. D., Gaudin, J. M., \& Howing, P. T. (1990). Maltreatment and the school age child: Major academic, socioemotional, and adaptive outcomes. Social Work, 35, 506-513.

Wyatt, G. E. (1988). The relationship between child sexual abuse and adolescent sexual functioning in Afro-American and white American women. Annals of the New York Academy of Sciences, 111-122.

Youngblade, L. M., \& Belsky, J. (1990). Social and emotional consequences of child maltreatment. In R. T. Ammerman \& M. Hersen (Eds.), Children at risk: An evaluation of factors contributing to child abuse and neglect (pp. 109-146). New York: Plenum.

Zimet, G. D., Dahlem, N. W., Zimet, S. G., \& Farley, G. K. (1988). The Multidimensional Scale of Perceived Social Support. Journal of Personality Assessment, 52, 30-41. 
Table 1

Parents' Educational Level

\begin{tabular}{lcccc}
\hline & \multicolumn{2}{c}{ Mother } & \multicolumn{2}{c}{ Father } \\
\cline { 2 - 5 } Level of Education & Frequency & Percent & Frequency & Percent \\
\hline No high school diploma & 3 & .6 & 14 & 2.8 \\
High school graduate, no college & 133 & 26.5 & 121 & 24.1 \\
Some college education, no degree & 126 & 25.1 & 113 & 22.5 \\
Degree from 4-year college or more & 238 & 47.4 & 246 & 49 \\
\hline
\end{tabular}


Table 2

Guidelines for Classification of CTQ Scale Total Scores

\begin{tabular}{lcccc}
\hline & \multicolumn{2}{c}{ Classification } & \\
\cline { 2 - 4 } & None & Low & Moderate & Severe \\
Scale & (or Minimal) & (to Moderate) & (to Severe) & (to Extreme) \\
\hline Emotional Abuse & $5-8$ & $9-12$ & $13-15$ & $\geq 16$ \\
Physical Abuse & $5-7$ & $8-9$ & $10-12$ & $\geq 13$ \\
Sexual Abuse & 5 & $6-7$ & $8-12$ & $\geq 13$ \\
Emotional Neglect & $5-9$ & $10-14$ & $15-17$ & $\geq 18$ \\
Physical Neglect & $5-7$ & & & \\
\hline
\end{tabular}

Note. This table was taken from Bernstein \& Fink (1998; p. 55). 
Table 3

Means and Standard Deviations of Measures and Comparisons with Available Norms

\begin{tabular}{|c|c|c|c|c|c|}
\hline Scale & Gender & $\begin{array}{l}\text { Current } \\
\text { Sample } \\
(M, S D)\end{array}$ & $\begin{array}{l}\text { Comparison } \\
\text { Sample } \\
(M, S D)\end{array}$ & t Value & z-Score \\
\hline History of Psychosocial Stressors - & Male & $2.9(2.0)$ & NA & NA & NA \\
\hline \multirow[t]{2}{*}{ Experienced Personally } & Female & $2.6(1.8)$ & NA & NA & NA \\
\hline & Total & $2.7(1.8)$ & $2.8(2.0)$ & -1.2 & -.05 \\
\hline History of Psychosocial Stressors - & Male & $1.4(1.5)$ & NA & NA & NA \\
\hline \multirow[t]{2}{*}{ Witnessed } & Female & $1.7(1.9)$ & NA & NA & NA \\
\hline & Total & $1.6(1.8)$ & $2.2(2.6)$ & $-7.1 * * *$ & -.23 \\
\hline Childhood Trauma Questionnaire - & Male & $8.1(3.5)$ & $8.5(4.0)$ & -1.5 & -.37 \\
\hline \multirow[t]{2}{*}{ Emotional Abuse Subscale } & Female & $8.5(4.6)$ & $10.6(5.2)$ & $-8.8 * * *$ & -.30 \\
\hline & Total & $8.4(4.3)$ & NA & NA & NA \\
\hline Childhood Trauma Questionnaire - & Male & $6.9(2.9)$ & $6.9(3.1)$ & .2 & -.44 \\
\hline \multirow[t]{2}{*}{ Physical Abuse Subscale } & Female & $6.5(2.9)$ & $6.3(2.4)$ & 1.0 & -.23 \\
\hline & Total & $6.6(2.9)$ & NA & NA & NA \\
\hline Childhood Trauma Questionnaire - & Male & $5.3(1.5)$ & $5.2(1.0)$ & .8 & -.35 \\
\hline \multirow[t]{2}{*}{ Sexual Abuse Subscale } & Female & $5.7(2.6)$ & $5.6(1.4)$ & 6 & -.35 \\
\hline & Total & $5.6(2.4)$ & NA & NA & NA \\
\hline Childhood Trauma Questionnaire - & Male & $9.2(3.9)$ & $9.7(4.3)$ & -.2 & -.37 \\
\hline \multirow[t]{2}{*}{ Emotional Neglect Subscale } & Female & $8.8(4.3)$ & $9.2(4.4)$ & -1.9 & -.42 \\
\hline & Total & $8.9(4.2)$ & NA & NA & NA \\
\hline Childhood Trauma Questionnaire - & Male & $6.4(2.0)$ & $6.8(2.2)$ & -2.1 & -.39 \\
\hline \multirow[t]{2}{*}{ Physical Neglect Subscale } & Female & $6.0(2.0)$ & $6.1(1.9)$ & -1.2 & -.29 \\
\hline & Total & $6.1(2.0)$ & NA & NA & NA \\
\hline
\end{tabular}

(table continues) 


\begin{tabular}{|c|c|c|c|c|c|}
\hline Scale & Gender & $\begin{array}{l}\text { Current } \\
\text { Sample } \\
(M, S D)\end{array}$ & $\begin{array}{l}\text { Comparison } \\
\text { Sample } \\
(M, S D)\end{array}$ & t Value & Z-Score \\
\hline Multidimensional Scale of Perceived & Male & $5.5(1.2)$ & $5.6(1.5)$ & -.8 & -.07 \\
\hline \multirow[t]{2}{*}{ Social Support - Past - Friends } & Female & $6.0(1.1)$ & $6.0(1.1)$ & .8 & .00 \\
\hline & Total & $5.9(1.1)$ & $5.5(1.2)$ & $7.8 * * *$ & .33 \\
\hline Multidimensional Scale of Perceived & Male & $5.5(1.4)$ & $5.5(1.6)$ & -.01 & .00 \\
\hline \multirow[t]{2}{*}{ Social Support - Past - Family } & Female & $5.8(1.4)$ & $5.1(1.8)$ & $8.9 * * *$ & .39 \\
\hline & Total & $5.7(1.4)$ & $5.5(1.1)$ & $3.0 * *$ & .18 \\
\hline Multidimensional Scale of Perceived & Male & $5.7(1.3)$ & $5.6(1.7)$ & .8 & .06 \\
\hline Social Support - Past - & Female & $6.2(1.1)$ & $5.9(1.4)$ & $4.6 * * *$ & .21 \\
\hline Significant Other & Total & $6.0(1.2)$ & $5.8(1.1)$ & $4.5 * * *$ & .18 \\
\hline Multidimensional Scale of Perceived & Male & $5.5(1.2)$ & $5.6(1.5)$ & -.7 & -.37 \\
\hline Social Support - Past - Total & Female & $6.0(1.1)$ & $5.6(1.2)$ & $6.3 * * *$ & .33 \\
\hline Score & Total & $5.8(1.1)$ & $5.6(.8)$ & $4.8 * * *$ & .25 \\
\hline Multidimensional Scale of Perceived & Male & $5.6(1.2)$ & $5.6(1.5)$ & -.4 & .00 \\
\hline Social Support - Present -- & Female & $6.2(.9)$ & $6.0(1.1)$ & $3.6 * * *$ & .18 \\
\hline Friends & Total & $6.0(1.1)$ & $5.5(1.2)$ & $10.6^{* * *}$ & .42 \\
\hline Multidimensional Scale of Perceived & Male & $5.7(1.3)$ & $5.5(1.6)$ & 1.7 & .13 \\
\hline Social Support - Present & Female & $5.9(1.4)$ & $5.1(1.8)$ & $10.9 * * *$ & .44 \\
\hline Family Subscale & Total & $5.8(1.4)$ & $5.5(1.1)$ & $5.6 * * *$ & .27 \\
\hline Multidimensional Scale of Perceived & Male & $5.6(1.5)$ & $5.6(1.7)$ & -.3 & .00 \\
\hline Social Support - Present & Female & $6.4(1.1)$ & $5.9(1.4)$ & $8.4 * * *$ & .36 \\
\hline Significant Other Subscale & Total & $6.1(1.2)$ & $5.8(1.1)$ & $6.2 * * *$ & .27 \\
\hline Multidimensional Scale of Perceived & Male & $5.6(1.1)$ & $5.6(1.5)$ & -.002 & -.37 \\
\hline Social Support - Present & Female & $6.1(.9)$ & $5.6(1.2)$ & $10.1 * * *$ & .42 \\
\hline Total Score & Total & $6.0(1.0)$ & $5.6(.8)$ & $7.9 * * *$ & .50 \\
\hline
\end{tabular}


Table 3 (continued)

\begin{tabular}{|c|c|c|c|c|c|}
\hline Scale & Gender & $\begin{array}{l}\text { Current } \\
\text { Sample } \\
(M, S D)\end{array}$ & $\begin{array}{l}\text { Comparison } \\
\text { Sample } \\
(M, S D)\end{array}$ & t Value & z-Score \\
\hline Perceived Social Support - Friend & Male & $14.3(4.5)$ & NA & NA & NA \\
\hline \multirow[t]{2}{*}{ Scale } & Female & $16.2(4.0)$ & NA & NA & NA \\
\hline & Total & $15.7(4.2)$ & $15.2(5.1)$ & $2.6^{*}$ & .10 \\
\hline Perceived Social Support - Family & Male & $15.5(4.5)$ & NA & NA & NA \\
\hline \multirow[t]{2}{*}{ Scale } & Female & $16.0(4.4)$ & NA & NA & NA \\
\hline & Total & $14.9(5.7)$ & $13.4(4.8)$ & $5.9 * * *$ & .31 \\
\hline \multirow[t]{3}{*}{ Parentification Questionnaire } & Male & $23.9(5.7)$ & NA & NA & NA \\
\hline & Female & $22.9(6.7)$ & NA & NA & NA \\
\hline & Total & $23.2(6.5)$ & $19.0(7.4)$ & $14.5 * * *$ & .57 \\
\hline Rotter Internal versus External Locus & Male & $11.2(3.5)$ & $8.2(3.9)$ & $9.9 * * *$ & .77 \\
\hline \multirow[t]{2}{*}{ of Control Scale } & Female & $12.3(3.6)$ & $8.4(4.1)$ & $20.4 * * *$ & .95 \\
\hline & Total & $12.0(3.6)$ & $8.3(4.0)$ & $22.7 * * *$ & .93 \\
\hline Attachment Style Questionnaire - & Male & $26.6(6.3)$ & NA & NA & NA \\
\hline Preoccupation with Relationships & Female & $28.7(6.6)$ & NA & NA & NA \\
\hline Subscale & Total & $28.1(6.6)$ & 28.9 (NA) & $-2.7 * *$ & NA \\
\hline Attachment Style Questionnaire - & Male & $22.0(6.3)$ & NA & NA & NA \\
\hline \multirow[t]{2}{*}{ Need for Approval Subscale } & Female & $22.9(5.9)$ & NA & NA & NA \\
\hline & Total & $22.7(6.0)$ & 23.8 (NA) & $-4.3 * * *$ & NA \\
\hline Attachment Style Questionnaire - & Male & $18.8(5.0)$ & NA & NA & NA \\
\hline Relationships as Secondary & Female & $16.7(4.6)$ & NA & NA & NA \\
\hline Subscale & Total & $17.3(4.8)$ & 16.2 (NA) & $5.2 * * *$ & NA \\
\hline Attachment Style Questionnaire - & Male & $34.1(8.1)$ & NA & NA & NA \\
\hline Discomfort with Closeness & Female & $33.0(9.8)$ & NA & NA & NA \\
\hline Subscale & Total & $33.3(9.4)$ & 34.2 (NA) & $-2.3 *$ & NA \\
\hline
\end{tabular}

(table continues) 
Table 3 (continued)

\begin{tabular}{|c|c|c|c|c|c|}
\hline Scale & Gender & $\begin{array}{l}\text { Current } \\
\text { Sample } \\
(M, S D)\end{array}$ & $\begin{array}{c}\text { Comparison } \\
\text { Sample } \\
(M, S D)\end{array}$ & t Value & z-Score \\
\hline Attachment Style Questionnaire - & Male & $35.9(5.9)$ & NA & NA & NA \\
\hline \multirow[t]{2}{*}{ Confidence Subscale } & Female & $36.0(6.0)$ & NA & NA & NA \\
\hline & Total & $36.0(6.0)$ & 33.6 (NA) & $9.1 * * *$ & NA \\
\hline Drug Use Screening Inventory - & Male & $4.6(3.6)$ & NA & NA & NA \\
\hline \multirow[t]{2}{*}{ Substance Use Domain } & Female & $3.8(3.2)$ & NA & NA & NA \\
\hline & Total & $4.1(3.4)$ & $5.5(13.4)$ & $-9.6^{* * *}$ & -.10 \\
\hline Drug Use Screening Inventory - & Male & $27.7(16.4)$ & NA & NA & NA \\
\hline \multirow[t]{2}{*}{ Behavior Patterns Domain } & Female & $26.1(15.3)$ & NA & NA & NA \\
\hline & Total & $26.6(15.6)$ & $24.6(19.4)$ & $2.8^{* *}$ & .10 \\
\hline Drug Use Screening Inventory - & Male & $27.2(14.7)$ & NA & NA & NA \\
\hline \multirow[t]{2}{*}{ Health Status Domain } & Female & $32.6(16.5)$ & NA & NA & NA \\
\hline & Total & $31.1(16.2)$ & $22.6(16.9)$ & $11.7 * * *$ & .50 \\
\hline Drug Use Screening Inventory - & Male & $25.9(15.6)$ & NA & NA & NA \\
\hline \multirow[t]{2}{*}{ Psychiatric Disorder Domain } & Female & $29.4(17.3)$ & NA & NA & NA \\
\hline & Total & $28.4(16.9)$ & $21.5(18.1)$ & $9.1 * * *$ & .41 \\
\hline Drug Use Screening Inventory - & Male & $22.5(16.6)$ & NA & NA & NA \\
\hline \multirow[t]{2}{*}{ Social Competency Domain } & Female & $27.5(17.9)$ & NA & NA & NA \\
\hline & Total & $26.1(17.7)$ & $17.8(17.3)$ & $10.5 * * *$ & .48 \\
\hline Drug Use Screening Inventory - & Male & $26.3(17.2)$ & NA & NA & NA \\
\hline \multirow[t]{2}{*}{ Family System Domain } & Female & $24.3(19.0)$ & NA & NA & NA \\
\hline & Total & $24.9(18.5)$ & $22.8(20.3)$ & $2.5^{*}$ & .05 \\
\hline Drug Use Screening Inventory - & Male & $24.2(14.3)$ & NA & NA & NA \\
\hline \multirow[t]{2}{*}{ School Performance Domain } & Female & $20.8(14.6)$ & NA & NA & NA \\
\hline & Total & $21.8(14.6)$ & $20.0(17.6)$ & $2.8^{* *}$ & .10 \\
\hline
\end{tabular}


Table 3 (continued)

\begin{tabular}{|c|c|c|c|c|c|}
\hline Scale & Gender & $\begin{array}{l}\text { Current } \\
\text { Sample } \\
(M, S D)\end{array}$ & $\begin{array}{c}\text { Comparison } \\
\text { Sample } \\
(M, S D)\end{array}$ & t Value & Z-Score \\
\hline Drug Use Screening Inventory - & Male & $13.3(14.3)$ & NA & NA & NA \\
\hline \multirow[t]{2}{*}{ Work Adjustment Domain } & Female & $6.7(9.7)$ & NA & NA & NA \\
\hline & Total & $8.6(11.6)$ & $4.8(10.8)$ & $7.2 * * *$ & .35 \\
\hline Drug Use Screening Inventory - Peer & Male & $38.5(17.8)$ & NA & NA & NA \\
\hline \multirow[t]{2}{*}{ Relationships Domain } & Female & $33.3(17.8)$ & NA & NA & NA \\
\hline & Total & $34.8(18.0)$ & $23.2(21.4)$ & $14.4 * * *$ & .54 \\
\hline Drug Use Screening Inventory - & Male & $36.0(17.1)$ & NA & NA & NA \\
\hline \multirow[t]{2}{*}{ Leisure/Recreation Domain } & Female & $35.4(18.1)$ & NA & NA & NA \\
\hline & Total & $35.6(17.8)$ & $23.1(18.0)$ & $15.4 * * *$ & .69 \\
\hline Drug Use Screening Inventory - & Male & $27.3(10.7)$ & NA & NA & NA \\
\hline \multirow[t]{2}{*}{ Overall Problem Density } & Female & $26.3(11.2)$ & NA & NA & NA \\
\hline & Total & $26.6(11.0)$ & $19.1(12.9)$ & $15.1 * * *$ & .58 \\
\hline Hendrick Sexual Attitude Scale - & Male & $3.7(.7)$ & $3.0(\mathrm{NA})$ & $11.0 * * *$ & NA \\
\hline \multirow[t]{2}{*}{ Permissiveness Subscale } & Female & $4.4(.5)$ & 4.0 (NA) & $13.2 * * *$ & NA \\
\hline & Total & $4.2(.7)$ & NA & NA & NA \\
\hline Hendrick Sexual Attitude Scale - & Male & $1.7(.6)$ & 2.0 (NA) & $-6.4 * * *$ & NA \\
\hline \multirow[t]{2}{*}{ Sexual Practices Subscale } & Female & $1.7(.6)$ & $2.1(\mathrm{NA})$ & $-13.1 * * *$ & NA \\
\hline & Total & $1.7(.6)$ & NA & NA & NA \\
\hline Hendrick Sexual Attitude Scale - & Male & $2.1(.7)$ & 1.9 (NA) & $3.4 * * *$ & NA \\
\hline Communion in the Relationship & Female & $2.1(.7)$ & 1.9 (NA) & $5.9 * * *$ & NA \\
\hline Subscale & Total & $2.1(.7)$ & NA & NA & NA \\
\hline Hendrick Sexual Attitude Scale - & Male & $3.4(.9)$ & $3.2(\mathrm{NA})$ & $2.8 * *$ & NA \\
\hline \multirow[t]{2}{*}{ Instrumentality Subscale } & Female & $3.6(.9)$ & $3.6(\mathrm{NA})$ & .1 & NA \\
\hline & Total & $3.5(.9)$ & NA & NA & NA \\
\hline
\end{tabular}

(table continues) 
Table 3 (continued)

\begin{tabular}{|c|c|c|c|c|c|}
\hline Scale & Gender & $\begin{array}{l}\text { Current } \\
\text { Sample } \\
(M, S D)\end{array}$ & $\begin{array}{c}\text { Comparison } \\
\text { Sample } \\
(M, S D)\end{array}$ & t Value & Z-Score \\
\hline Social Phobia and Anxiety Inventory & Male & $18.9(11.1)$ & $23.0(10.0)$ & $-4.4 * * *$ & -.41 \\
\hline \multirow{2}{*}{ - Agoraphobia Subscale } & Female & $23.6(13.0)$ & $25.5(10.4)$ & $-2.7 * *$ & -.18 \\
\hline & Total & $22.3(12.7)$ & $24.5(10.3)$ & $-3.9 * * *$ & -.21 \\
\hline Social Phobia and Anxiety Inventory & Male & $73.0(36.3)$ & $80.3(25.5)$ & $-2.4^{*}$ & -.29 \\
\hline \multirow{2}{*}{ - Social Phobia Subscale } & Female & $75.2(34.1)$ & $84.2(26.5)$ & $-5.0 * * *$ & -.34 \\
\hline & Total & $74.5(34.7)$ & $82.7(26.1)$ & $-5.3 * * *$ & -.31 \\
\hline Social Phobia and Anxiety Inventory & Male & $54.1(30.6)$ & $57.4(21.2)$ & -1.3 & -.16 \\
\hline \multirow[t]{2}{*}{ - Difference Subscale } & Female & $51.6(28.7)$ & $58.7(23.2)$ & $-4.7 * * *$ & -.31 \\
\hline & Total & $52.3(29.3)$ & $58.2(22.4)$ & $-4.6 * * *$ & -.26 \\
\hline \multirow[t]{3}{*}{ Beck Depression Inventory-II } & Male & $8.1(7.6)$ & $12.9(9.8)$ & $-7.5 * * *$ & -.49 \\
\hline & Female & $10.8(8.5)$ & $11.4(7.1)$ & -1.3 & -.08 \\
\hline & Total & $10.1(8.4)$ & $12.6(9.9)$ & $-6.8 * * *$ & -.25 \\
\hline \multirow[t]{3}{*}{ Beck Anxiety Inventory } & Male & $6.8(6.8)$ & NA & NA & NA \\
\hline & Female & $10.0(8.7)$ & NA & NA & NA \\
\hline & Total & $9.1(8.3)$ & $11.1(9.1)$ & $-5.4 * * *$ & -.22 \\
\hline
\end{tabular}

Note. $* p<.05, * * p<.01, * * * p<.001, \mathrm{NA}=$ not available. 
Table 4

Trauma Exposure

Level of Exposure

\begin{tabular}{|c|c|c|c|c|}
\hline Trauma & $\begin{array}{c}\text { Did Not } \\
\text { Experience }\end{array}$ & $\begin{array}{l}\text { Experienced } \\
\text { Personally }\end{array}$ & Witnessed & $\begin{array}{c}\text { Experienced and } \\
\text { Witnessed }\end{array}$ \\
\hline Motor vehicle accident & $135(26.9 \%)$ & $262(52.2 \%)$ & $68(13.5 \%)$ & $36(7.2 \%)$ \\
\hline $\begin{array}{l}\text { Death of loved one or } \\
\text { someone close }\end{array}$ & $208(41.4 \%)$ & $241(48 \%)$ & $35(7 \%)$ & $15(3 \%)$ \\
\hline Severe injuries & $300(59.8 \%)$ & $116(23.1 \%)$ & $70(13.9 \%)$ & $11(2.2 \%)$ \\
\hline Natural disaster & $318(63.3 \%)$ & $90(17.9 \%)$ & $79(15.7 \%)$ & $8(1.6 \%)$ \\
\hline $\begin{array}{l}\text { Treating patients in } \\
\text { emergency room }\end{array}$ & $324(64.5 \%)$ & $82(16.3 \%)$ & $83(16.5 \%)$ & $6(1.2 \%)$ \\
\hline $\begin{array}{l}\text { Abuse (sexual, physical, } \\
\text { emotional) }\end{array}$ & $353(70.3 \%)$ & $100(19.9 \%)$ & $37(7.4 \%)$ & $6(1.2 \%)$ \\
\hline House/building fire & $366(72.9 \%)$ & $22(4.4 \%)$ & $95(18.9 \%)$ & $1(.2 \%)$ \\
\hline $\begin{array}{l}\text { Divorce/separation from } \\
\text { spouse/significant other }\end{array}$ & $373(74.3 \%)$ & $57(11.4 \%)$ & $54(10.8 \%)$ & $3(.6 \%)$ \\
\hline $\begin{array}{l}\text { Performing emergency } \\
\text { rescue }\end{array}$ & $396(78.9 \%)$ & $49(9.8 \%)$ & $50(10.0 \%)$ & $4(.8 \%)$ \\
\hline Abortion or miscarriage & $401(79.9 \%)$ & $20(4.0 \%)$ & $77(15.3 \%)$ & $2(.4 \%)$ \\
\hline Pedestrian accident & $432(86.1 \%)$ & $10(2.0 \%)$ & $52(10.4 \%)$ & $4(.8 \%)$ \\
\hline Living in high crime area & $437(87.1 \%)$ & $40(8.0 \%)$ & $20(4.0 \%)$ & $4(.8 \%)$ \\
\hline Assault with a weapon & $423(84.3 \%)$ & $49(9.8 \%)$ & $20(4.0 \%)$ & $7(1.4 \%)$ \\
\hline Firefighting & $460(91.6 \%)$ & $5(1.0 \%)$ & $33(6.6 \%)$ & $0(0 \%)$ \\
\hline Military combat & $463(92.2 \%)$ & $5(1.0 \%)$ & $26(5.2 \%)$ & $1(.2 \%)$ \\
\hline
\end{tabular}

(table continues) 
Table 4 (continued)

\begin{tabular}{lcccc}
\hline & \multicolumn{3}{c}{ Level of Exposure } \\
\cline { 2 - 4 } & $\begin{array}{c}\text { Did Not } \\
\text { Experience }\end{array}$ & $\begin{array}{c}\text { Experienced } \\
\text { Personally }\end{array}$ & Witnessed & $\begin{array}{c}\text { Experienced and } \\
\text { Witnessed }\end{array}$ \\
\hline $\begin{array}{l}\text { Finding or seeing a } \\
\text { dead body }\end{array}$ & $451(90.6 \%)$ & $33(6.6 \%)$ & $14(2.8 \%)$ & $0(0 \%)$ \\
Other traumatic event & $307(61.2 \%)$ & $64(12.7 \%)$ & $6(1.2 \%)$ & $2(.4 \%)$ \\
\hline
\end{tabular}

Note. The numbers in this table reflect the absolute numbers of participants who endorsed each item at the different levels of exposure. The percentage of the sample who endorsed each item is included in parentheses. 
Table 5

Rates of Maltreatment at Each Classification Level

\begin{tabular}{|c|c|c|c|c|c|}
\hline \multirow[b]{2}{*}{ Scale } & \multirow[b]{2}{*}{ Gender } & \multicolumn{4}{|c|}{ Classification } \\
\hline & & $\begin{array}{c}\text { None } \\
\text { (or Minimal) }\end{array}$ & $\begin{array}{c}\text { Low } \\
\text { (to Moderate) }\end{array}$ & $\begin{array}{l}\text { Moderate } \\
\text { (to Severe) }\end{array}$ & $\begin{array}{c}\text { Severe } \\
\text { (to Extreme) }\end{array}$ \\
\hline \multirow[t]{3}{*}{ Emotional abuse } & Male & 96 & 32 & 10 & 5 \\
\hline & Female & 242 & 58 & 22 & 35 \\
\hline & Total & 338 & 90 & 32 & 40 \\
\hline \multirow[t]{3}{*}{ Physical abuse } & Male & 104 & 23 & 9 & 7 \\
\hline & Female & 284 & 41 & 15 & 17 \\
\hline & Total & 388 & 64 & 24 & 24 \\
\hline \multirow[t]{3}{*}{ Sexual abuse } & Male & 132 & 7 & 1 & 3 \\
\hline & Female & 316 & 16 & 11 & 14 \\
\hline & Total & 448 & 23 & 12 & 17 \\
\hline \multirow[t]{3}{*}{ Emotional neglect } & Male & 91 & 35 & 12 & 5 \\
\hline & Female & 242 & 70 & 26 & 19 \\
\hline & Total & 333 & 105 & 38 & 24 \\
\hline \multirow[t]{3}{*}{ Physical neglect } & Male & 114 & 18 & 7 & 4 \\
\hline & Female & 309 & 31 & 11 & 6 \\
\hline & Total & 423 & 49 & 18 & 10 \\
\hline
\end{tabular}

Note. The numbers in this table reflect the numbers of participants whose responses resulted in scores at each of the classification levels. 
Table 6

Correlations among Measures

\begin{tabular}{|c|c|c|c|c|c|c|c|c|c|c|c|c|c|c|}
\hline & 1 & 2 & 3 & 4 & 5 & 6 & 7 & 8 & 9 & 10 & 11 & 12 & 13 & 14 \\
\hline 1 & & $.22 * *$ & $.19 * *$ & .03 & $.15^{* *}$ & $.09 *$ & $-.12 * *$ & $-.11 *$ & .004 & -.08 & $-.20 *$ & .03 & .06 & -.02 \\
\hline 2 & & & $.60 * *$ & $.32 * *$ & $.73 * *$ & $.58 * *$ & $-.43 * *$ & $-.33 * *$ & $-.15^{* *}$ & $-.48 * *$ & $-.50 * *$ & $.16^{* *}$ & $.23 * *$ & $.25^{* *}$ \\
\hline 3 & & & & $.30 * *$ & $.43 * *$ & $.47 * *$ & $-.25 * *$ & $-.13 * *$ & -.07 & $-.17 * *$ & $-.27 * *$ & -.02 & .009 & -.01 \\
\hline 4 & & & & & $.25^{* *}$ & $.38 * *$ & $-.18^{* *}$ & -.006 & .002 & -.005 & $-.16^{* *}$ & -.008 & .06 & .08 \\
\hline 5 & & & & & & $.66^{* *}$ & $-.55^{* *}$ & $-.44 * *$ & $-.22 * *$ & $-.68 * *$ & $-.47 * *$ & $.21 * *$ & $.22 * *$ & $.25 * *$ \\
\hline 6 & & & & & & & $-.45^{* *}$ & $-.31 * *$ & $-.14 * *$ & $-.38 * *$ & $-.39 * *$ & .07 & .07 & $.11^{*}$ \\
\hline 7 & & & & & & & & $.76^{* *}$ & $.44^{* *}$ & $.53 * *$ & $.32 * *$ & $.15^{* *}$ & $.15^{* *}$ & $.23^{* *}$ \\
\hline 8 & & & & & & & & & $.54 * *$ & $.51 * *$ & $.24 * *$ & $-.15 * *$ & $-.17^{* *}$ & $-.22 * *$ \\
\hline 9 & & & & & & & & & & $.33^{* *}$ & $.13^{* *}$ & $-.13 * *$ & $-.19 * *$ & $-.22 * *$ \\
\hline 10 & & & & & & & & & & & $.32 * *$ & $-.23 * *$ & $-.24 * *$ & $-.29 * *$ \\
\hline 11 & & & & & & & & & & & & $-.17 * *$ & $-.26 * *$ & -.22 \\
\hline 12 & & & & & & & & & & & & & $.20 * *$ & $.26^{* *}$ \\
\hline 13 & & & & & & & & & & & & & & .62 \\
\hline 14 & & & & & & & & & & & & & & \\
\hline
\end{tabular}


Table 6 (continued)

\begin{tabular}{|c|c|c|c|c|c|c|c|c|c|c|c|c|c|c|}
\hline & 15 & 16 & 17 & 18 & 19 & 20 & 21 & 22 & 23 & 24 & 25 & 26 & 27 & 28 \\
\hline 1 & .06 & $.12 * *$ & $-.10 * *$ & $.10^{*}$ & $.25 * *$ & $-.10^{*}$ & $-.15 * *$ & -.02 & .03 & .006 & -.03 & -.04 & $.12 * *$ & $.13 * *$ \\
\hline 2 & $.16^{* *}$ & $.37 * *$ & $-.36 * *$ & $.14^{* *}$ & $.47 * *$ & $-.13 * *$ & -.04 & -.02 & -.07 & $.19 * *$ & $.19 * *$ & $.14 * *$ & $.38 * *$ & $.30 * *$ \\
\hline 3 & $.15 * *$ & $.15^{* *}$ & -.05 & .03 & $.23 * *$ & $-.14 * *$ & .02 & .01 & -.02 & .08 & .05 & .03 & $.12 * *$ & $.15^{* *}$ \\
\hline 4 & .07 & .08 & $-.09 *$ & .04 & $.12 * *$ & -.05 & .05 & $.09 *$ & .03 & .08 & $.10^{*}$ & .08 & $.11 *$ & .05 \\
\hline 5 & $.22 * *$ & $.40 * *$ & $-.45 * *$ & $.14^{* *}$ & $.45^{* *}$ & $-.21 * *$ & .02 & .05 & -.07 & $.17 * *$ & $.24 * *$ & $.22 * *$ & $.37 * *$ & $.26^{* *}$ \\
\hline 6 & $.18 * *$ & $.23 * *$ & $-.26 * *$ & .07 & $.26 * *$ & $-.16 * *$ & .03 & .05 & -.05 & $.13 * *$ & $.15^{* *}$ & $.12 * *$ & $.20 * *$ & $.15^{* *}$ \\
\hline 7 & $-.25 * *$ & $-.44 * *$ & $.49 * *$ & $-.10 *$ & $-.35 * *$ & $.17 * *$ & -.06 & -.04 & .06 & $-.19 * *$ & $-.28 * *$ & $-.25 * *$ & $-.33 * *$ & $-.19 * *$ \\
\hline 8 & $-.29 * *$ & $-.40 * *$ & $.48^{* *}$ & $-.13 * *$ & $-.37 * *$ & $.17^{* *}$ & -.05 & -.05 & $.12 * *$ & $-.16^{* *}$ & $-.23 * *$ & $-.20 * *$ & $-.34 * *$ & $-.14^{* *}$ \\
\hline 9 & $-.28 * *$ & $-.41 * *$ & $.44 * *$ & .005 & $-.25 * *$ & $.11^{*}$ & $-.10 *$ & -.07 & $.09 *$ & $-.14 * *$ & $-.32 * *$ & $-.31 * *$ & $-.27 * *$ & $-.14 * *$ \\
\hline 10 & $-.21 * *$ & $-.41 * *$ & $.48 * *$ & $-.13 * *$ & $-.41 * *$ & $.19 * *$ & -.01 & -.02 & $.11^{*}$ & $-.14 * *$ & $-.23 * *$ & $-.21 * *$ & $-.39 * *$ & -.23 \\
\hline 11 & $-.14 * *$ & $-.32 * *$ & $.21 * *$ & $-.13 * *$ & $-.37 * *$ & $.12^{* *}$ & .003 & .08 & $.15^{* *}$ & $-.19 * *$ & $-.13 * *$ & -.07 & $-.27 * *$ & $-.21 * *$ \\
\hline 12 & .05 & $.22 * *$ & $-.32 * *$ & .09 & $.30 * *$ & -.04 & .07 & .01 & -.08 & $.17 * *$ & $.29 * *$ & $.27 * *$ & $.30 * *$ & $.22 * *$ \\
\hline 13 & $.22 * *$ & $.41 * *$ & $-.39 * *$ & $.22 * *$ & $.45^{* *}$ & -.03 & -.04 & $-.10^{*}$ & $-.11 *$ & $.33 * *$ & $.37 * *$ & $.29 * *$ & $.41 * *$ & $.33 * *$ \\
\hline 14 & $.30 * *$ & $.44 * *$ & $-.43 * *$ & $.15^{* *}$ & $.38 * *$ & -.05 & .03 & .001 & $-.15^{*}$ & $.32 * *$ & $.49 * *$ & $.44 * *$ & $.45 * *$ & $.29 * *$ \\
\hline
\end{tabular}


Table 6 (continued)

\begin{tabular}{|c|c|c|c|c|c|c|c|c|c|c|c|c|c|c|}
\hline & 15 & 16 & 17 & 18 & 19 & 20 & 21 & 22 & 23 & 24 & 25 & 26 & 27 & 28 \\
\hline 15 & & $.44 * *$ & $-.33 * *$ & $.10^{*}$ & $.22 * *$ & $-.20 * *$ & .07 & .07 & -.26 & $.17^{* *}$ & $.28^{* *}$ & $.26^{* *}$ & $.16^{* *}$ & .03 \\
\hline 16 & & & $-.68 * *$ & $.13 * *$ & $.46^{* *}$ & $-.19 * *$ & .05 & -.009 & $-.15 * *$ & $.25^{* *}$ & $.42 * *$ & $.39 * *$ & $.46^{* *}$ & $.30 * *$ \\
\hline 17 & & & & -.08 & $-.44 * *$ & .08 & -.04 & $-.11^{*}$ & .08 & $-.25 * *$ & $-.50 * *$ & $-.49 * *$ & $-.52 * *$ & $-.29 * *$ \\
\hline 18 & & & & & $.66^{* *}$ & $-.40 * *$ & $-.12 * *$ & -.08 & $-.22 * *$ & $.21 * *$ & $.11^{*}$ & .04 & $.23^{* *}$ & $.22^{* *}$ \\
\hline 19 & & & & & & $-.37 * *$ & -.07 & -.006 & $-.19 * *$ & $.36^{* *}$ & $.39 * *$ & $.31 * *$ & $.65^{* *}$ & $.52 * *$ \\
\hline 20 & & & & & & & $.15^{* *}$ & .06 & $.43^{* *}$ & -.03 & -.03 & -.02 & -.04 & -.03 \\
\hline 21 & & & & & & & & $.39 * *$ & .03 & -.01 & .05 & .06 & -.002 & .028 \\
\hline 22 & & & & & & & & & .18 & -.006 & .06 & .08 & .02 & .04 \\
\hline 23 & & & & & & & & & & $-.15 * *$ & $-.10 *$ & -.05 & -.001 & -.02 \\
\hline 24 & & & & & & & & & & & $.58 * *$ & $.26^{* *}$ & $.42 * *$ & $.41^{* *}$ \\
\hline 25 & & & & & & & & & & & & $.94^{* *}$ & $.47 * *$ & $.37 * *$ \\
\hline 26 & & & & & & & & & & & & & $.37 * *$ & $.27^{* *}$ \\
\hline 27 & & & & & & & & & & & & & & $.61 * *$ \\
\hline 28 & & & & & & & & & & & & & & \\
\hline
\end{tabular}

Note. ${ }^{*} p<.05,{ }^{* *} p<.01$. For the correlation matrix, $1=$ HPS Experienced or Witnessed, $2=\mathrm{CTQ}-$ Emotional Abuse Subscale, $3=$ 
CTQ - Physical Abuse Subscale, 4 = CTQ - Sexual Abuse Subscale, $5=$ CTQ - Emotional Neglect Subscale, $6=$ CTQ - Physical Neglect Subscale, 7 = MSPSS - Past Total Score, $8=$ MSPSS - Present Total Score, $9=$ PSS-Friend Scale, $10=$ PSS-Family Scale, $11=$ PQ, $12=$ Rotter Locus of Control Scale, $13=$ ASQ - Preoccupations with Relationships Subscale, $14=$ ASQ - Need for Approval Subscale, 15 = ASQ - Relationships as Secondary Subscale, $16=$ ASQ - Discomfort with Closeness Subscale, $17=$ ASQ Confidence Subscale, 18 = DUSI - Substance Use Domain, $19=$ DUSI - Overall Problem Density, $20=$ HSAS - Permissiveness Subscale, 21 = HSAS - Sexual Practices Subscale, $22=$ HSAS - Communion in the Relationship Subscale, $23=$ HSAS -

Instrumentality Subscale, 24 = SPAI - Agoraphobia Subscale, 25 = SPAI - Social Phobia Subscale, $26=$ SPAI - Difference Subscale, $27=$ BDI-II, $28=$ BAI. 
Table 7

Hierarchical Regression Analysis Evaluating the Moderating Effects of Social Support, Parentification, Locus of Control, and Attachment Styles on Substance Use Resulting from

Emotional Abuse

\begin{tabular}{|c|c|c|c|c|c|}
\hline \multicolumn{2}{|l|}{ Model } & \multirow{2}{*}{$\beta$} & \multirow{2}{*}{$\begin{array}{l}\text { Sig. } \\
.001\end{array}$} & \multirow{2}{*}{$\Delta \mathrm{R}^{2}$} & \multirow{2}{*}{$\frac{F(\mathrm{df})}{2.73(2,479)}$} \\
\hline 1 & (Constant) & & & & \\
\hline & Gender & -.61 & .07 & & \\
\hline & Age & -.09 & .11 & & \\
\hline $2 * * *$ & (Constant) & 7.50 & .001 & .10 & $3.75(12,467)$ \\
\hline & Gender & -.90 & .01 & & \\
\hline & Age & -.08 & .17 & & \\
\hline & Social Support Past Total Score & .17 & .44 & & \\
\hline & Social Support Present Total Score & -.47 & .05 & & \\
\hline & $\begin{array}{l}\text { Attachment Style Questionnaire-Need for } \\
\text { Approval subscale }\end{array}$ & -.01 & .82 & & \\
\hline & $\begin{array}{l}\text { Attachment Style Questionnaire-Discomfort } \\
\text { with closeness subscale }\end{array}$ & .03 & .29 & & \\
\hline & Emotional Abuse Scale Total Score & .08 & .08 & & \\
\hline & $\begin{array}{l}\text { Perceived Social Support Friends Centered } \\
\quad \text { Score }\end{array}$ & .10 & .02 & & \\
\hline & $\begin{array}{l}\text { Perceived Social Support Family Centered } \\
\quad \text { Score }\end{array}$ & .01 & .73 & & \\
\hline & $\begin{array}{l}\text { Parentification Questionnaire Total Centered } \\
\text { Score }\end{array}$ & -.01 & .68 & & \\
\hline & Locus of Control Centered Score & .05 & .25 & & \\
\hline & $\begin{array}{l}\text { ASQ Relationships as Secondary Subscale } \\
\text { Centered Score }\end{array}$ & .02 & .52 & & \\
\hline
\end{tabular}

(table continues) 
Table 7 (continued)

\begin{tabular}{|c|c|c|c|c|c|}
\hline \multicolumn{2}{|c|}{ Model } & \multirow{2}{*}{ B } & \multirow{2}{*}{$\begin{array}{l}\text { Sig. } \\
.12\end{array}$} & \multirow[t]{2}{*}{$\Delta \mathrm{R}^{2}$} & \multirow[t]{2}{*}{$F(\mathrm{df})$} \\
\hline $2 * * *$ & ASQ Confidence Subscale Centered Score & & & & \\
\hline & ASQ Preoccupation with Relationships & .11 & .001 & & \\
\hline \multicolumn{6}{|c|}{ Subscale Centered Score } \\
\hline 3 & (Constant) & 5.43 & .021 & .13 & $1.41(11,456)$ \\
\hline & Gender & -.70 & .06 & & \\
\hline & Age & -.02 & .72 & & \\
\hline & Social Support Past Total Score & .09 & .71 & & \\
\hline & Social Support Present Total Score & -.36 & .16 & & \\
\hline & Attachment Style Questionnaire-Need for & -.004 & .90 & & \\
\hline \multicolumn{6}{|c|}{ Approval subscale } \\
\hline & $\begin{array}{l}\text { Attachment Style Questionnaire-Discomfort } \\
\text { with closeness subscale }\end{array}$ & .02 & .36 & & \\
\hline & Emotional Abuse Scale Total Score & .16 & .30 & & \\
\hline & Perceived Social Support Friends Centered & .10 & .02 & & \\
\hline \multicolumn{6}{|c|}{ Score } \\
\hline & \multicolumn{4}{|l|}{ Score } & \\
\hline & \multicolumn{4}{|l|}{ Score } & \\
\hline & Locus of Control Centered Score & .06 & .22 & & \\
\hline & ASQ Relationships as Secondary Subscale & .03 & .36 & & \\
\hline \multicolumn{6}{|c|}{ Centered Score } \\
\hline & ASQ Confidence Subscale Centered Score & .05 & .24 & & \\
\hline & ASQ Preoccupation with Relationships & .09 & .002 & & \\
\hline \multicolumn{6}{|c|}{ Subscale Centered Score } \\
\hline & Emotional Abuse X Social Support Past & .06 & .08 & & \\
\hline
\end{tabular}

(table continues) 
Table 7 (continued)

\begin{tabular}{clccc}
\hline \multirow{2}{*}{ Model } & & B & Sig. $\Delta \mathrm{R}^{2}$ & $F(\mathrm{df})$ \\
\hline 3 & Emotional Abuse X Social Support Present & .07 & .22 \\
& Emotional abuse X Friend Social Support & -.001 & .94 \\
Emotional abuse X Family Social Support & -.01 & .24 \\
Emotional abuse X Parentification & .01 & .17 \\
Emotional abuse X Locus of Control & .01 & .25 \\
Emotional abuse X ASQ Need for Approval & -.001 & .86 \\
Emotional abuse X ASQ Relationships as & -.01 & .28 \\
$\quad$ Secondary & & \\
Emotional abuse X ASQ Preoccupation with & .01 & .28 \\
$\quad$ Relationships & & \\
Emotional abuse X ASQ Confidence & -.01 & .26 \\
Emotional abuse X Discomfort with & -.002 & .77 \\
Closeness & & \\
\hline
\end{tabular}

Note. ${ }^{* * *} p<.05 ; \mathrm{ASQ}=$ Attachment Style Questionnaire. 
Table 8

Hierarchical Regression Analysis Evaluating the Moderating Effects of Social Support,

Parentification, Locus of Control, and Attachment Styles on DUSI Overall Problems Resulting

from Emotional Abuse

\begin{tabular}{|c|c|c|c|c|c|}
\hline \multicolumn{2}{|l|}{ Model } & \multirow{2}{*}{$\begin{array}{c}\beta \\
24.06\end{array}$} & \multirow{2}{*}{$\begin{array}{l}\text { Sig. } \\
.001\end{array}$} & \multirow{2}{*}{$\frac{\Delta \mathrm{R}^{2}}{.05}$} & \multirow{2}{*}{$\begin{array}{c}F(\mathrm{df}) \\
.66(2,479)\end{array}$} \\
\hline 1 & (Constant) & & & & \\
\hline & Gender & -.62 & .58 & & \\
\hline & Age & .17 & .33 & & \\
\hline $2 * * *$ & (Constant) & 24.47 & .001 & .43 & $28.94(12,467)$ \\
\hline & Gender & -1.98 & .036 & & \\
\hline & Age & .004 & .76 & & \\
\hline & Social Support Past Total Score & .65 & .25 & & \\
\hline & Social Support Present Total Score & -1.53 & .02 & & \\
\hline & Attachment Style Questionnaire-Need for & .003 & .97 & & \\
\hline & Approval subscale & & & & \\
\hline & $\begin{array}{l}\text { Attachment Style Questionnaire-Discomfort } \\
\text { with closeness subscale }\end{array}$ & .14 & .03 & & \\
\hline & Emotional Abuse Scale Total Score & .62 & .001 & & \\
\hline & $\begin{array}{l}\text { Perceived Social Support Friends Centered } \\
\quad \text { Score }\end{array}$ & .03 & .79 & & \\
\hline & $\begin{array}{l}\text { Perceived Social Support Family Centered } \\
\quad \text { Score }\end{array}$ & -.08 & .34 & & \\
\hline & $\begin{array}{l}\text { Parentification Questionnaire Total Centered } \\
\text { Score }\end{array}$ & -.16 & .03 & & \\
\hline & Locus of Control Centered Score & .39 & .001 & & \\
\hline & $\begin{array}{l}\text { ASQ Relationships as Secondary Subscale } \\
\text { Centered Score }\end{array}$ & -.01 & .92 & & \\
\hline & ASQ Confidence Subscale Centered Score & -.07 & .46 & & \\
\hline
\end{tabular}

(table continues) 
Table 8 (continued)

\begin{tabular}{lcccc}
\hline Model & B & Sig. & $\Delta \mathrm{R}^{2}$ & $F(\mathrm{df})$ \\
\hline ASQ Preoccupation with Relationships & .45 & .001 & & \\
$\quad$ Subscale Centered Score & & & & \\
3 (Constant) & 18.54 & .003 & .02 & $1.31(11,456)$ \\
Gender & -1.73 & .07 & & \\
Age & .17 & .28 & \\
Social Support Past Total Score & .79 & .22 & \\
Social Support Present Total Score & -1.44 & .03 & \\
Attachment Style Questionnaire-Need for & -.17 & .85 & \\
$\quad$ Approval subscale & & & \\
Attachment Style Questionnaire-Discomfort & .13 & .03 & \\
$\quad \quad$ with closeness subscale & & & \\
Emotional Abuse Scale Total Score & .95 & .02 & \\
Perceived Social Support Friends Centered & .03 & .77 & \\
$\quad$ Score & & & & \\
Perceived Social Support Family Centered & -.08 & .37 & .03 \\
$\quad$ Score & & & &
\end{tabular}

(table continues) 
Table 8 (continued)

\begin{tabular}{lcccc}
\hline Model & B & Sig. & $\Delta \mathrm{R}^{2}$ & $F(\mathrm{df})$ \\
\hline Emotional abuse X Family Social Support & -.02 & .31 & \\
Emotional abuse X Parentification & .04 & .02 & \\
Emotional abuse X Locus of Control & .06 & .04 & \\
Emotional abuse X ASQ Need for Approval & -.01 & .61 \\
Emotional abuse X ASQ Relationships as & -.003 & .88 \\
$\quad$ Secondary & & \\
Emotional abuse X ASQ Preoccupation with & .01 & .46 \\
$\quad$ Relationships & & \\
Emotional abuse X ASQ Confidence & -.01 & .52 \\
Emotional abuse X Discomfort with & -.01 & .68 \\
$\quad$ Closeness & & \\
\hline
\end{tabular}

Note. ${ }^{* * *} p<.05 ; \mathrm{ASQ}=$ Attachment Style Questionnaire. 
Table 9

Hierarchical Regression Analysis Evaluating the Moderating Effects of Social Support, Parentification, Locus of Control, and Attachment Styles on Permissiveness Resulting from

Emotional Abuse

\begin{tabular}{|c|c|c|c|c|c|}
\hline \multicolumn{2}{|c|}{ Model } & \multirow{2}{*}{ B } & \multirow{2}{*}{$\begin{array}{l}\text { Sig. } \\
.001\end{array}$} & \multirow{2}{*}{$\frac{\Delta \mathrm{R}^{2}}{.21}$} & \multirow{2}{*}{$\frac{F(\mathrm{df})}{64.86(2,476)}$} \\
\hline $1 * * *$ & (Constant) & & & & \\
\hline & Gender & .67 & .001 & & \\
\hline & Age & -.01 & .18 & & \\
\hline $2 * * *$ & (Constant) & 3.41 & .001 & .07 & $3.47(12,464)$ \\
\hline & Gender & .69 & .001 & & \\
\hline & Age & -.01 & .26 & & \\
\hline & Social Support Past Total Score & .001 & .99 & & \\
\hline & Social Support Present Total Score & -.01 & .75 & & \\
\hline & Parentification Questionnaire Total Score & .01 & .14 & & \\
\hline & Attachment Style Questionnaire-Need for & .003 & .63 & & \\
\hline \multicolumn{6}{|c|}{ Approval subscale } \\
\hline & $\begin{array}{l}\text { Attachment Style Questionnaire-Discomfort } \\
\text { with closeness subscale }\end{array}$ & \multicolumn{3}{|c|}{ with closeness subscale } & \\
\hline & Emotional Abuse Scale Total Score & -.01 & .45 & & \\
\hline & Perceived Social Support Friends Centered & -.01 & .24 & & \\
\hline \multicolumn{6}{|c|}{ Score } \\
\hline & Perceived Social Support Family Centered & .01 & .05 & & \\
\hline \multicolumn{6}{|c|}{ Score } \\
\hline & Locus of Control Centered Score & -.02 & .03 & & \\
\hline & ASQ Relationships as Secondary Subscale & -.01 & .09 & & \\
\hline \multicolumn{6}{|c|}{ Centered Score } \\
\hline & ASQ Confidence Subscale Centered Score & -.01 & .04 & & \\
\hline
\end{tabular}

(table continues) 
Table 9 (continued)

\begin{tabular}{|c|c|c|c|c|c|}
\hline \multicolumn{2}{|c|}{ Model } & \multirow{2}{*}{$\begin{array}{c}\mathrm{B} \\
-.004\end{array}$} & \multirow{2}{*}{$\begin{array}{l}\text { Sig. } \\
.42\end{array}$} & \multirow[t]{2}{*}{$\Delta \mathrm{R}^{2}$} & \multirow[t]{2}{*}{$F(\mathrm{df})$} \\
\hline & ASQ Preoccupation with Relationships & & & & \\
\hline \multicolumn{6}{|c|}{ Subscale Centered Score } \\
\hline 3 & (Constant) & 3.16 & .001 & .02 & $.94(11,453)$ \\
\hline & Gender & .68 & .001 & & \\
\hline & Age & -.02 & .07 & & \\
\hline & Social Support Past Total Score & .01 & .87 & & \\
\hline & Social Support Present Total Score & -.02 & .67 & & \\
\hline & Parentification Questionnaire Total Score & .01 & .14 & & \\
\hline & Attachment Style Questionnaire-Need for & .004 & .53 & & \\
\hline \multicolumn{6}{|c|}{ Approval subscale } \\
\hline & $\begin{array}{l}\text { Attachment Style Questionnaire-Discomfort } \\
\text { with closeness subscale }\end{array}$ & -.01 & .03 & & \\
\hline & Emotional Abuse Scale Total Score & .04 & .13 & & \\
\hline & Perceived Social Support Friends Centered & -.01 & .20 & & \\
\hline \multicolumn{6}{|c|}{ Score } \\
\hline & Perceived Social Support Family Centered & .09 & .13 & & \\
\hline \multicolumn{6}{|c|}{ Score } \\
\hline & Locus of Control Centered Score & -.02 & .04 & & \\
\hline & ASQ Relationships as Secondary Subscale & -.01 & .06 & & \\
\hline \multicolumn{6}{|c|}{ Centered Score } \\
\hline & ASQ Confidence Subscale Centered Score & -.01 & .05 & & \\
\hline & ASQ Preoccupation with Relationships & -.01 & .38 & & \\
\hline \multicolumn{6}{|c|}{ Subscale Centered Score } \\
\hline & Emotional Abuse X Social Support Past & -.003 & .60 & & \\
\hline & Emotional Abuse X Social Support Present & -.001 & .88 & & \\
\hline & Emotional abuse X Friend Social Support & -.001 & .53 & & \\
\hline & Emotional abuse X Family Social Support & .003 & .074 & & \\
\hline
\end{tabular}

(table continues) 
Table 9 (continued)

\begin{tabular}{|c|c|c|c|c|}
\hline Model & $\mathrm{B}$ & Sig. & $\Delta \mathrm{R}^{2}$ & $F(\mathrm{df})$ \\
\hline Emotional abuse X Parentification & -.0003 & .79 & & \\
\hline Emotional abuse X Locus of Control & -.002 & .42 & & \\
\hline Emotional abuse X ASQ Need for Approval & -.002 & .10 & & \\
\hline $\begin{array}{l}\text { Emotional abuse X ASQ Relationships as } \\
\text { Secondary }\end{array}$ & \multicolumn{3}{|c|}{ Secondary } & \\
\hline Emotional abuse X ASQ Preoccupation with & .001 & .57 & & \\
\hline \multicolumn{5}{|l|}{ Relationships } \\
\hline Emotional abuse X ASQ Confidence & -.001 & .72 & & \\
\hline Emotional abuse X Discomfort with & -.0001 & .88 & & \\
\hline Closeness & & & & \\
\hline
\end{tabular}

Note. ${ }^{* *} p<.05 ; \mathrm{ASQ}=$ Attachment Style Questionnaire. 
Table 10

Hierarchical Regression Analysis Evaluating the Moderating Effects of Social Support, Parentification, Locus of Control, and Attachment Styles on Depression Resulting from

Emotional Abuse

\begin{tabular}{lcccc}
\hline Model & B & Sig. & $\Delta \mathrm{R}^{2}$ & $F(\mathrm{df})$ \\
\hline $1^{* * *}$ (Constant) & -4.70 & .19 & .05 & $11.15(2,477)$ \\
Gender & 3.30 & .001 & & \\
Age & .45 & .01 & & \\
$2^{* * *}$ (Constant) & -13.24 & .002 & .38 & $25.67(12,465)$ \\
Gender & 2.77 & .001 & & \\
Age & .36 & .01 & & \\
Social Support Past Total Score & .26 & .54 & & \\
Attachment Style Questionnaire-Discomfort & .10 & .03 & & \\
$\quad$ with closeness subscale & & & & \\
Emotional Abuse Scale Total Score & .23 & .01 & & \\
Social Support Present Centered Score & -.88 & .06 & & \\
Perceived Social Support Friends Centered & -.67 & .43 & & \\
$\quad$ Score & & & & \\
Perceived Social Support Family Centered & -.08 & .21 & & \\
$\quad$ Score & & & & \\
Parentification Questionnaire Total Centered & -.03 & .56 & \\
$\quad$ Score & & & &
\end{tabular}


Table 10 (continued)

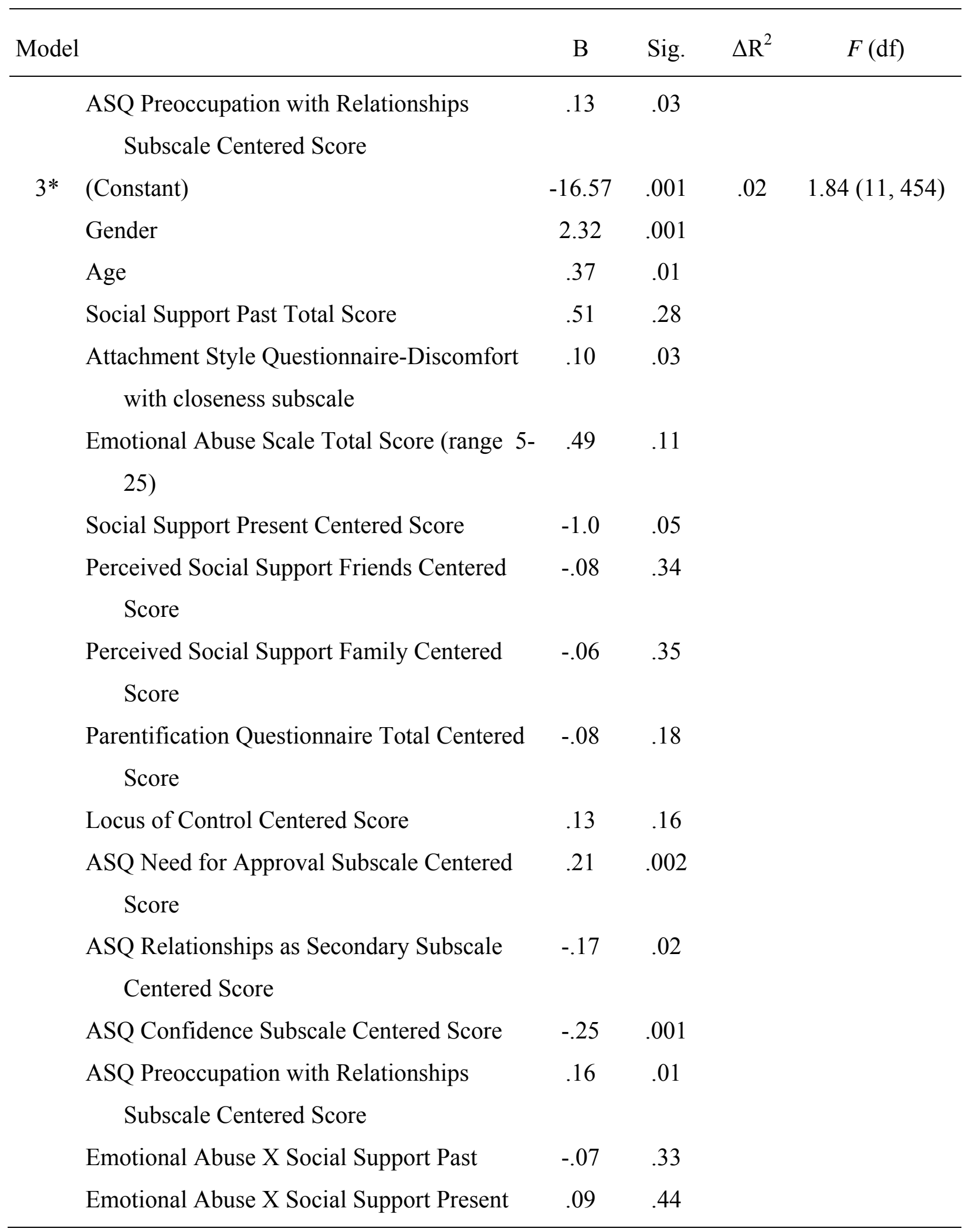

(table continues) 
Table 10 (continued)

\begin{tabular}{|c|c|c|c|c|}
\hline Model & $\mathrm{B}$ & Sig. & $\Delta \mathrm{R}^{2}$ & $F(\mathrm{df})$ \\
\hline Emotional abuse X Friend Social Support & -.02 & .40 & & \\
\hline Emotional abuse X Family Social Support & -.03 & .12 & & \\
\hline Emotional abuse $\mathrm{X}$ Parentification & .01 & .46 & & \\
\hline Emotional abuse X Locus of Control & .04 & .04 & & \\
\hline Emotional abuse X ASQ Need for Approval & -.02 & .16 & & \\
\hline Emotional abuse X ASQ Relationships as & -.01 & .40 & & \\
\hline \multicolumn{5}{|l|}{ Secondary } \\
\hline Emotional abuse X ASQ Preoccupation with & .05 & .70 & & \\
\hline \multicolumn{5}{|l|}{ Relationships } \\
\hline Emotional abuse X ASQ Confidence & .001 & .97 & & \\
\hline Emotional abuse $\mathrm{X}$ Discomfort with & .02 & .14 & & \\
\hline Closeness & & & & \\
\hline
\end{tabular}

Note. ${ }^{* *} p<.001, * p<.05$; ASQ $=$ Attachment Style Questionnaire. 
Table 11

Hierarchical Regression Analysis Evaluating the Moderating Effects of Social Support, Parentification, Locus of Control, and Attachment Styles on Anxiety Resulting from Emotional Abuse

\begin{tabular}{|c|c|c|c|c|c|}
\hline \multicolumn{2}{|c|}{ Model } & \multirow{2}{*}{$\begin{array}{c}B \\
-5.66\end{array}$} & \multirow{2}{*}{$\begin{array}{l}\text { Sig. } \\
.11\end{array}$} & \multirow{2}{*}{$\begin{array}{c}\Delta \mathrm{R}^{2} \\
.05\end{array}$} & \multirow{2}{*}{$\begin{array}{c}F(\mathrm{df}) \\
12.70(2,476)\end{array}$} \\
\hline $1 * * *$ & (Constant) & & & & \\
\hline & Gender & 3.61 & .001 & & \\
\hline & Age & .43 & .01 & & \\
\hline $2 * * *$ & (Constant) & -12.86 & .04 & .18 & $8.80(12,464)$ \\
\hline & Gender & 2.62 & .001 & & \\
\hline & Age & .40 & .01 & & \\
\hline & Social Support Past Total Score & -.41 & .40 & & \\
\hline & Social Support Present Total Score & .30 & .58 & & \\
\hline & $\begin{array}{l}\text { Attachment Style Questionnaire-Need for } \\
\text { Approval subscale }\end{array}$ & .04 & .63 & & \\
\hline & Attachment Style Questionnaire- & -.18 & .03 & & \\
\hline & Relationships as Secondary subscale & & & & \\
\hline & $\begin{array}{l}\text { Attachment Style Questionnaire-Discomfort } \\
\text { with closeness subscale }\end{array}$ & .12 & .03 & & \\
\hline & $\begin{array}{l}\text { Attachment Style Questionnaire-Confidence } \\
\text { subscale }\end{array}$ & -.01 & .88 & & \\
\hline & Attachment Style Questionnaire- & .24 & .001 & & \\
\hline & $\begin{array}{l}\text { Preoccupation with Relationships } \\
\text { subscale }\end{array}$ & & & & \\
\hline & Emotional Abuse Scale Total Score & .27 & .01 & & \\
\hline & $\begin{array}{l}\text { Perceived Social Support Friends Centered } \\
\quad \text { Score }\end{array}$ & -.07 & .47 & & \\
\hline
\end{tabular}


Table 11 (continued)

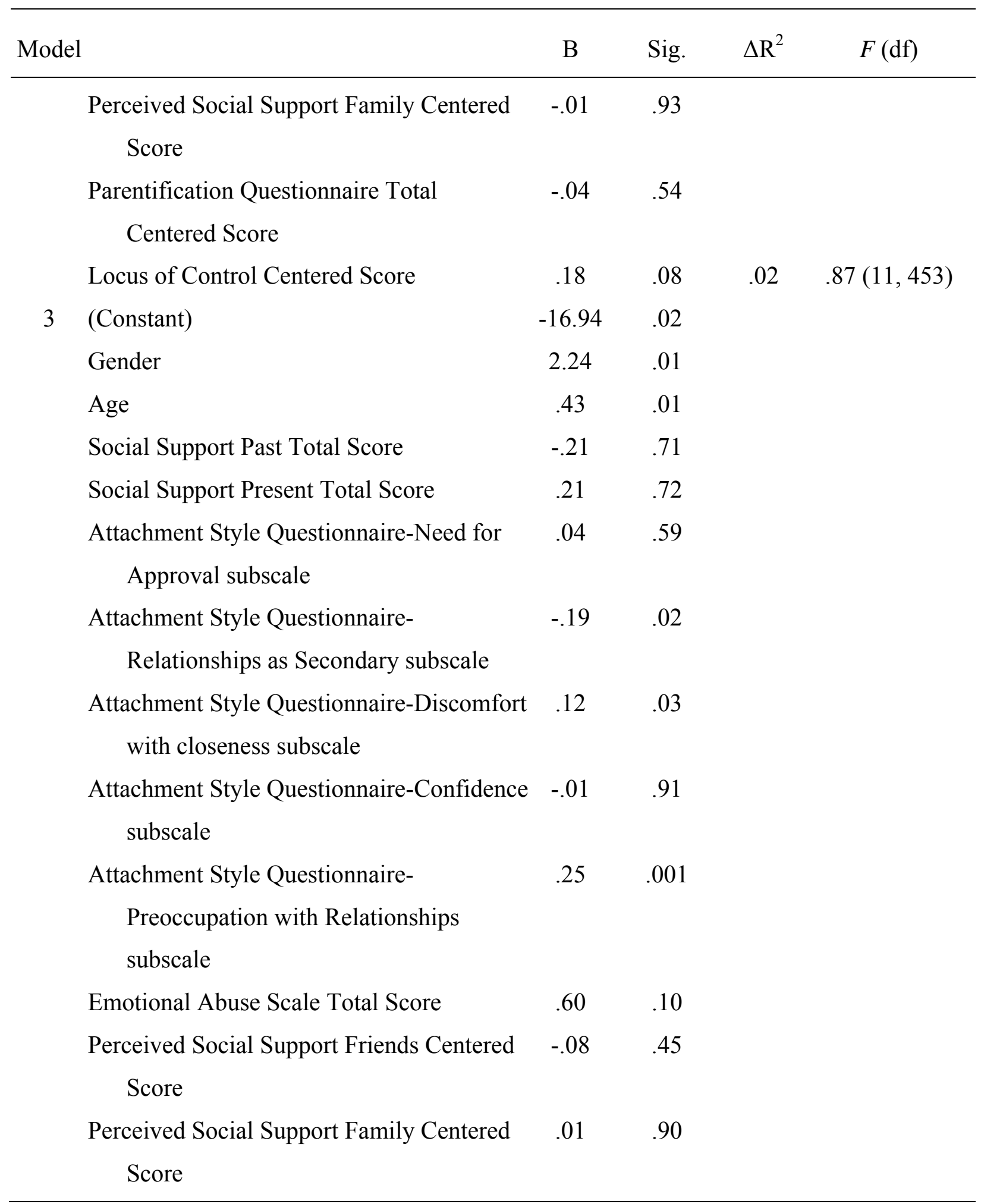

(table continues) 
Table 11 (continued)

\begin{tabular}{|c|c|c|c|c|}
\hline Model & B & Sig. & $\Delta \mathrm{R}^{2}$ & $F(\mathrm{df})$ \\
\hline Parentification Questionnaire Total & -.06 & .36 & & \\
\hline \multicolumn{5}{|l|}{ Centered Score } \\
\hline Locus of Control Centered Score & .18 & .08 & & \\
\hline Emotional Abuse X Social Support Past & -.02 & .78 & & \\
\hline Emotional Abuse X Social Support Present & .10 & .44 & & \\
\hline Emotional abuse X Friend Social Support & -.002 & .94 & & \\
\hline Emotional abuse X Family Social Support & -.01 & .63 & & \\
\hline Emotional abuse X Parentification & .004 & .78 & & \\
\hline Emotional abuse X Locus of Control & .04 & .10 & & \\
\hline Emotional abuse X ASQ Need for Approval & -.02 & .24 & & \\
\hline Emotional abuse X ASQ Relationships as & -.01 & 47 & & \\
\hline \multicolumn{5}{|l|}{ Secondary } \\
\hline Emotional abuse X ASQ Preoccupation with & -.004 & .79 & & \\
\hline \multicolumn{5}{|l|}{ Relationships } \\
\hline Emotional abuse X ASQ Confidence & .01 & .73 & & \\
\hline Emotional abuse X Discomfort with & .03 & .05 & & \\
\hline Closeness & & & & \\
\hline
\end{tabular}

Note. ${ }^{* * *} p<.001 ; \mathrm{ASQ}=$ Attachment Style Questionnaire. 
Table 12

Hierarchical Regression Analysis Evaluating the Moderating Effects of Social Support, Parentification, Locus of Control, and Attachment Styles on Social Anxiety Resulting from

Emotional Abuse

\begin{tabular}{|c|c|c|c|c|c|}
\hline \multicolumn{2}{|c|}{ Model } & \multirow{2}{*}{$\begin{array}{c}\mathrm{B} \\
62.52\end{array}$} & \multirow{2}{*}{$\begin{array}{l}\text { Sig. } \\
.001\end{array}$} & \multirow{2}{*}{$\begin{array}{l}\Delta \mathrm{R}^{2} \\
.002\end{array}$} & \multirow{2}{*}{$\begin{array}{c}F(\mathrm{df}) \\
.36(2,476)\end{array}$} \\
\hline 1 & (Constant) & & & & \\
\hline & Gender & 2.35 & .51 & & \\
\hline & Age & .41 & .55 & & \\
\hline $2 * * *$ & (Constant) & 58.76 & .002 & .38 & $23.34(12,464)$ \\
\hline & Gender & 2.08 & .51 & & \\
\hline & Age & .10 & .86 & & \\
\hline & Social Support Past Total Score & -5.15 & .01 & & \\
\hline & Parentification Questionnaire Total & .23 & .34 & & \\
\hline \multicolumn{6}{|c|}{ Score } \\
\hline & $\begin{array}{l}\text { Attachment Style Questionnaire-Need } \\
\text { for Approval subscale }\end{array}$ & 1.62 & .001 & & \\
\hline & Emotional Abuse Scale Total Score & -.15 & .70 & & \\
\hline & Social Support Present Centered Score & 5.34 & .01 & & \\
\hline & Perceived Social Support Friends & -1.01 & .01 & & \\
\hline \multicolumn{6}{|c|}{ Centered Score } \\
\hline & Perceived Social Support Family & .43 & .15 & & \\
\hline \multicolumn{6}{|c|}{ Centered Score } \\
\hline & Locus of Control Centered Score & .97 & .01 & & \\
\hline & ASQ Relationships as Secondary & .63 & .04 & & \\
\hline \multicolumn{6}{|c|}{ Subscale Centered Score } \\
\hline & ASQ Discomfort with Closeness & .004 & .98 & & \\
\hline & Subscale Centered Score & & & & \\
\hline
\end{tabular}


Table 12 (continued)

\begin{tabular}{|c|c|c|c|c|c|}
\hline \multirow[t]{4}{*}{ Model } & & B & Sig. & $\Delta \mathrm{R}^{2}$ & $F(\mathrm{df})$ \\
\hline & ASQ Confidence Subscale Centered Score & -1.74 & .001 & & \\
\hline & ASQ Preoccupation with Relationships & .21 & .42 & & \\
\hline & Subscale Centered Score & & & & \\
\hline \multirow[t]{18}{*}{3} & (Constant) & 45.26 & .05 & .02 & $1.14(11,453)$ \\
\hline & Gender & .94 & .77 & & \\
\hline & Age & -.03 & .96 & & \\
\hline & Social Support Past Total Score & -3.79 & .07 & & \\
\hline & Parentification Questionnaire Total Score & .22 & .39 & & \\
\hline & $\begin{array}{l}\text { Attachment Style Questionnaire-Need for } \\
\text { Approval subscale }\end{array}$ & 1.66 & .001 & & \\
\hline & Emotional Abuse Scale Total Score & .98 & .48 & & \\
\hline & Social Support Present Centered Score & 4.74 & .04 & & \\
\hline & $\begin{array}{l}\text { Perceived Social Support Friends Centered } \\
\text { Score }\end{array}$ & -1.09 & .01 & & \\
\hline & $\begin{array}{l}\text { Perceived Social Support Family Centered } \\
\text { Score }\end{array}$ & .45 & .14 & & \\
\hline & Locus of Control Centered Score & .91 & .02 & & \\
\hline & $\begin{array}{l}\text { ASQ Relationships as Secondary Subscale } \\
\text { Centered Score }\end{array}$ & .49 & .12 & & \\
\hline & $\begin{array}{l}\text { ASQ Discomfort with Closeness Subscale } \\
\text { Centered Score }\end{array}$ & .04 & .86 & & \\
\hline & ASQ Confidence Subscale Centered Score & -1.58 & .001 & & \\
\hline & $\begin{array}{l}\text { ASQ Preoccupation with Relationships } \\
\quad \text { Subscale Centered Score }\end{array}$ & .32 & .24 & & \\
\hline & Emotional Abuse X Social Support Past & -.27 & .38 & & \\
\hline & Emotional Abuse X Social Support Present & .32 & .51 & & \\
\hline & Emotional abuse X Friend Social Support & -.02 & .86 & & \\
\hline
\end{tabular}

(table continues) 
Table 12 (continued)

\begin{tabular}{|c|c|c|c|c|}
\hline Model & B & Sig. & $\Delta \mathrm{R}^{2}$ & $F(\mathrm{df})$ \\
\hline Emotional abuse X Family Social Support & -.02 & .81 & & \\
\hline Emotional abuse X Parentification & .01 & .90 & & \\
\hline Emotional abuse X Locus of Control & .11 & .23 & & \\
\hline Emotional abuse X ASQ Need for Approval & -.05 & .44 & & \\
\hline $\begin{array}{l}\text { Emotional abuse X ASQ Relationships as } \\
\text { Secondary }\end{array}$ & .10 & .14 & & \\
\hline $\begin{array}{l}\text { Emotional abuse X ASQ Preoccupation with } \\
\text { Relationships }\end{array}$ & -.06 & .30 & & \\
\hline Emotional abuse X ASQ Confidence & -.09 & .17 & & \\
\hline $\begin{array}{l}\text { Emotional abuse X Discomfort with } \\
\text { Closeness }\end{array}$ & -.06 & .22 & & \\
\hline
\end{tabular}

Note. ${ }^{* * *} p<.001 ; \mathrm{ASQ}=$ Attachment Style Questionnaire. 
Table 13

Hierarchical Regression Analysis Evaluating the Moderating Effects of Social Support, Parentification, Locus of Control, and Attachment Styles on Agoraphobia Resulting from

Emotional Abuse

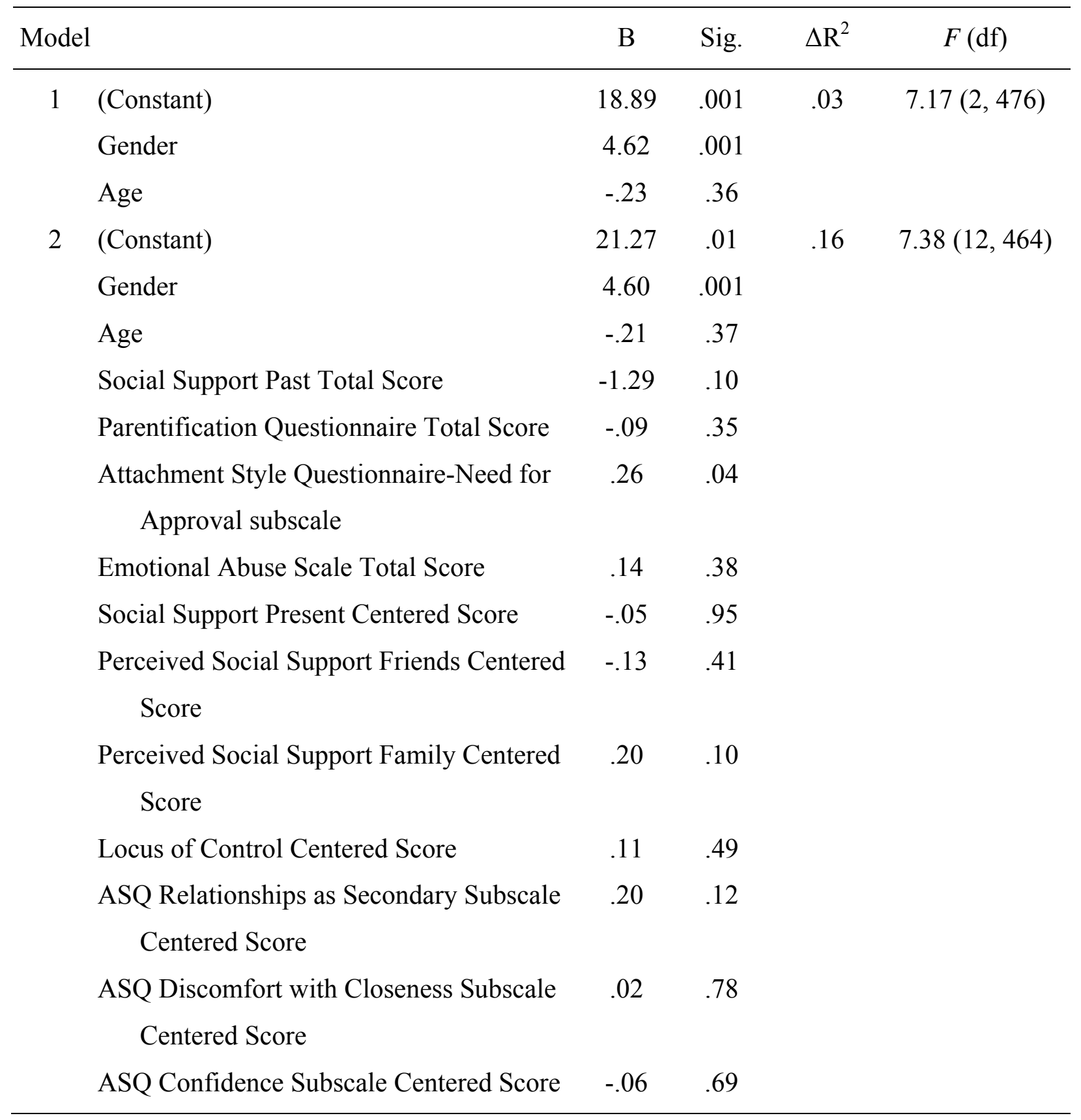

(table continues) 
Table 13 (continued)

\begin{tabular}{|c|c|c|c|c|c|}
\hline \multicolumn{2}{|c|}{ Model } & \multirow{2}{*}{$\begin{array}{l}\mathrm{B} \\
.31\end{array}$} & \multirow{2}{*}{$\begin{array}{l}\text { Sig. } \\
.01\end{array}$} & $\Delta \mathrm{R}^{2}$ & \multirow[t]{2}{*}{$F(\mathrm{df})$} \\
\hline & $\begin{array}{l}\text { ASQ Preoccupation with Relationships } \\
\text { Subscale Centered Score }\end{array}$ & & & & \\
\hline 3 & (Constant) & 15.96 & .10 & .03 & $1.56(11,453)$ \\
\hline & Gender & 4.24 & .002 & & \\
\hline & Age & -.13 & .58 & & \\
\hline & Social Support Past Total Score & -1.61 & .07 & & \\
\hline & Parentification Questionnaire Total Score & -.11 & .31 & & \\
\hline & $\begin{array}{l}\text { Attachment Style Questionnaire-Need for } \\
\text { Approval subscale }\end{array}$ & .25 & .04 & & \\
\hline & Emotional Abuse Scale Total Score & .92 & .11 & & \\
\hline & Social Support Present Centered Score & .43 & .65 & & \\
\hline & $\begin{array}{l}\text { Perceived Social Support Friends Centered } \\
\quad \text { Score }\end{array}$ & -.14 & .39 & & \\
\hline & $\begin{array}{l}\text { Perceived Social Support Family Centered } \\
\text { Score }\end{array}$ & .22 & .09 & & \\
\hline & Locus of Control Centered Score & .05 & .78 & & \\
\hline & $\begin{array}{l}\text { ASQ Relationships as Secondary Subscale } \\
\quad \text { Centered Score }\end{array}$ & .17 & .19 & & \\
\hline & $\begin{array}{l}\text { ASQ Discomfort with Closeness Subscale } \\
\text { Centered Score }\end{array}$ & .03 & .73 & & \\
\hline & ASQ Confidence Subscale Centered Score & -.05 & .73 & & \\
\hline & $\begin{array}{l}\text { ASQ Preoccupation with Relationships } \\
\text { Subscale Centered Score }\end{array}$ & .36 & .001 & & \\
\hline & Emotional Abuse X Social Support Past & .05 & .71 & & \\
\hline & Emotional Abuse X Social Support Present & -.03 & .87 & & \\
\hline & Emotional abuse X Friend Social Support & -.04 & .35 & & \\
\hline & Emotional abuse X Family Social Support & -.02 & .58 & & \\
\hline
\end{tabular}

(table continues) 
Table 13 (continued)

\begin{tabular}{lcccc}
\hline Model & $\beta$ & Sig. & $\Delta \mathrm{R}^{2}$ & $F(\mathrm{df})$ \\
\hline Emotional abuse X Parentification & -.003 & .88 & & \\
Emotional abuse X Locus of Control & .09 & .01 & \\
Emotional abuse X ASQ Need for Approval & -.04 & .13 & \\
Emotional abuse X ASQ Relationships as & .04 & .15 & \\
$\quad$ Secondary & & & \\
Emotional abuse X ASQ Preoccupation with & -.01 & .68 & \\
$\quad$ Relationships & & & .57 \\
Emotional abuse X ASQ Confidence & .02 & .57 \\
Emotional abuse X Discomfort with & -.004 & .83 \\
$\quad$ Closeness & &
\end{tabular}

Note. ${ }^{* * *} p<.001 ; \mathrm{ASQ}=$ Attachment Style Questionnaire. 
Table 14

Hierarchical Regression Analysis Evaluating the Moderating Effects of Social Support, Parentification, Locus of Control, and Attachment Styles on Substance Use Resulting from

Physical Abuse

\begin{tabular}{|c|c|c|c|c|c|}
\hline \multicolumn{2}{|l|}{ Model } & \multirow{2}{*}{$\begin{array}{c}\mathrm{B} \\
6.76\end{array}$} & \multirow{2}{*}{$\begin{array}{l}\text { Sig. } \\
.001\end{array}$} & \multirow{2}{*}{$\frac{\Delta \mathrm{R}^{2}}{.01}$} & \multirow{2}{*}{$\frac{F(\mathrm{df})}{2.73(2,479)}$} \\
\hline 1 & (Constant) & & & & \\
\hline & Gender & -.61 & .07 & & \\
\hline & Age & -.09 & .11 & & \\
\hline $2 * * *$ & (Constant) & 7.93 & .001 & .08 & $3.47(12,467)$ \\
\hline & Gender & -.86 & .02 & & \\
\hline & Age & -.06 & .27 & & \\
\hline & Social Support Past Total Score & .12 & .58 & & \\
\hline & Social Support Present Total Score & -.46 & .06 & & \\
\hline & Attachment Style Questionnaire-Need for & -.004 & .89 & & \\
\hline \multicolumn{6}{|c|}{ Approval subscale } \\
\hline & $\begin{array}{l}\text { Attachment Style Questionnaire-Discomfort } \\
\text { with closeness subscale }\end{array}$ & .03 & .25 & & \\
\hline \multicolumn{5}{|c|}{ Score } & \\
\hline \multicolumn{5}{|c|}{ Score } & \\
\hline & Parentification Questionnaire Total & -.03 & .30 & & \\
\hline \multicolumn{6}{|c|}{ Centered Score } \\
\hline & Locus of Control Centered Score & .05 & .27 & & \\
\hline & ASQ Relationships as Secondary Subscale & .02 & .57 & & \\
\hline \multicolumn{6}{|c|}{ Centered Score } \\
\hline & ASQ Confidence Subscale Centered Score & .06 & .15 & & \\
\hline
\end{tabular}

(table continues) 
Table 14 (continued)

\begin{tabular}{|c|c|c|c|c|c|}
\hline \multicolumn{2}{|c|}{ Model } & \multirow{2}{*}{$\begin{array}{l}\mathrm{B} \\
.11\end{array}$} & \multirow{2}{*}{$\begin{array}{l}\text { Sig. } \\
.001\end{array}$} & \multirow[t]{2}{*}{$\Delta \mathrm{R}^{2}$} & \multirow[t]{2}{*}{$F(\mathrm{df})$} \\
\hline & $\begin{array}{l}\text { ASQ Preoccupation with Relationships } \\
\text { Subscale Centered Score }\end{array}$ & & & & \\
\hline & Physical Abuse Centered & .02 & .79 & & \\
\hline 3 & (Constant) & 7.06 & .001 & .02 & $.90(11,456)$ \\
\hline & Gender & -.83 & .03 & & \\
\hline & Age & -.04 & .56 & & \\
\hline & Social Support Past Total Score & .11 & .66 & & \\
\hline & Social Support Present Total Score & -.37 & .16 & & \\
\hline & $\begin{array}{l}\text { Attachment Style Questionnaire-Need for } \\
\text { Approval subscale }\end{array}$ & -.01 & .88 & & \\
\hline & $\begin{array}{l}\text { Attachment Style Questionnaire-Discomfort } \\
\text { with closeness subscale }\end{array}$ & .03 & .29 & & \\
\hline & $\begin{array}{l}\text { Perceived Social Support Friends Centered } \\
\quad \text { Score }\end{array}$ & .09 & .04 & & \\
\hline & $\begin{array}{l}\text { Perceived Social Support Family Centered } \\
\text { Score }\end{array}$ & -.01 & .87 & & \\
\hline & $\begin{array}{l}\text { Parentification Questionnaire Total } \\
\quad \text { Centered Score }\end{array}$ & -.03 & .32 & & \\
\hline & Locus of Control Centered Score & .05 & .31 & & \\
\hline & $\begin{array}{l}\text { ASQ Relationships as Secondary Subscale } \\
\text { Centered Score }\end{array}$ & .02 & .52 & & \\
\hline & ASQ Confidence Subscale Centered Score & .05 & .23 & & \\
\hline & $\begin{array}{l}\text { ASQ Preoccupation with Relationships } \\
\text { Subscale Centered Score }\end{array}$ & .11 & .001 & & \\
\hline & Physical Abuse Centered & .13 & .56 & & \\
\hline & Physical Abuse X Social Support Past & .05 & .32 & & \\
\hline & Physical Abuse X Social Support Present & .13 & .14 & & \\
\hline
\end{tabular}

(table continues) 
Table 14 (continued)

\begin{tabular}{lcccc}
\hline Model & B & Sig. & $\Delta \mathrm{R}^{2}$ & $F(\mathrm{df})$ \\
\hline Physical abuse X Friend Social Support & -.04 & .03 & \\
Physical abuse X Family Social Support & -.01 & .58 & \\
Physical abuse X Parentification & .001 & .88 & \\
Physical abuse X Locus of Control & .03 & .06 & \\
Physical abuse X ASQ Need for Approval & -.004 & .72 \\
Physical abuse X ASQ Relationships as & -.02 & .26 \\
$\quad$ Secondary & & & \\
Physical abuse X ASQ Preoccupation with & -.01 & .42 \\
$\quad$ Relationships & & & \\
Physical abuse X ASQ Confidence & -.003 & .81 \\
Physical abuse X Discomfort with & .001 & .95 \\
Closeness & & \\
\hline
\end{tabular}

Note. ${ }^{* * *} p<.001 ; \mathrm{ASQ}=$ Attachment Style Questionnaire. 
Table 15

Hierarchical Regression Analysis Evaluating the Moderating Effects of Social Support, Parentification, Locus of Control, and Attachment Styles on DUSI Overall Problems Resulting from Physical Abuse

\begin{tabular}{|c|c|c|c|c|c|}
\hline \multicolumn{2}{|c|}{ Model } & \multirow{2}{*}{$\frac{B}{24.06}$} & \multirow{2}{*}{$\begin{array}{l}\text { Sig. } \\
.001\end{array}$} & \multirow{2}{*}{$\Delta \mathrm{R}^{2}$} & \multirow{2}{*}{$\frac{F(\mathrm{df})}{.66(2,479)}$} \\
\hline 1 & (Constant) & & & & \\
\hline & Gender & -.62 & .58 & & \\
\hline & Age & .17 & .33 & & \\
\hline $2 * * *$ & (Constant) & 28.22 & .001 & .41 & $27.38(12,467)$ \\
\hline & Gender & -1.58 & .10 & & \\
\hline & Age & .08 & .57 & & \\
\hline & Social Support Past Total Score & .64 & .26 & & \\
\hline & Social Support Present Total Score & -1.73 & .01 & & \\
\hline & $\begin{array}{l}\text { Attachment Style Questionnaire-Need for } \\
\text { Approval subscale }\end{array}$ & .05 & .56 & & \\
\hline & $\begin{array}{l}\text { Attachment Style Questionnaire-Discomfort } \\
\text { with closeness subscale }\end{array}$ & .14 & .02 & & \\
\hline & $\begin{array}{l}\text { Perceived Social Support Friends Centered } \\
\quad \text { Score }\end{array}$ & .09 & .41 & & \\
\hline & $\begin{array}{l}\text { Perceived Social Support Family Centered } \\
\text { Score }\end{array}$ & -.19 & .03 & & \\
\hline & $\begin{array}{l}\text { Parentification Questionnaire Total } \\
\text { Centered Score }\end{array}$ & -.24 & .001 & & \\
\hline & Locus of Control Centered Score & .39 & .001 & & \\
\hline & $\begin{array}{l}\text { ASQ Relationships as Secondary Subscale } \\
\text { Centered Score }\end{array}$ & -.056 & .55 & & \\
\hline & ASQ Confidence Subscale Centered Score & -.14 & .16 & & \\
\hline
\end{tabular}


Table 15 (continued)

\begin{tabular}{|c|c|c|c|c|c|}
\hline \multicolumn{2}{|c|}{ Model } & \multirow{2}{*}{$\begin{array}{l}\text { B } \\
.45\end{array}$} & \multirow{2}{*}{$\begin{array}{l}\text { Sig. } \\
.001\end{array}$} & \multirow[t]{2}{*}{$\Delta \mathrm{R}^{2}$} & \multirow[t]{2}{*}{$F(\mathrm{df})$} \\
\hline & $\begin{array}{l}\text { ASQ Preoccupation with Relationships } \\
\text { Subscale Centered Score }\end{array}$ & & & & \\
\hline & Physical Abuse Centered & .62 & .001 & & \\
\hline 3 & (Constant) & 25.85 & .001 & .03 & $2.03(11,456)$ \\
\hline & Gender & -1.75 & .07 & & \\
\hline & Age & .13 & .44 & & \\
\hline & Social Support Past Total Score & .61 & .32 & & \\
\hline & Social Support Present Total Score & -1.35 & .05 & & \\
\hline & $\begin{array}{l}\text { Attachment Style Questionnaire-Need for } \\
\text { Approval subscale }\end{array}$ & .05 & .58 & & \\
\hline & $\begin{array}{l}\text { Attachment Style Questionnaire-Discomfort } \\
\text { with closeness subscale }\end{array}$ & .14 & .03 & & \\
\hline & $\begin{array}{l}\text { Perceived Social Support Friends Centered } \\
\quad \text { Score }\end{array}$ & .03 & .83 & & \\
\hline & $\begin{array}{l}\text { Perceived Social Support Family Centered } \\
\text { Score }\end{array}$ & -.18 & .04 & & \\
\hline & $\begin{array}{l}\text { Parentification Questionnaire Total } \\
\text { Centered Score }\end{array}$ & -.25 & .001 & & \\
\hline & Locus of Control Centered Score & .38 & .001 & & \\
\hline & $\begin{array}{l}\text { ASQ Relationships as Secondary Subscale } \\
\text { Centered Score }\end{array}$ & -.05 & .62 & & \\
\hline & ASQ Confidence Subscale Centered Score & -.15 & .14 & & \\
\hline & $\begin{array}{l}\text { ASQ Preoccupation with Relationships } \\
\text { Subscale Centered Score }\end{array}$ & .45 & .001 & & \\
\hline & Physical Abuse Centered & .89 & .11 & & \\
\hline & Physical Abuse X Social Support Past & .17 & .18 & & \\
\hline & Physical Abuse X Social Support Present & .38 & .08 & & \\
\hline
\end{tabular}

(table continues) 
Table 15 (continued)

\begin{tabular}{|c|c|c|c|c|}
\hline Model & B & Sig. & $\Delta \mathrm{R}^{2}$ & $F(\mathrm{df})$ \\
\hline Physical abuse X Friend Social Support & -.15 & .003 & & \\
\hline Physical abuse X Family Social Support & -.02 & .52 & & \\
\hline Physical abuse X Parentification & .02 & .94 & & \\
\hline Physical abuse X Locus of Control & .13 & .002 & & \\
\hline Physical abuse X ASQ Need for Approval & -.01 & .67 & & \\
\hline $\begin{array}{l}\text { Physical abuse X ASQ Relationships as } \\
\text { Secondary }\end{array}$ & -.05 & .21 & & \\
\hline $\begin{array}{l}\text { Physical abuse X ASQ Preoccupation with } \\
\text { Relationships }\end{array}$ & -.05 & .06 & & \\
\hline Physical abuse X ASQ Confidence & -.02 & .51 & & \\
\hline $\begin{array}{l}\text { Physical abuse X Discomfort with } \\
\text { Closeness }\end{array}$ & .01 & .65 & & \\
\hline
\end{tabular}

Note. ${ }^{* * *} p<.001 ; \mathrm{ASQ}=$ Attachment Style Questionnaire. 
Table 16

Hierarchical Regression Analysis Evaluating the Moderating Effects of Social Support, Parentification, Locus of Control, and Attachment Styles on Permissiveness Resulting from

Physical Abuse

\begin{tabular}{|c|c|c|c|c|c|}
\hline \multicolumn{2}{|c|}{ Model } & \multirow{2}{*}{$\beta$} & \multirow{2}{*}{$\begin{array}{l}\text { Sig. } \\
.001\end{array}$} & \multirow{2}{*}{$\Delta \mathrm{R}^{2}$} & \multirow{2}{*}{$\frac{F(\mathrm{df})}{64.86(2,476)}$} \\
\hline $1 * * *$ & (Constant) & & & & \\
\hline & Gender & 67 & .001 & & \\
\hline & Age & -.01 & .18 & & \\
\hline $2 * * *$ & (Constant) & 3.37 & .001 & .07 & $3.50(12,464)$ \\
\hline & Gender & .68 & .001 & & \\
\hline & Age & -.01 & .27 & & \\
\hline & Social Support Past Total Score & -.002 & .96 & & \\
\hline & Social Support Present Total Score & -.01 & .81 & & \\
\hline & Parentification Questionnaire Total Score & .01 & .10 & & \\
\hline & Attachment Style Questionnaire-Need for & .002 & .71 & & \\
\hline \multicolumn{6}{|c|}{ Approval subscale } \\
\hline & $\begin{array}{l}\text { Attachment Style Questionnaire-Discomfort } \\
\text { with closeness subscale }\end{array}$ & -.01 & .03 & & \\
\hline & \multicolumn{4}{|l|}{ Score } & \\
\hline \multicolumn{6}{|c|}{ Score } \\
\hline & Locus of Control Centered Score & -.02 & .03 & & \\
\hline & $\begin{array}{l}\text { ASQ Relationships as Secondary Subscale } \\
\text { Centered Score }\end{array}$ & -.01 & .11 & & \\
\hline & ASQ Confidence Subscale Centered Score & -.01 & .05 & & \\
\hline & ASQ Preoccupation with Relationships & -.004 & .42 & & \\
\hline & Subscale Centered Score & & & & \\
\hline
\end{tabular}


Table 16 (continued)

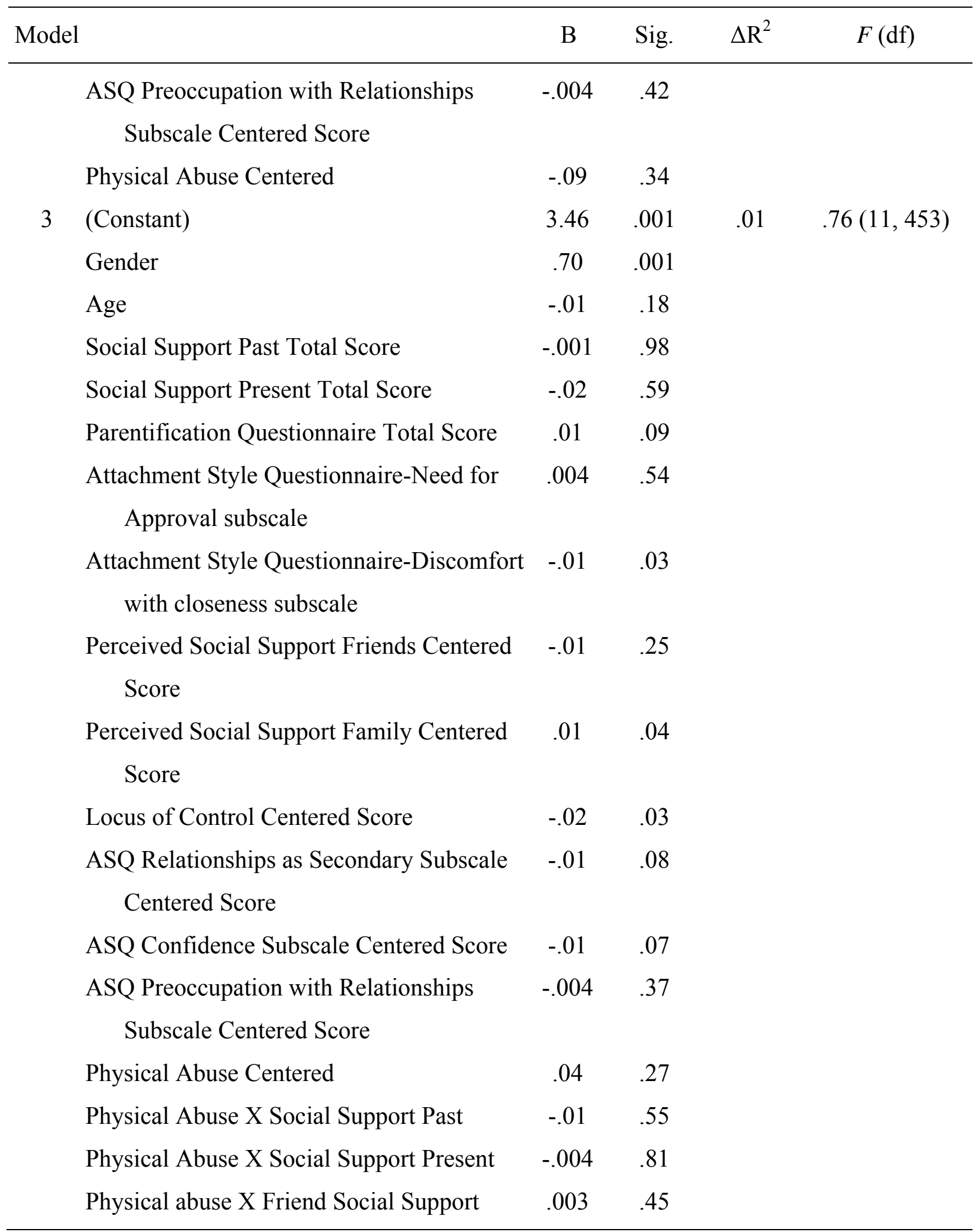


Table 16 (continued)

\begin{tabular}{lcccc}
\hline Model & B & Sig. & $\Delta \mathrm{R}^{2}$ & $F(\mathrm{df})$ \\
\hline Physical abuse X Family Social Support & .002 & .43 & \\
Physical abuse X Parentification & -.0003 & .85 & \\
Physical abuse X Locus of Control & -.001 & .76 & \\
Physical abuse X ASQ Need for Approval & -.002 & .18 & \\
Physical abuse X ASQ Relationships as & -.001 & .81 & \\
$\quad$ Secondary & & & \\
Physical abuse X ASQ Preoccupation with & .004 & .03 \\
$\quad$ Relationships & & & \\
Physical abuse X ASQ Confidence & -.001 & .52 & \\
Physical abuse X Discomfort with & -.001 & .35 \\
$\quad$ Closeness & &
\end{tabular}

Note. ${ }^{* * *} p<.001 ; \mathrm{ASQ}=$ Attachment Style Questionnaire. 
Table 17

Hierarchical Regression Analysis Evaluating the Moderating Effects of Social Support, Parentification, Locus of Control, and Attachment Styles on Depression Resulting from Physical Abuse

\begin{tabular}{|c|c|c|c|c|c|}
\hline \multicolumn{2}{|l|}{ Model } & \multirow{2}{*}{$\frac{\beta}{-4.70}$} & \multirow{2}{*}{$\begin{array}{l}\text { Sig. } \\
.19\end{array}$} & \multirow{2}{*}{$\begin{array}{l}\Delta \mathrm{R}^{2} \\
.05\end{array}$} & \multirow{2}{*}{$\frac{F(\mathrm{df})}{11.15(2,477)}$} \\
\hline $1 * * *$ & (Constant) & & & & \\
\hline & Gender & 3.30 & .001 & & \\
\hline & Age & .45 & .01 & & \\
\hline $2 * * *$ & (Constant) & -9.63 & .03 & .38 & $25.28(12,465)$ \\
\hline & Gender & 2.92 & .001 & & \\
\hline & Age & .39 & .003 & & \\
\hline & Social Support Past Total Score & .25 & .56 & & \\
\hline & Attachment Style Questionnaire- & -.16 & .02 & & \\
\hline \multicolumn{6}{|c|}{ Relationships as Secondary subscale } \\
\hline & $\begin{array}{l}\text { Attachment Style Questionnaire-Discomfort } \\
\text { with closeness subscale }\end{array}$ & .10 & .03 & & \\
\hline & Social Support Present Centered Score & -.95 & .05 & & \\
\hline & $\begin{array}{l}\text { Perceived Social Support Friends Centered } \\
\quad \text { Score }\end{array}$ & -.04 & .62 & & \\
\hline & $\begin{array}{l}\text { Perceived Social Support Family Centered } \\
\quad \text { Score }\end{array}$ & \multicolumn{3}{|c|}{ Score } & \\
\hline & \multicolumn{4}{|l|}{ Centered Score } & \\
\hline & Locus of Control Centered Score & .13 & .13 & & \\
\hline & $\begin{array}{l}\text { ASQ Need for Approval Subscale Centered } \\
\text { Score }\end{array}$ & .24 & .001 & & \\
\hline & ASQ Confidence Subscale Centered Score & -.31 & .001 & & \\
\hline
\end{tabular}


Table 17 (continued)

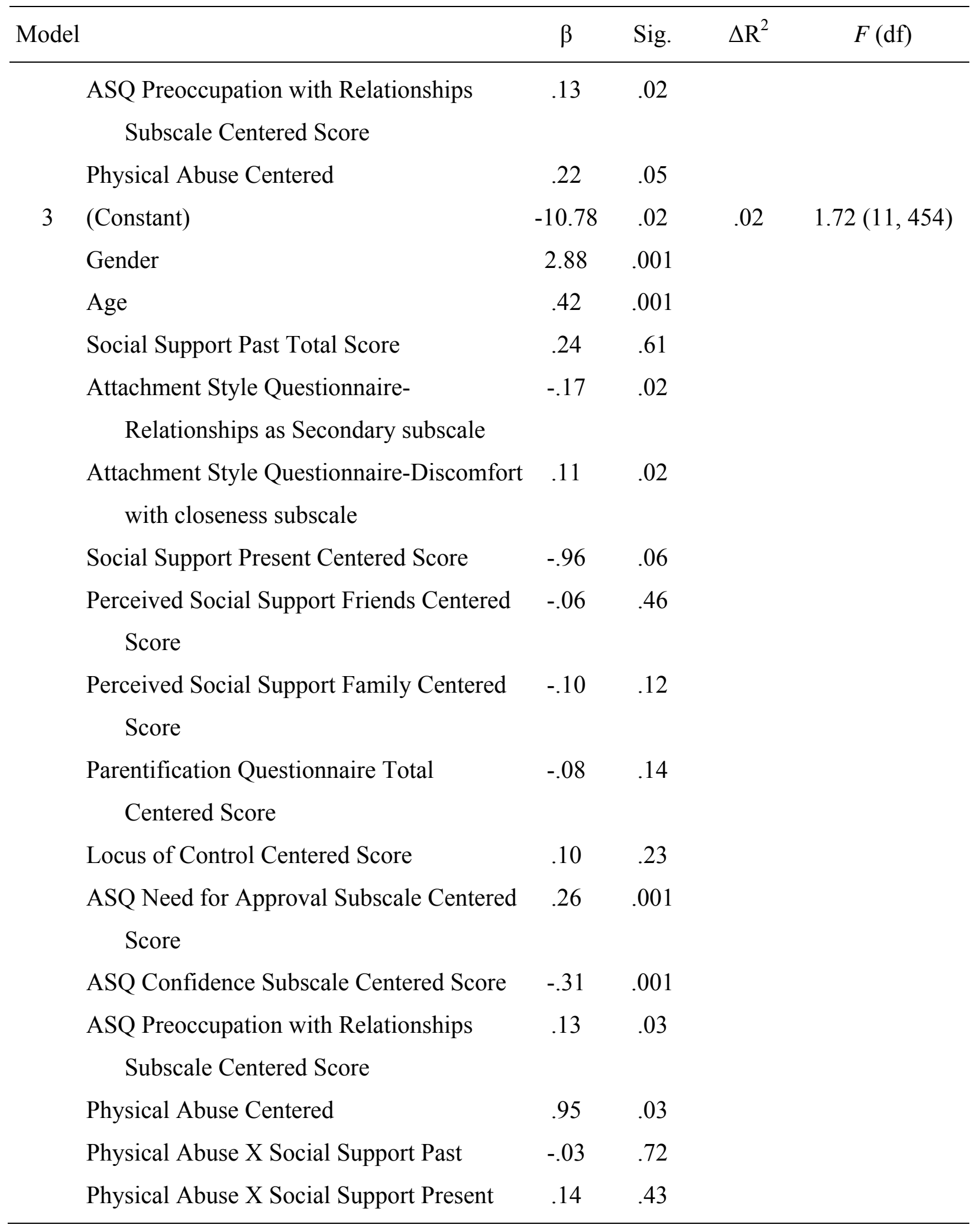

(table continues) 
Table 17 (continued)

\begin{tabular}{|c|c|c|c|c|}
\hline Model & $\beta$ & Sig. & $\Delta \mathrm{R}^{2}$ & $F(\mathrm{df})$ \\
\hline Physical abuse X Friend Social Support & -.02 & .56 & & \\
\hline Physical abuse X Family Social Support & -.02 & .45 & & \\
\hline Physical abuse X Parentification & -.003 & .89 & & \\
\hline Physical abuse X Locus of Control & .06 & .06 & & \\
\hline Physical abuse X ASQ Need for Approval & -.05 & .03 & & \\
\hline $\begin{array}{l}\text { Physical abuse X ASQ Relationships as } \\
\text { Secondary }\end{array}$ & -.03 & .32 & & \\
\hline $\begin{array}{l}\text { Physical abuse X ASQ Preoccupation with } \\
\text { Relationships }\end{array}$ & .01 & .78 & & \\
\hline Physical abuse X ASQ Confidence & .04 & .09 & & \\
\hline $\begin{array}{l}\text { Physical abuse X Discomfort with } \\
\text { Closeness }\end{array}$ & .05 & .01 & & \\
\hline
\end{tabular}

Note. ${ }^{* * *} p<.001 ; \mathrm{ASQ}=$ Attachment Style Questionnaire. 
Table 18

Hierarchical Regression Analysis Evaluating the Moderating Effects of Social Support, Parentification, Locus of Control, and Attachment Styles on Anxiety Resulting from Physical Abuse

\begin{tabular}{|c|c|c|c|c|c|}
\hline \multicolumn{2}{|l|}{ Model } & \multirow{2}{*}{$\begin{array}{c}\mathrm{B} \\
-5.66\end{array}$} & \multirow{2}{*}{$\begin{array}{l}\text { Sig. } \\
.11\end{array}$} & \multirow{2}{*}{$\begin{array}{c}\Delta \mathrm{R}^{2} \\
.05\end{array}$} & \multirow{2}{*}{$\frac{F(\mathrm{df})}{12.70(2,476)}$} \\
\hline $1 * * *$ & (Constant) & & & & \\
\hline & Gender & 3.61 & .001 & & \\
\hline & Age & .43 & .01 & & \\
\hline $2 * * *$ & (Constant) & -10.25 & .05 & .18 & $8.96(12,464)$ \\
\hline & Gender & 2.83 & .001 & & \\
\hline & Age & .43 & .003 & & \\
\hline & Social Support Past Total Score & -.34 & .48 & & \\
\hline & Social Support Present Total Score & .17 & .76 & & \\
\hline & Parentification Questionnaire Total Score & -.06 & .28 & & \\
\hline \multicolumn{5}{|c|}{ Approval subscale } & \\
\hline & Attachment Style Questionnaire- & -.20 & .01 & & \\
\hline \multicolumn{6}{|c|}{ Relationships as Secondary subscale } \\
\hline & $\begin{array}{l}\text { Attachment Style Questionnaire-Discomfort } \\
\text { with closeness subscale }\end{array}$ & .12 & .03 & & \\
\hline & Attachment Style Questionnaire- & .24 & .001 & & \\
\hline \multicolumn{6}{|c|}{ Preoccupation with Relationships } \\
\hline \multicolumn{5}{|c|}{ Score } & \\
\hline \multicolumn{5}{|c|}{ Score } & \\
\hline & Locus of Control Centered Score & .18 & .07 & & \\
\hline
\end{tabular}


Table 18 (continued)

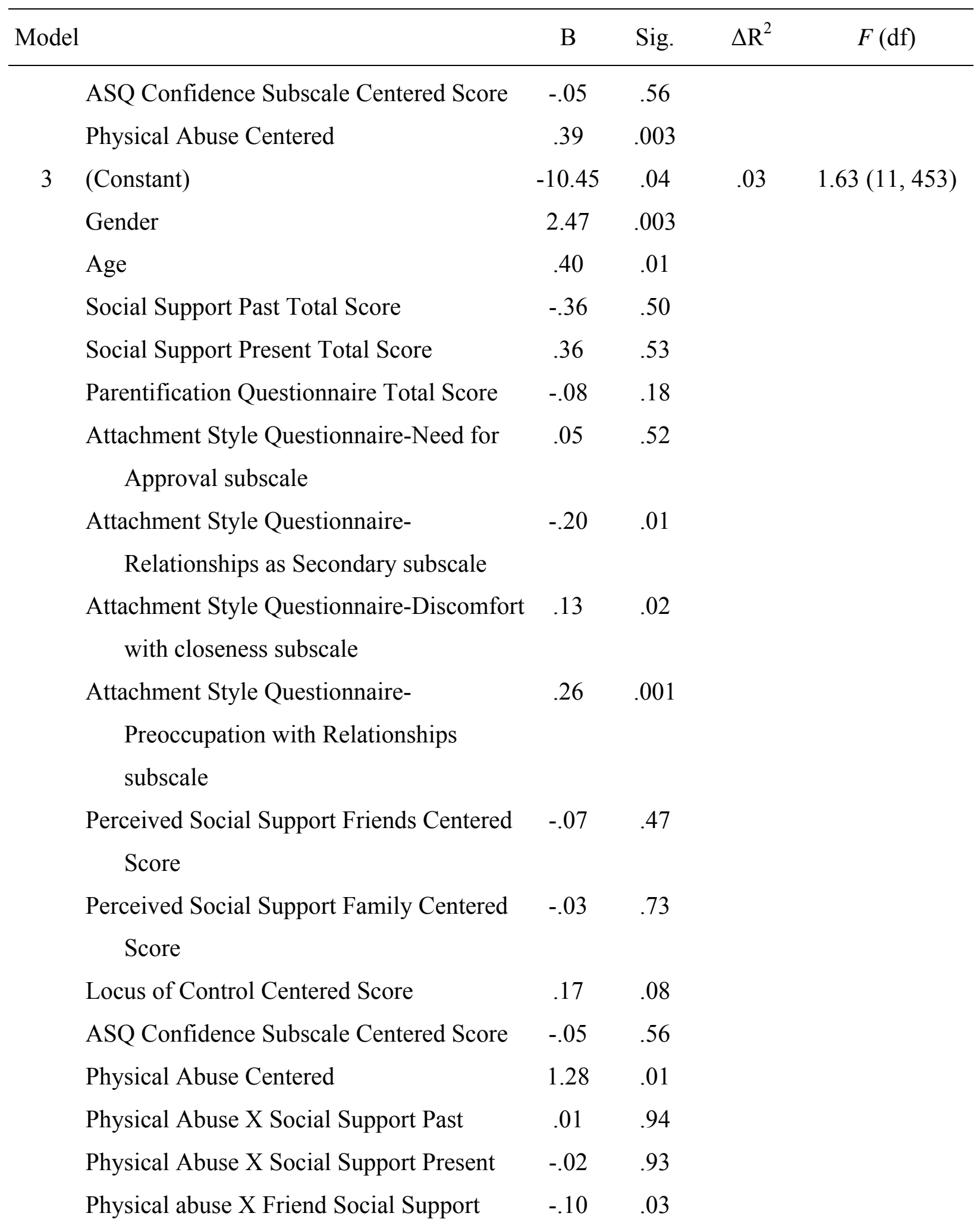


Table 18 (continued)

\begin{tabular}{lcccc}
\hline Model & B & Sig. & $\Delta \mathrm{R}^{2}$ & $F(\mathrm{df})$ \\
\hline Physical abuse X Family Social Support & .01 & .86 & \\
Physical abuse X Parentification & -.02 & .41 & \\
Physical abuse X Locus of Control & .04 & .23 & \\
Physical abuse X ASQ Need for Approval & -.05 & .03 & \\
Physical abuse X ASQ Relationships as & -.06 & .04 & \\
$\quad$ Secondary & & & \\
Physical abuse X ASQ Preoccupation with & -.01 & .78 \\
$\quad$ Relationships & & & \\
Physical abuse X ASQ Confidence & .002 & .95 & \\
Physical abuse X Discomfort with & .03 & .19 \\
$\quad$ Closeness & &
\end{tabular}

Note. ${ }^{* * *} p<.001 ; \mathrm{ASQ}=$ Attachment Style Questionnaire. 
Table 19

Hierarchical Regression Analysis Evaluating the Moderating Effects of Social Support, Parentification, Locus of Control, and Attachment Styles on Social Anxiety Resulting from

Physical Abuse

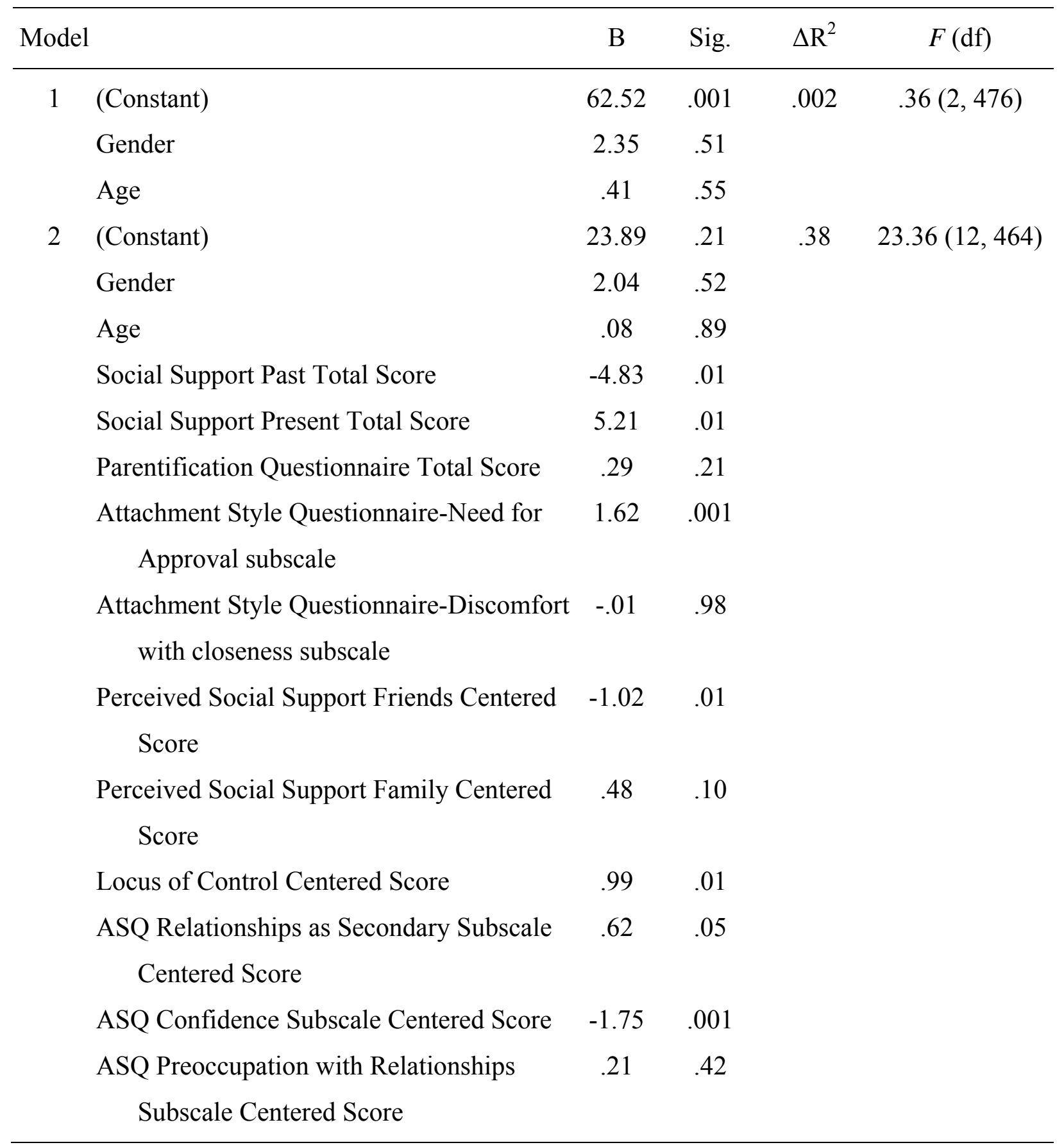


Table 19 (continued)

\begin{tabular}{lcccc}
\hline Model & B & Sig. & $\Delta \mathrm{R}^{2}$ & $F(\mathrm{df})$ \\
\hline Physical Abuse Centered & .31 & .54 & & \\
(Constant) & 20.31 & .30 & .01 & $.51(11,453)$ \\
Gender & 1.47 & .65 & & \\
Age & .14 & .81 & & \\
Social Support Past Total Score & -4.63 & .03 & \\
Social Support Present Total Score & 5.22 & .02 & \\
Parentification Questionnaire Total Score & .37 & .12 & \\
Attachment Style Questionnaire-Need for & 1.64 & .001 & \\
$\quad$ Approval subscale & & & \\
Attachment Style Questionnaire-Discomfort & -.01 & .95 & \\
$\quad$ with closeness subscale & & & \\
Perceived Social Support Friends Centered & -1.01 & .01 & \\
$\quad$ Score & & & \\
Perceived Social Support Family Centered & .41 & .17 & \\
$\quad$ Score & & & \\
Locus of Control Centered Score & .96 & .02 & \\
ASQ Relationships as Secondary Subscale & .63 & .05 & .54 \\
$\quad$ Centered Score & & & & \\
ASQ Confidence Subscale Centered Score & -1.75 & .001 & \\
ASQ Preoccupation with Relationships & .24 & .36 & \\
$\quad$ Subscale Centered Score & & & \\
Physical Abuse Centered & 1.16 & .56 & \\
Physical Abuse X Social Support Past & -.15 & .73 & \\
Physical Abuse X Social Support Present & -.26 & .74 & \\
Physical abuse X Friend Social Support & .07 & .66 & \\
Physical abuse X Family Social Support & -.05 & .71 & \\
Physical abuse X Parentification & .06 & .54 & \\
\hline
\end{tabular}

(table continues) 
Table 19 (continued)

\begin{tabular}{lcccc}
\hline Model & B & Sig. & $\Delta \mathrm{R}^{2}$ & $F(\mathrm{df})$ \\
\hline Physical abuse X Locus of Control & -.05 & .73 & & \\
Physical abuse X ASQ Need for Approval & -.04 & .71 & \\
$\quad$ Physical abuse X ASQ Relationships as & .11 & .38 & \\
$\quad$ Secondary & & & \\
$\quad$ Physical abuse X ASQ Preoccupation with & -.09 & .34 & \\
$\quad$ Relationships & & & \\
Physical abuse X ASQ Confidence & .004 & .97 & \\
Physical abuse X Discomfort with & -.06 & .45 & \\
$\quad$ Closeness & &
\end{tabular}

Note. ${ }^{* * *} p<.001 ; \mathrm{ASQ}=$ Attachment Style Questionnaire. 
Table 20

Hierarchical Regression Analysis Evaluating the Moderating Effects of Social Support, Parentification, Locus of Control, and Attachment Styles on Agoraphobia Resulting from

Physical Abuse

\begin{tabular}{llllll}
\hline Model & & $\beta$ & Sig. & $\Delta \mathrm{R}^{2}$ & $F(\mathrm{df})$ \\
\hline $1 \quad$ (Constant) & 18.89 & .001 & .03 & $7.17(2,476)$ \\
Gender & 4.62 & .001 & & \\
Age & -.23 & .36 & & \\
2 (Constant) & 21.77 & .01 & .16 & $7.39(12,464)$ \\
Gender & 4.70 & .001 & & \\
Age & -.19 & .41 & & \\
Social Support Past Total Score & -1.25 & .11 & & \\
Social Support Present Total Score & -.122 & .89 & & \\
Parentification Questionnaire Total Score & -.11 & .26 & & \\
Attachment Style Questionnaire-Need for & .27 & .03 & & \\
$\quad$ Approval subscale & & & & \\
Attachment Style Questionnaire-Discomfort & .02 & .79 & & \\
$\quad$ with closeness subscale & & & & \\
Perceived Social Support Friends Centered & -.11 & .47 & & \\
$\quad$ Score & & & & \\
Perceived Social Support Family Centered & .18 & .13 & \\
$\quad$ Score & & & .004 & \\
Locus of Control Centered Score & .11 & .49 & \\
ASQ Relationships as Secondary Subscale & .19 & .14 & \\
$\quad$ Centered Score & & & \\
ASQ Confidence Subscale Centered Score & -.07 & .59 & \\
ASQ Preoccupation with Relationships & .31 & .004 & & \\
$\quad$ Subscale Centered Score & & & & \\
\hline
\end{tabular}


Table 20 (continued)

\begin{tabular}{|c|c|c|c|c|c|}
\hline \multicolumn{2}{|c|}{ Model } & \multirow{2}{*}{$\begin{array}{c}\mathrm{B} \\
.201\end{array}$} & \multirow{2}{*}{$\begin{array}{r}\text { Sig. } \\
34\end{array}$} & \multirow{3}{*}{$\begin{array}{c}\Delta \mathrm{R}^{2} \\
.04\end{array}$} & \multirow{3}{*}{$\begin{array}{c}F(\mathrm{df}) \\
1.88(11,453)\end{array}$} \\
\hline & Physical Abuse Centered & & & & \\
\hline 3 & (Constant) & 20.56 & .01 & & \\
\hline & Gender & 4.46 & .001 & & \\
\hline & Age & -.17 & .48 & & \\
\hline & Social Support Past Total Score & -2.09 & .01 & & \\
\hline & Social Support Present Total Score & 1.08 & .24 & & \\
\hline & Parentification Questionnaire Total Score & -.09 & .38 & & \\
\hline & $\begin{array}{l}\text { Attachment Style Questionnaire-Need for } \\
\quad \text { Approval subscale }\end{array}$ & .25 & .05 & & \\
\hline & $\begin{array}{l}\text { Attachment Style Questionnaire-Discomfort } \\
\text { with closeness subscale }\end{array}$ & -.004 & .96 & & \\
\hline & $\begin{array}{l}\text { Perceived Social Support Friends Centered } \\
\quad \text { Score }\end{array}$ & -.11 & .50 & & \\
\hline & $\begin{array}{l}\text { Perceived Social Support Family Centered } \\
\text { Score }\end{array}$ & .19 & .11 & & \\
\hline & Locus of Control Centered Score & .08 & .64 & & \\
\hline & $\begin{array}{l}\text { ASQ Relationships as Secondary Subscale } \\
\text { Centered Score }\end{array}$ & .21 & .10 & & \\
\hline & ASQ Confidence Subscale Centered Score & -.18 & .22 & & \\
\hline & $\begin{array}{l}\text { ASQ Preoccupation with Relationships } \\
\text { Subscale Centered Score }\end{array}$ & .32 & .003 & & \\
\hline & Physical Abuse Centered & .79 & .33 & & \\
\hline & Physical Abuse X Social Support Past & .28 & .12 & & \\
\hline & Physical Abuse X Social Support Present & -.49 & .13 & & \\
\hline & Physical abuse X Friend Social Support & -.11 & .12 & & \\
\hline & Physical abuse X Family Social Support & -.02 & .68 & & \\
\hline & Physical abuse X Parentification & .02 & .53 & & \\
\hline
\end{tabular}

(table continues) 
Table 20 (continued)

\begin{tabular}{lcccc}
\hline Model & $\mathrm{B}$ & Sig. & $\Delta \mathrm{R}^{2}$ & $F(\mathrm{df})$ \\
\hline Physical abuse X Locus of Control & .05 & .37 & & \\
Physical abuse X ASQ Need for Approval & -.02 & .63 & \\
$\quad$ Physical abuse X ASQ Relationships as & -.01 & .84 & \\
$\quad$ Secondary & & & \\
$\quad$ Physical abuse X ASQ Preoccupation with & -.03 & .48 & \\
$\quad$ Relationships & & & \\
Physical abuse X ASQ Confidence & .01 & .88 & \\
Physical abuse X Discomfort with & -.06 & .11 & \\
$\quad$ Closeness & &
\end{tabular}

Note. ${ }^{* * *} p<.001 ; \mathrm{ASQ}=$ Attachment Style Questionnaire. 
Table 21

Hierarchical Regression Analysis Evaluating the Moderating Effects of Social Support, Parentification, Locus of Control, and Attachment Styles on Substance Use Resulting from

Sexual Abuse

\begin{tabular}{|c|c|c|c|c|c|}
\hline \multicolumn{2}{|l|}{ Model } & \multirow{2}{*}{$\beta$} & \multirow{2}{*}{$\begin{array}{l}\text { Sig. } \\
.001\end{array}$} & \multirow{2}{*}{$\Delta \mathrm{R}^{2}$} & \multirow{2}{*}{$\frac{F(\mathrm{df})}{2.73(2,479)}$} \\
\hline 1 & (Constant) & & & & \\
\hline & Gender & -.61 & .07 & & \\
\hline & Age & -.09 & .11 & & \\
\hline $2 * * *$ & (Constant) & 8.01 & .001 & .08 & $3.51(12,467)$ \\
\hline & Gender & -.88 & .02 & & \\
\hline & Age & -.06 & .24 & & \\
\hline & Social Support Past Total Score & .15 & .51 & & \\
\hline & Social Support Present Total Score & -.49 & .05 & & \\
\hline \multicolumn{6}{|c|}{ Approval subscale } \\
\hline & $\begin{array}{l}\text { Attachment Style Questionnaire-Discomfort } \\
\text { with closeness subscale }\end{array}$ & .03 & .23 & & \\
\hline \multicolumn{5}{|c|}{ Score } & \\
\hline & $\begin{array}{l}\text { Perceived Social Support Family Centered } \\
\text { Score }\end{array}$ & -.01 & .84 & Score & \\
\hline \multicolumn{6}{|c|}{ Centered Score } \\
\hline & Locus of Control Centered Score & .05 & .26 & & \\
\hline & $\begin{array}{l}\text { ASQ Relationships as Secondary Subscale } \\
\text { Centered Score }\end{array}$ & .02 & .57 & & \\
\hline & ASQ Confidence Subscale Centered Score & .06 & .14 & & \\
\hline
\end{tabular}

(table continues) 
Table 21 (continued)

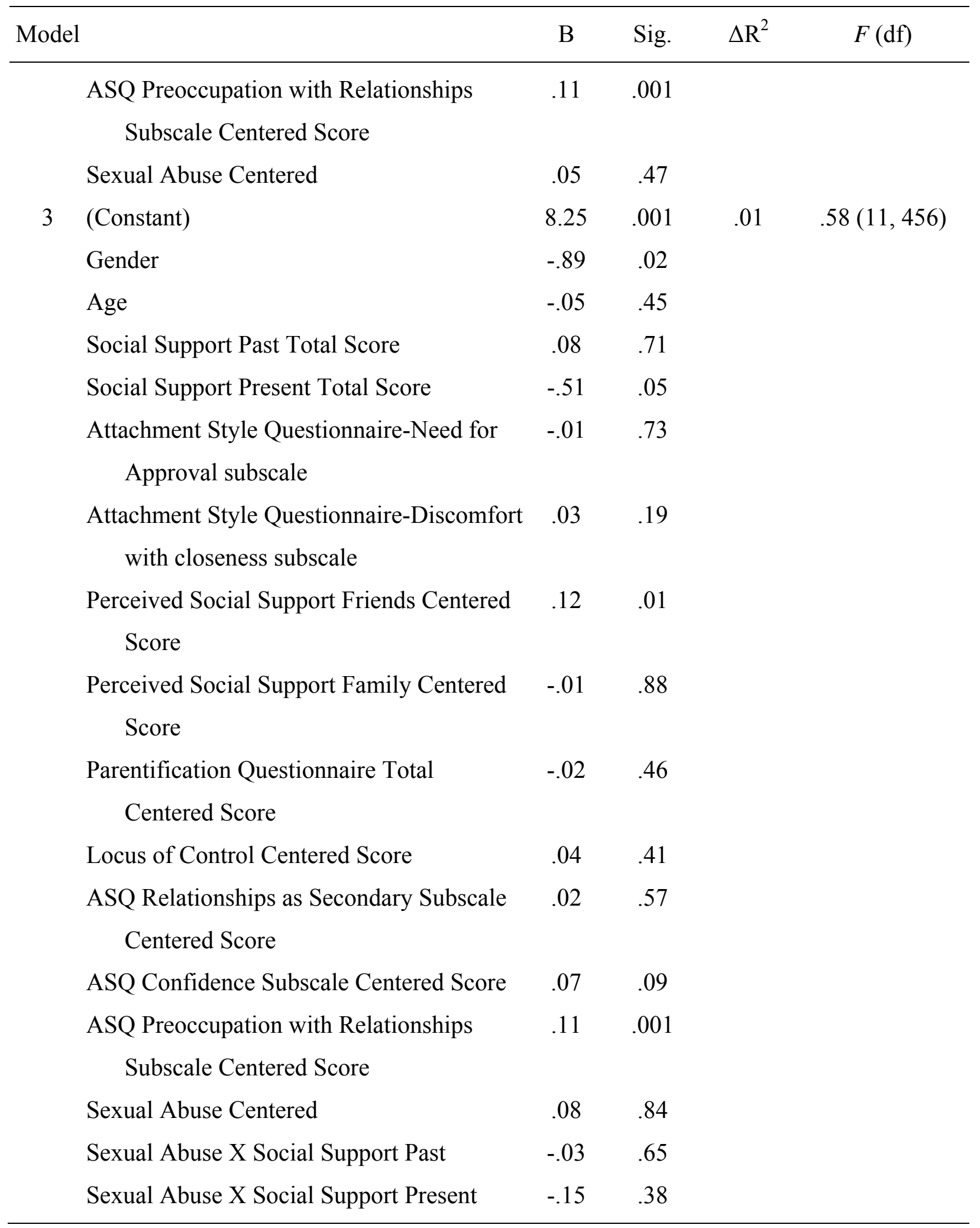

(table continues) 
Table 21 (continued)

\begin{tabular}{|c|c|c|c|c|}
\hline Model & $\mathrm{B}$ & Sig. & $\Delta \mathrm{R}^{2}$ & $F(\mathrm{df})$ \\
\hline Sexual abuse X Friend Social Support & -.03 & .94 & & \\
\hline Sexual abuse X Family Social Support & .08 & .56 & & \\
\hline Sexual abuse X Parentification & .02 & .42 & & \\
\hline Sexual abuse X Locus of Control & -.04 & .29 & & \\
\hline Sexual abuse X ASQ Need for Approval & -.0004 & .98 & & \\
\hline Sexual abuse X ASQ Relationships as & -.001 & .98 & & \\
\hline \multicolumn{5}{|l|}{ Secondary } \\
\hline Sexual abuse X ASQ Preoccupation with & .01 & .63 & & \\
\hline \multicolumn{5}{|l|}{ Relationships } \\
\hline Sexual abuse X ASQ Confidence & .004 & .82 & & \\
\hline Sexual abuse X Discomfort with Closeness & .01 & .72 & & \\
\hline
\end{tabular}

Note. ${ }^{* * *} p<.001 ; \mathrm{ASQ}=$ Attachment Style Questionnaire. 
Table 22

Hierarchical Regression Analysis Evaluating the Moderating Effects of Social Support, Parentification, Locus of Control, and Attachment Styles on DUSI Overall Problems Resulting from Sexual Abuse

\begin{tabular}{|c|c|c|c|c|c|}
\hline \multicolumn{2}{|l|}{ Model } & \multirow{2}{*}{$\frac{\beta}{24.06}$} & \multirow{2}{*}{$\begin{array}{l}\text { Sig. } \\
.001\end{array}$} & \multirow{2}{*}{$\begin{array}{l}\Delta \mathrm{R}^{2} \\
.003\end{array}$} & \multirow{2}{*}{$\begin{array}{c}F(\mathrm{df}) \\
.66(2,479)\end{array}$} \\
\hline 1 & (Constant) & & & & \\
\hline & Gender & -.62 & .58 & & \\
\hline & Age & .17 & .33 & & \\
\hline $2 * * *$ & (Constant) & 28.30 & .001 & .39 & $25.44(12,467)$ \\
\hline & Gender & -1.78 & .07 & & \\
\hline & Age & .14 & .35 & & \\
\hline & Social Support Past Total Score & .43 & .46 & & \\
\hline & Social Support Present Total Score & -1.65 & .01 & & \\
\hline & Attachment Style Questionnaire-Need for & .02 & .83 & & \\
\hline \multicolumn{6}{|c|}{ Approval subscale } \\
\hline & $\begin{array}{l}\text { Attachment Style Questionnaire-Discomfort } \\
\text { with closeness subscale }\end{array}$ & .16 & .01 & & \\
\hline \multicolumn{5}{|c|}{ Score } & \\
\hline \multicolumn{5}{|c|}{ Score } & \\
\hline & $\begin{array}{l}\text { Parentification Questionnaire Total } \\
\text { Centered Score }\end{array}$ & -.28 & .001 & & \\
\hline & Locus of Control Centered Score & .39 & .001 & & \\
\hline \multicolumn{5}{|c|}{ Centered Score } & \\
\hline & ASQ Confidence Subscale Centered Score & -.10 & .35 & & \\
\hline
\end{tabular}


Table 22 (continued)

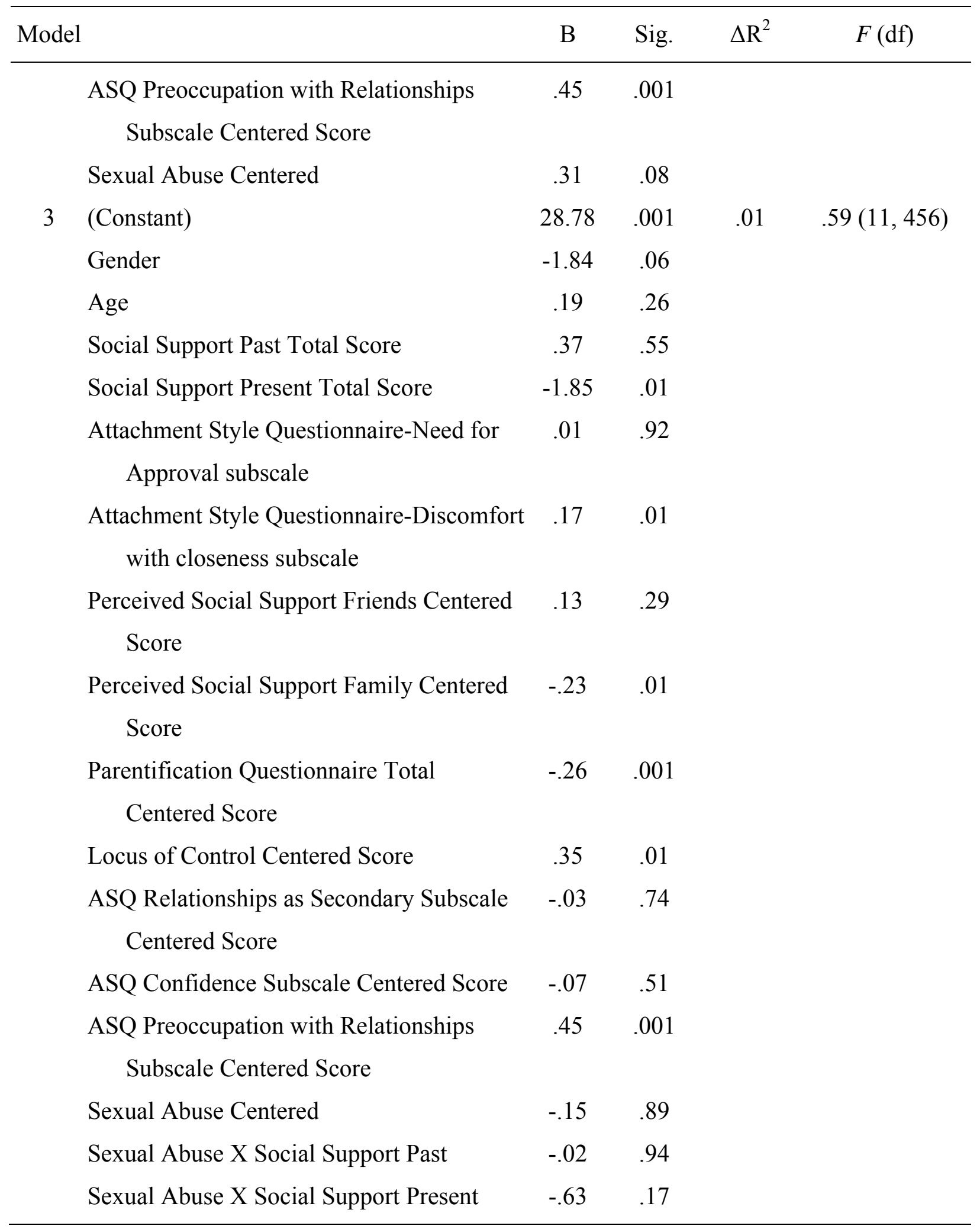


Table 22 (continued)

\begin{tabular}{lcccc}
\hline Model & B & Sig. & $\Delta \mathrm{R}^{2}$ & $F(\mathrm{df})$ \\
\hline Sexual abuse X Friend Social Support & .06 & .56 & & \\
Sexual abuse X Family Social Support & -.01 & .74 & \\
Sexual abuse X Parentification & .04 & .45 & \\
Sexual abuse X Locus of Control & -.10 & .31 & \\
Sexual abuse X ASQ Need for Approval & .03 & .56 & \\
Sexual abuse X ASQ Relationships as & -.05 & .46 & \\
$\quad$ Secondary & & & \\
Sexual abuse X ASQ Preoccupation with & -.02 & .72 \\
$\quad$ Relationships & & & \\
Sexual abuse X ASQ Confidence & -.02 & .76 \\
Sexual abuse X Discomfort with Closeness & .02 & .63 \\
\hline
\end{tabular}

Note. ${ }^{* * *} p<.001 ; \mathrm{ASQ}=$ Attachment Style Questionnaire. 
Table 23

Hierarchical Regression Analysis Evaluating the Moderating Effects of Social Support, Parentification, Locus of Control, and Attachment Styles on Permissiveness Resulting from

Sexual Abuse

\begin{tabular}{|c|c|c|c|c|c|}
\hline \multicolumn{2}{|l|}{ Model } & \multirow{2}{*}{$\begin{array}{c}\mathrm{B} \\
3.27\end{array}$} & \multirow{2}{*}{$\begin{array}{l}\text { Sig. } \\
.001\end{array}$} & \multirow{2}{*}{$\Delta \mathrm{R}^{2}$} & \multirow{2}{*}{$\frac{F(\mathrm{df})}{64.86(2,476)}$} \\
\hline $1 * * *$ & (Constant) & & & & \\
\hline & Gender & .67 & .001 & & \\
\hline & Age & -.01 & .18 & & \\
\hline $2 * * *$ & (Constant) & 3.34 & .001 & .07 & $3.60(12,464)$ \\
\hline & Gender & .69 & .001 & & \\
\hline & Age & -.01 & .28 & & \\
\hline & Social Support Past Total Score & -.01 & .84 & & \\
\hline & Social Support Present Total Score & -.004 & .92 & & \\
\hline & Parentification Questionnaire Total Score & .01 & .09 & & \\
\hline \multicolumn{5}{|c|}{ Approval subscale } & \\
\hline & $\begin{array}{l}\text { Attachment Style Questionnaire-Discomfort } \\
\text { with closeness subscale }\end{array}$ & -.01 & .02 & & \\
\hline & $\begin{array}{l}\text { Perceived Social Support Friends Centered } \\
\quad \text { Score }\end{array}$ & -.01 & .22 & Score & \\
\hline & $\begin{array}{l}\text { Perceived Social Support Family Centered } \\
\text { Score }\end{array}$ & .01 & .02 & & \\
\hline & Locus of Control Centered Score & -.02 & .03 & & \\
\hline & $\begin{array}{l}\text { ASQ Relationships as Secondary Subscale } \\
\text { Centered Score }\end{array}$ & -.01 & .11 & & \\
\hline & ASQ Confidence Subscale Centered Score & -.01 & .03 & & \\
\hline & ASQ Preoccupation with Relationships & -.004 & .43 & & \\
\hline & Subscale Centered Score & & & & \\
\hline
\end{tabular}


Table 23 (continued)

\begin{tabular}{lcccc}
\hline Model & B & Sig. & $\Delta \mathrm{R}^{2}$ & $F(\mathrm{df})$ \\
\hline Sexual Abuse Centered & -.02 & .16 & & \\
(Constant) & 3.38 & .001 & .02 & $1.19(11,453)$ \\
Gender & .68 & .001 & & \\
Age & -.02 & .10 & & \\
Social Support Past Total Score & -.003 & .94 & \\
Social Support Present Total Score & .01 & .78 & \\
Parentification Questionnaire Total Score & .01 & .14 & \\
Attachment Style Questionnaire-Need for & .004 & .47 & \\
$\quad$ Approval subscale & & & \\
Attachment Style Questionnaire-Discomfort & -.01 & .02 & \\
$\quad$ with closeness subscale & & & \\
Perceived Social Support Friends Centered & -.01 & .17 & \\
$\quad$ Score & & & \\
Perceived Social Support Family Centered & .01 & .02 & \\
$\quad$ Score & & & \\
Locus of Control Centered Score & -.02 & .04 \\
ASQ Relationships as Secondary Subscale & -.01 & .09 \\
$\quad$ Centered Score & & & .02 \\
ASQ Confidence Subscale Centered Score & -.02 & .02 & \\
ASQ Preoccupation with Relationships & -.01 & .31 & \\
$\quad$ Subscale Centered Score & & & \\
Sexual Abuse Centered & .02 & .77 & \\
Sexual Abuse X Social Support Past & .01 & .34 & \\
Sexual Abuse X Social Support Present & .02 & .47 & \\
Sexual abuse X Friend Social Support & -.001 & .88 & \\
Sexual abuse X Parentification & .002 & .42 & \\
\hline
\end{tabular}


Table 23 (continued)

\begin{tabular}{lcccc}
\hline Model & B & Sig. & $\Delta \mathrm{R}^{2}$ & $F(\mathrm{df})$ \\
\hline Sexual abuse X Locus of Control & .001 & .89 & \\
$\quad$ Sexual abuse X ASQ Need for Approval & -.002 & .49 & \\
$\quad$ Sexual abuse X ASQ Relationships as & -.001 & .91 & \\
$\quad$ Secondary & & & \\
$\quad$ Sexual abuse X ASQ Preoccupation with & -.003 & .48 & \\
$\quad$ Relationships & & & \\
$\quad$ Sexual abuse X ASQ Confidence & -.01 & .04 & \\
$\quad$ Sexual abuse X Discomfort with Closeness & -.003 & .32 & \\
\hline
\end{tabular}

Note. ${ }^{* * *} p<.001 ; \mathrm{ASQ}=$ Attachment Style Questionnaire. 
Table 24

Hierarchical Regression Analysis Evaluating the Moderating Effects of Social Support, Parentification, Locus of Control, and Attachment Styles on Depression Resulting from Sexual Abuse

\begin{tabular}{|c|c|c|c|c|c|}
\hline \multicolumn{2}{|l|}{ Model } & \multirow{2}{*}{$\begin{array}{c}\beta \\
-4.70\end{array}$} & \multirow{2}{*}{$\begin{array}{l}\text { Sig. } \\
.19\end{array}$} & \multirow{2}{*}{$\frac{\Delta \mathrm{R}^{2}}{.05}$} & \multirow{2}{*}{$\frac{F(\mathrm{df})}{11.15(2,477)}$} \\
\hline $1 * * *$ & (Constant) & & & & \\
\hline & Gender & 3.30 & .001 & & \\
\hline & Age & .45 & .01 & & \\
\hline $2 * * *$ & (Constant) & -12.21 & .01 & .37 & $24.88(12,465)$ \\
\hline & Gender & 2.84 & .001 & & \\
\hline & Age & .40 & .002 & & \\
\hline & Social Support Past Total Score & .19 & .66 & & \\
\hline & $\begin{array}{l}\text { Attachment Style Questionnaire-Discomfort } \\
\text { with closeness subscale }\end{array}$ & .11 & .02 & & \\
\hline & Social Support Present Centered Score & -.93 & .05 & & \\
\hline & $\begin{array}{l}\text { Perceived Social Support Friends Centered } \\
\quad \text { Score }\end{array}$ & -.04 & .61 & & \\
\hline & $\begin{array}{l}\text { Perceived Social Support Family Centered } \\
\quad \text { Score }\end{array}$ & -.14 & .04 & & \\
\hline & $\begin{array}{l}\text { Parentification Questionnaire Total } \\
\quad \text { Centered Score }\end{array}$ & -.08 & .14 & & \\
\hline & Locus of Control Centered Score & .13 & .14 & & \\
\hline & $\begin{array}{l}\text { ASQ Need for Approval Subscale Centered } \\
\text { Score }\end{array}$ & .23 & .001 & & \\
\hline & $\begin{array}{l}\text { ASQ Relationships as Secondary Subscale } \\
\text { Centered Score }\end{array}$ & -.15 & .03 & & \\
\hline & ASQ Confidence Subscale Centered Score & -.29 & .001 & & \\
\hline
\end{tabular}


Table 24 (continued)

\begin{tabular}{lcccc}
\hline Model & B & Sig. & $\Delta \mathrm{R}^{2}$ & $F(\mathrm{df})$ \\
\hline ASQ Preoccupation with Relationships & .13 & .02 & & \\
$\quad$ Subscale Centered Score & & & & \\
$\quad$ Sexual Abuse Centered & .13 & .34 & & $.81(11,454)$ \\
(Constant) & -12.31 & .01 & .01 & \\
Gender & 2.68 & .001 & \\
Age & .37 & .004 & \\
Social Support Past Total Score & .29 & .52 & \\
Attachment Style Questionnaire-Discomfort & .11 & .03 & \\
$\quad$ with closeness subscale & & & \\
Social Support Present Centered Score & -1.04 & .04 & \\
Perceived Social Support Friends Centered & -.04 & .67 & \\
$\quad$ Score & & & \\
Perceived Social Support Family Centered & -.15 & .03 & \\
$\quad$ Score & & & \\
Parentification Questionnaire Total & -.07 & .23 \\
$\quad$ Centered Score & & &
\end{tabular}

(table continues) 
Table 24 (continued)

\begin{tabular}{|c|c|c|c|c|}
\hline Model & $\mathrm{B}$ & Sig. & $\Delta \mathrm{R}^{2}$ & $F(\mathrm{df})$ \\
\hline Sexual abuse X Friend Social Support & -.01 & .84 & & \\
\hline Sexual abuse X Family Social Support & -.02 & 67 & & \\
\hline Sexual abuse X Parentification & .03 & .48 & & \\
\hline Sexual abuse X Locus of Control & -.06 & .43 & & \\
\hline Sexual abuse X ASQ Need for Approval & .08 & .14 & & \\
\hline Sexual abuse X ASQ Relationships as & .04 & .54 & & \\
\hline \multicolumn{5}{|l|}{ Secondary } \\
\hline Sexual abuse X ASQ Preoccupation with & -.10 & .08 & & \\
\hline \multicolumn{5}{|l|}{ Relationships } \\
\hline Sexual abuse X ASQ Confidence & -.03 & .48 & & \\
\hline Sexual abuse X Discomfort with Closeness & .01 & .74 & & \\
\hline
\end{tabular}

Note. ${ }^{* * *} p<.001 ; \mathrm{ASQ}=$ Attachment Style Questionnaire. 
Table 25

Hierarchical Regression Analysis Evaluating the Moderating Effects of Social Support, Parentification, Locus of Control, and Attachment Styles on Anxiety Resulting from Sexual Abuse

\begin{tabular}{|c|c|c|c|c|c|}
\hline \multicolumn{2}{|l|}{ Model } & \multirow{2}{*}{$\begin{array}{c}B \\
-5.66\end{array}$} & \multirow{2}{*}{$\begin{array}{l}\text { Sig. } \\
.11\end{array}$} & \multirow{2}{*}{$\frac{\Delta \mathrm{R}^{2}}{.05}$} & \multirow{2}{*}{$\frac{F(\mathrm{df})}{12.70(2,476)}$} \\
\hline $1 * * *$ & (Constant) & & & & \\
\hline & Gender & 3.61 & .001 & & \\
\hline & Age & .43 & .01 & & \\
\hline $2 * * *$ & (Constant) & -13.51 & .03 & .16 & $8.01(12,464)$ \\
\hline & Gender & 2.79 & .001 & & \\
\hline & Age & .43 & .004 & & \\
\hline & Social Support Past Total Score & -.66 & .18 & & \\
\hline & Social Support Present Total Score & .39 & .49 & & \\
\hline & $\begin{array}{l}\text { Attachment Style Questionnaire-Need for } \\
\text { Approval subscale }\end{array}$ & .05 & .52 & & \\
\hline & $\begin{array}{l}\text { Attachment Style Questionnaire-Discomfort } \\
\text { with closeness subscale }\end{array}$ & .12 & .02 & & \\
\hline & $\begin{array}{l}\text { Attachment Style Questionnaire-Confidence } \\
\text { subscale }\end{array}$ & -.03 & .73 & & \\
\hline & Attachment Style Questionnaire- & .24 & .001 & & \\
\hline & $\begin{array}{l}\text { Preoccupation with Relationships } \\
\text { subscale }\end{array}$ & & & & \\
\hline & $\begin{array}{l}\text { Perceived Social Support Friends Centered } \\
\quad \text { Score }\end{array}$ & -.04 & .67 & & \\
\hline & $\begin{array}{l}\text { Perceived Social Support Family Centered } \\
\text { Score }\end{array}$ & -.06 & .39 & & \\
\hline & $\begin{array}{l}\text { Parentification Questionnaire Total } \\
\text { Centered Score }\end{array}$ & -.10 & .10 & & \\
\hline & Locus of Control Centered Score & .16 & .11 & & \\
\hline
\end{tabular}


Table 25 (continued)

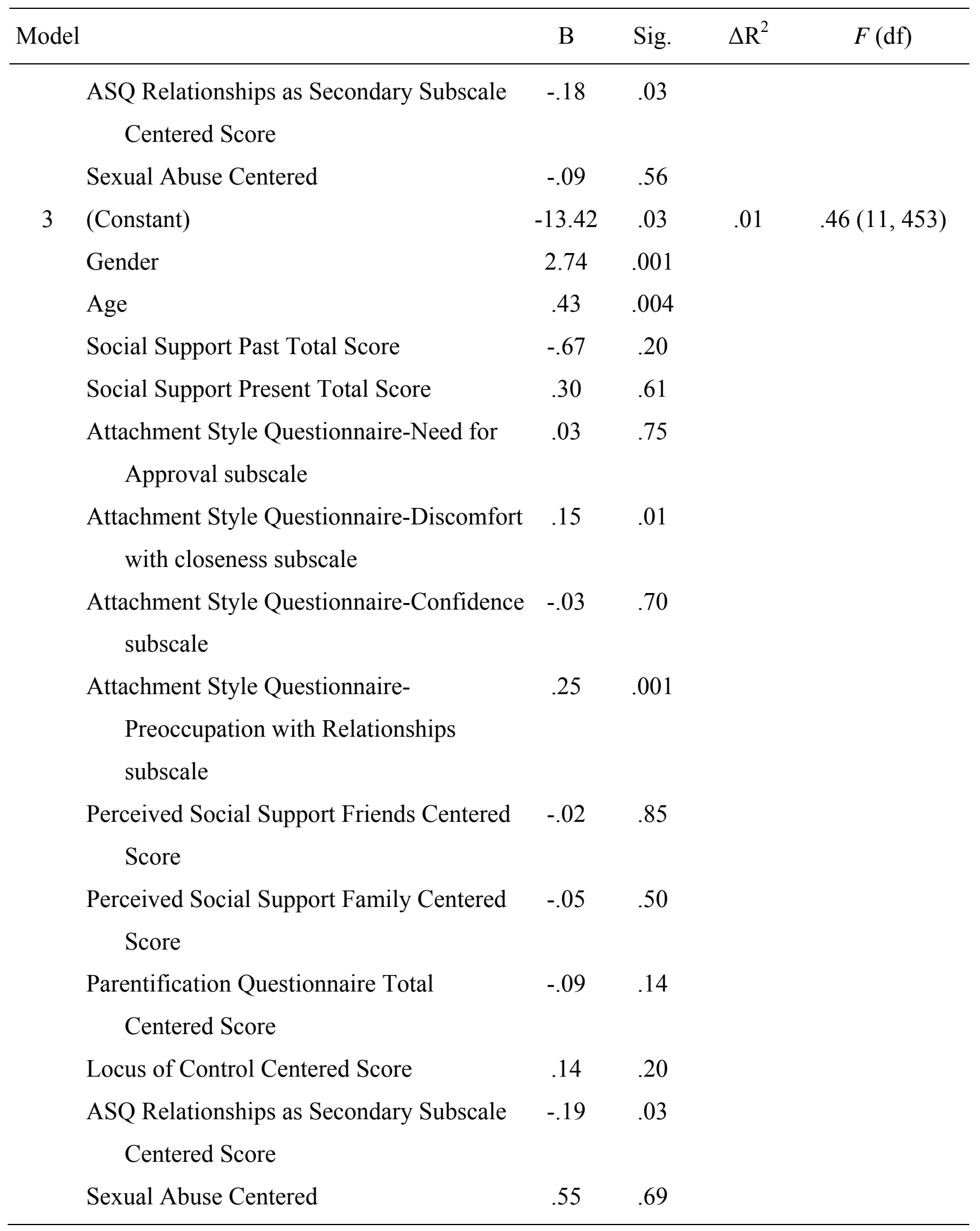

(table continues) 
Table 25 (continued)

\begin{tabular}{lcccc}
\hline Model & B & Sig. & $\Delta \mathrm{R}^{2}$ & $F(\mathrm{df})$ \\
\hline Sexual Abuse X Social Support Past & -.13 & .42 & \\
Sexual Abuse X Social Support Present & -.23 & .57 & \\
Sexual abuse X Friend Social Support & .06 & .46 & \\
Sexual abuse X Family Social Support & .07 & .11 & \\
Sexual abuse X Parentification & .01 & .76 \\
Sexual abuse X Locus of Control & -.05 & .54 & \\
Sexual abuse X ASQ Need for Approval & -.03 & .60 \\
Sexual abuse X ASQ Relationships as & -.02 & .75 & \\
$\quad$ Secondary & & & \\
Sexual abuse X ASQ Preoccupation with & .01 & .83 & \\
$\quad$ Relationships & & & \\
Sexual abuse X ASQ Confidence & .01 & .83 & \\
Sexual abuse X Discomfort with Closeness & .06 & .19 & \\
\hline
\end{tabular}

Note. ${ }^{* * *} p<.001 ; \mathrm{ASQ}=$ Attachment Style Questionnaire. 
Table 26

Hierarchical Regression Analysis Evaluating the Moderating Effects of Social Support, Parentification, Locus of Control, and Attachment Styles on Social Anxiety Resulting from

Sexual Abuse

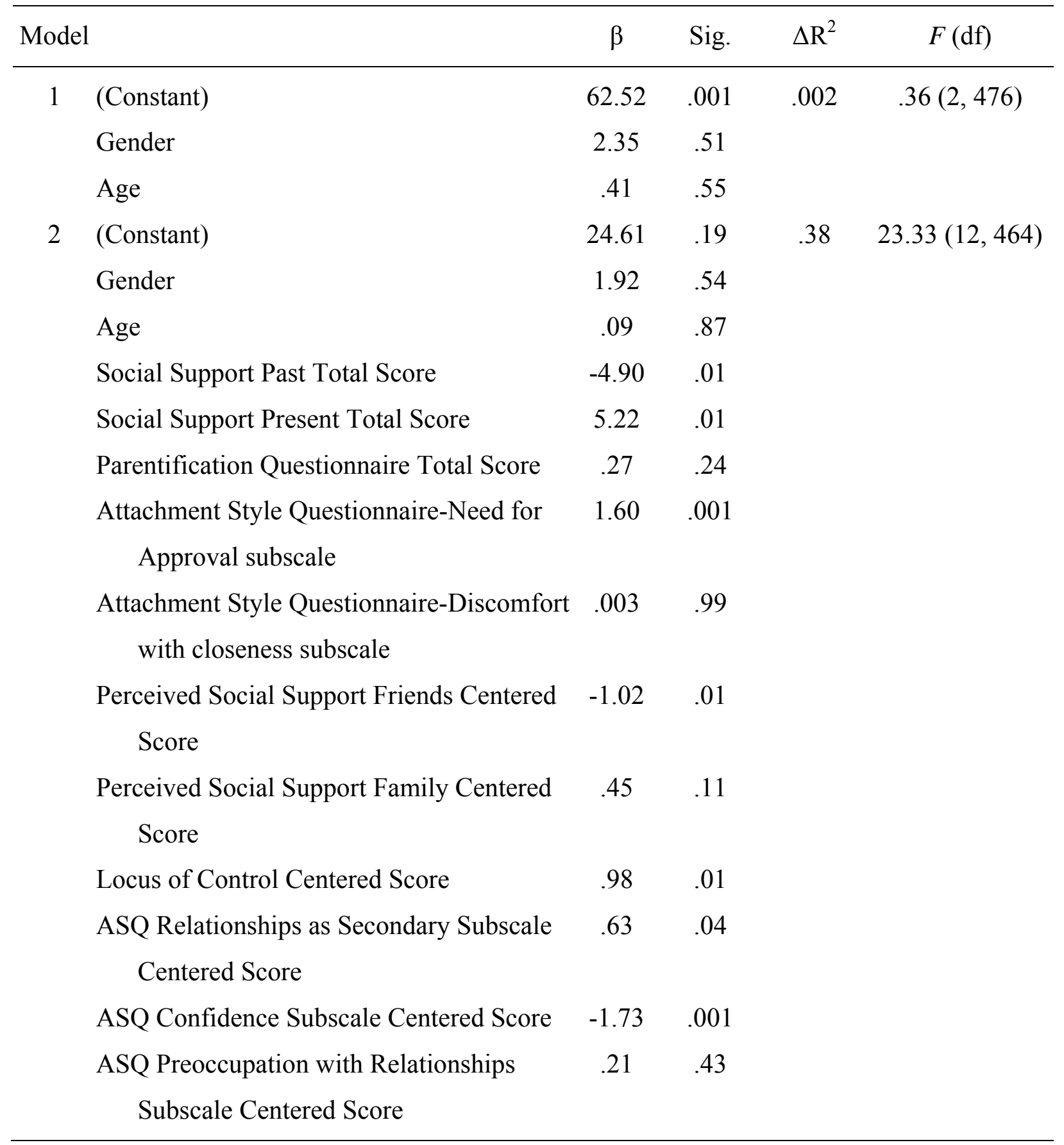


Table 26 (continued)

\begin{tabular}{lcccc}
\hline Model & $\beta$ & Sig. & $\Delta \mathrm{R}^{2}$ & $F(\mathrm{df})$ \\
\hline Sexual Abuse Centered & .19 & .75 & & \\
(Constant) & 28.57 & .14 & .01 & $.62(11,453)$ \\
Gender & 1.59 & .62 & & \\
Age & .06 & .91 & & \\
Social Support Past Total Score & -5.30 & .01 & \\
Social Support Present Total Score & 4.47 & .05 & \\
Parentification Questionnaire Total Score & .37 & .13 & \\
Attachment Style Questionnaire-Need for & 1.67 & .001 & \\
$\quad$ Approval subscale & & & \\
Attachment Style Questionnaire-Discomfort & .03 & .91 & \\
$\quad$ with closeness subscale & & & \\
Perceived Social Support Friends Centered & -.88 & .03 & \\
$\quad$ Score & & & \\
Perceived Social Support Family Centered & .42 & .15 & \\
$\quad$ Score & & & \\
Locus of Control Centered Score & .81 & .05 & \\
ASQ Relationships as Secondary Subscale & .63 & .06 & \\
$\quad$ Centered Score & & .13 & .37 & \\
ASQ Confidence Subscale Centered Score & -1.66 & .001 & \\
ASQ Preoccupation with Relationships & .15 & .59 & \\
$\quad$ Subscale Centered Score & & & \\
Sexual Abuse Centered & -.59 & .93 & \\
Sexual Abuse X Social Support Past & .05 & .94 & \\
Sexual Abuse X Social Support Present & -3.12 & .04 & \\
Sexual abuse X Friend Social Support & .47 & .15 & \\
Sexual abuse X Family Social Support & -.0004 & 1.00 & \\
Sexual abuse X Parentification & .18 & & \\
\hline
\end{tabular}


Table 26 (continued)

\begin{tabular}{lcccc}
\hline Model & $\beta$ & Sig. & $\Delta \mathrm{R}^{2}$ & $F(\mathrm{df})$ \\
\hline Sexual abuse X Locus of Control & -.34 & .31 & \\
Sexual abuse X ASQ Need for Approval & .08 & .79 & \\
$\quad$ Sexual abuse X ASQ Relationships as & -.07 & .79 & \\
$\quad$ Secondary & & & \\
$\quad$ Sexual abuse X ASQ Preoccupation with & -.23 & .36 & \\
$\quad$ Relationships & & & \\
$\quad$ Sexual abuse X ASQ Confidence & -.02 & .92 & \\
$\quad$ Sexual abuse X Discomfort with Closeness & .08 & .68 & \\
\hline
\end{tabular}

Note. ${ }^{* * *} p<.001 ; \mathrm{ASQ}=$ Attachment Style Questionnaire. 
Table 27

Hierarchical Regression Analysis Evaluating the Moderating Effects of Social Support, Parentification, Locus of Control, and Attachment Styles on Agoraphobia Resulting from Sexual Abuse

\begin{tabular}{|c|c|c|c|c|c|}
\hline \multicolumn{2}{|c|}{ Model } & \multirow{2}{*}{$\beta$} & \multirow{2}{*}{$\begin{array}{l}\text { Sig. } \\
.001\end{array}$} & \multirow{2}{*}{$\begin{array}{l}\Delta \mathrm{R}^{2} \\
.03\end{array}$} & \multirow{2}{*}{$\frac{F(\mathrm{df})}{7.17(2,476)}$} \\
\hline $1 * * *$ & (Constant) & & & & \\
\hline & Gender & 4.62 & .001 & & \\
\hline & Age & -.23 & .36 & & \\
\hline $2 * * *$ & (Constant) & 22.36 & .01 & .15 & $7.31(12,464)$ \\
\hline & Gender & 4.66 & .001 & & \\
\hline & Age & -.19 & .42 & & \\
\hline & Social Support Past Total Score & -1.36 & .09 & & \\
\hline & Social Support Present Total Score & -.06 & .94 & & \\
\hline & Parentification Questionnaire Total Score & -.12 & .19 & & \\
\hline & Attachment Style Questionnaire-Need for & .26 & .03 & & \\
\hline \multicolumn{6}{|c|}{ Approval subscale } \\
\hline & $\begin{array}{l}\text { Attachment Style Questionnaire-Discomfort } \\
\text { with closeness subscale }\end{array}$ & .03 & .74 & & \\
\hline \multicolumn{5}{|c|}{ Score } & \\
\hline \multicolumn{5}{|c|}{ Score } & \\
\hline & Locus of Control Centered Score & .11 & .51 & & \\
\hline & ASQ Relationships as Secondary Subscale & .20 & .13 & & \\
\hline \multicolumn{6}{|c|}{ Centered Score } \\
\hline & ASQ Confidence Subscale Centered Score & -.06 & .65 & & \\
\hline & ASQ Preoccupation with Relationships & .31 & .01 & & \\
\hline & Subscale Centered Score & & & & \\
\hline
\end{tabular}


Table 27 (continued)

\begin{tabular}{lcccc}
\hline Model & $\beta$ & Sig. & $\Delta \mathrm{R}^{2}$ & $F(\mathrm{df})$ \\
\hline Sexual Abuse Centered & .04 & .88 & & \\
(Constant) & 25.29 & .002 & .02 & $.99(11,453)$ \\
Gender & 4.83 & .001 & & \\
Age & -.22 & .36 & & \\
Social Support Past Total Score & -1.87 & .02 & \\
Social Support Present Total Score & -.30 & .75 & \\
Parentification Questionnaire Total Score & -.07 & .50 & \\
Attachment Style Questionnaire-Need for & .34 & .01 & \\
$\quad$ Approval subscale & & & \\
Attachment Style Questionnaire-Discomfort & -.01 & .91 & \\
$\quad$ with closeness subscale & & & \\
Perceived Social Support Friends Centered & -.06 & .70 & \\
$\quad$ Score & & & \\
Perceived Social Support Family Centered & .16 & .20 & \\
$\quad$ Score & & & \\
Locus of Control Centered Score & .04 & .84 \\
ASQ Relationships as Secondary Subscale & .26 & .06 \\
$\quad$ Centered Score & & & .06 \\
ASQ Confidence Subscale Centered Score & -.01 & .93 & \\
ASQ Preoccupation with Relationships & .28 & .02 & \\
$\quad$ Subscale Centered Score & & & \\
Sexual Abuse Centered & -4.02 & .15 & \\
Sexual Abuse X Social Support Past & -.27 & .31 & \\
Sexual abuse X Friend Social Support & .13 & .34 & \\
Sexual abuse X Family Social Support & .003 & .97 & \\
Sexual abuse X Parentification & .10 & .21 & \\
\hline
\end{tabular}


Table 27 (continued)

\begin{tabular}{lcccc}
\hline Model & $\beta$ & Sig. & $\Delta \mathrm{R}^{2}$ & $F(\mathrm{df})$ \\
\hline Sexual abuse X Locus of Control & -.09 & .53 & \\
Sexual abuse X ASQ Need for Approval & .19 & .14 & \\
Sexual abuse X ASQ Relationships as & .12 & .26 & \\
$\quad$ Secondary & & & \\
$\quad$ Sexual abuse X ASQ Preoccupation with & -.06 & .58 & \\
$\quad$ Relationships & & & \\
$\quad$ Sexual abuse X ASQ Confidence & .09 & .22 & \\
Sexual abuse X Discomfort with Closeness & -.05 & .49 &
\end{tabular}

Note. ${ }^{* * *} p<.001 ; \mathrm{ASQ}=$ Attachment Style Questionnaire. 
Table 28

Hierarchical Regression Analysis Evaluating the Moderating Effects of Social Support, Parentification, Locus of Control, and Attachment Styles on Substance Use Resulting from

Emotional Neglect

\begin{tabular}{|c|c|c|c|c|c|}
\hline \multicolumn{2}{|l|}{ Model } & \multirow{2}{*}{$\frac{B}{6.76}$} & \multirow{2}{*}{$\begin{array}{l}\text { Sig. } \\
.001\end{array}$} & \multirow{2}{*}{$\frac{\Delta \mathrm{R}^{2}}{.01}$} & \multirow{2}{*}{$\frac{F(\mathrm{df})}{2.73(2,479)}$} \\
\hline 1 & (Constant) & & & & \\
\hline & Gender & -.61 & .07 & & \\
\hline & Age & -.09 & .11 & & \\
\hline $2 * * *$ & (Constant) & 7.17 & .001 & .08 & $3.61(12,467)$ \\
\hline & Gender & -.86 & .02 & & \\
\hline & Age & -.07 & .22 & & \\
\hline & Social Support Past Total Score & .17 & .42 & & \\
\hline & Social Support Present Total Score & -.48 & .05 & & \\
\hline & $\begin{array}{l}\text { Attachment Style Questionnaire-Need for } \\
\text { Approval subscale }\end{array}$ & -.004 & .89 & & \\
\hline & $\begin{array}{l}\text { Attachment Style Questionnaire-Discomfort } \\
\text { with closeness subscale }\end{array}$ & .03 & .23 & & \\
\hline & Emotional Neglect Scale Total Score & .07 & .20 & & \\
\hline & $\begin{array}{l}\text { Perceived Social Support Friends Centered } \\
\quad \text { Score }\end{array}$ & .11 & .02 & & \\
\hline & $\begin{array}{l}\text { Perceived Social Support Family Centered } \\
\quad \text { Score }\end{array}$ & .02 & .59 & & \\
\hline & $\begin{array}{l}\text { Parentification Questionnaire Total } \\
\text { Centered Score }\end{array}$ & -.02 & .51 & & \\
\hline & Locus of Control Centered Score & .04 & .30 & & \\
\hline & ASQ Relationships as Secondary Subscale & .02 & .60 & & \\
\hline & Centered Score & & & & \\
\hline & ASQ Confidence Subscale Centered Score & .06 & .10 & & \\
\hline
\end{tabular}


Table 28 (continued)

\begin{tabular}{|c|c|c|c|c|c|}
\hline \multicolumn{2}{|c|}{ Model } & \multirow{2}{*}{$\begin{array}{l}\beta \\
.11\end{array}$} & \multirow{2}{*}{$\begin{array}{l}\text { Sig. } \\
.001\end{array}$} & \multirow[t]{2}{*}{$\Delta \mathrm{R}^{2}$} & \multirow[t]{2}{*}{$F(\mathrm{df})$} \\
\hline & $\begin{array}{l}\text { ASQ Preoccupation with Relationships } \\
\text { Subscale Centered Score }\end{array}$ & & & & \\
\hline 3 & (Constant) & 6.65 & .01 & .03 & $1.50(11,456)$ \\
\hline & Gender & -.74 & .05 & & \\
\hline & Age & -.06 & .30 & & \\
\hline & Social Support Past Total Score & .18 & .47 & & \\
\hline & Social Support Present Total Score & -.37 & .16 & & \\
\hline & $\begin{array}{l}\text { Attachment Style Questionnaire-Need for } \\
\quad \text { Approval subscale }\end{array}$ & .007 & .83 & & \\
\hline & $\begin{array}{l}\text { Attachment Style Questionnaire-Discomfort } \\
\text { with closeness subscale }\end{array}$ & .03 & .22 & & \\
\hline & Emotional Neglect Scale Total Score & -.01 & .93 & & \\
\hline & $\begin{array}{l}\text { Perceived Social Support Friends Centered } \\
\text { Score }\end{array}$ & .09 & .06 & & \\
\hline & $\begin{array}{l}\text { Perceived Social Support Family Centered } \\
\quad \text { Score }\end{array}$ & .04 & .35 & & \\
\hline & $\begin{array}{l}\text { Parentification Questionnaire Total } \\
\quad \text { Centered Score }\end{array}$ & -.01 & .76 & & \\
\hline & Locus of Control Centered Score & .05 & .28 & & \\
\hline & $\begin{array}{l}\text { ASQ Relationships as Secondary Subscale } \\
\text { Centered Score }\end{array}$ & .02 & .56 & & \\
\hline & ASQ Confidence Subscale Centered Score & .06 & .16 & & \\
\hline & ASQ Preoccupation with Relationships & .09 & .004 & & \\
\hline & Subscale Centered Score & & & & \\
\hline & Emotional Neglect X Social Support Past & .07 & .08 & & \\
\hline & Emotional Neglect X Social Support Present & .07 & .20 & & \\
\hline & Emotional Neglect X Friend Social Support & -.02 & .86 & & \\
\hline
\end{tabular}

(table continues) 
Table 28 (continued)

\begin{tabular}{lcccc}
\hline Model & $\beta$ & Sig. & $\Delta \mathrm{R}^{2}$ & $F(\mathrm{df})$ \\
\hline Emotional Neglect X Family Social Support & -.01 & .48 & \\
Emotional Neglect X Parentification & -.0003 & .96 & \\
Emotional Neglect X Locus of Control & .01 & .56 & \\
Emotional Neglect X ASQ Need for & .01 & .33 & \\
$\quad$ Approval & & & \\
Emotional Neglect X ASQ Relationships as & -.01 & .48 \\
$\quad$ Secondary & & & \\
Emotional Neglect X ASQ Preoccupation & .01 & .31 \\
$\quad$ with Relationships & & & \\
Emotional Neglect X ASQ Confidence & -.01 & .53 \\
Emotional Neglect X Discomfort with & -.001 & .93 \\
$\quad$ Closeness & & \\
\hline
\end{tabular}

Note. ${ }^{* * *} p<.001 ; \mathrm{ASQ}=$ Attachment Style Questionnaire. 
Table 29

Hierarchical Regression Analysis Evaluating the Moderating Effects of Social Support, Parentification, Locus of Control, and Attachment Styles on DUSI Overall Problems Resulting from Emotional Neglect

\begin{tabular}{|c|c|c|c|c|c|}
\hline \multicolumn{2}{|l|}{ Model } & \multirow{2}{*}{$\frac{\beta}{24.06}$} & \multirow{2}{*}{$\begin{array}{l}\text { Sig. } \\
.001\end{array}$} & \multirow{2}{*}{$\begin{array}{l}\Delta \mathrm{R}^{2} \\
.003\end{array}$} & \multirow{2}{*}{$\begin{array}{c}F(\mathrm{df}) \\
.66(2,479)\end{array}$} \\
\hline 1 & (Constant) & & & & \\
\hline & Gender & -.62 & .58 & & \\
\hline & Age & .17 & .33 & & \\
\hline $2 * * *$ & (Constant) & 22.15 & .001 & .41 & $26.83(12,467)$ \\
\hline & Gender & -1.65 & .09 & & \\
\hline & Age & .11 & .46 & & \\
\hline & Social Support Past Total Score & 69 & .23 & & \\
\hline & Social Support Present Total Score & -1.63 & .01 & & \\
\hline & Attachment Style Questionnaire-Need for & .03 & .76 & & \\
\hline \multicolumn{6}{|c|}{ Approval subscale } \\
\hline \multicolumn{5}{|c|}{ with closeness subscale } & \\
\hline & Emotional Neglect Scale Total Score & .53 & .001 & & \\
\hline & Perceived Social Support Friends Centered & .05 & .70 & & \\
\hline \multicolumn{6}{|c|}{ Score } \\
\hline \multicolumn{5}{|c|}{ Score } & \\
\hline & Parentification Questionnaire Total & -.21 & .004 & & \\
\hline \multicolumn{6}{|c|}{ Centered Score } \\
\hline & Locus of Control Centered Score & .36 & .003 & & \\
\hline & ASQ Relationships as Secondary Subscale & -.04 & .68 & & \\
\hline \multicolumn{6}{|c|}{ Centered Score } \\
\hline & ASQ Confidence Subscale Centered Score & -.05 & .60 & & \\
\hline
\end{tabular}


Table 29 (continued)

\begin{tabular}{|c|c|c|c|c|c|}
\hline \multicolumn{2}{|c|}{ Model } & \multirow{2}{*}{$\beta$} & \multirow{2}{*}{$\begin{array}{l}\text { Sig. } \\
.001\end{array}$} & \multirow[t]{2}{*}{$\Delta \mathrm{R}^{2}$} & \multirow[t]{2}{*}{$F(\mathrm{df})$} \\
\hline & $\begin{array}{l}\text { ASQ Preoccupation with Relationships } \\
\text { Subscale Centered Score }\end{array}$ & & & & \\
\hline \multirow[t]{19}{*}{3} & (Constant) & 22.30 & .001 & .02 & $1.17(11,456)$ \\
\hline & Gender & -1.54 & .12 & & \\
\hline & Age & .14 & .35 & & \\
\hline & Social Support Past Total Score & .84 & .20 & & \\
\hline & Social Support Present Total Score & -1.49 & .04 & & \\
\hline & $\begin{array}{l}\text { Attachment Style Questionnaire-Need for } \\
\text { Approval subscale }\end{array}$ & .02 & .80 & & \\
\hline & $\begin{array}{l}\text { Attachment Style Questionnaire-Discomfort } \\
\text { with closeness subscale }\end{array}$ & .17 & .01 & & \\
\hline & Emotional Neglect Scale Total Score & .20 & .65 & & \\
\hline & $\begin{array}{l}\text { Perceived Social Support Friends Centered } \\
\text { Score }\end{array}$ & .03 & .79 & & \\
\hline & $\begin{array}{l}\text { Perceived Social Support Family Centered } \\
\quad \text { Score }\end{array}$ & .04 & .75 & & \\
\hline & $\begin{array}{l}\text { Parentification Questionnaire Total } \\
\quad \text { Centered Score }\end{array}$ & -.23 & .002 & & \\
\hline & Locus of Control Centered Score & .34 & .01 & & \\
\hline & $\begin{array}{l}\text { ASQ Relationships as Secondary Subscale } \\
\text { Centered Score }\end{array}$ & -.04 & .67 & & \\
\hline & ASQ Confidence Subscale Centered Score & -.05 & .65 & & \\
\hline & ASQ Preoccupation with Relationships & .44 & .001 & & \\
\hline & Subscale Centered Score & & & & \\
\hline & Emotional Neglect X Social Support Past & .04 & .67 & & \\
\hline & Emotional Neglect X Social Support Present & .14 & .35 & & \\
\hline & Emotional Neglect X Friend Social Support & -.01 & .78 & & \\
\hline
\end{tabular}

(table continues) 
Table 29 (continued)

\begin{tabular}{lcccc}
\hline Model & $\beta$ & Sig. & $\Delta \mathrm{R}^{2}$ & $F(\mathrm{df})$ \\
\hline Emotional Neglect X Family Social Support & -.02 & .36 & \\
Emotional Neglect X Parentification & .01 & .38 & \\
Emotional Neglect X Locus of Control & .05 & .05 & \\
Emotional Neglect X ASQ Need for & .02 & .36 & \\
$\quad$ Approval & & & \\
Emotional Neglect X ASQ Relationships as & -.02 & .29 \\
$\quad$ Secondary & & & \\
Emotional Neglect X ASQ Preoccupation & .01 & .49 \\
$\quad$ with Relationships & & & \\
Emotional Neglect X ASQ Confidence & -.001 & .96 \\
Emotional Neglect X Discomfort with & .01 & .55 \\
$\quad$ Closeness & & \\
\hline
\end{tabular}

Note. ${ }^{* * *} p<.001 ; \mathrm{ASQ}=$ Attachment Style Questionnaire. 
Table 30

Hierarchical Regression Analysis Evaluating the Moderating Effects of Social Support, Parentification, Locus of Control, and Attachment Styles on Permissiveness Resulting from

Emotional Neglect

\begin{tabular}{lcccc}
\hline Model & $\beta$ & Sig. & $\Delta \mathrm{R}^{2}$ & $F(\mathrm{df})$ \\
\hline $1^{* * *}$ (Constant) & 3.27 & .001 & .21 & $64.86(2,476)$ \\
Gender & .67 & .001 & & \\
Age & -.01 & .18 & & \\
$2^{* * *}$ (Constant) & 3.64 & .001 & .07 & $3.83(12,464)$ \\
Gender & .68 & .001 & & \\
Age & -.01 & .31 & & \\
Social Support Past Total Score & -.01 & .71 & & \\
Social Support Present Total Score & -.01 & .85 & & \\
Parentification Questionnaire Total Score & .01 & .26 & & \\
Attachment Style Questionnaire-Need for & .002 & .68 & & \\
$\quad$ Approval subscale & & & & \\
Attachment Style Questionnaire-Discomfort & -.01 & .02 & & \\
$\quad$ with closeness subscale & & & & \\
Emotional Neglect Scale Total Score & -.02 & .03 & & \\
Perceived Social Support Friends Centered & -.01 & .33 & & \\
$\quad$ Score & & & & \\
Perceived Social Support Family Centered & .01 & .40 & \\
$\quad$ Score & & & .02 & \\
Locus of Control Centered Score & -.02 & .04 & \\
ASQ Relationships as Secondary Subscale & -.01 & .12 & \\
$\quad$ Centered Score & & & \\
ASQ Confidence Subscale Centered Score & -.02 & .02 & \\
\hline
\end{tabular}

(table continues) 
Table 30 (continued)

\begin{tabular}{|c|c|c|c|c|c|}
\hline \multicolumn{2}{|c|}{ Model } & \multirow{2}{*}{$\begin{array}{c}\beta \\
-.004\end{array}$} & \multirow{2}{*}{$\begin{array}{r}\text { Sig. } \\
.43\end{array}$} & \multirow[t]{2}{*}{$\Delta \mathrm{R}^{2}$} & \multirow[t]{2}{*}{$F(\mathrm{df})$} \\
\hline & $\begin{array}{l}\text { ASQ Preoccupation with Relationships } \\
\text { Subscale Centered Score }\end{array}$ & & & & \\
\hline \multirow[t]{20}{*}{$3 *$} & (Constant) & 3.49 & .001 & .04 & $2.27(11,453)$ \\
\hline & Gender & .70 & .001 & & \\
\hline & Age & -.01 & .25 & & \\
\hline & Social Support Past Total Score & -.02 & .66 & & \\
\hline & Social Support Present Total Score & -.04 & .36 & & \\
\hline & Parentification Questionnaire Total Score & .003 & .50 & & \\
\hline & $\begin{array}{l}\text { Attachment Style Questionnaire-Need for } \\
\text { Approval subscale }\end{array}$ & .001 & .92 & & \\
\hline & $\begin{array}{l}\text { Attachment Style Questionnaire-Discomfort } \\
\text { with closeness subscale }\end{array}$ & -.01 & .01 & & \\
\hline & Emotional Neglect Scale Total Score & .04 & .18 & & \\
\hline & $\begin{array}{l}\text { Perceived Social Support Friends Centered } \\
\quad \text { Score }\end{array}$ & -.002 & .77 & & \\
\hline & $\begin{array}{l}\text { Perceived Social Support Family Centered } \\
\quad \text { Score }\end{array}$ & .0004 & .95 & & \\
\hline & Locus of Control Centered Score & -.02 & .03 & & \\
\hline & $\begin{array}{l}\text { ASQ Relationships as Secondary Subscale } \\
\text { Centered Score }\end{array}$ & -.01 & .09 & & \\
\hline & ASQ Confidence Subscale Centered Score & -.02 & .03 & & \\
\hline & ASQ Preoccupation with Relationships & -.002 & .77 & & \\
\hline & Subscale Centered Score & & & & \\
\hline & Emotional Neglect X Social Support Past & -.02 & .02 & & \\
\hline & Emotional Neglect X Social Support Present & -.01 & .23 & & \\
\hline & Emotional Neglect X Friend Social Support & -.001 & .45 & & \\
\hline & Emotional Neglect X Family Social Support & .003 & .07 & & \\
\hline
\end{tabular}


Table 30 (continued)

\begin{tabular}{ccccc}
\hline Model & $\beta$ & Sig. & $\Delta \mathrm{R}^{2}$ & $F(\mathrm{df})$ \\
\hline Emotional Neglect X Parentification & .001 & .54 & \\
Emotional Neglect X Locus of Control & -.001 & .57 & \\
Emotional Neglect X ASQ Need for & -.003 & .02 & \\
$\quad$ Approval & & & \\
$\quad$ Emotional Neglect X ASQ Relationships as & .003 & .06 & \\
$\quad$ Secondary & & & \\
Emotional Neglect X ASQ Preoccupation & .002 & .16 \\
$\quad$ with Relationships & & & \\
$\quad$ Emotional Neglect X ASQ Confidence & -.0004 & .80 \\
Emotional Neglect X Discomfort with & -.002 & .04 \\
$\quad$ Closeness & &
\end{tabular}

Note. ${ }^{* * *} p<.001,{ }^{*} p<.05$; ASQ $=$ Attachment Style Questionnaire. 
Table 31

Hierarchical Regression Analysis Evaluating the Moderating Effects of Social Support, Parentification, Locus of Control, and Attachment Styles on Depression Resulting from

Emotional Neglect

\begin{tabular}{|c|c|c|c|c|c|}
\hline \multicolumn{2}{|l|}{ Model } & \multirow{2}{*}{$\begin{array}{c}\beta \\
-4.70\end{array}$} & \multirow{2}{*}{$\begin{array}{l}\text { Sig. } \\
.19\end{array}$} & \multirow{2}{*}{$\frac{\Delta \mathrm{R}^{2}}{.05}$} & \multirow{2}{*}{$\frac{F(\mathrm{df})}{11.15(2,477)}$} \\
\hline $1 * * *$ & (Constant) & & & & \\
\hline & Gender & 3.30 & .001 & & \\
\hline & Age & .45 & .01 & & \\
\hline $2 * * *$ & (Constant) & -13.33 & .003 & .37 & $24.98(12,465)$ \\
\hline & Gender & 2.88 & .001 & & \\
\hline & Age & .38 & .004 & & \\
\hline & Social Support Past Total Score & .23 & .60 & & \\
\hline & $\begin{array}{l}\text { Attachment Style Questionnaire-Discomfort } \\
\text { with closeness subscale }\end{array}$ & .11 & .02 & & \\
\hline & Emotional Neglect Scale Total Score & .14 & .21 & & \\
\hline & Social Support Present Centered Score & -.89 & .06 & & \\
\hline & $\begin{array}{l}\text { Perceived Social Support Friends Centered } \\
\text { Score }\end{array}$ & -.06 & .51 & & \\
\hline & $\begin{array}{l}\text { Perceived Social Support Family Centered } \\
\quad \text { Score }\end{array}$ & -.08 & .27 & & \\
\hline & $\begin{array}{l}\text { Parentification Questionnaire Total } \\
\text { Centered Score }\end{array}$ & -.06 & .27 & & \\
\hline & Locus of Control Centered Score & .12 & .17 & & \\
\hline & $\begin{array}{l}\text { ASQ Need for Approval Subscale Centered } \\
\text { Score }\end{array}$ & .24 & .001 & & \\
\hline & $\begin{array}{l}\text { ASQ Relationships as Secondary Subscale } \\
\text { Centered Score }\end{array}$ & -.16 & .03 & & \\
\hline & ASQ Confidence Subscale Centered Score & -.28 & .001 & & \\
\hline
\end{tabular}


Table 31 (continued)

\begin{tabular}{lcccc}
\hline Model & $\beta$ & Sig. & $\Delta \mathrm{R}^{2}$ & $F(\mathrm{df})$ \\
\hline ASQ Preoccupation with Relationships & .13 & .03 & & \\
$\quad$ Subscale Centered Score & & & & \\
3 (Constant) & -13.37 & .02 & .02 & $1.62(11,454)$ \\
Gender & 2.64 & .001 & & \\
Age & .37 & .01 & \\
Social Support Past Total Score & .23 & .64 & \\
Attachment Style Questionnaire-Discomfort & .11 & .02 & \\
$\quad$ with closeness subscale & & & \\
Emotional Neglect Scale Total Score & .19 & .57 & \\
Social Support Present Centered Score & -.90 & .09 & \\
Perceived Social Support Friends Centered & -.05 & .57 & \\
$\quad$ Score & & & \\
Perceived Social Support Family Centered & -.03 & .69 & \\
$\quad$ Score & & & \\
Parentification Questionnaire Total & -.09 & .10 \\
$\quad$ Centered Score & & & .01
\end{tabular}


Table 31 (continued)

\begin{tabular}{lcccc}
\hline Model & $\beta$ & Sig. & $\Delta \mathrm{R}^{2}$ & $F(\mathrm{df})$ \\
\hline Emotional Neglect X Family Social Support & -.002 & .89 & \\
Emotional Neglect X Parentification & .003 & .83 & \\
Emotional Neglect X Locus of Control & .04 & .03 & \\
Emotional Neglect X ASQ Need for & -.01 & .70 & \\
$\quad$ Approval & & & \\
Emotional Neglect X ASQ Relationships as & -.03 & .10 \\
$\quad$ Secondary & & & \\
Emotional Neglect X ASQ Preoccupation & .02 & .09 \\
$\quad$ with Relationships & & & \\
Emotional Neglect X ASQ Confidence & -.004 & .80 \\
Emotional Neglect X Discomfort with & .01 & .37 \\
$\quad$ Closeness & & \\
\hline
\end{tabular}

Note. ${ }^{* * *} p<.001 ; \mathrm{ASQ}=$ Attachment Style Questionnaire. 
Table 32

Hierarchical Regression Analysis Evaluating the Moderating Effects of Social Support, Parentification, Locus of Control, and Attachment Styles on Anxiety Resulting from Emotional Neglect

\begin{tabular}{|c|c|c|c|c|c|}
\hline \multicolumn{2}{|l|}{ Model } & \multirow{2}{*}{$\begin{array}{c}\beta \\
-5.66\end{array}$} & \multirow{2}{*}{$\begin{array}{l}\text { Sig. } \\
.11\end{array}$} & \multirow{2}{*}{$\frac{\Delta \mathrm{R}^{2}}{.05}$} & \multirow{2}{*}{$\frac{F(\mathrm{df})}{12.70(2,476)}$} \\
\hline $1 * * *$ & (Constant) & & & & \\
\hline & Gender & 3.61 & .001 & & \\
\hline & Age & .43 & .01 & & \\
\hline $2 * * *$ & (Constant) & -13.76 & .03 & .17 & $8.42(12,464)$ \\
\hline & Gender & 2.76 & .001 & & \\
\hline & Age & .41 & .01 & & \\
\hline & Social Support Past Total Score & -.38 & .44 & & \\
\hline & Social Support Present Total Score & .26 & .63 & & \\
\hline \multicolumn{6}{|c|}{ Approval subscale } \\
\hline & Attachment Style Questionnaire- & -.19 & .02 & & \\
\hline \multicolumn{6}{|c|}{ Relationships as Secondary subscale } \\
\hline & $\begin{array}{l}\text { Attachment Style Questionnaire-Discomfort } \\
\text { with closeness subscale }\end{array}$ & .13 & .02 & & \\
\hline & $\begin{array}{l}\text { Attachment Style Questionnaire-Confidence } \\
\text { subscale }\end{array}$ & -.004 & .96 & & \\
\hline & Attachment Style Questionnaire- & .24 & .001 & & \\
\hline \multicolumn{6}{|c|}{ Preoccupation with Relationships } \\
\hline \multicolumn{6}{|c|}{ subscale } \\
\hline & Emotional Neglect Scale Total Score & .24 & .06 & & \\
\hline & $\begin{array}{l}\text { Perceived Social Support Friends Centered } \\
\quad \text { Score }\end{array}$ & -.01 & .50 & & \\
\hline
\end{tabular}


Table 32 (continued)

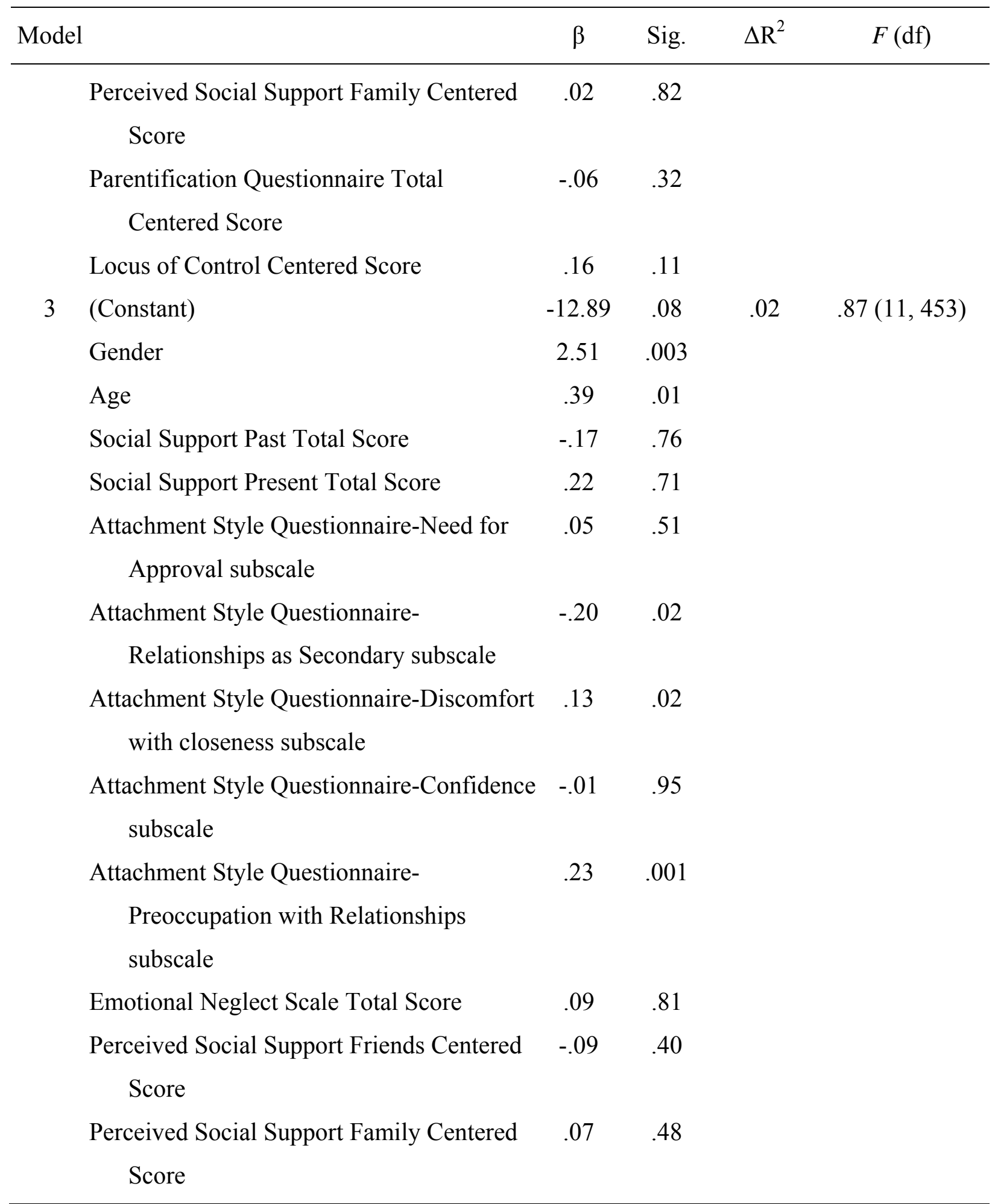

(table continues) 
Table 32 (continued)

\begin{tabular}{|c|c|c|c|c|}
\hline Model & $\beta$ & Sig. & $\Delta \mathrm{R}^{2}$ & $F(\mathrm{df})$ \\
\hline $\begin{array}{l}\text { Parentification Questionnaire Total } \\
\quad \text { Centered Score }\end{array}$ & -.07 & .24 & & \\
\hline Locus of Control Centered Score & .16 & .12 & & \\
\hline Emotional Neglect X Social Support Past & -.007 & .94 & & \\
\hline Emotional Neglect X Social Support Present & .07 & .56 & & \\
\hline Emotional Neglect X Friend Social Support & .01 & .60 & & \\
\hline Emotional Neglect X Family Social Support & -.01 & .62 & & \\
\hline Emotional Neglect X Parentification & .01 & .69 & & \\
\hline Emotional Neglect X Locus of Control & .03 & .16 & & \\
\hline $\begin{array}{l}\text { Emotional Neglect X ASQ Need for } \\
\quad \text { Approval }\end{array}$ & .01 & .69 & & \\
\hline $\begin{array}{l}\text { Emotional Neglect X ASQ Relationships as } \\
\text { Secondary }\end{array}$ & -.03 & .09 & & \\
\hline $\begin{array}{l}\text { Emotional Neglect X ASQ Preoccupation } \\
\quad \text { with Relationships }\end{array}$ & .01 & .74 & & \\
\hline Emotional Neglect X ASQ Confidence & .001 & .94 & & \\
\hline $\begin{array}{l}\text { Emotional Neglect X Discomfort with } \\
\text { Closeness }\end{array}$ & .02 & .15 & & \\
\hline
\end{tabular}

Note. ${ }^{* * *} p<.001 ; \mathrm{ASQ}=$ Attachment Style Questionnaire. 
Table 33

Hierarchical Regression Analysis Evaluating the Moderating Effects of Social Support, Parentification, Locus of Control, and Attachment Styles on Social Anxiety Resulting from

Emotional Neglect

\begin{tabular}{llcccc}
\hline Model & $\beta$ & Sig. & $\Delta \mathrm{R}^{2}$ & $F(\mathrm{df})$ \\
\hline $1 \quad$ Constant $)$ & 62.52 & .001 & .002 & $.36(2,476)$ \\
Gender & 2.35 & .51 & & \\
Age & .41 & .55 & & \\
$2^{* * * *}$ (Constant) & 54.00 & .01 & .38 & $23.33(12,464)$ \\
Gender & 2.00 & .52 & & \\
Age & .06 & .92 & & \\
Social Support Past Total Score & -4.88 & .01 & & \\
Parentification Questionnaire Total Score & .29 & .22 & & \\
Attachment Style Questionnaire-Need for & 1.61 & .001 & & \\
$\quad$ Approval subscale & & & & \\
Emotional Neglect Scale Total Score & .18 & .71 & & \\
Social Support Present Centered Score & 5.28 & .01 & & \\
Perceived Social Support Friends Centered & -1.04 & .01 & & \\
$\quad$ Score & & & & \\
Perceived Social Support Family Centered & .53 & .11 & \\
$\quad$ Score & & & .01 & \\
Locus of Control Centered Score & .97 & .01 & \\
ASQ Relationships as Secondary Subscale & .63 & .04 & \\
$\quad$ Centered Score & & & & \\
ASQ Discomfort with Closeness Subscale & .002 & .99 & \\
$\quad$ Centered Score & & & \\
ASQ Confidence Subscale Centered Score & -1.72 & .001 & \\
\hline
\end{tabular}

(table continues) 
Table 33 (continued)

\begin{tabular}{|c|c|c|c|c|c|}
\hline \multicolumn{2}{|c|}{ Model } & \multirow{2}{*}{$\begin{array}{l}\beta \\
20\end{array}$} & \multirow{2}{*}{$\begin{array}{r}\text { Sig. } \\
.43\end{array}$} & \multirow[t]{2}{*}{$\Delta \mathrm{R}^{2}$} & \multirow[t]{2}{*}{$F(\mathrm{df})$} \\
\hline & $\begin{array}{l}\text { ASQ Preoccupation with Relationships } \\
\text { Subscale Centered Score }\end{array}$ & & & & \\
\hline \multirow[t]{20}{*}{3} & (Constant) & 46.21 & .06 & .01 & $.81(11,453)$ \\
\hline & Gender & 1.72 & .60 & & \\
\hline & Age & .02 & .97 & & \\
\hline & Social Support Past Total Score & -4.04 & .06 & & \\
\hline & Parentification Questionnaire Total Score & .27 & .26 & & \\
\hline & $\begin{array}{l}\text { Attachment Style Questionnaire-Need for } \\
\quad \text { Approval subscale }\end{array}$ & 1.62 & .001 & & \\
\hline & Emotional Neglect Scale Total Score & .59 & .69 & & \\
\hline & Social Support Present Centered Score & 4.21 & .07 & & \\
\hline & $\begin{array}{l}\text { Perceived Social Support Friends Centered } \\
\text { Score }\end{array}$ & -1.08 & .01 & & \\
\hline & $\begin{array}{l}\text { Perceived Social Support Family Centered } \\
\text { Score }\end{array}$ & .61 & .09 & & \\
\hline & Locus of Control Centered Score & 1.02 & .01 & & \\
\hline & $\begin{array}{l}\text { ASQ Relationships as Secondary Subscale } \\
\text { Centered Score }\end{array}$ & .57 & .07 & & \\
\hline & $\begin{array}{l}\text { ASQ Discomfort with Closeness Subscale } \\
\text { Centered Score }\end{array}$ & .01 & .97 & & \\
\hline & ASQ Confidence Subscale Centered Score & -1.65 & .001 & & \\
\hline & ASQ Preoccupation with Relationships & .25 & .36 & & \\
\hline & Subscale Centered Score & & & & \\
\hline & Emotional Neglect X Social Support Past & -.41 & .24 & & \\
\hline & Emotional Neglect X Social Support Present & .05 & .92 & & \\
\hline & Emotional Neglect X Friend Social Support & .17 & .08 & & \\
\hline & Emotional Neglect X Family Social Support & .05 & .57 & & \\
\hline
\end{tabular}

(table continues) 
Table 33 (continued)

\begin{tabular}{ccccc}
\hline Model & $\beta$ & Sig. & $\Delta \mathrm{R}^{2}$ & $F(\mathrm{df})$ \\
\hline Emotional Neglect X Parentification & -.06 & .91 & \\
Emotional Neglect X Locus of Control & .14 & .12 & \\
Emotional Neglect X ASQ Need for & -.03 & .69 & \\
$\quad$ Approval & & & \\
Emotional Neglect X ASQ Relationships as & .08 & .28 & \\
$\quad$ Secondary & & & \\
Emotional Neglect X ASQ Preoccupation & .001 & .99 \\
$\quad$ with Relationships & & & \\
Emotional Neglect X ASQ Confidence & -.10 & .18 \\
Emotional Neglect X Discomfort with & -.05 & .36 \\
$\quad$ Closeness & &
\end{tabular}

Note. ${ }^{* * *} p<.001 ; \mathrm{ASQ}=$ Attachment Style Questionnaire. 
Table 34

Hierarchical Regression Analysis Evaluating the Moderating Effects of Social Support, Parentification, Locus of Control, and Attachment Styles on Agoraphobia Resulting from

Emotional Neglect

\begin{tabular}{|c|c|c|c|c|c|}
\hline \multicolumn{2}{|l|}{ Model } & \multirow{2}{*}{$\beta$} & \multirow{2}{*}{$\begin{array}{l}\text { Sig. } \\
.001\end{array}$} & \multirow{2}{*}{$\frac{\Delta \mathrm{R}^{2}}{.03}$} & \multirow{2}{*}{$\frac{F(\mathrm{df})}{7.17(2,476)}$} \\
\hline $1 * * *$ & (Constant) & & & & \\
\hline & Gender & 4.62 & .001 & & \\
\hline & Age & -.23 & .36 & & \\
\hline $2 * * *$ & (Constant) & 22.64 & .01 & .15 & $7.30(12,464)$ \\
\hline & Gender & 4.68 & .001 & & \\
\hline & Age & -.19 & .41 & & \\
\hline & Social Support Past Total Score & -1.36 & .09 & & \\
\hline & Parentification Questionnaire Total Score & -.12 & .23 & & \\
\hline & $\begin{array}{l}\text { Attachment Style Questionnaire-Need for } \\
\text { Approval subscale }\end{array}$ & \multicolumn{3}{|c|}{ Approval subscale } & \\
\hline & Emotional Neglect Scale Total Score & .03 & .89 & & \\
\hline & Social Support Present Centered Score & -.05 & .96 & & \\
\hline & \multicolumn{4}{|l|}{ Score } & \\
\hline & $\begin{array}{l}\text { Perceived Social Support Family Centered } \\
\text { Score }\end{array}$ & .18 & .19 & \multicolumn{2}{|c|}{ Score } \\
\hline & Locus of Control Centered Score & .10 & .52 & & \\
\hline & \multicolumn{4}{|l|}{ Centered Score } & \\
\hline & \multicolumn{5}{|l|}{ Centered Score } \\
\hline & ASQ Confidence Subscale Centered Score & -.06 & .66 & & \\
\hline
\end{tabular}

(table continues) 
Table 34 (continued)

\begin{tabular}{|c|c|c|c|c|c|}
\hline \multicolumn{2}{|c|}{ Model } & \multirow{2}{*}{$\beta$} & \multirow{2}{*}{$\begin{array}{r}\text { Sig. } \\
.01\end{array}$} & \multirow[t]{2}{*}{$\Delta \mathrm{R}^{2}$} & \multirow[t]{2}{*}{$F(\mathrm{df})$} \\
\hline & $\begin{array}{l}\text { ASQ Preoccupation with Relationships } \\
\text { Subscale Centered Score }\end{array}$ & & & & \\
\hline \multirow[t]{20}{*}{3} & (Constant) & 27.43 & .01 & .02 & $1.03(11,453)$ \\
\hline & Gender & 4.38 & .001 & & \\
\hline & Age & -.15 & .53 & & \\
\hline & Social Support Past Total Score & -1.99 & .03 & & \\
\hline & Parentification Questionnaire Total Score & -.12 & .23 & & \\
\hline & $\begin{array}{l}\text { Attachment Style Questionnaire-Need for } \\
\text { Approval subscale }\end{array}$ & .24 & .06 & & \\
\hline & Emotional Neglect Scale Total Score & -.06 & .92 & & \\
\hline & Social Support Present Centered Score & .40 & .68 & & \\
\hline & $\begin{array}{l}\text { Perceived Social Support Friends Centered } \\
\text { Score }\end{array}$ & -.09 & .59 & & \\
\hline & $\begin{array}{l}\text { Perceived Social Support Family Centered } \\
\text { Score }\end{array}$ & .19 & .21 & & \\
\hline & Locus of Control Centered Score & .12 & .46 & & \\
\hline & $\begin{array}{l}\text { ASQ Relationships as Secondary Subscale } \\
\text { Centered Score }\end{array}$ & .20 & .12 & & \\
\hline & $\begin{array}{l}\text { ASQ Discomfort with Closeness Subscale } \\
\text { Centered Score }\end{array}$ & .04 & .66 & & \\
\hline & ASQ Confidence Subscale Centered Score & -.06 & .68 & & \\
\hline & ASQ Preoccupation with Relationships & .35 & .002 & & \\
\hline & Subscale Centered Score & & & & \\
\hline & Emotional Neglect X Social Support Past & .09 & .51 & & \\
\hline & Emotional Neglect X Social Support Present & -.25 & .21 & & \\
\hline & Emotional Neglect X Friend Social Support & .03 & .38 & & \\
\hline & Emotional Neglect X Family Social Support & .04 & .23 & & \\
\hline
\end{tabular}

(table continues) 
Table 34 (continued)

\begin{tabular}{lcccc}
\hline Model & $\beta$ & Sig. & $\Delta \mathrm{R}^{2}$ & $F(\mathrm{df})$ \\
\hline Emotional Neglect X Parentification & -.03 & .20 & \\
Emotional Neglect X Locus of Control & .08 & .03 & \\
Emotional Neglect X ASQ Need for & .001 & .98 & \\
$\quad$ Approval & & & \\
Emotional Neglect X ASQ Relationships as & .04 & .22 \\
$\quad$ Secondary & & & \\
Emotional Neglect X ASQ Preoccupation & .002 & .93 \\
$\quad$ with Relationships & & & \\
Emotional Neglect X ASQ Confidence & .02 & .48 \\
Emotional Neglect X Discomfort with & .01 & .79 \\
$\quad$ Closeness & &
\end{tabular}

Note. ${ }^{* * *} p<.001 ; \mathrm{ASQ}=$ Attachment Style Questionnaire. 
Table 35

Hierarchical Regression Analysis Evaluating the Moderating Effects of Social Support, Parentification, Locus of Control, and Attachment Styles on Substance Use Resulting from

Physical Neglect

\begin{tabular}{|c|c|c|c|c|c|}
\hline \multicolumn{2}{|c|}{ Model } & \multirow{2}{*}{$\frac{\beta}{6.76}$} & \multirow{2}{*}{$\begin{array}{l}\text { Sig. } \\
.001\end{array}$} & \multirow{2}{*}{$\frac{\Delta \mathrm{R}^{2}}{.01}$} & \multirow{2}{*}{$\begin{array}{c}F(\mathrm{df}) \\
2.73(2,479)\end{array}$} \\
\hline 1 & (Constant) & & & & \\
\hline & Gender & -.61 & .07 & & \\
\hline & Age & -.09 & .11 & & \\
\hline $2 * * *$ & (Constant) & 7.77 & .001 & .08 & $3.46(12,467)$ \\
\hline & Gender & -.86 & .02 & & \\
\hline & Age & -.06 & .27 & & \\
\hline & Social Support Past Total Score & .12 & .58 & & \\
\hline & Social Support Present Total Score & -.46 & .06 & & \\
\hline & $\begin{array}{l}\text { Attachment Style Questionnaire-Need for } \\
\text { Approval subscale }\end{array}$ & -.004 & .89 & & \\
\hline & $\begin{array}{l}\text { Attachment Style Questionnaire-Discomfort } \\
\text { with closeness subscale }\end{array}$ & .03 & .24 & & \\
\hline & Physical Neglect Scale Total Score & .02 & .84 & & \\
\hline & $\begin{array}{l}\text { Perceived Social Support Friends Centered } \\
\quad \text { Score }\end{array}$ & .11 & .01 & & \\
\hline & $\begin{array}{l}\text { Perceived Social Support Family Centered } \\
\text { Score }\end{array}$ & -.004 & .91 & & \\
\hline & $\begin{array}{l}\text { Parentification Questionnaire Total } \\
\quad \text { Centered Score }\end{array}$ & -.03 & .32 & & \\
\hline & Locus of Control Centered Score & .05 & .27 & & \\
\hline & $\begin{array}{l}\text { ASQ Relationships as Secondary Subscale } \\
\text { Centered Score }\end{array}$ & .02 & .56 & & \\
\hline & ASQ Confidence Subscale Centered Score & .06 & .14 & & \\
\hline
\end{tabular}

(table continues) 
Table 35 (continued)

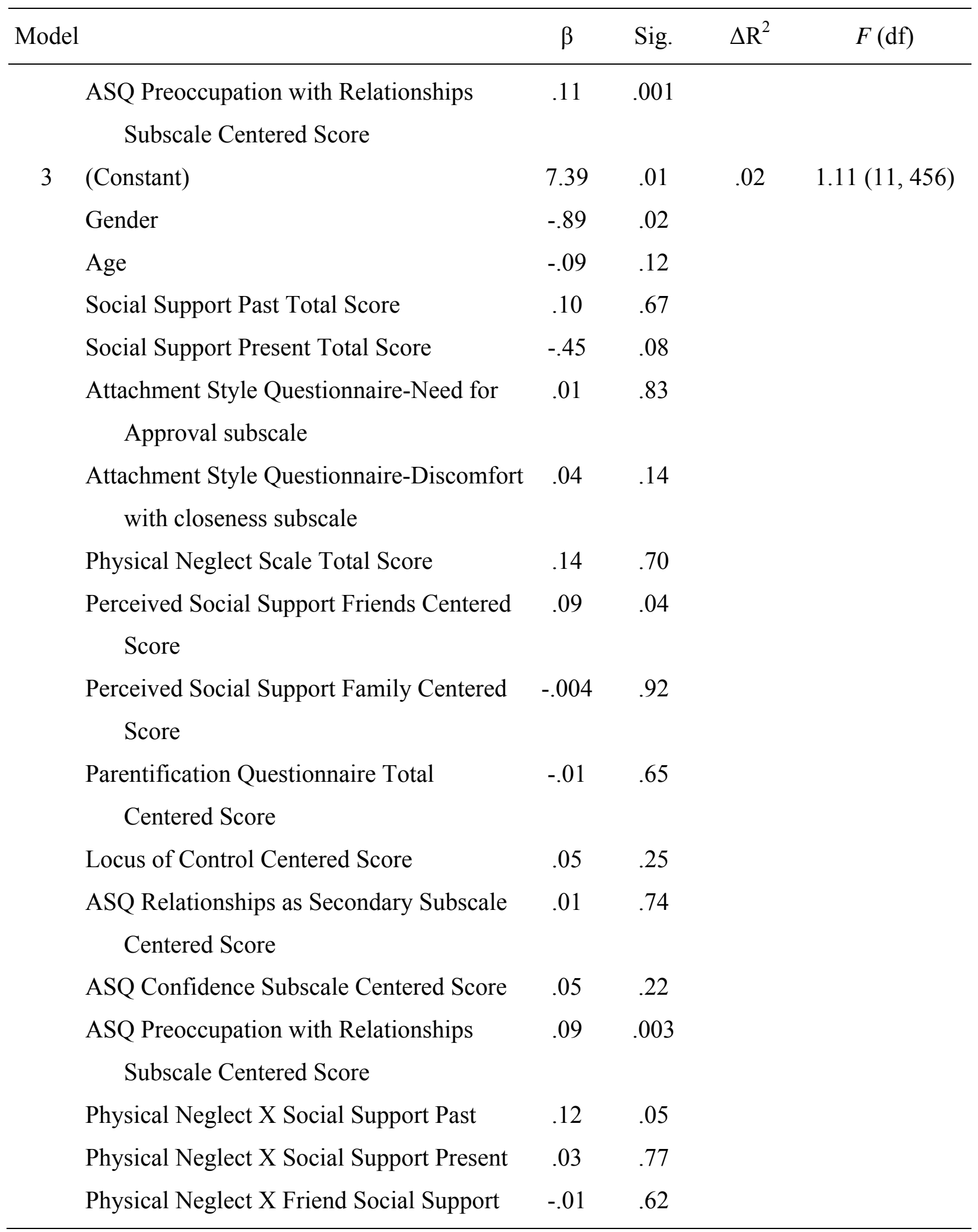

(table continues) 
Table 35 (continued)

\begin{tabular}{lcccc}
\hline Model & $\beta$ & Sig. & $\Delta \mathrm{R}^{2}$ & $F(\mathrm{df})$ \\
\hline Physical Neglect X Family Social Support & .008 & .67 & \\
Physical Neglect X Parentification & -.02 & .16 & \\
Physical Neglect X Locus of Control & -.02 & .43 & \\
Physical Neglect X ASQ Need for Approval & .00002 & 1.0 & \\
Physical Neglect X ASQ Relationships as & -.03 & .22 & \\
$\quad$ Secondary & & & \\
Physical Neglect X ASQ Preoccupation & .01 & .66 \\
$\quad$ with Relationships & & & \\
Physical Neglect X ASQ Confidence & .01 & .46 \\
Physical Neglect X Discomfort with & .02 & .21 \\
$\quad$ Closeness & &
\end{tabular}

Note. ${ }^{* * *} p<.001 ; \mathrm{ASQ}=$ Attachment Style Questionnaire. 
Table 36

Hierarchical Regression Analysis Evaluating the Moderating Effects of Social Support, Parentification, Locus of Control, and Attachment Styles on DUSI Overall Problems Resulting from Physical Neglect

\begin{tabular}{|c|c|c|c|c|c|}
\hline \multicolumn{2}{|c|}{ Model } & \multirow{2}{*}{$\frac{B}{24.06}$} & \multirow{2}{*}{$\begin{array}{l}\text { Sig. } \\
.001\end{array}$} & \multirow{2}{*}{$\frac{\Delta \mathrm{R}^{2}}{.003}$} & \multirow{2}{*}{$\begin{array}{c}F(\mathrm{df}) \\
.66(2,479)\end{array}$} \\
\hline 1 & (Constant) & & & & \\
\hline & Gender & -.62 & .58 & & \\
\hline & Age & .17 & .33 & & \\
\hline $2 * * *$ & (Constant) & 25.28 & .001 & .39 & $25.25(12,467)$ \\
\hline & Gender & -1.58 & .10 & & \\
\hline & Age & .14 & .33 & & \\
\hline & Social Support Past Total Score & .39 & .51 & & \\
\hline & Social Support Present Total Score & -1.53 & .02 & & \\
\hline & $\begin{array}{l}\text { Attachment Style Questionnaire-Need for } \\
\text { Approval subscale }\end{array}$ & .03 & .75 & & \\
\hline & $\begin{array}{l}\text { Attachment Style Questionnaire-Discomfort } \\
\text { with closeness subscale }\end{array}$ & .16 & .01 & & \\
\hline & Physical Neglect Scale Total Score & .31 & .20 & & \\
\hline & $\begin{array}{l}\text { Perceived Social Support Friends Centered } \\
\quad \text { Score }\end{array}$ & .09 & .45 & & \\
\hline & $\begin{array}{l}\text { Perceived Social Support Family Centered } \\
\quad \text { Score }\end{array}$ & -.19 & .03 & & \\
\hline & $\begin{array}{l}\text { Parentification Questionnaire Total } \\
\quad \text { Centered Score }\end{array}$ & -.27 & .001 & & \\
\hline & Locus of Control Centered Score & .38 & .001 & & \\
\hline & $\begin{array}{l}\text { ASQ Relationships as Secondary Subscale } \\
\text { Centered Score }\end{array}$ & -.03 & .77 & & \\
\hline & ASQ Confidence Subscale Centered Score & -.10 & .35 & & \\
\hline
\end{tabular}


Table 36 (continued)

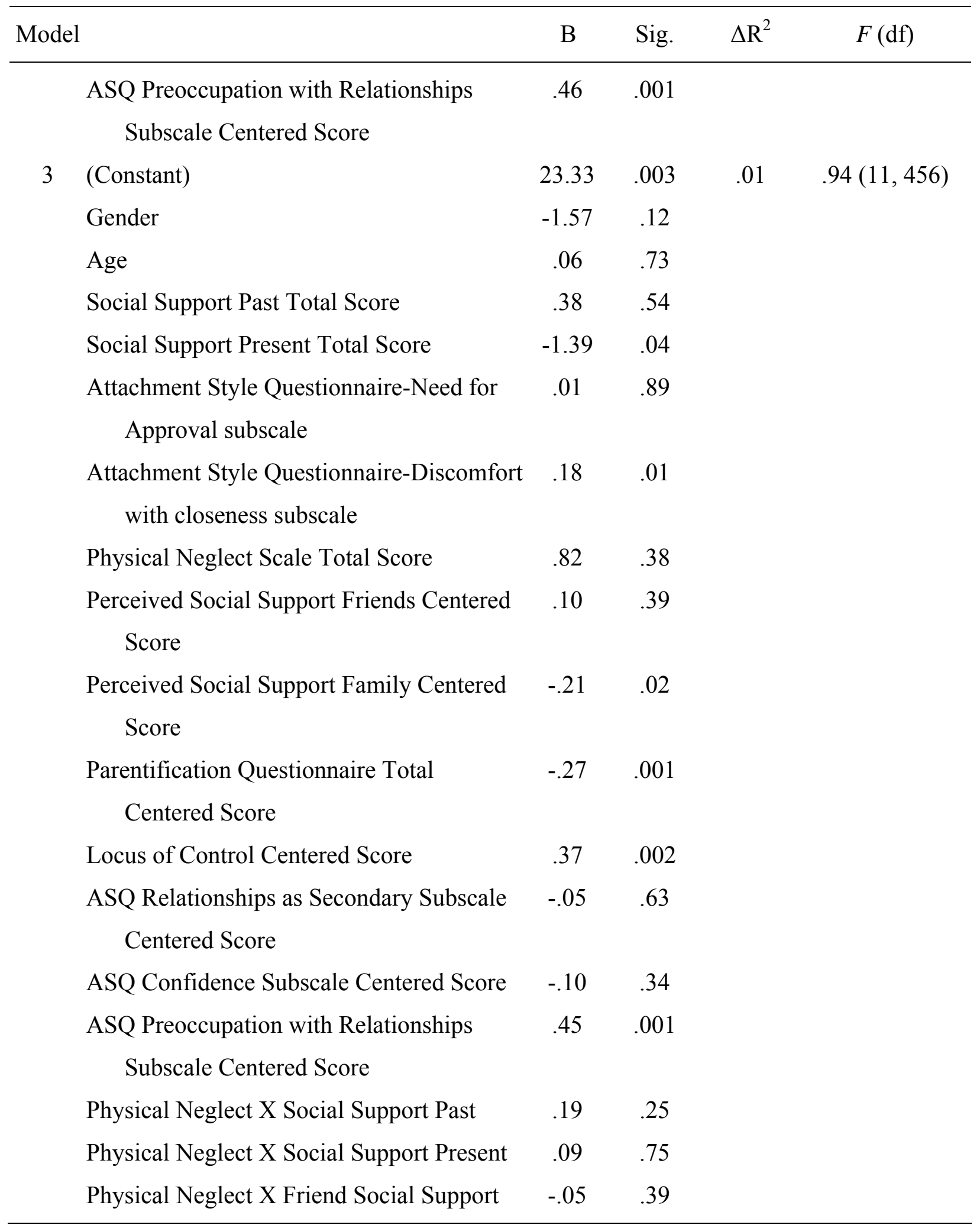


Table 36 (continued)

\begin{tabular}{|c|c|c|c|c|}
\hline Model & B & Sig. & $\Delta \mathrm{R}^{2}$ & $F(\mathrm{df})$ \\
\hline Physical Neglect X Family Social Support & .06 & .19 & & \\
\hline Physical Neglect X Parentification & .003 & .95 & & \\
\hline Physical Neglect X Locus of Control & .04 & .50 & & \\
\hline Physical Neglect X ASQ Need for Approval & -.004 & .93 & & \\
\hline $\begin{array}{l}\text { Physical Neglect X ASQ Relationships as } \\
\text { Secondary }\end{array}$ & -.07 & .26 & & \\
\hline $\begin{array}{l}\text { Physical Neglect X ASQ Preoccupation } \\
\text { with Relationships }\end{array}$ & .001 & .98 & & \\
\hline Physical Neglect X ASQ Confidence & .01 & .87 & & \\
\hline $\begin{array}{l}\text { Physical Neglect X Discomfort with } \\
\text { Closeness }\end{array}$ & .06 & .13 & & \\
\hline
\end{tabular}

Note. ${ }^{* * *} p<.001 ; \mathrm{ASQ}=$ Attachment Style Questionnaire. 
Table 37

Hierarchical Regression Analysis Evaluating the Moderating Effects of Social Support, Parentification, Locus of Control, and Attachment Styles on Permissiveness Resulting from

Physical Neglect

\begin{tabular}{|c|c|c|c|c|c|}
\hline \multicolumn{2}{|c|}{ Model } & \multirow{2}{*}{$\frac{\beta}{3.27}$} & \multirow{2}{*}{$\begin{array}{l}\text { Sig. } \\
.001\end{array}$} & \multirow{2}{*}{$\frac{\Delta \mathrm{R}^{2}}{.21}$} & \multirow{2}{*}{$\begin{array}{c}F(\mathrm{df}) \\
64.86(2,476)\end{array}$} \\
\hline $1 * * *$ & (Constant) & & & & \\
\hline & Gender & .67 & .001 & & \\
\hline & Age & -.01 & .18 & & \\
\hline $2 * * *$ & (Constant) & 3.46 & .001 & .07 & $3.46(12,464)$ \\
\hline & Gender & .68 & .001 & & \\
\hline & Age & -.01 & .25 & & \\
\hline & Social Support Past Total Score & -.02 & .96 & & \\
\hline & Social Support Present Total Score & -.01 & .77 & & \\
\hline & Parentification Questionnaire Total Score & .01 & .11 & & \\
\hline & Attachment Style Questionnaire-Need for & .002 & .68 & & \\
\hline \multicolumn{6}{|c|}{ Approval subscale } \\
\hline & $\begin{array}{l}\text { Attachment Style Questionnaire-Discomfort } \\
\text { with closeness subscale }\end{array}$ & -.01 & .02 & & \\
\hline & Physical Neglect Scale Total Score & -.01 & .48 & & \\
\hline \multicolumn{5}{|c|}{ Score } & \\
\hline \multicolumn{5}{|c|}{ Score } & \\
\hline & Locus of Control Centered Score & -.02 & .03 & & \\
\hline & ASQ Relationships as Secondary Subscale & -.01 & .10 & & \\
\hline \multicolumn{6}{|c|}{ Centered Score } \\
\hline & ASQ Confidence Subscale Centered Score & -.01 & .04 & & \\
\hline
\end{tabular}

(table continues) 
Table 37 (continued)

\begin{tabular}{|c|c|c|c|c|c|}
\hline \multicolumn{2}{|c|}{ Model } & \multirow{2}{*}{$\begin{array}{c}\mathrm{B} \\
-.004\end{array}$} & \multirow{2}{*}{$\begin{array}{r}\text { Sig. } \\
.41\end{array}$} & \multirow[t]{2}{*}{$\Delta \mathrm{R}^{2}$} & \multirow[t]{2}{*}{$F(\mathrm{df})$} \\
\hline & $\begin{array}{l}\text { ASQ Preoccupation with Relationships } \\
\text { Subscale Centered Score }\end{array}$ & & & & \\
\hline \multirow[t]{20}{*}{$3 *$} & (Constant) & 3.06 & .001 & .04 & $2.09(11,453)$ \\
\hline & Gender & .71 & .001 & & \\
\hline & Age & -.01 & .53 & & \\
\hline & Social Support Past Total Score & .003 & .94 & & \\
\hline & Social Support Present Total Score & -.04 & .39 & & \\
\hline & Parentification Questionnaire Total Score & .01 & .30 & & \\
\hline & $\begin{array}{l}\text { Attachment Style Questionnaire-Need for } \\
\text { Approval subscale }\end{array}$ & .002 & .78 & & \\
\hline & $\begin{array}{l}\text { Attachment Style Questionnaire-Discomfort } \\
\text { with closeness subscale }\end{array}$ & -.01 & .003 & & \\
\hline & Physical Neglect Scale Total Score & .08 & .190 & & \\
\hline & $\begin{array}{l}\text { Perceived Social Support Friends Centered } \\
\text { Score }\end{array}$ & -.01 & .46 & & \\
\hline & $\begin{array}{l}\text { Perceived Social Support Family Centered } \\
\text { Score }\end{array}$ & .01 & .03 & & \\
\hline & Locus of Control Centered Score & -.02 & .03 & & \\
\hline & $\begin{array}{l}\text { ASQ Relationships as Secondary Subscale } \\
\text { Centered Score }\end{array}$ & -.01 & .35 & & \\
\hline & ASQ Confidence Subscale Centered Score & -.02 & .02 & & \\
\hline & ASQ Preoccupation with Relationships & -.003 & .56 & & \\
\hline & Subscale Centered Score & & & & \\
\hline & Physical Neglect X Social Support Past & -.03 & .01 & & \\
\hline & Physical Neglect X Social Support Present & -.02 & .37 & & \\
\hline & Physical Neglect X Friend Social Support & -.001 & .87 & & \\
\hline & Physical Neglect X Family Social Support & .002 & .48 & & \\
\hline
\end{tabular}


Table 37 (continued)

\begin{tabular}{|c|c|c|c|c|}
\hline Model & $\mathrm{B}$ & Sig. & $\Delta \mathrm{R}^{2}$ & $F(\mathrm{df})$ \\
\hline Physical Neglect X Parentification & .003 & .19 & & \\
\hline Physical Neglect X Locus of Control & .001 & .88 & & \\
\hline Physical Neglect X ASQ Need for Approval & -.01 & .05 & & \\
\hline $\begin{array}{l}\text { Physical Neglect X ASQ Relationships as } \\
\text { Secondary }\end{array}$ & .01 & .01 & & \\
\hline $\begin{array}{l}\text { Physical Neglect X ASQ Preoccupation } \\
\text { with Relationships }\end{array}$ & .004 & .06 & & \\
\hline Physical Neglect X ASQ Confidence & -.002 & .52 & & \\
\hline $\begin{array}{l}\text { Physical Neglect X Discomfort with } \\
\text { Closeness }\end{array}$ & -.01 & .004 & & \\
\hline
\end{tabular}

Note. ${ }^{* *} p<.001, * p<.05$; ASQ $=$ Attachment Style Questionnaire. 
Table 38

Hierarchical Regression Analysis Evaluating the Moderating Effects of Social Support, Parentification, Locus of Control, and Attachment Styles on Depression Resulting from Physical Neglect

\begin{tabular}{lcccc}
\hline Model & $\beta$ & Sig. & $\Delta \mathrm{R}^{2}$ & $F(\mathrm{df})$ \\
\hline $1^{* * *}$ (Constant) & -4.70 & .19 & .05 & $11.15(2,477)$ \\
Gender & 3.30 & .001 & & \\
Age & .45 & .01 & & \\
$2^{* * *}$ (Constant) & 6.40 & .25 & .37 & $24.76(12,465)$ \\
Gender & 2.89 & .001 & & \\
Age & .39 & .003 & & \\
Social Support Past Total Score & .13 & .77 & & \\
Social Support Present Total Score & -.86 & .07 & & \\
Attachment Style Questionnaire- & -.15 & .03 & & \\
$\quad$ Relationships as Secondary subscale & & & & \\
Attachment Style Questionnaire-Discomfort & .11 & .02 & & \\
$\quad$ with closeness subscale & & & & \\
Attachment Style Questionnaire-Confidence & -.30 & .001 & & \\
$\quad$ subscale & & & & \\
Physical Neglect Scale Total Score & .04 & .82 & \\
Perceived Social Support Friends Centered & -.04 & .60 & \\
$\quad$ Score & & & .13 &
\end{tabular}

(table continued) 
Table 38 (continued)

\begin{tabular}{|c|c|c|c|c|c|}
\hline \multicolumn{2}{|c|}{ Model } & \multirow{2}{*}{$\begin{array}{l}\mathrm{B} \\
.24\end{array}$} & \multirow{2}{*}{$\begin{array}{l}\text { Sig. } \\
.001\end{array}$} & \multirow[t]{2}{*}{$\Delta \mathrm{R}^{2}$} & \multirow[t]{2}{*}{$F(\mathrm{df})$} \\
\hline & $\begin{array}{l}\text { ASQ Need for Approval Subscale Centered } \\
\text { Score }\end{array}$ & & & & \\
\hline & $\begin{array}{l}\text { ASQ Preoccupation with Relationships } \\
\text { Subscale Centered Score }\end{array}$ & .13 & .02 & & \\
\hline 3 & (Constant) & 3.71 & .60 & .02 & $1.10(11,454)$ \\
\hline & Gender & 2.82 & .001 & & \\
\hline & Age & .35 & .01 & & \\
\hline & Social Support Past Total Score & .19 & .68 & & \\
\hline & Social Support Present Total Score & -.96 & .06 & & \\
\hline & $\begin{array}{l}\text { Attachment Style Questionnaire- } \\
\text { Relationships as Secondary subscale }\end{array}$ & -.19 & .01 & & \\
\hline & $\begin{array}{l}\text { Attachment Style Questionnaire-Discomfort } \\
\text { with closeness subscale }\end{array}$ & .12 & .01 & & \\
\hline & $\begin{array}{l}\text { Attachment Style Questionnaire-Confidence } \\
\text { subscale }\end{array}$ & -.28 & .001 & & \\
\hline & Physical Neglect Scale Total Score & .65 & .38 & & \\
\hline & $\begin{array}{l}\text { Perceived Social Support Friends Centered } \\
\text { Score }\end{array}$ & -.04 & .69 & & \\
\hline & $\begin{array}{l}\text { Perceived Social Support Family Centered } \\
\quad \text { Score }\end{array}$ & -.13 & .06 & & \\
\hline & $\begin{array}{l}\text { Parentification Questionnaire Total } \\
\quad \text { Centered Score }\end{array}$ & -.10 & .08 & & \\
\hline & Locus of Control Centered Score & .12 & .19 & & \\
\hline & $\begin{array}{l}\text { ASQ Need for Approval Subscale Centered } \\
\text { Score }\end{array}$ & .23 & .001 & & \\
\hline & $\begin{array}{l}\text { ASQ Preoccupation with Relationships } \\
\text { Subscale Centered Score }\end{array}$ & .14 & .02 & & \\
\hline
\end{tabular}

(table continues) 
Table 38 (continued)

\begin{tabular}{lcccc}
\hline Model & B & Sig. & $\Delta \mathrm{R}^{2}$ & $F(\mathrm{df})$ \\
\hline Physical Neglect X Social Support Past & -.04 & .73 & \\
Physical Neglect X Social Support Present & -.07 & .76 & \\
Physical Neglect X Friend Social Support & -.05 & .33 & \\
Physical Neglect X Family Social Support & .04 & .31 & \\
Physical Neglect X Parentification & .01 & .78 \\
Physical Neglect X Locus of Control & -.04 & .42 \\
Physical Neglect X ASQ Need for Approval & -.03 & .44 \\
Physical Neglect X ASQ Relationships as & -.08 & .11 & \\
Secondary & & & \\
Physical Neglect X ASQ Preoccupation & .05 & .05 \\
$\quad$ with Relationships & & \\
Physical Neglect X ASQ Confidence & -.02 & .62 \\
Physical Neglect X Discomfort with & .04 & .26 \\
Closeness & & \\
\hline
\end{tabular}

Note. ${ }^{* * *} p<.001 ; \mathrm{ASQ}=$ Attachment Style Questionnaire. 
Table 39

Hierarchical Regression Analysis Evaluating the Moderating Effects of Social Support, Parentification, Locus of Control, and Attachment Styles on Anxiety Resulting from Physical Neglect

\begin{tabular}{lcccc}
\hline Model & B & Sig. & $\Delta \mathrm{R}^{2}$ & $F(\mathrm{df})$ \\
\hline $1^{* * *}$ (Constant) & -5.66 & .11 & .05 & $12.70(2,476)$ \\
Gender & 3.61 & .001 & & \\
Age & .43 & .01 & & \\
$2^{* * *}$ (Constant) & -14.56 & .01 & .17 & $8.15(12,464)$ \\
Gender & 2.81 & .001 & & \\
Age & .42 & .004 & & \\
Social Support Past Total Score & -.48 & .33 & & \\
Social Support Present Total Score & .30 & .59 & & \\
Parentification Questionnaire Total Score & -.08 & .19 & & \\
Attachment Style Questionnaire-Need for & .05 & .51 & & \\
$\quad$ Approval subscale & & & & \\
Attachment Style Questionnaire-Discomfort & .13 & .02 & & \\
$\quad$ with closeness subscale & & & & \\
Attachment Style Questionnaire- & .24 & .001 & & \\
$\quad$ Preoccupation with Relationships & & & & \\
$\quad$ subscale & & & & \\
Physical Neglect Scale Total Score & .20 & .34 & \\
Perceived Social Support Friends Centered & -.05 & .61 & \\
$\quad$ Score & & & .09 & \\
$\quad$ Perceived Social Support Family Centered & -.05 & .50 & \\
$\quad$ Score & & & & \\
Locus of Control Centered Score & .17 & .09 & \\
\hline
\end{tabular}


Table 39 (continued)

\begin{tabular}{lcccc}
\hline Model & $\mathrm{B}$ & Sig. & $\Delta \mathrm{R}^{2}$ & $F(\mathrm{df})$ \\
\hline ASQ Relationships as Secondary Subscale & -.19 & .02 & & \\
$\quad$ Centered Score & & & & \\
ASQ Confidence Subscale Centered Score & -.02 & .81 & & $.73(11,453)$ \\
3 (Constant) & -13.46 & .07 & .01 & \\
Gender & 2.50 & .004 & \\
Age & .37 & .02 & \\
Social Support Past Total Score & -.36 & .49 & \\
Social Support Present Total Score & .26 & .65 & \\
Parentification Questionnaire Total Score & -.08 & .20 & \\
Attachment Style Questionnaire-Need for & .05 & .53 & \\
$\quad$ Approval subscale & & & \\
Attachment Style Questionnaire-Discomfort & .15 & .01 & \\
$\quad$ with closeness subscale & & & \\
Attachment Style Questionnaire- & .24 & .001 & \\
$\quad$ Preoccupation with Relationships & & & & \\
$\quad$ subscale & & & &
\end{tabular}

(table continues) 
Table 39 (continued)

\begin{tabular}{lcccc}
\hline Model & B & Sig. & $\Delta \mathrm{R}^{2}$ & $F(\mathrm{df})$ \\
\hline Physical Neglect X Friend Social Support & -.01 & .92 & \\
Physical Neglect X Family Social Support & .02 & .66 & \\
Physical Neglect X Parentification & -.01 & .85 & \\
Physical Neglect X Locus of Control & -.04 & .44 & \\
Physical Neglect X ASQ Need for Approval & .01 & .83 \\
Physical Neglect X ASQ Relationships as & -.11 & .05 \\
$\quad$ Secondary & & \\
Physical Neglect X ASQ Preoccupation & .003 & .92 \\
$\quad$ with Relationships & & & \\
Physical Neglect X ASQ Confidence & -.02 & .70 \\
Physical Neglect X Discomfort with & .06 & .13 \\
Closeness & & \\
\hline
\end{tabular}

Note. ${ }^{* * *} p<.001 ; \mathrm{ASQ}=$ Attachment Style Questionnaire. 
Table 40

Hierarchical Regression Analysis Evaluating the Moderating Effects of Social Support, Parentification, Locus of Control, and Attachment Styles on Social Anxiety Resulting from

Physical Neglect

\begin{tabular}{|c|c|c|c|c|c|}
\hline \multicolumn{2}{|l|}{ Model } & \multirow{2}{*}{$\frac{\beta}{62.52}$} & \multirow{2}{*}{$\begin{array}{l}\text { Sig. } \\
.001\end{array}$} & \multirow{2}{*}{$\frac{\Delta \mathrm{R}^{2}}{.002}$} & \multirow{2}{*}{$\frac{F(\mathrm{df})}{.36(2,476)}$} \\
\hline 1 & (Constant) & & & & \\
\hline & Gender & 2.35 & .51 & & \\
\hline & Age & .41 & .55 & & \\
\hline $2 * * *$ & (Constant) & 54.75 & .004 & .38 & $23.36(12,464)$ \\
\hline & Gender & 2.09 & .51 & & \\
\hline & Age & .06 & .92 & & \\
\hline & Social Support Past Total Score & -4.78 & .01 & & \\
\hline & Parentification Questionnaire Total Score & .30 & .21 & & \\
\hline & $\begin{array}{l}\text { Attachment Style Questionnaire-Need for } \\
\text { Approval subscale }\end{array}$ & 1.61 & .001 & & \\
\hline & Social Support Present Centered Score & 5.26 & .01 & & \\
\hline & $\begin{array}{l}\text { Perceived Social Support Friends Centered } \\
\text { Score }\end{array}$ & -1.04 & .01 & & \\
\hline & $\begin{array}{l}\text { Perceived Social Support Family Centered } \\
\text { Score }\end{array}$ & .49 & .09 & & \\
\hline & Locus of Control Centered Score & .98 & .01 & & \\
\hline & $\begin{array}{l}\text { ASQ Relationships as Secondary Subscale } \\
\text { Centered Score }\end{array}$ & .62 & .05 & & \\
\hline & $\begin{array}{l}\text { ASQ Discomfort with Closeness Subscale } \\
\text { Centered Score }\end{array}$ & .01 & .97 & & \\
\hline & ASQ Confidence Subscale Centered Score & -1.72 & .001 & & \\
\hline & $\begin{array}{l}\text { ASQ Preoccupation with Relationships } \\
\text { Subscale Centered Score }\end{array}$ & .21 & .42 & & \\
\hline
\end{tabular}


Table 40 (continued)

\begin{tabular}{lcccc}
\hline Model & B & Sig. & $\Delta \mathrm{R}^{2}$ & $F(\mathrm{df})$ \\
\hline Physical Neglect Centered & .43 & .58 & & \\
(Constant) & 66.85 & .001 & .02 & $.99(11.453)$ \\
Gender & 1.58 & .63 & & \\
Age & .01 & 1.00 & & \\
Social Support Past Total Score & -5.88 & .004 & \\
Parentification Questionnaire Total Score & .26 & .28 & \\
Attachment Style Questionnaire-Need for & 1.49 & .001 & \\
$\quad$ Approval subscale & & & & \\
Social Support Present Centered Score & 5.07 & .02 & \\
Perceived Social Support Friends Centered & -.86 & .03 & \\
$\quad$ Score & & & \\
Perceived Social Support Family Centered & .56 & .06 & \\
$\quad$ Score & & & \\
Locus of Control Centered Score & 1.07 & .01 & \\
ASQ Relationships as Secondary Subscale & .71 & .03 & \\
$\quad$ Centered Score & & & .03 & \\
ASQ Discomfort with Closeness Subscale & -.02 & .91 & \\
$\quad$ Centered Score & & & & \\
ASQ Confidence Subscale Centered Score & -1.70 & .001 & \\
ASQ Preoccupation with Relationships & .40 & .15 & \\
$\quad$ Subscale Centered Score & & & \\
Physical Neglect Centered & 3.12 & .37 & \\
Physical Neglect X Social Support Past & -.22 & .68 & \\
Physical Neglect X Social Support Present & -2.36 & .02 & \\
Physical Neglect X Friend Social Support & .27 & .19 & \\
Physical Neglect X Family Social Support & .48 & .01 & \\
Physical Neglect X Parentification & -.10 & .47 & \\
\hline
\end{tabular}

(table continues) 
Table 40 (continued)

\begin{tabular}{lcccc}
\hline Model & B & Sig. & $\Delta \mathrm{R}^{2}$ & $F(\mathrm{df})$ \\
\hline Physical Neglect X Locus of Control & .232 & .27 & \\
Physical Neglect X ASQ Need for Approval & -.158 & .33 & \\
Physical Neglect X ASQ Relationships as & .02 & .92 & \\
$\quad$ Secondary & & & \\
$\quad$ Physical Neglect X ASQ Preoccupation & .04 & .73 \\
$\quad$ with Relationships & & & \\
Physical Neglect X ASQ Confidence & -.17 & .28 & \\
Physical Neglect X Discomfort with & -.09 & .52 & \\
$\quad$ Closeness & &
\end{tabular}

Note. ${ }^{* * *} p<.001 ; \mathrm{ASQ}=$ Attachment Style Questionnaire. 
Table 41

Hierarchical Regression Analysis Evaluating the Moderating Effects of Social Support, Parentification, Locus of Control, and Attachment Styles on Agoraphobia Resulting from

Physical Neglect

\begin{tabular}{|c|c|c|c|c|c|}
\hline \multicolumn{2}{|l|}{ Model } & \multirow{2}{*}{$\beta$} & \multirow{2}{*}{$\begin{array}{l}\text { Sig. } \\
.001\end{array}$} & \multirow{2}{*}{$\frac{\Delta \mathrm{R}^{2}}{.03}$} & \multirow{2}{*}{$\frac{F(\mathrm{df})}{7.17(2.476)}$} \\
\hline $1 * * *$ & (Constant) & & & & \\
\hline & Gender & 4.62 & .001 & & \\
\hline & Age & -.23 & .36 & & \\
\hline $2 * * *$ & (Constant) & 21.50 & .01 & .16 & $7.40(12,464)$ \\
\hline & Gender & 4.74 & .001 & & \\
\hline & Age & -.21 & .38 & & \\
\hline & Social Support Past Total Score & -1.19 & .14 & & \\
\hline & Parentification Questionnaire Total Score & -.10 & .31 & & \\
\hline & $\begin{array}{l}\text { Attachment Style Questionnaire-Need for } \\
\text { Approval subscale }\end{array}$ & \\
\hline & Social Support Present Centered Score & -.10 & .91 & & \\
\hline & \multicolumn{4}{|l|}{ Score } & \\
\hline & $\begin{array}{l}\text { Perceived Social Support Family Centered } \\
\quad \text { Score }\end{array}$ & .19 & .11 & & \\
\hline & Locus of Control Centered Score & .11 & .49 & & \\
\hline & \multicolumn{5}{|l|}{ Centered Score } \\
\hline & \multicolumn{5}{|l|}{ Centered Score } \\
\hline & ASQ Confidence Subscale Centered Score & -.05 & .70 & & \\
\hline & ASQ Preoccupation with Relationships & .31 & .004 & & \\
\hline
\end{tabular}


Table 41 (continued)

\begin{tabular}{|c|c|c|c|c|c|}
\hline \multicolumn{2}{|c|}{ Model } & \multirow{2}{*}{$\begin{array}{l}\mathrm{B} \\
.33\end{array}$} & \multirow{2}{*}{$\begin{array}{r}\text { Sig. } \\
32\end{array}$} & \multirow[t]{2}{*}{$\Delta \mathrm{R}^{2}$} & \multirow[t]{2}{*}{$F(\mathrm{df})$} \\
\hline & Physical Neglect Centered & & & & \\
\hline 3 & (Constant) & 26.17 & .002 & .02 & $.75(11,453)$ \\
\hline & Gender & 4.37 & .001 & & \\
\hline & Age & -.27 & .26 & & \\
\hline & Social Support Past Total Score & -1.61 & .06 & & \\
\hline & Parentification Questionnaire Total Score & -.09 & .39 & & \\
\hline & $\begin{array}{l}\text { Attachment Style Questionnaire-Need for } \\
\text { Approval subscale }\end{array}$ & .24 & .06 & & \\
\hline & Social Support Present Centered Score & .25 & .79 & & \\
\hline & $\begin{array}{l}\text { Perceived Social Support Friends Centered } \\
\text { Score }\end{array}$ & -.13 & .42 & & \\
\hline & $\begin{array}{l}\text { Perceived Social Support Family Centered } \\
\text { Score }\end{array}$ & .22 & .08 & & \\
\hline & Locus of Control Centered Score & .14 & .39 & & \\
\hline & $\begin{array}{l}\text { ASQ Relationships as Secondary Subscale } \\
\text { Centered Score }\end{array}$ & .18 & .18 & & \\
\hline & $\begin{array}{l}\text { ASQ Discomfort with Closeness Subscale } \\
\text { Centered Score }\end{array}$ & .05 & .54 & & \\
\hline & ASQ Confidence Subscale Centered Score & -.03 & .82 & & \\
\hline & ASQ Preoccupation with Relationships & .33 & .004 & & \\
\hline & Subscale Centered Score & & & & \\
\hline & Physical Neglect Centered & .33 & .82 & & \\
\hline & Physical Neglect X Social Support Past & .34 & .14 & & \\
\hline & Physical Neglect X Social Support Present & -.48 & .24 & & \\
\hline & Physical Neglect X Friend Social Support & .07 & .44 & & \\
\hline & Physical Neglect X Family Social Support & .10 & .22 & & \\
\hline & Physical Neglect X Parentification & -.06 & .31 & & \\
\hline
\end{tabular}

(table continues) 
Table 41 (continued)

\begin{tabular}{ccccc}
\hline Model & B & Sig. & $\Delta \mathrm{R}^{2}$ & $F(\mathrm{df})$ \\
\hline Physical Neglect X Locus of Control & -.001 & .99 & & \\
Physical Neglect X ASQ Need for Approval & .01 & .86 & \\
$\quad$ Physical Neglect X ASQ Relationships as & -.03 & .77 & \\
$\quad$ Secondary & & & \\
Physical Neglect X ASQ Preoccupation & -.02 & .68 & \\
$\quad$ with Relationships & & & \\
Physical Neglect X ASQ Confidence & .05 & .46 & \\
Physical Neglect X Discomfort with & .10 & .11 & \\
$\quad$ Closeness & &
\end{tabular}

Note. ${ }^{* * *} p<.001 ; \mathrm{ASQ}=$ Attachment Style Questionnaire. 


\section{List of Figures}

Figure 1. Association of emotional abuse, parentification, and problem behaviors.

Figure 2. Association of emotional abuse, locus of control, and problem behaviors.

Figure 3. Association of emotional abuse, locus of control, and depression.

Figure 4. Association of emotional abuse, locus of control, and agoraphobia.

Figure 5. Association of emotional abuse, social support from friends, and substance use.

Figure 6. Association of physical abuse, social support from friends, and problem behaviors.

Figure 7. Association of physical abuse, locus of control, and problem behaviors.

Figure 8. Association of physical abuse, preoccupation with relationships attachment style, and permissiveness.

Figure 9. Association of physical abuse, need for approval attachment style, and depression.

Figure 10. Association of physical abuse, discomfort with closeness attachment style, and depression.

Figure 11. Association of physical abuse, social support from friends, and anxiety.

Figure 12. Association of physical abuse, need for approval attachment style, and anxiety.

Figure 13. Association of physical abuse, relationships as secondary attachment style, and anxiety.

Figure 14. Association of sexual abuse, confidence attachment style, and permissiveness.

Figure 15. Association of sexual abuse, present social support, and social anxiety.

Figure 16. Association of sexual abuse, present social support, and agoraphobia.

Figure 17. Association of emotional neglect, locus of control, and problem behaviors.

Figure 18. Association of emotional neglect, past social support, and permissiveness.

Figure 19. Association of emotional neglect, need for approval attachment style, and permissiveness.

Figure 20. Association of emotional neglect, discomfort with closeness attachment style, and permissiveness.

Figure 21. Association of emotional neglect, locus of control, and depression.

Figure 22. Association of emotional neglect, locus of control, and agoraphobia.

Figure 23. Association of physical neglect, past social support, and permissiveness.

Figure 24. Association of physical neglect, need for approval attachment style, and permissiveness.

Figure 25. Association of physical neglect, relationships as secondary attachment style, and permissiveness.

Figure 26. Association of physical neglect, discomfort with closeness attachment style, and permissiveness.

Figure 27. Association of physical neglect, relationships as secondary attachment style, and anxiety.

Figure 28. Association of physical neglect, present social support, and social anxiety.

Figure 29. Association of physical neglect, social support from family, and agoraphobia. 
Figure 1. Association of emotional abuse, parentification, and problem behaviors.

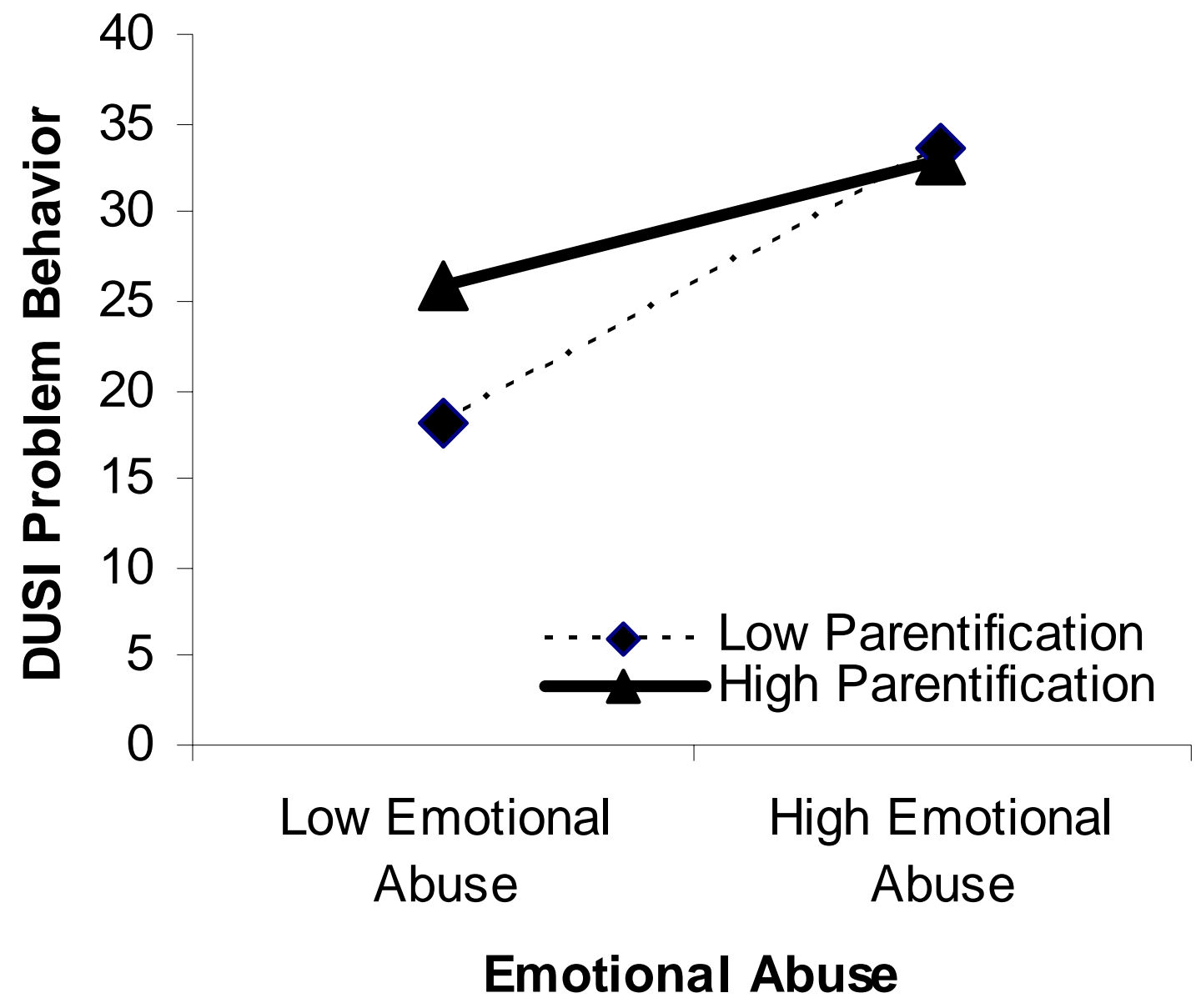


Figure 2. Association of emotional abuse, locus of control, and problem behaviors.

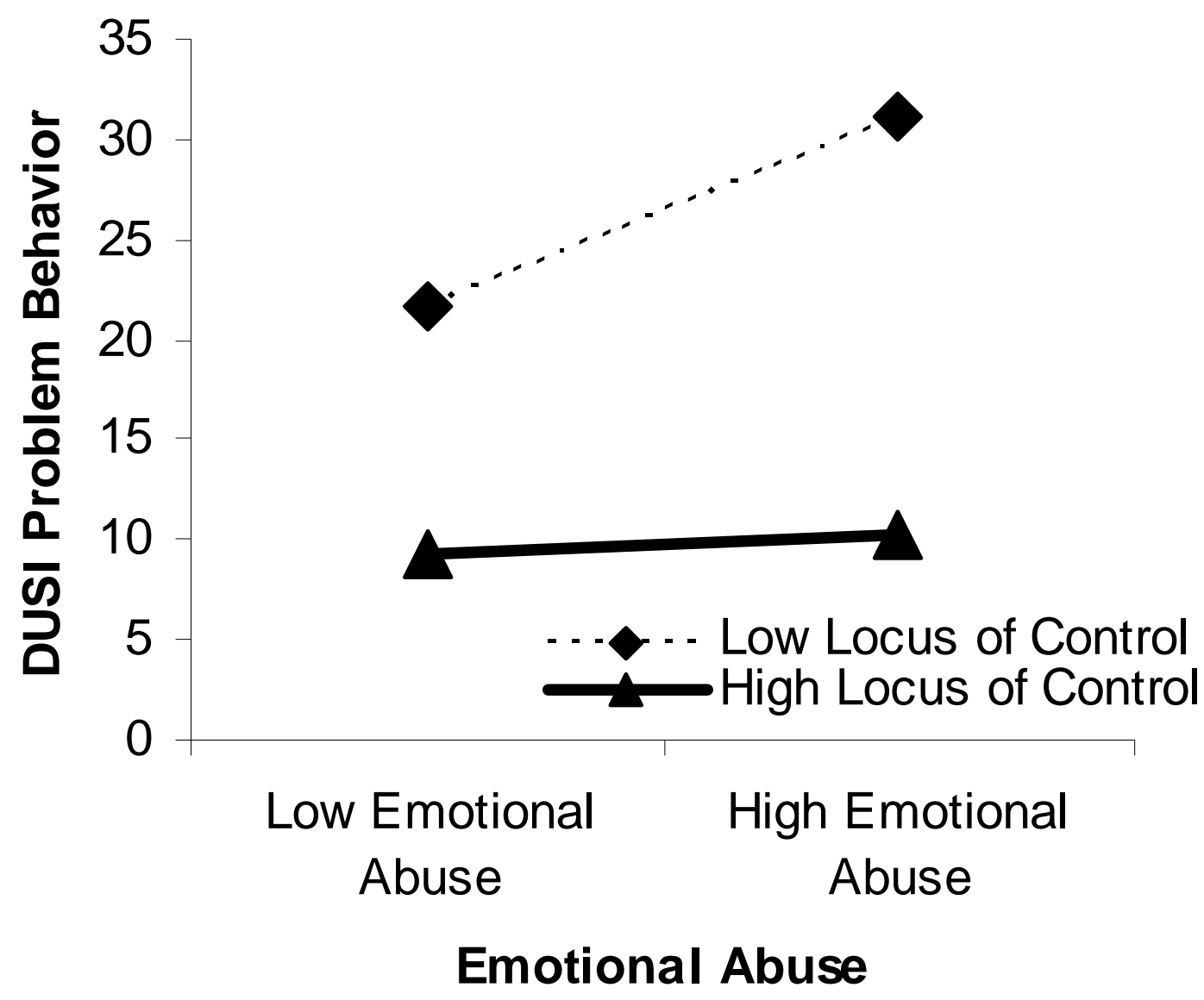


Figure 3. Association of emotional abuse, locus of control, and depression.

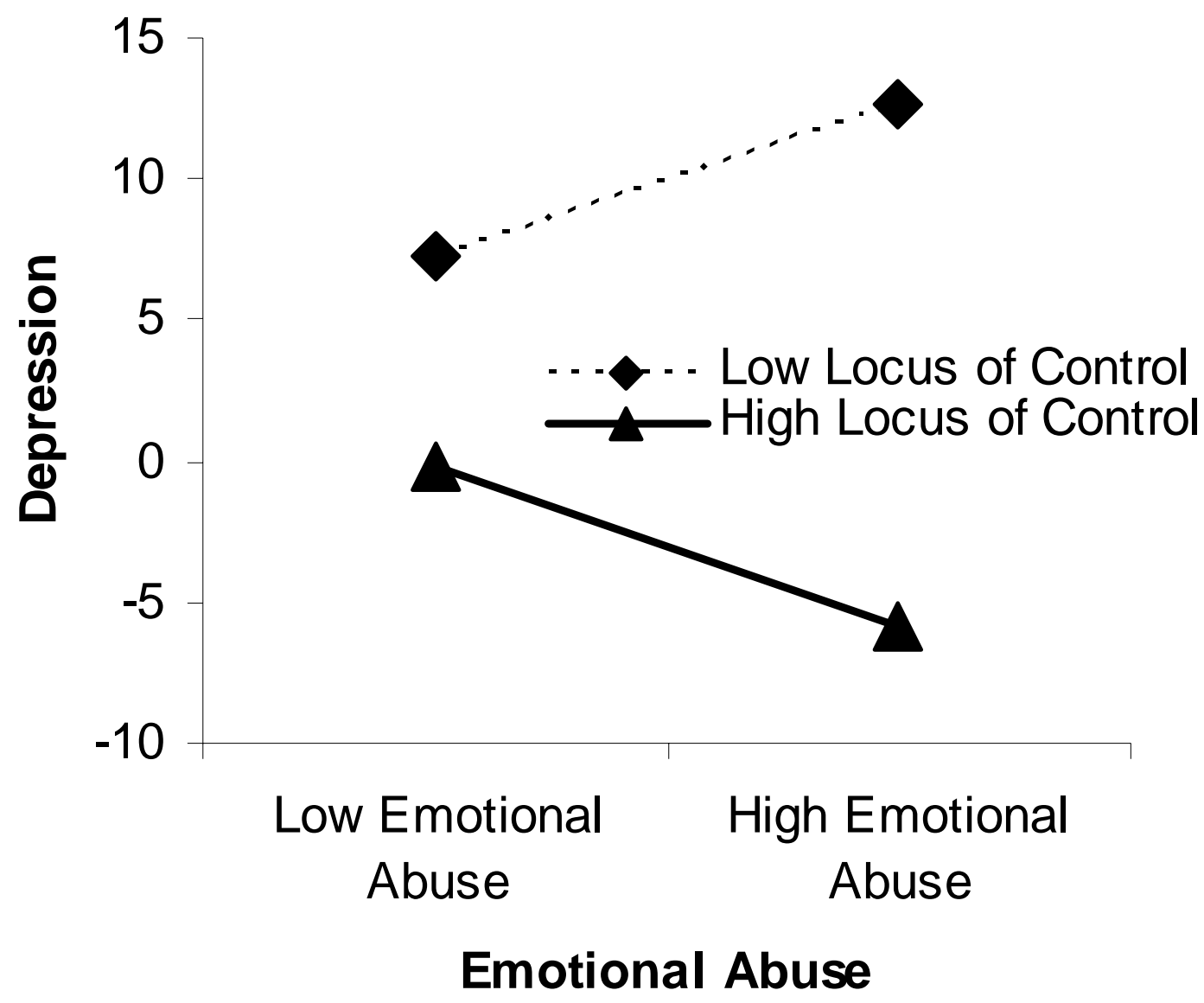


Figure 4. Association of emotional abuse, locus of control, and agoraphobia.

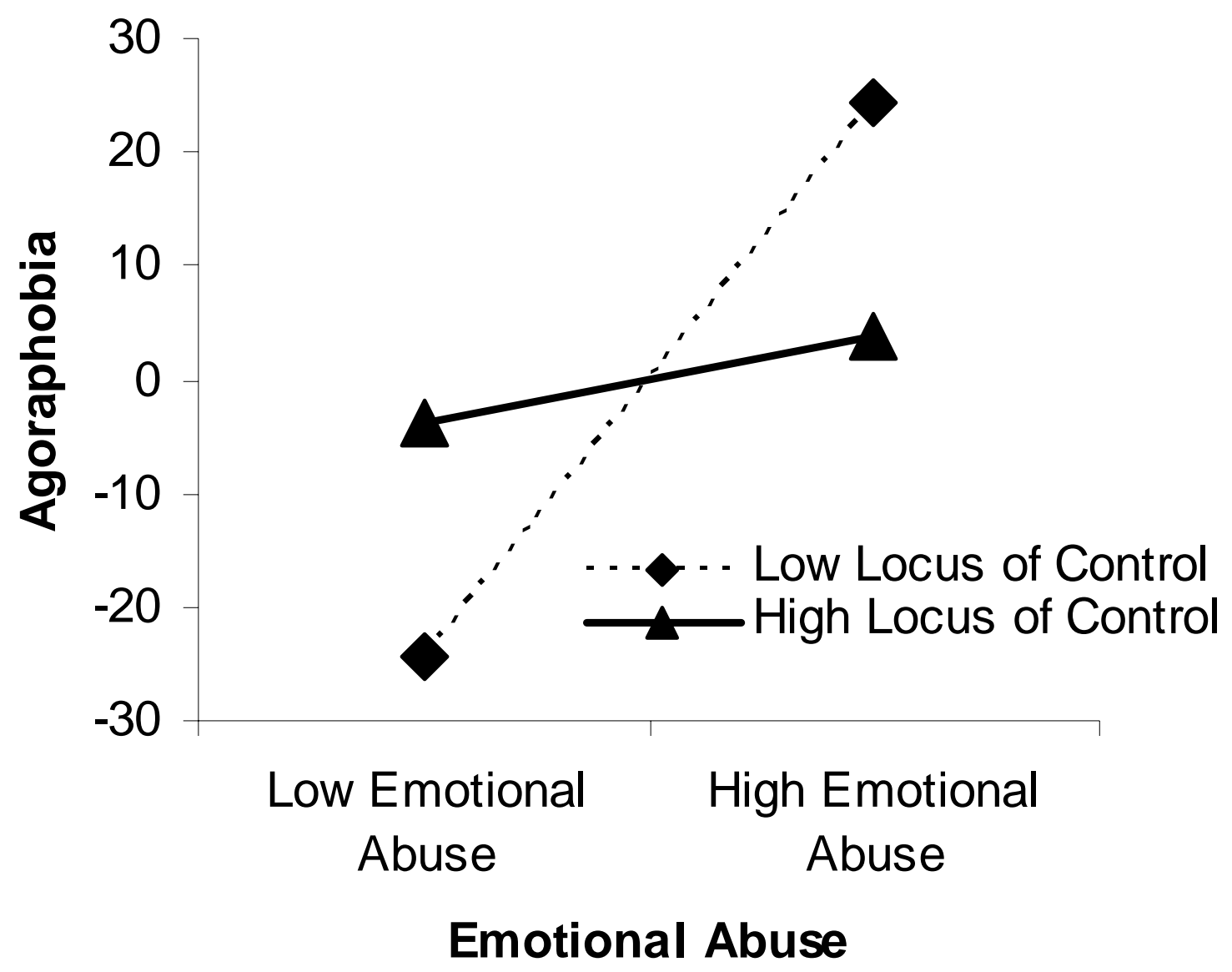


Figure 5. Association of emotional abuse, social support from friends, and substance use.

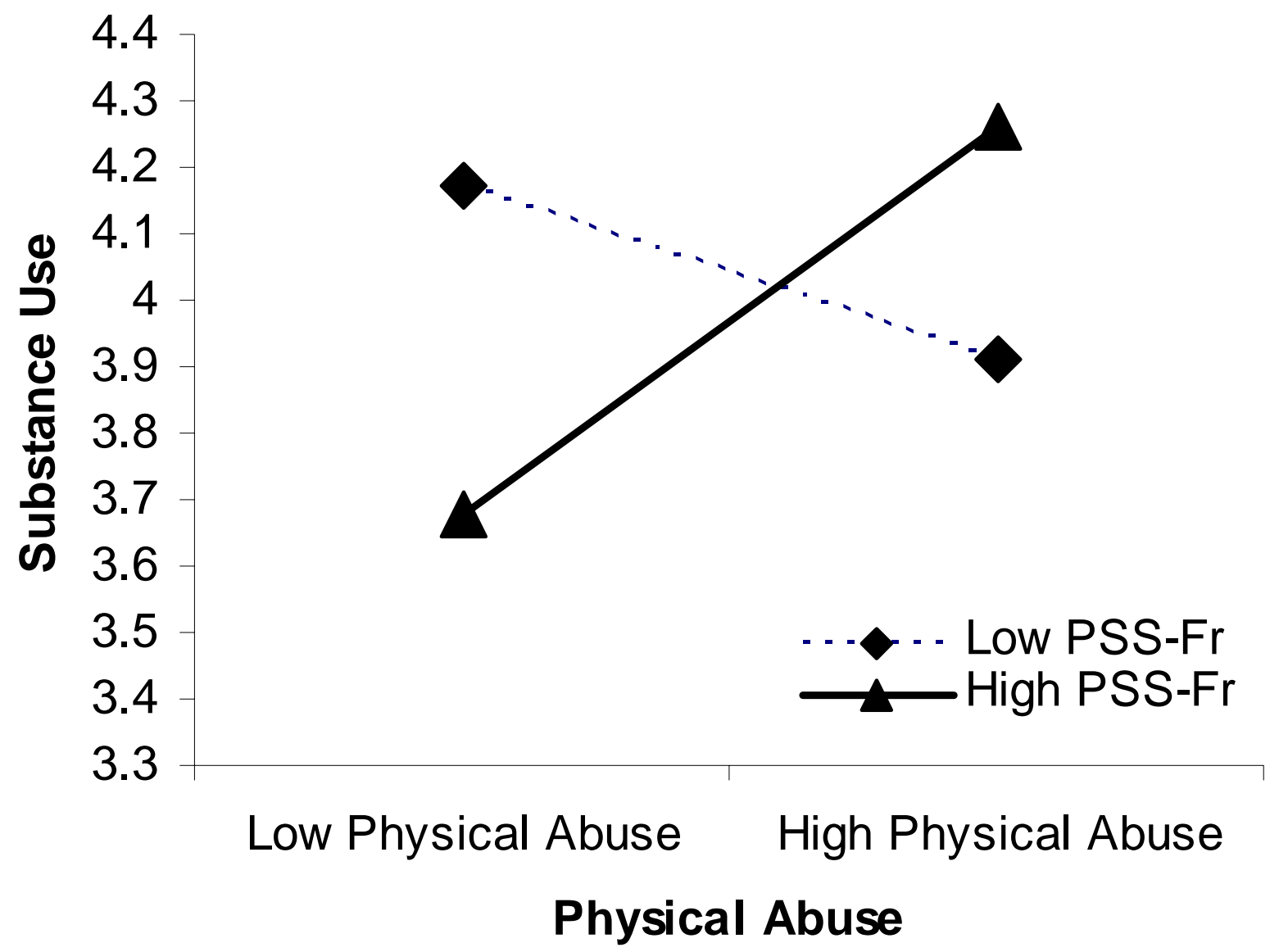


Figure 6. Association of physical abuse, social support from friends, and problem behaviors.

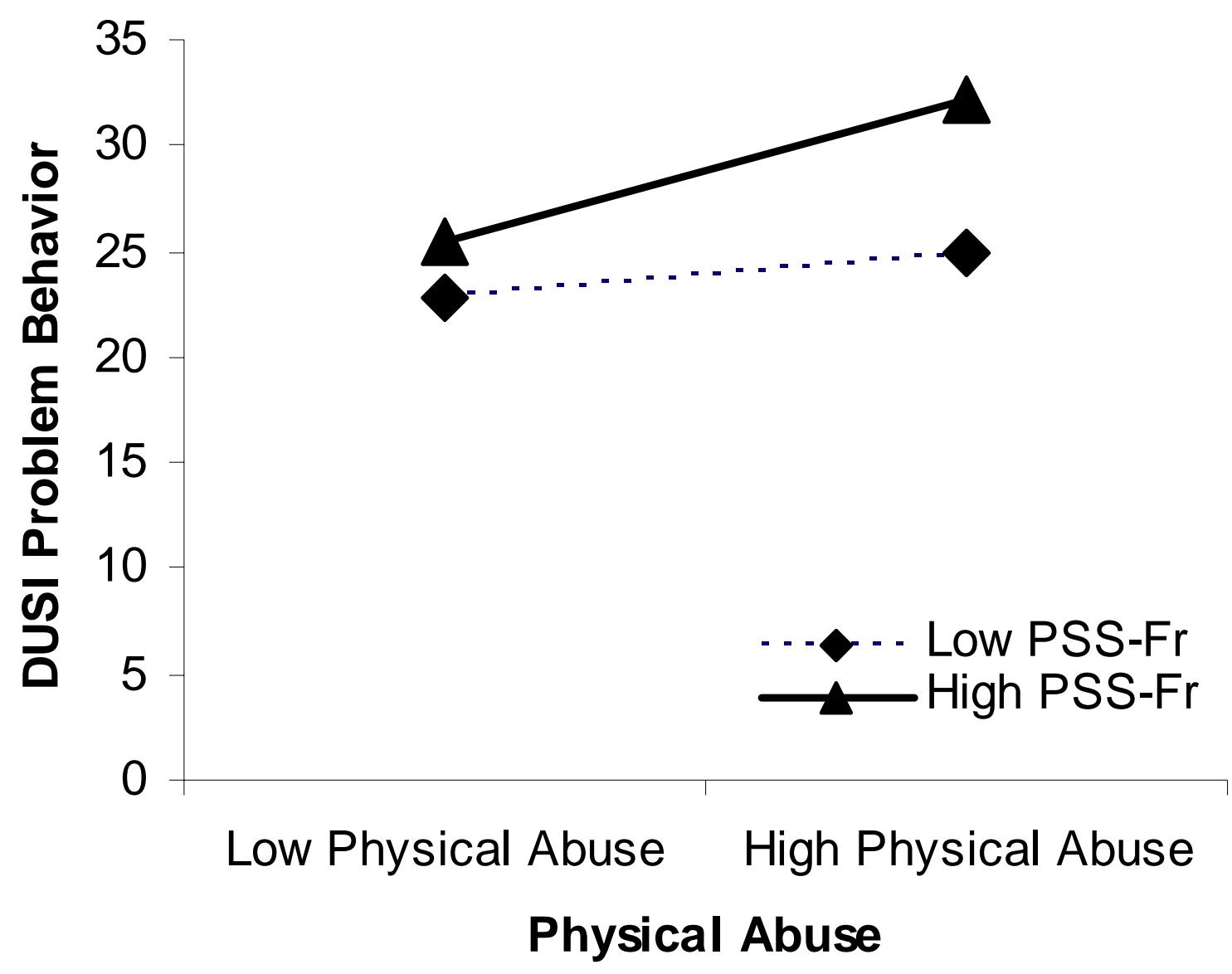


Figure 7. Association of physical abuse, locus of control, and problem behaviors.

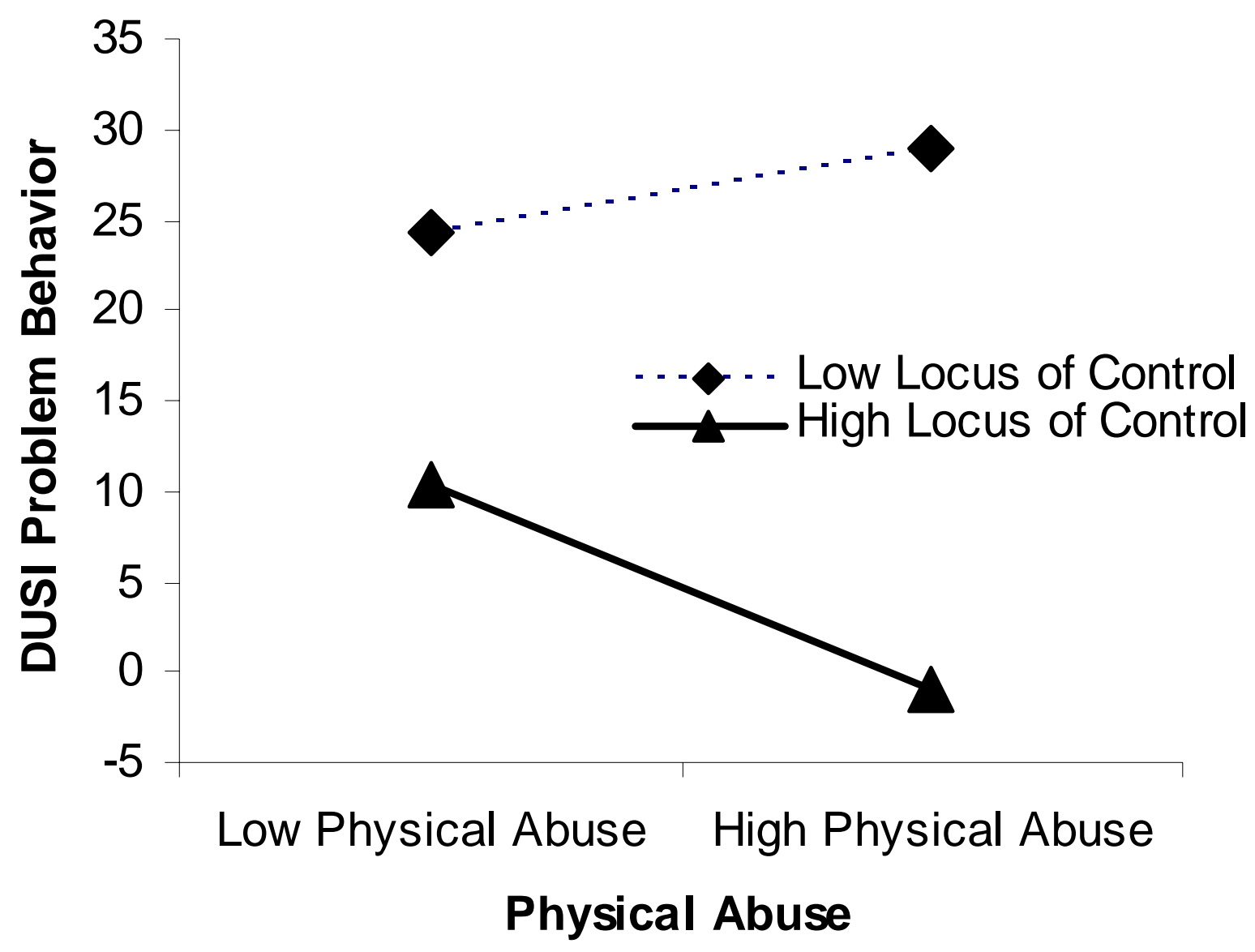


Figure 8. Association of physical abuse, preoccupation with relationships attachment style, and permissiveness.

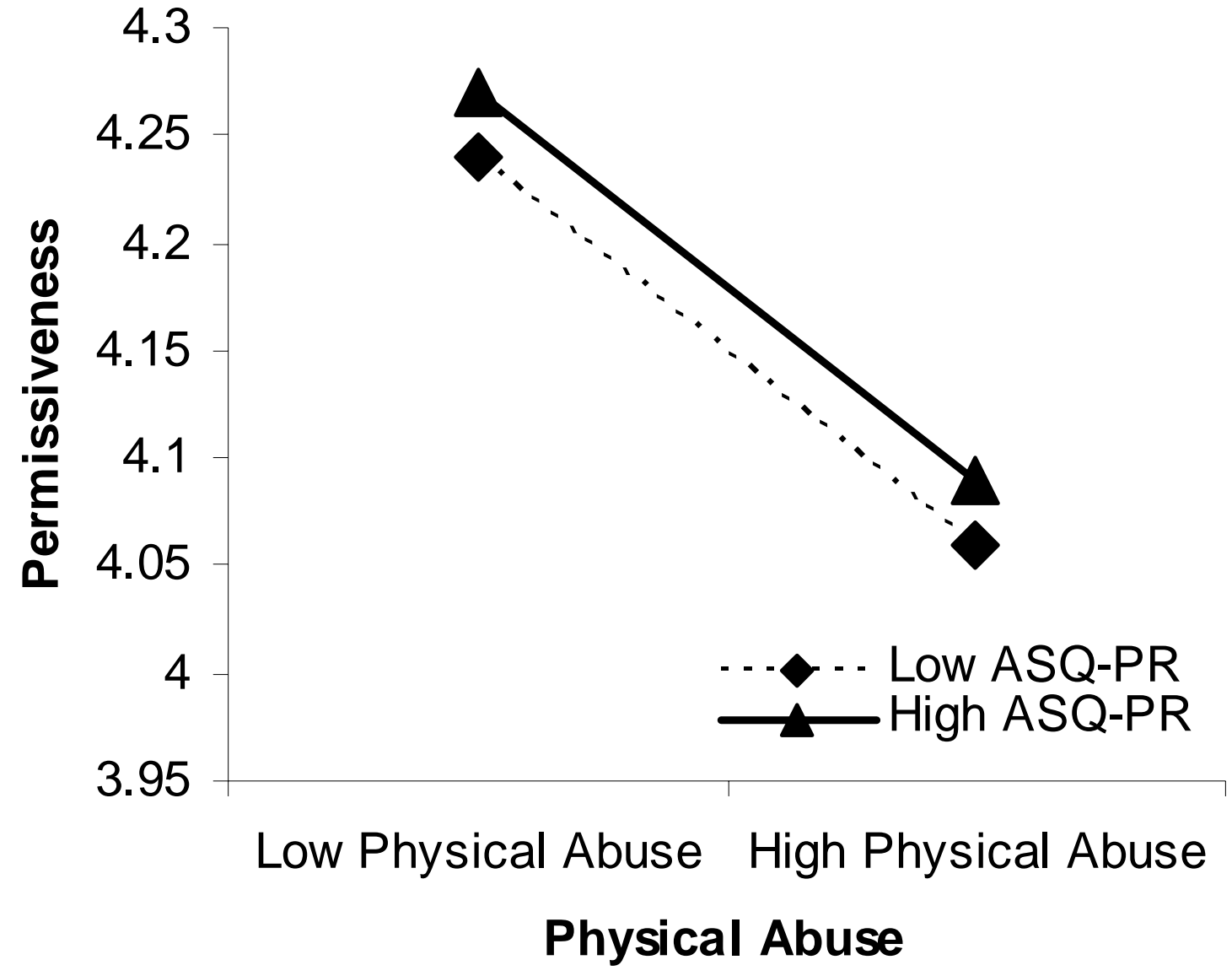


Figure 9. Association of physical abuse, need for approval attachment style, and depression.

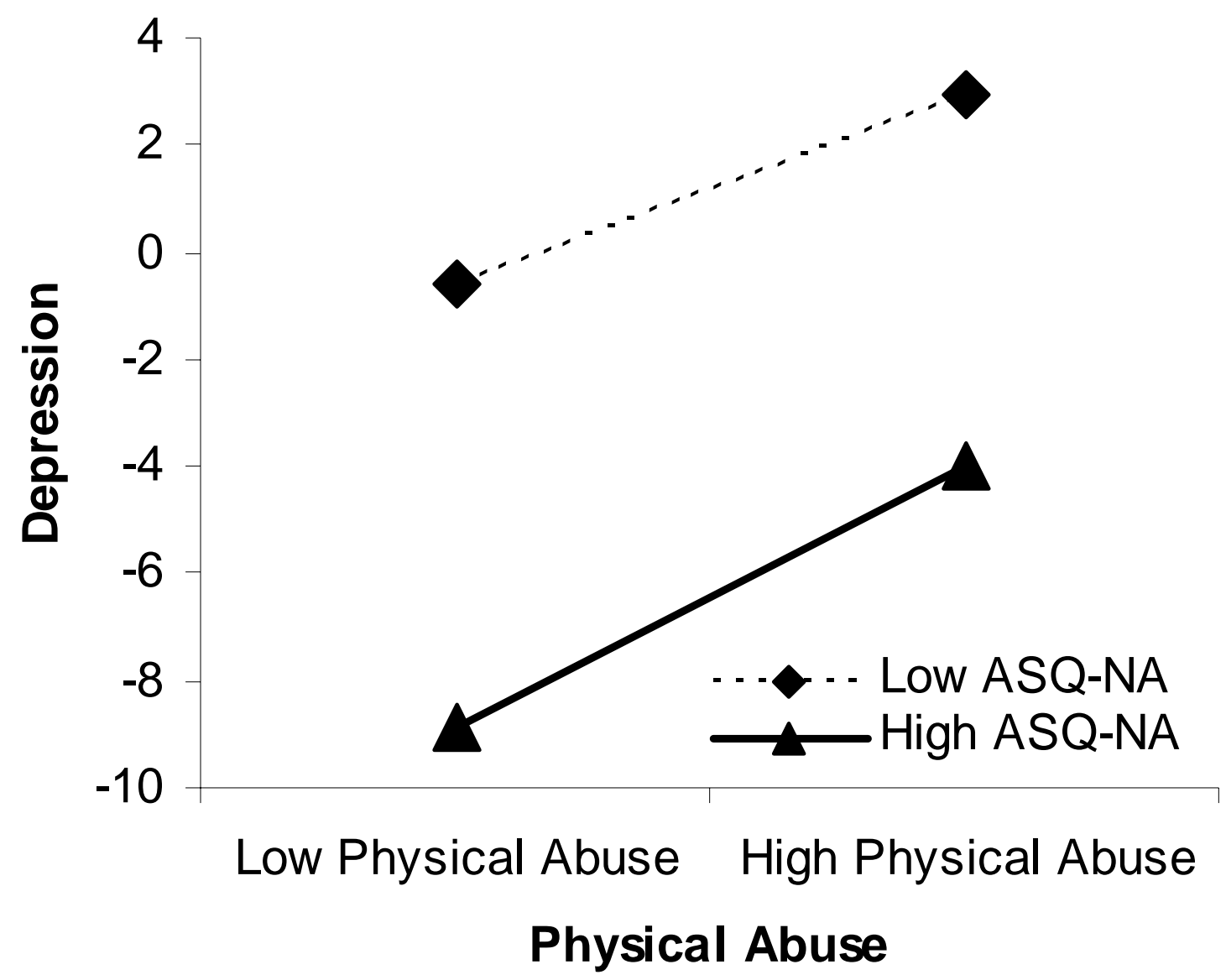


Figure 10. Association of physical abuse, discomfort with closeness attachment style, and depression.

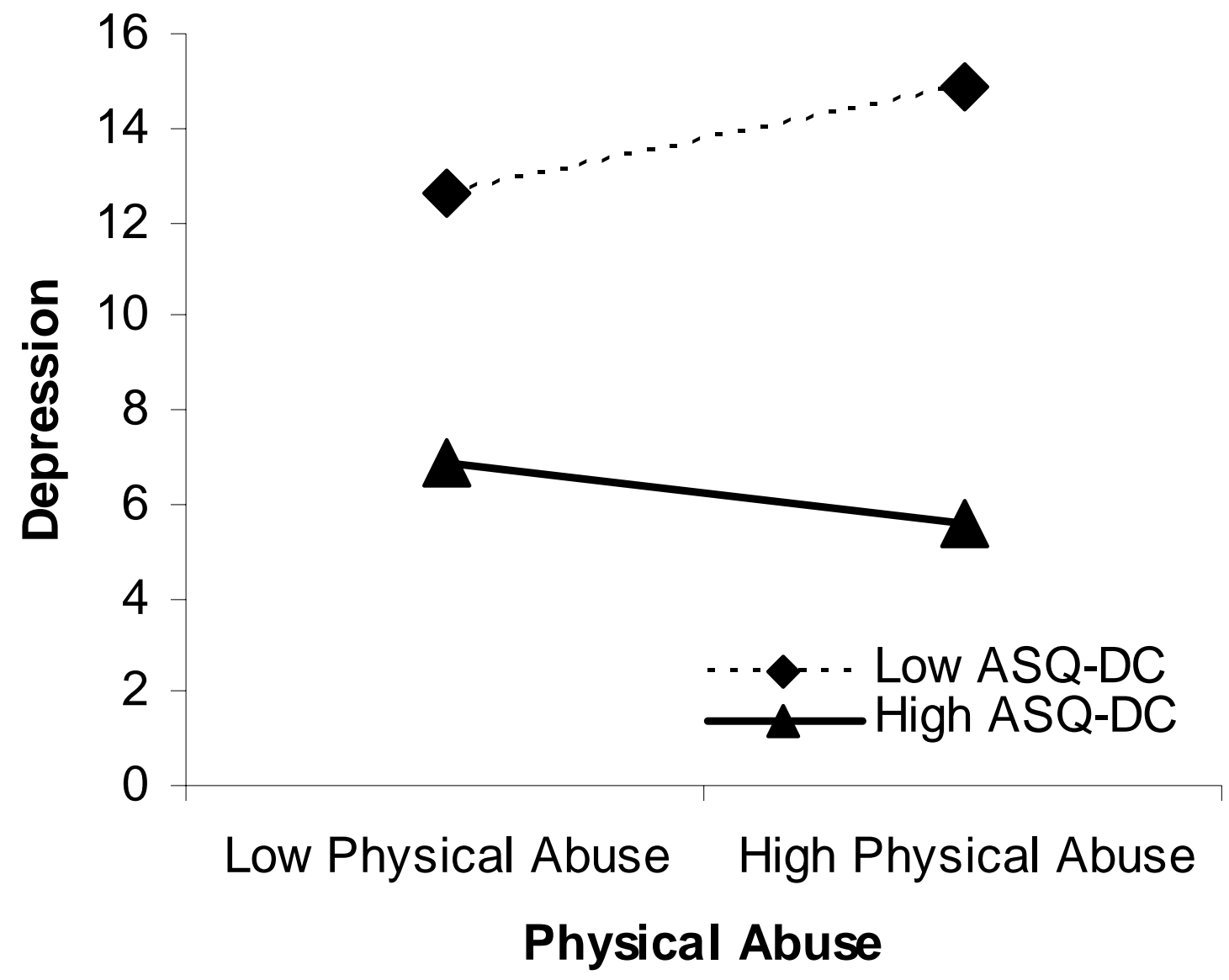


Figure 11. Association of physical abuse, social support from friends, and anxiety.

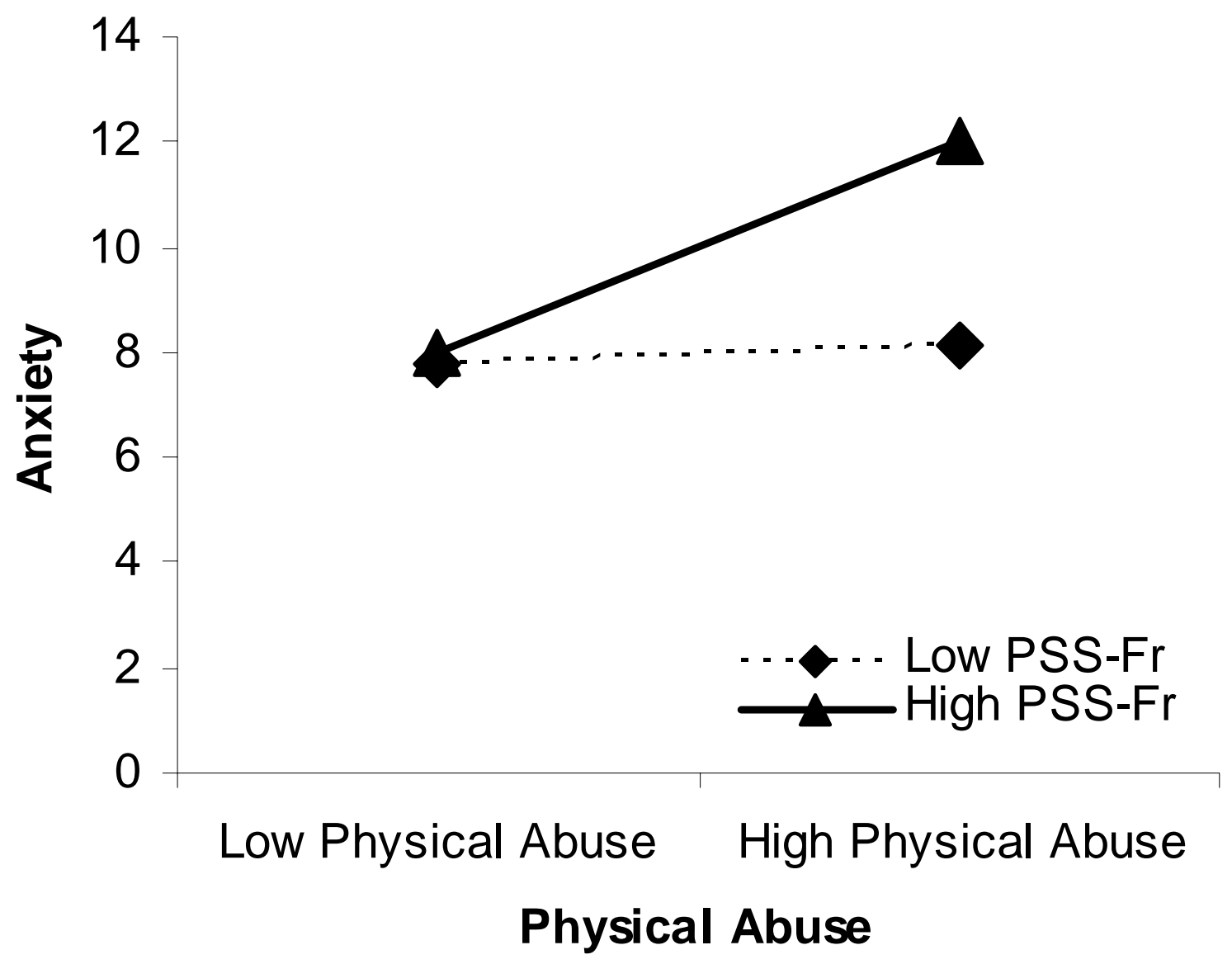


Figure 12. Association of physical abuse, need for approval attachment style, and anxiety.

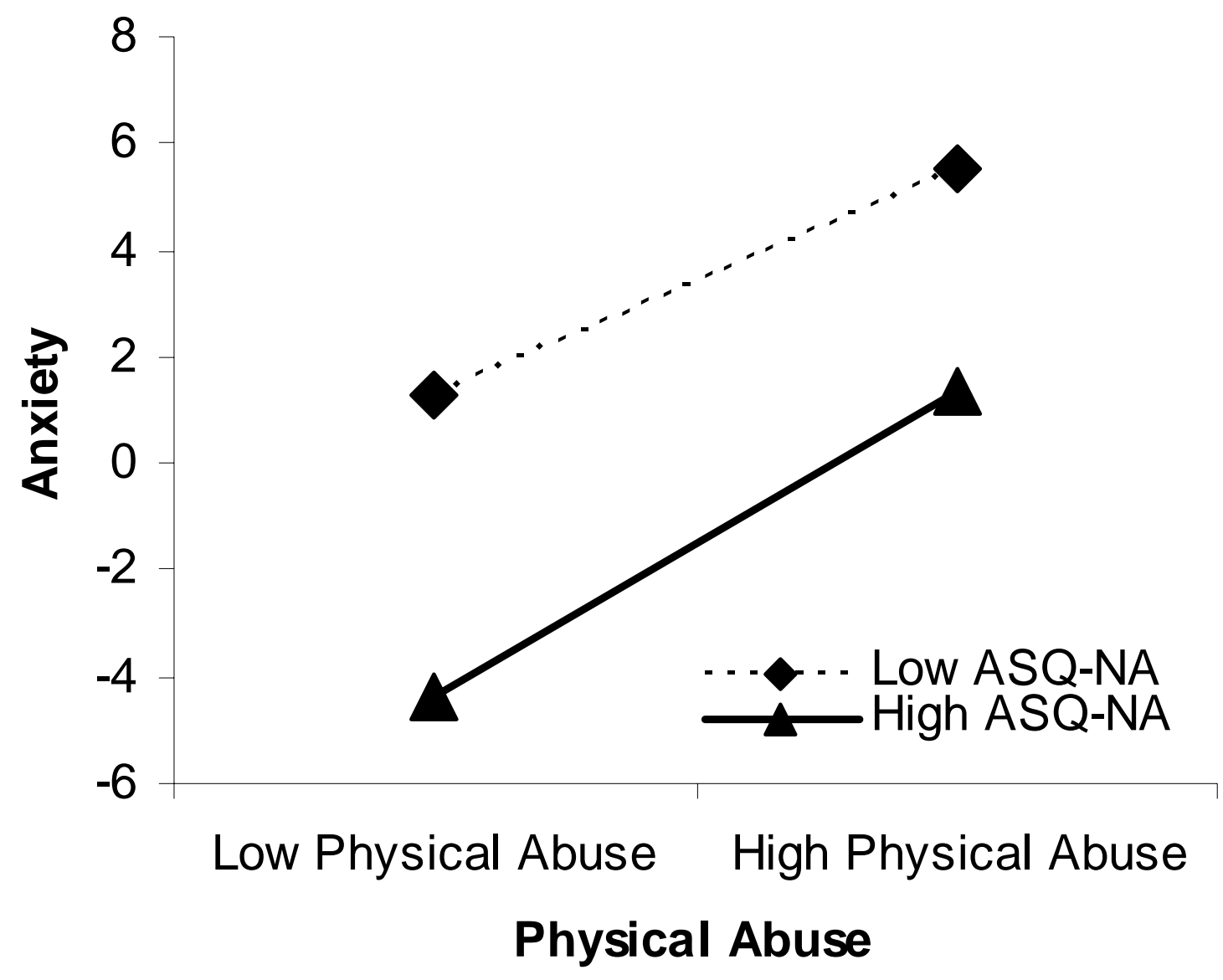


Figure 13. Association of physical abuse, relationships as secondary attachment style, and anxiety.

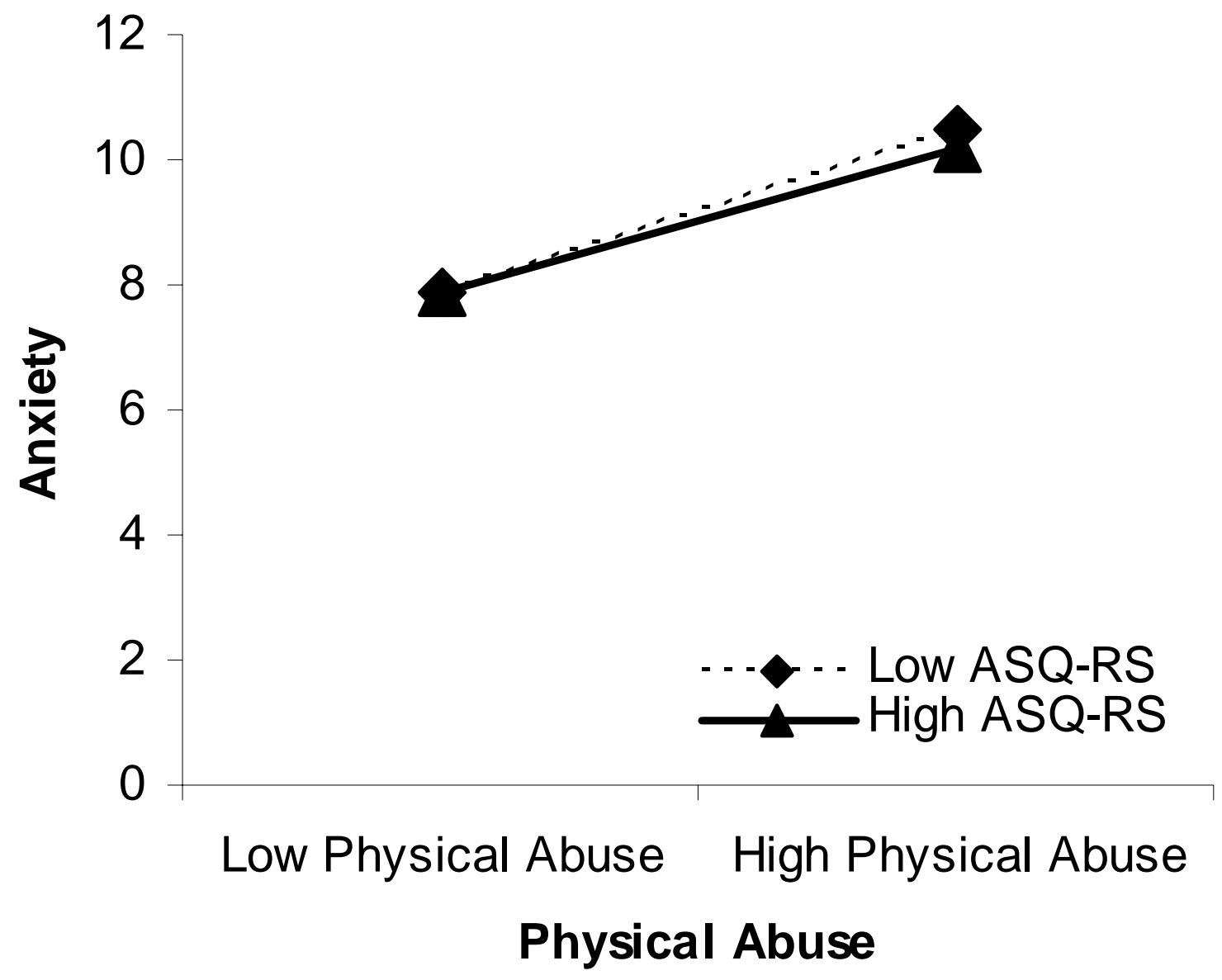


Figure 14. Association of sexual abuse, confidence attachment style, and permissiveness.

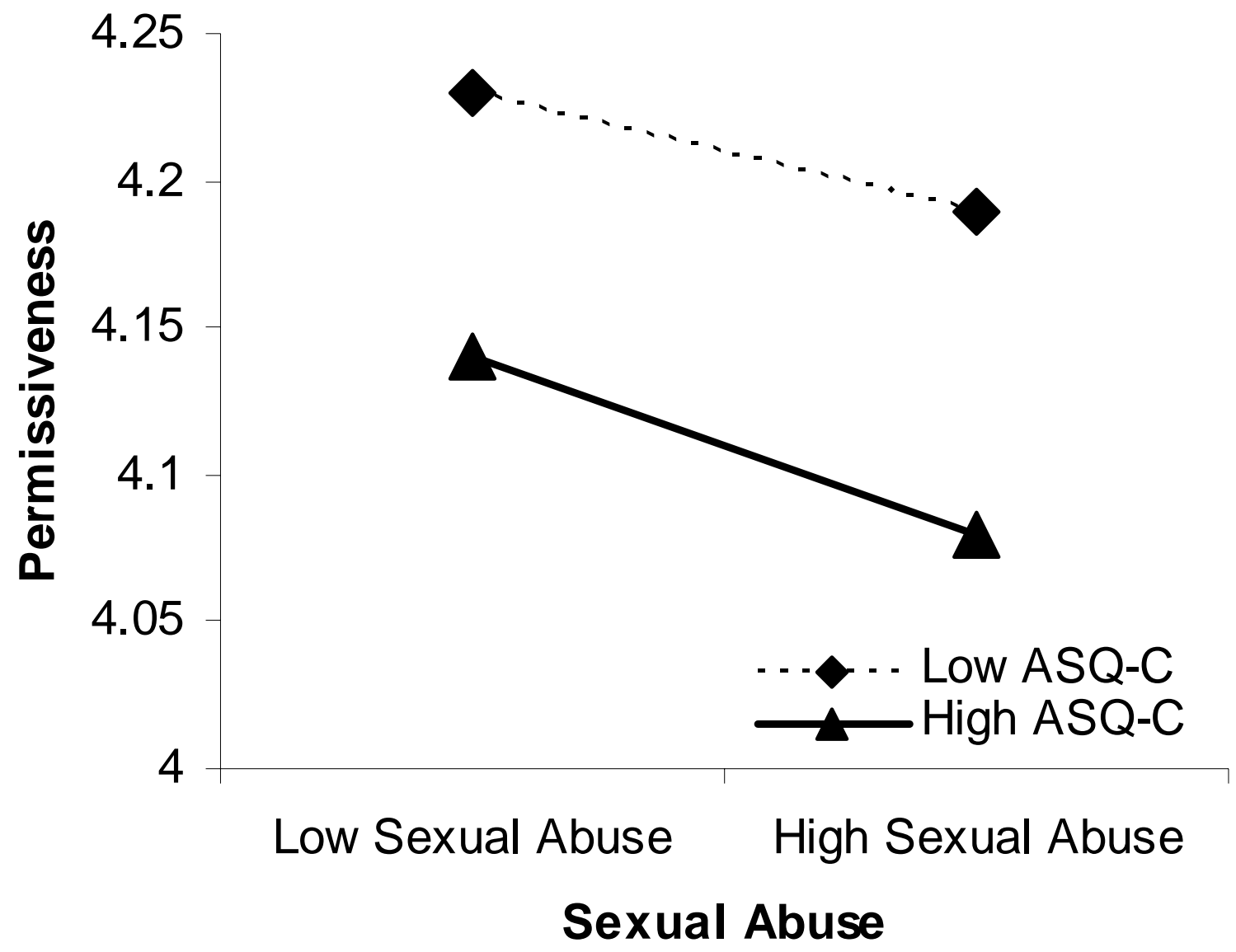


Figure 15. Association of sexual abuse, present social support, and social anxiety.

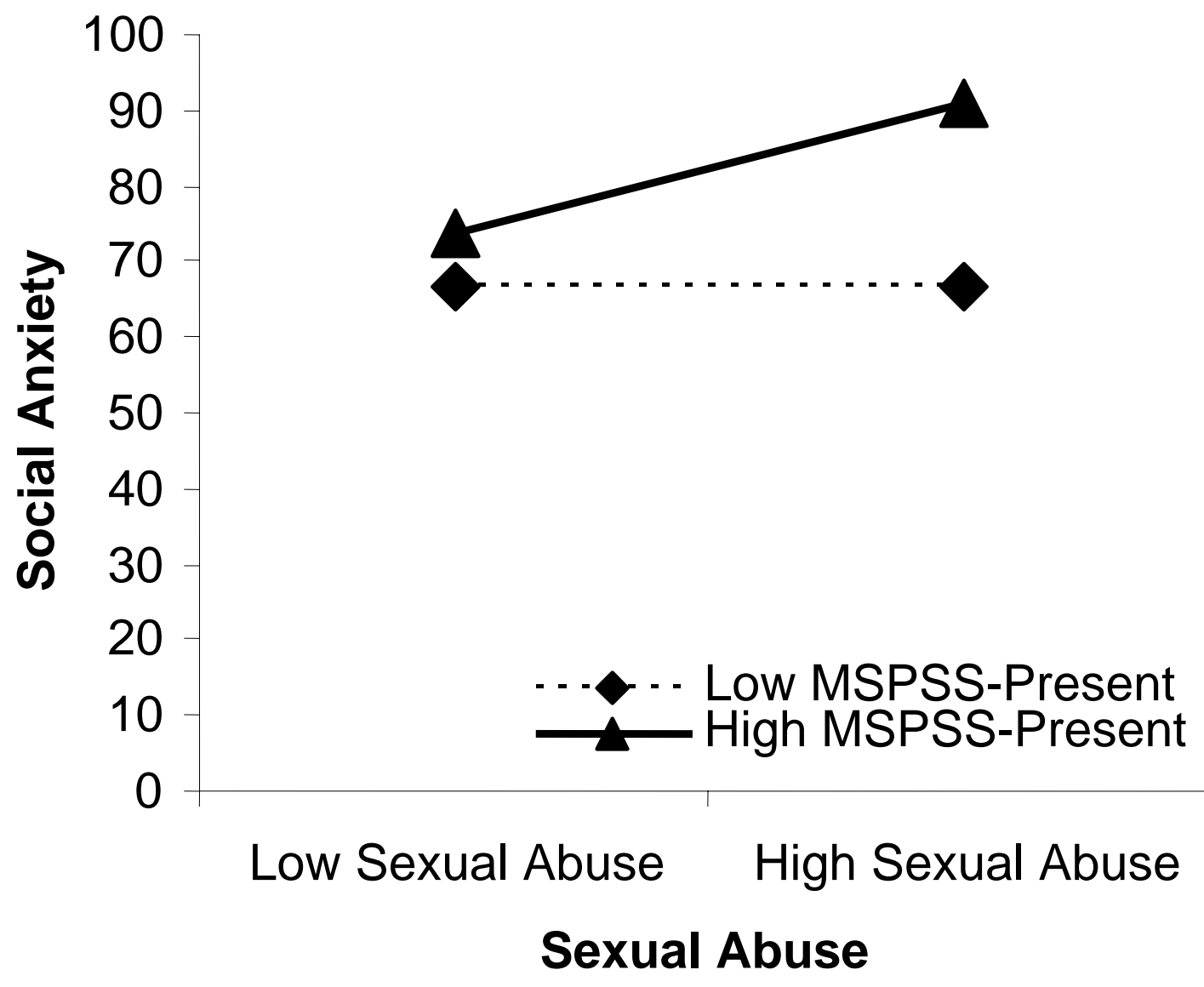


Figure 16. Association of sexual abuse, present social support, and agoraphobia.

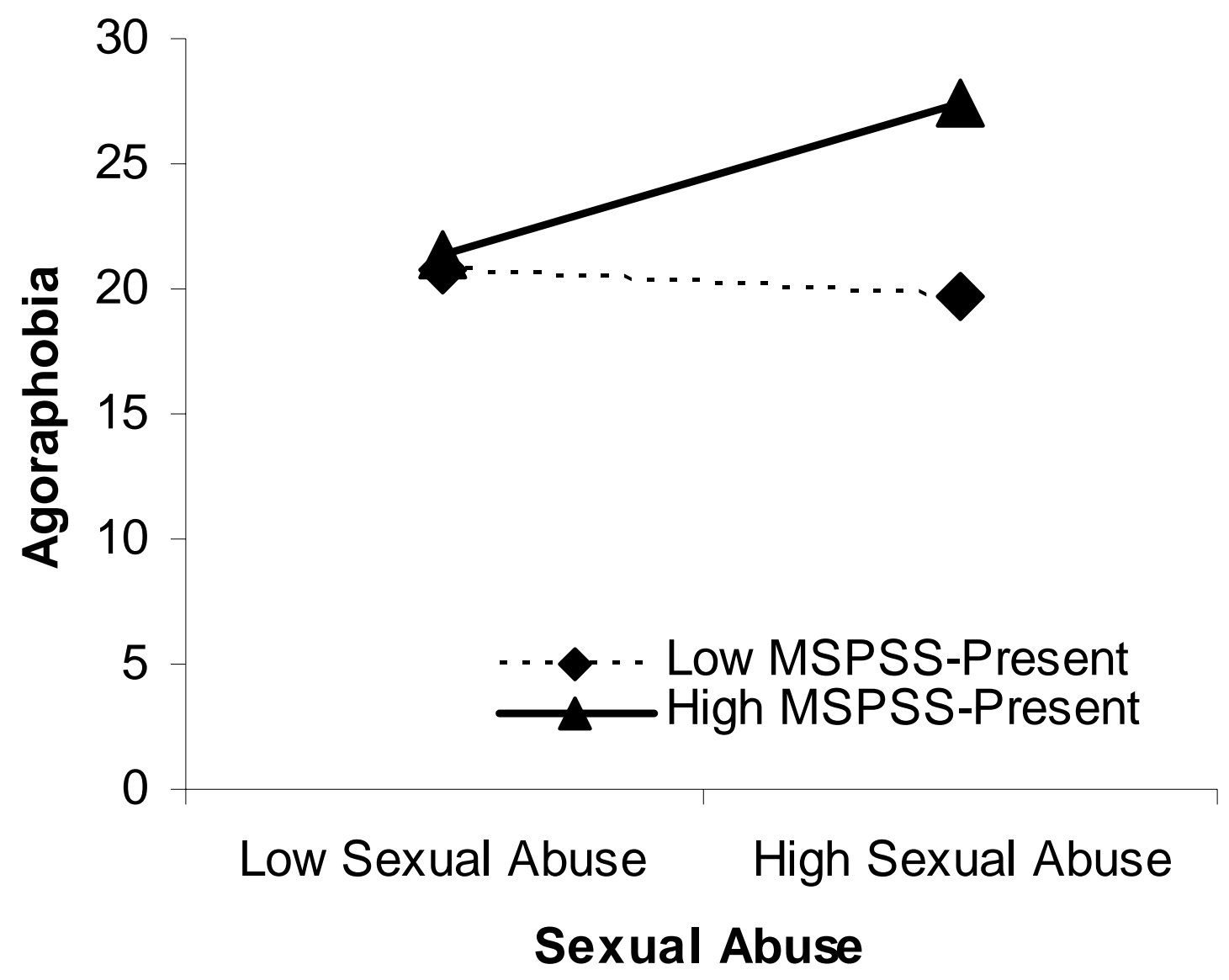


Figure 17. Association of emotional neglect, locus of control, and problem behaviors.

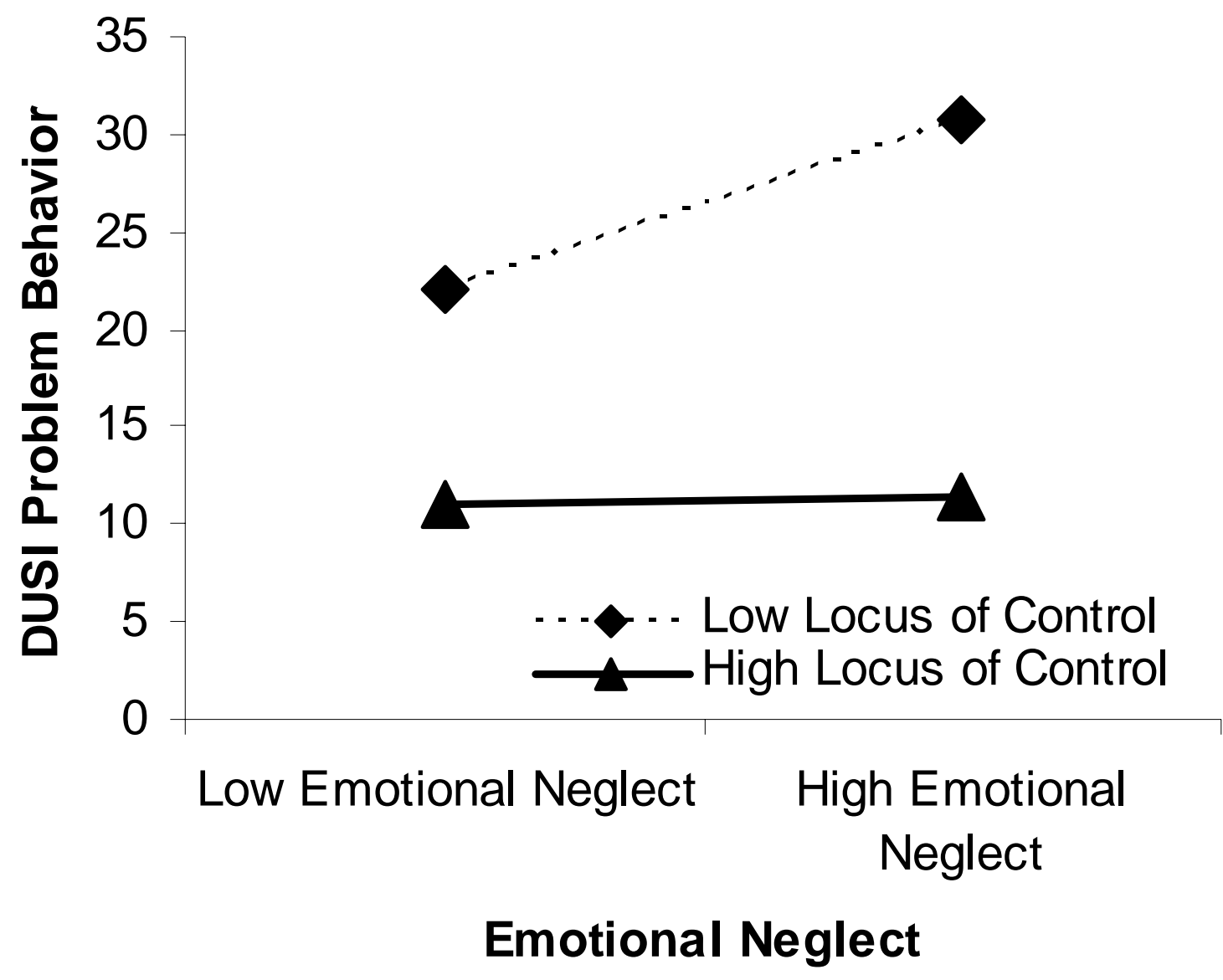


Figure 18. Association of emotional neglect, past social support, and permissiveness.

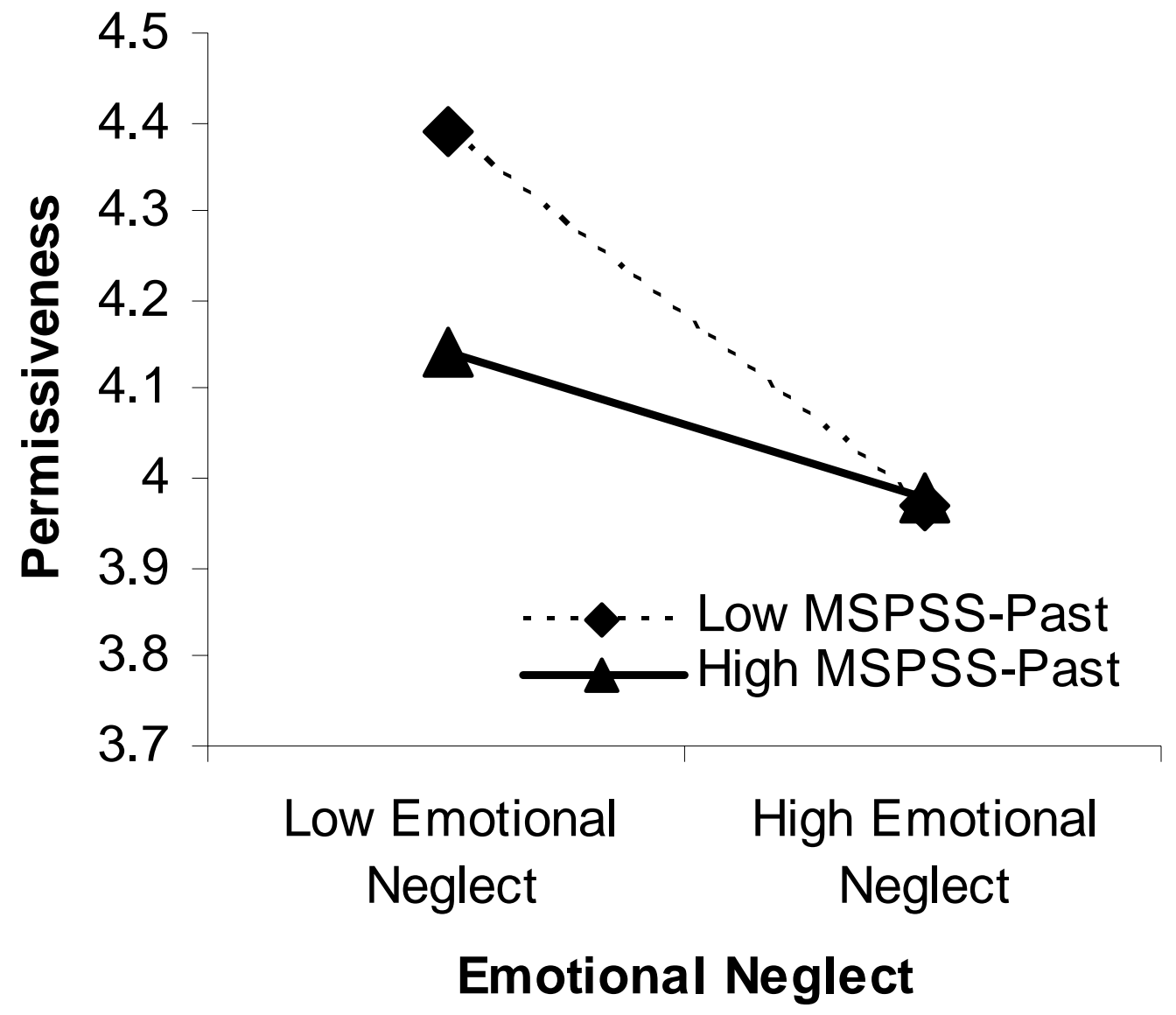


Figure 19. Association of emotional neglect, need for approval attachment style, and permissiveness.

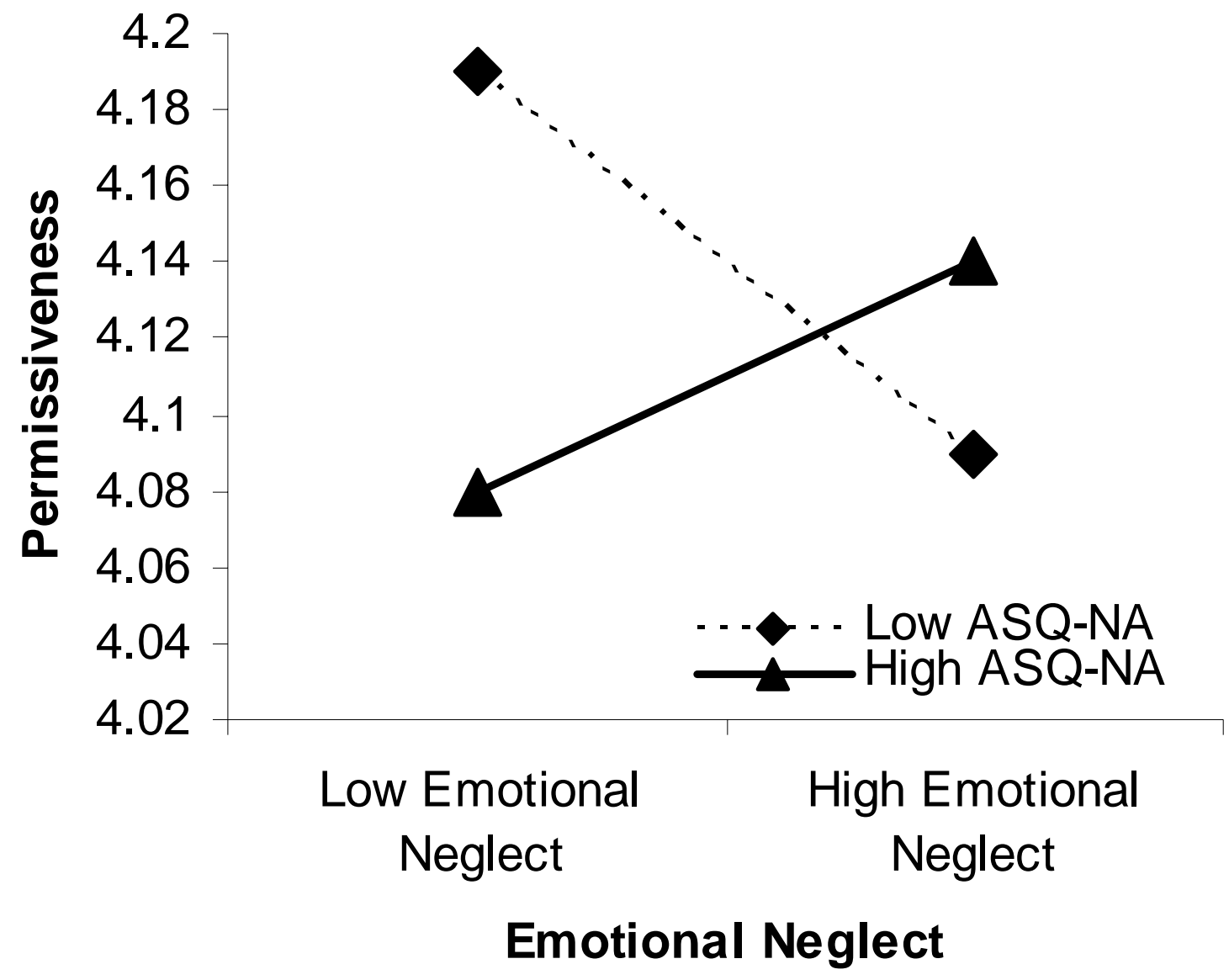


Figure 20. Association of emotional neglect, discomfort with closeness attachment style, and permissiveness.

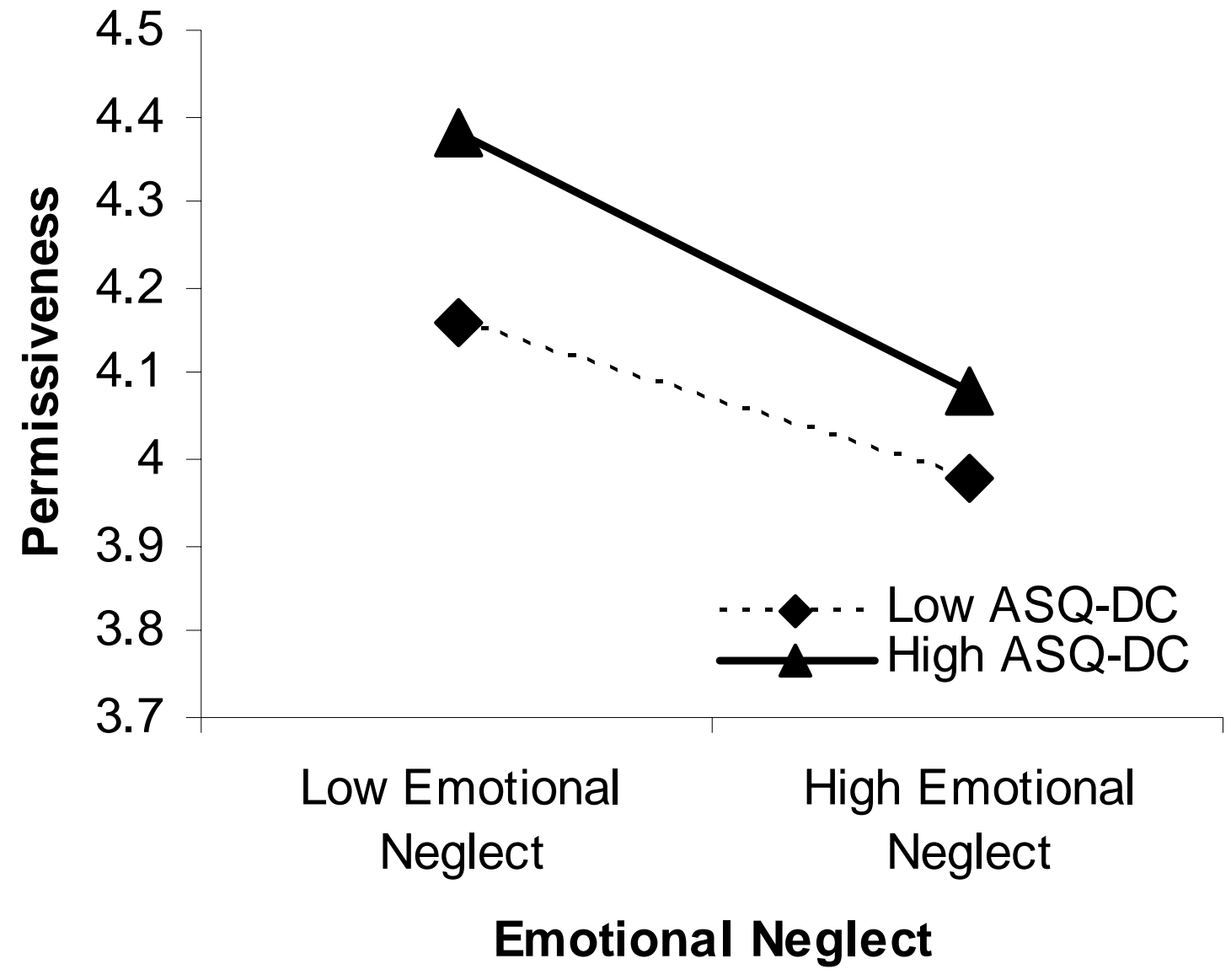


Figure 21. Association of emotional neglect, locus of control, and depression.

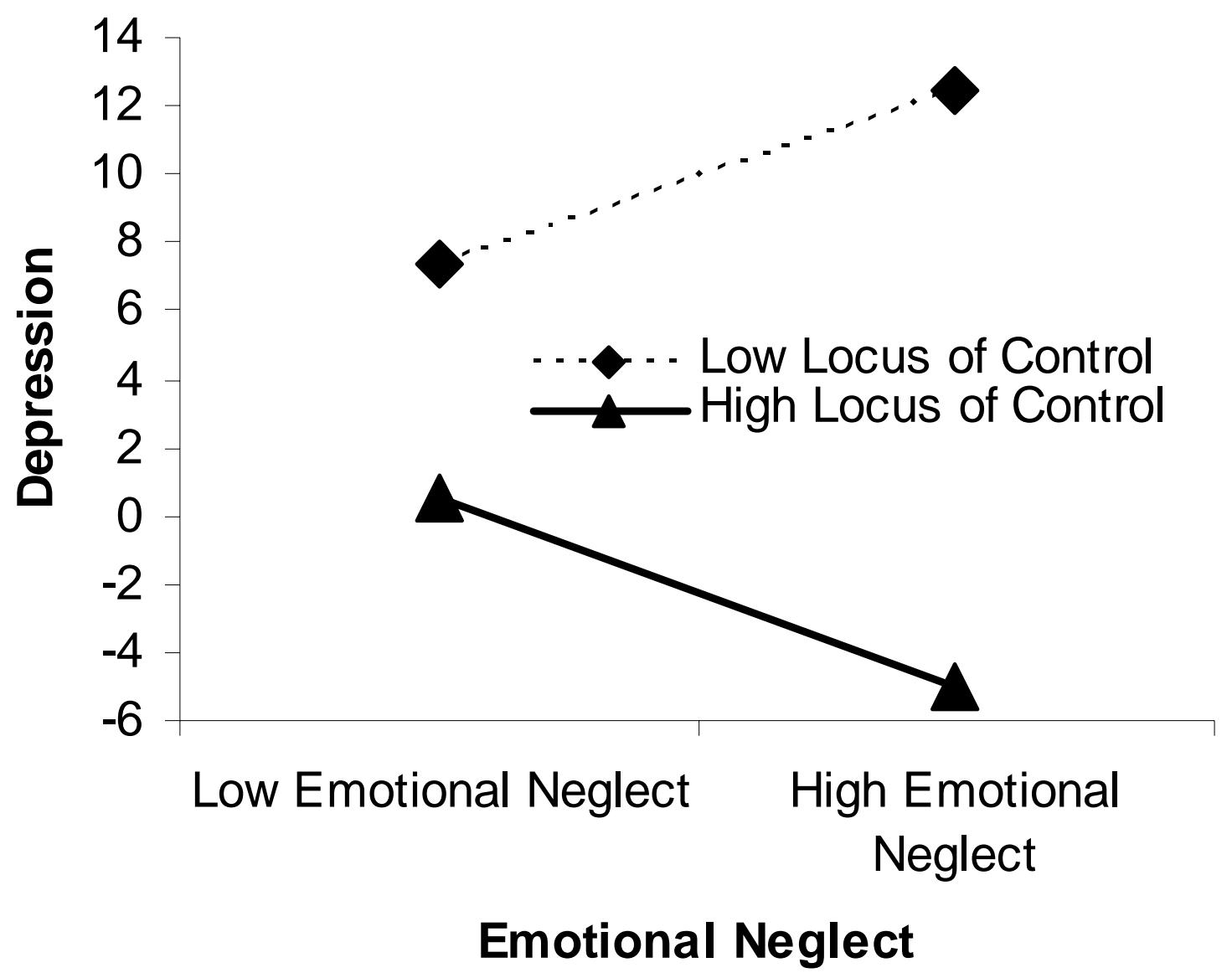


Figure 22. Association of emotional neglect, locus of control, and agoraphobia.

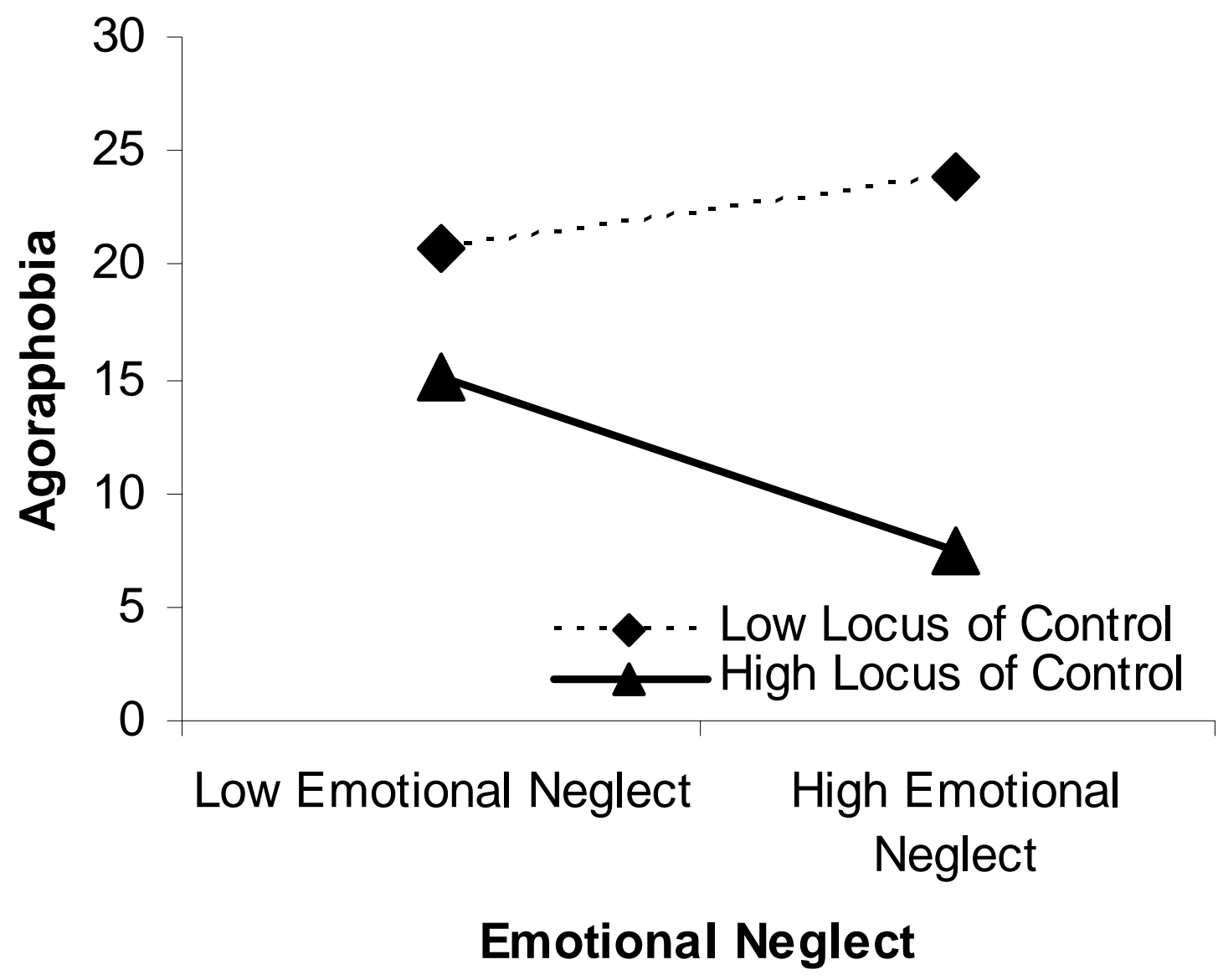


Figure 23. Association of physical neglect, past social support, and permissiveness.

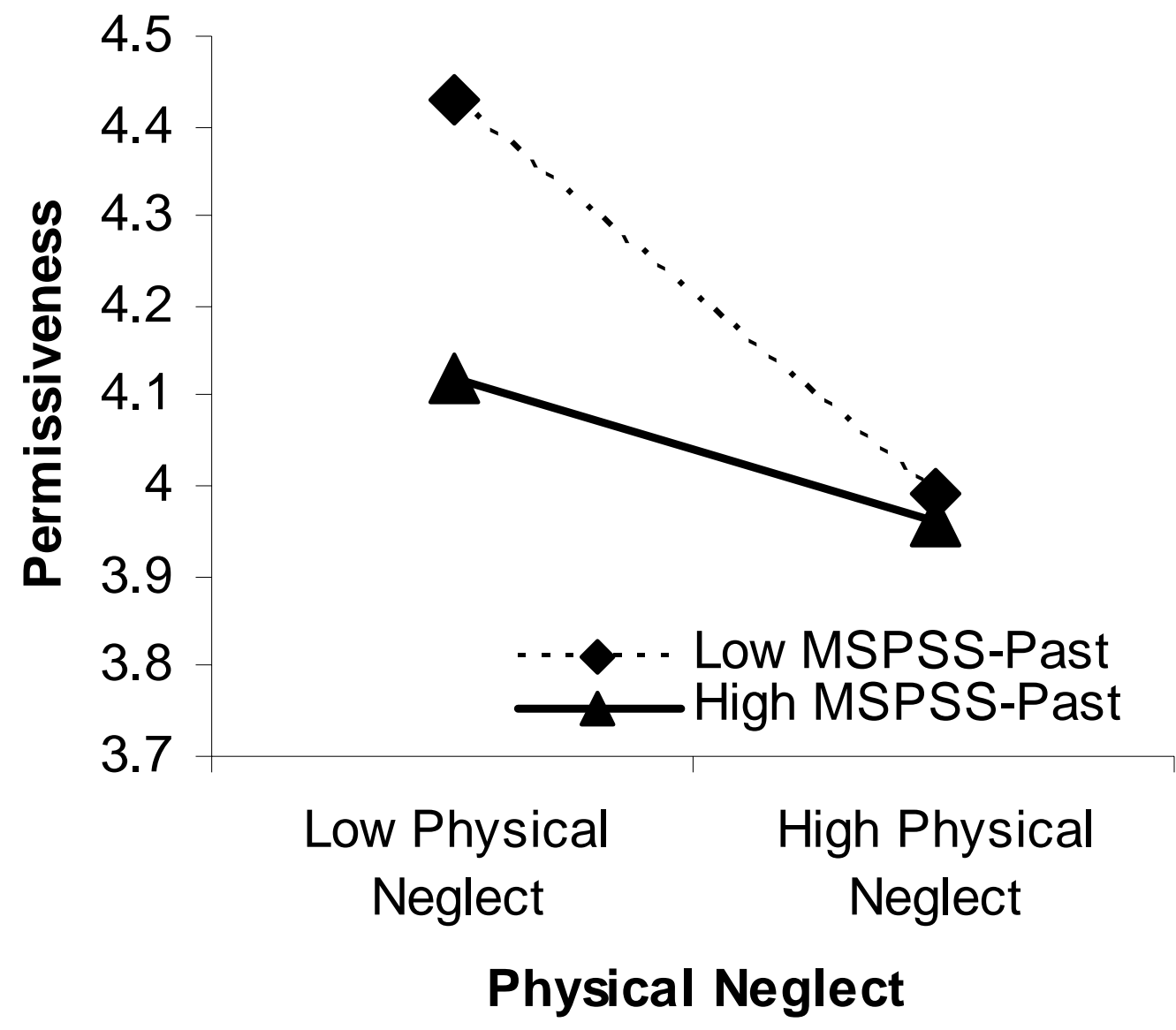


Figure 24. Association of physical neglect, need for approval attachment style, and permissiveness.

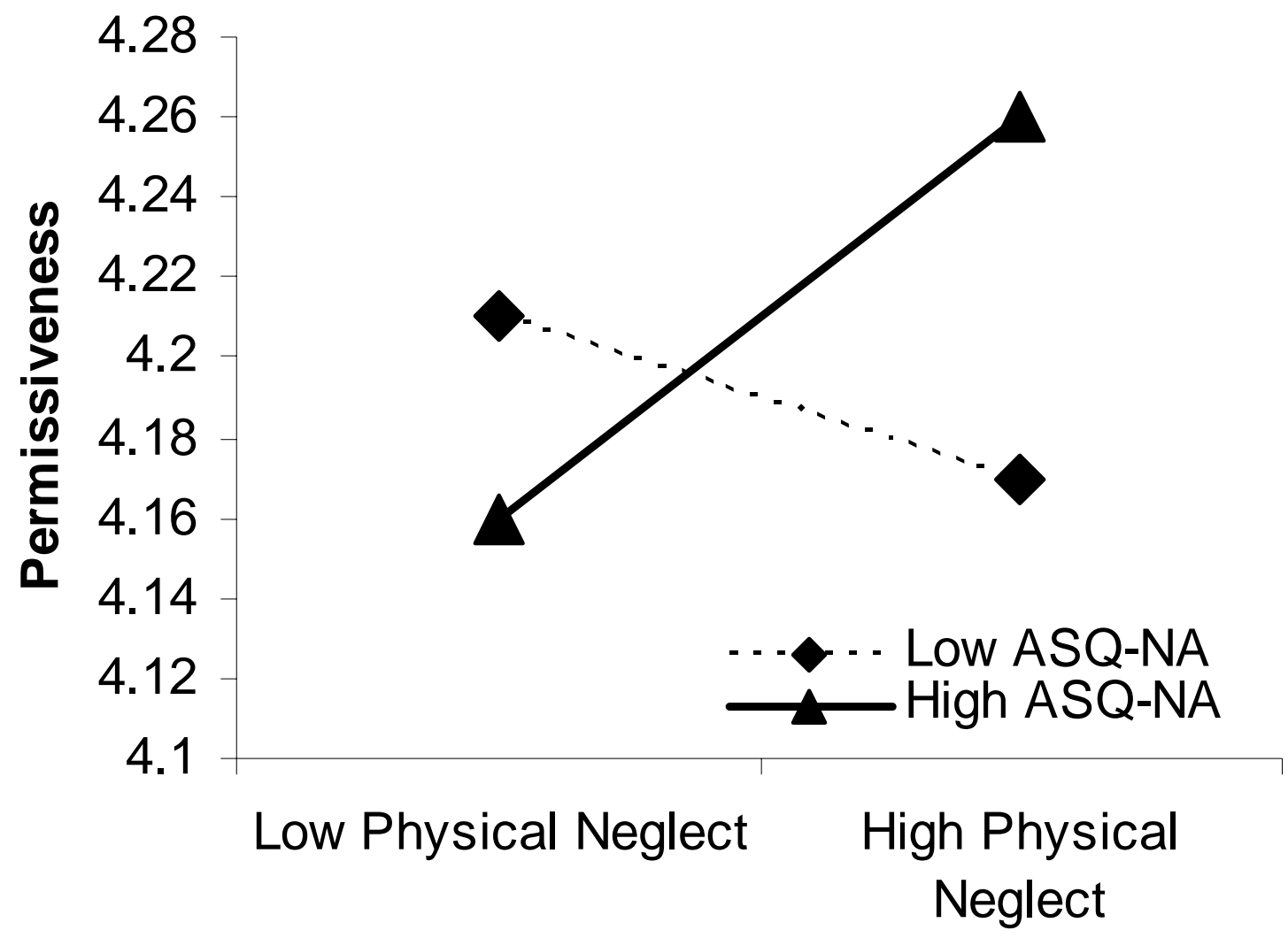

Physical Neglect 
Figure 25. Association of physical neglect, relationships as secondary attachment style, and permissiveness.

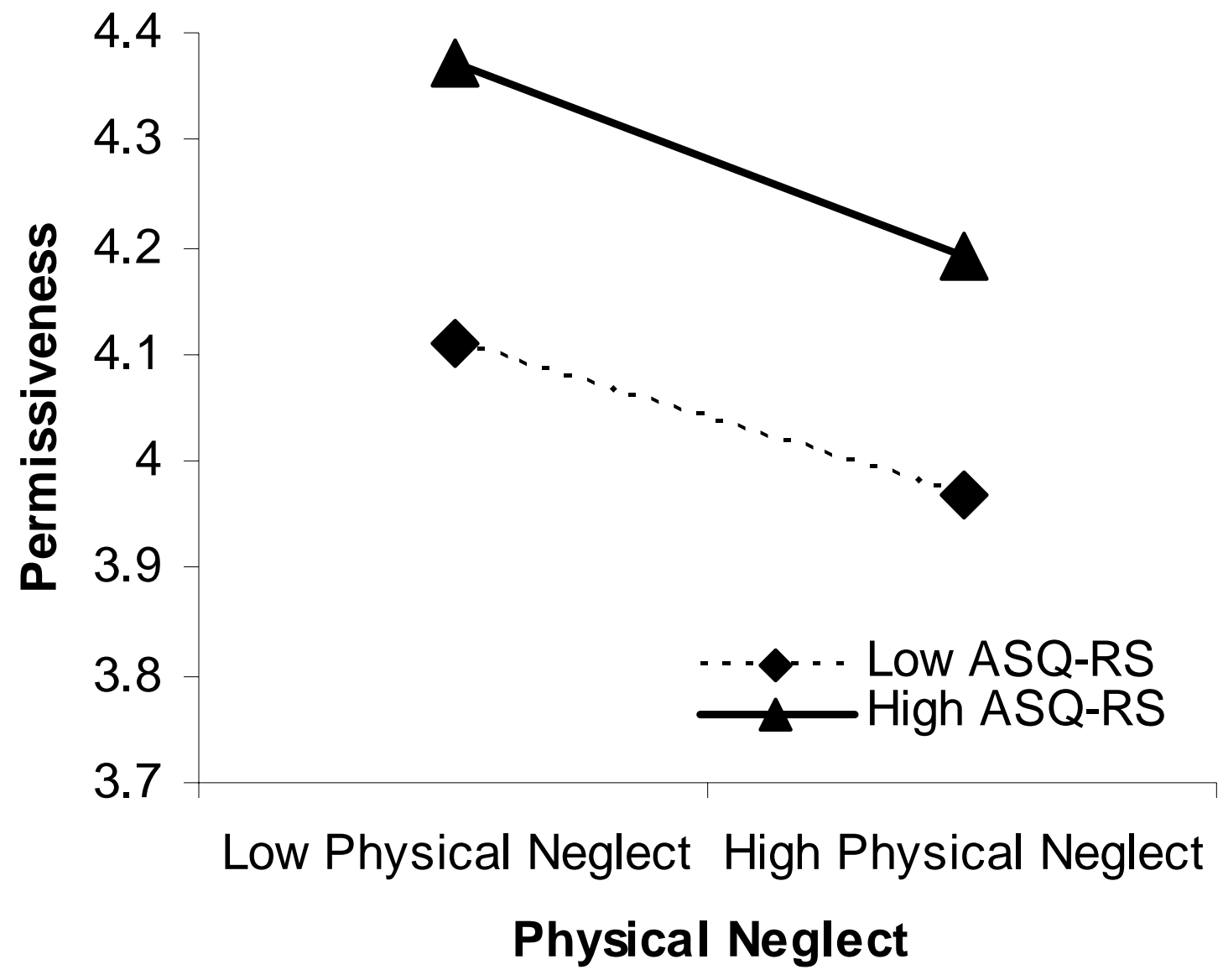


Figure 26. Association of physical neglect, discomfort with closeness attachment style, and permissiveness.

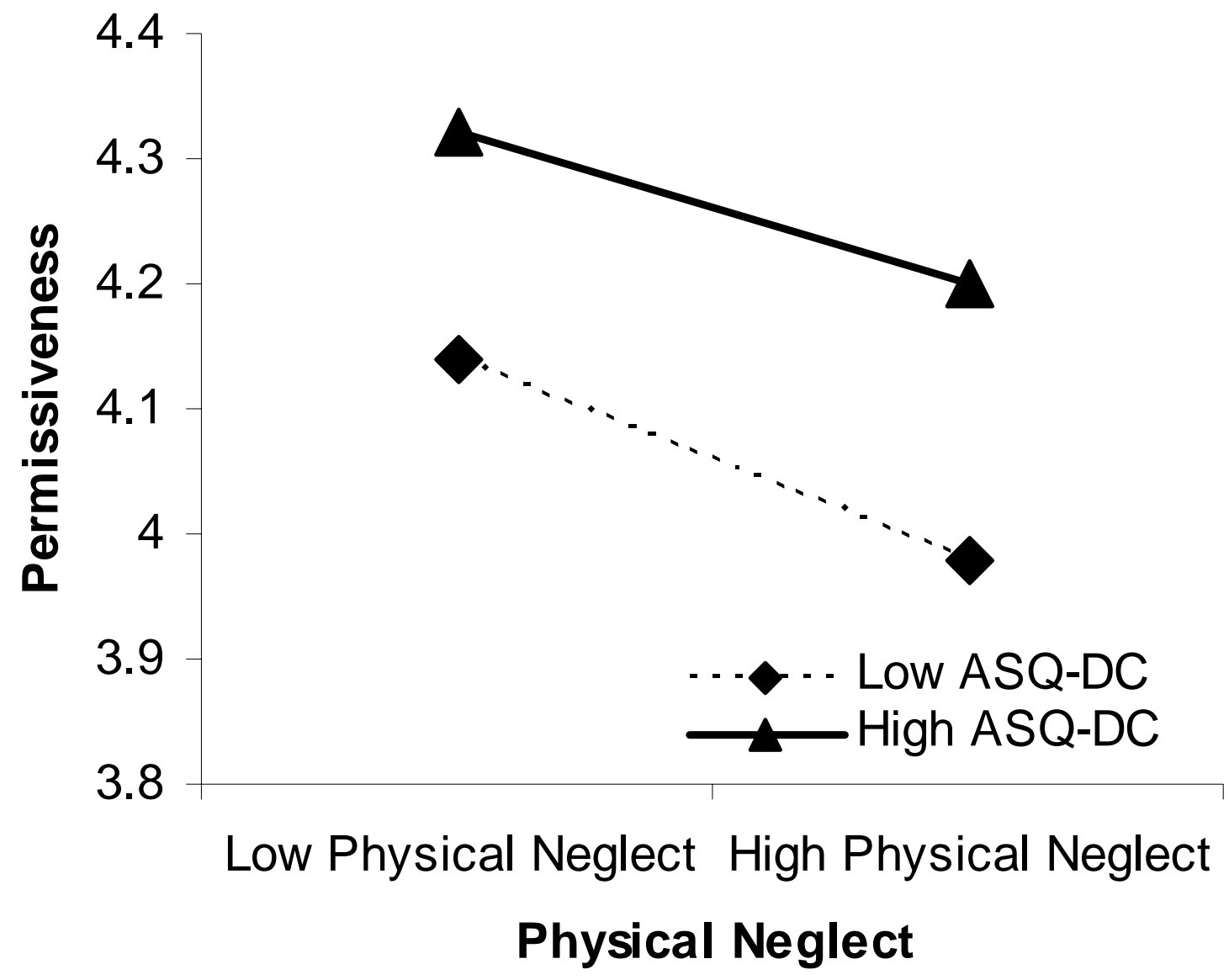


Figure 27. Association of physical neglect, relationships as secondary attachment style, and anxiety.

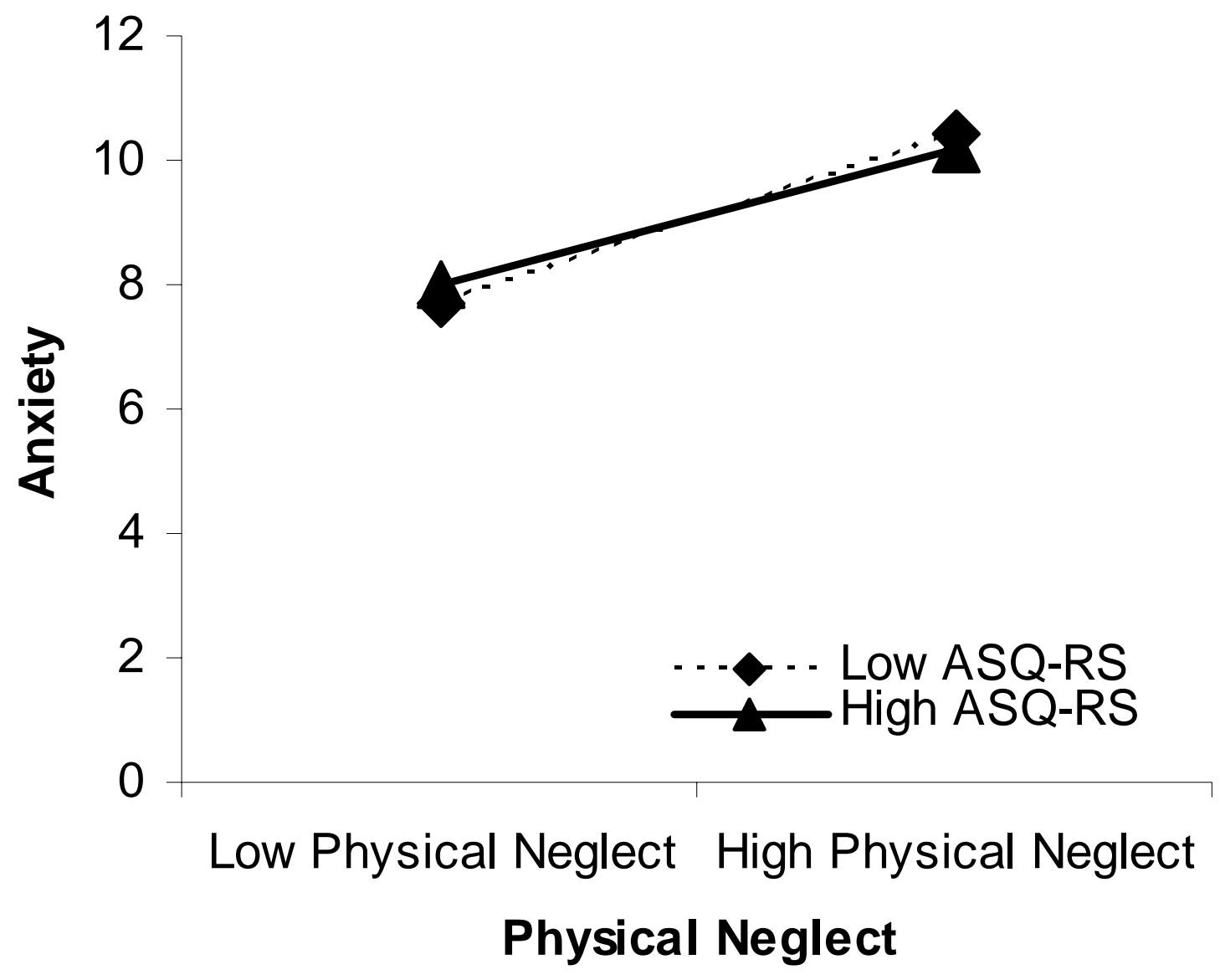


Figure 28. Association of physical neglect, present social support, and social anxiety.

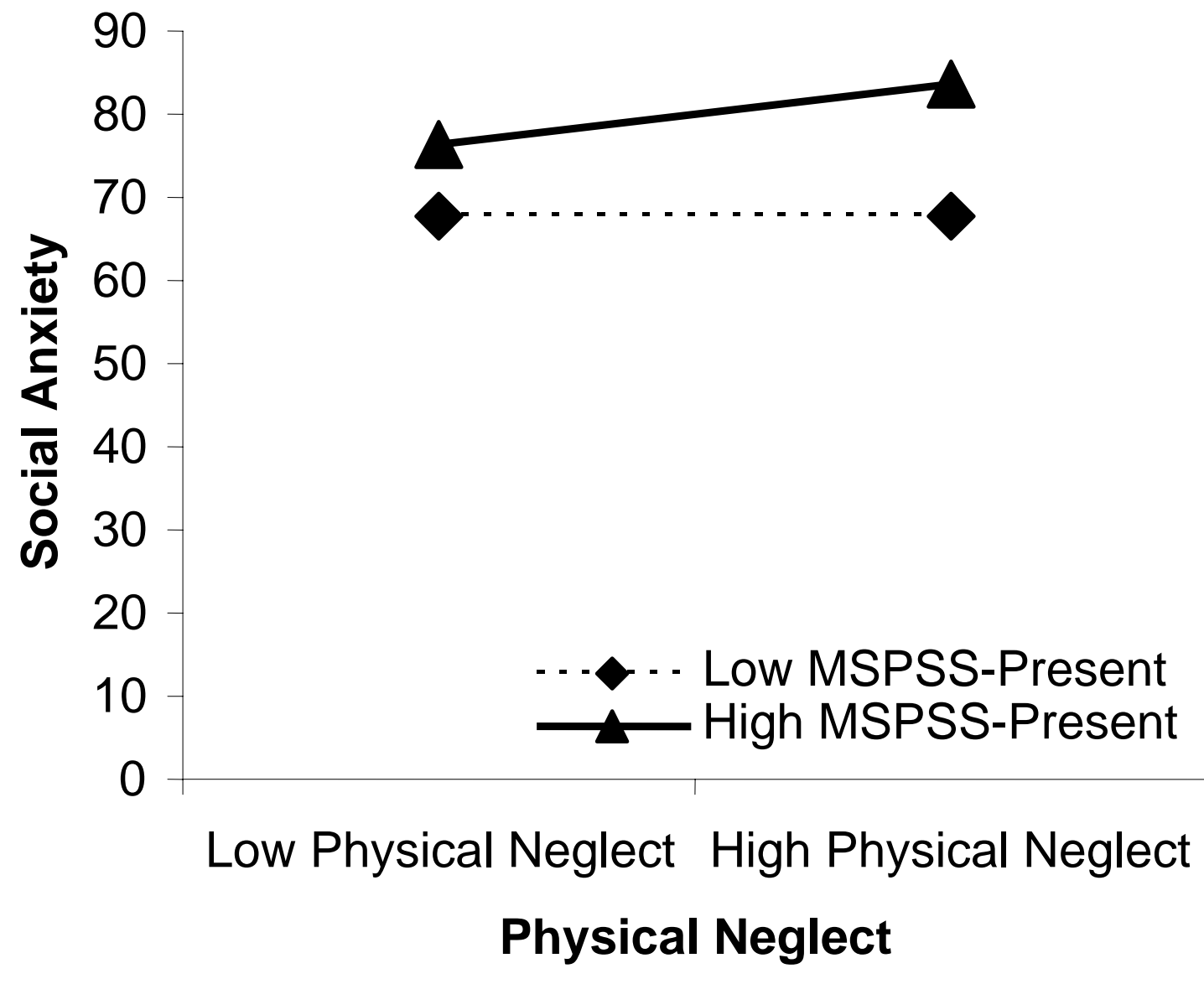


Figure 29. Association of physical neglect, social support from family, and agoraphobia.

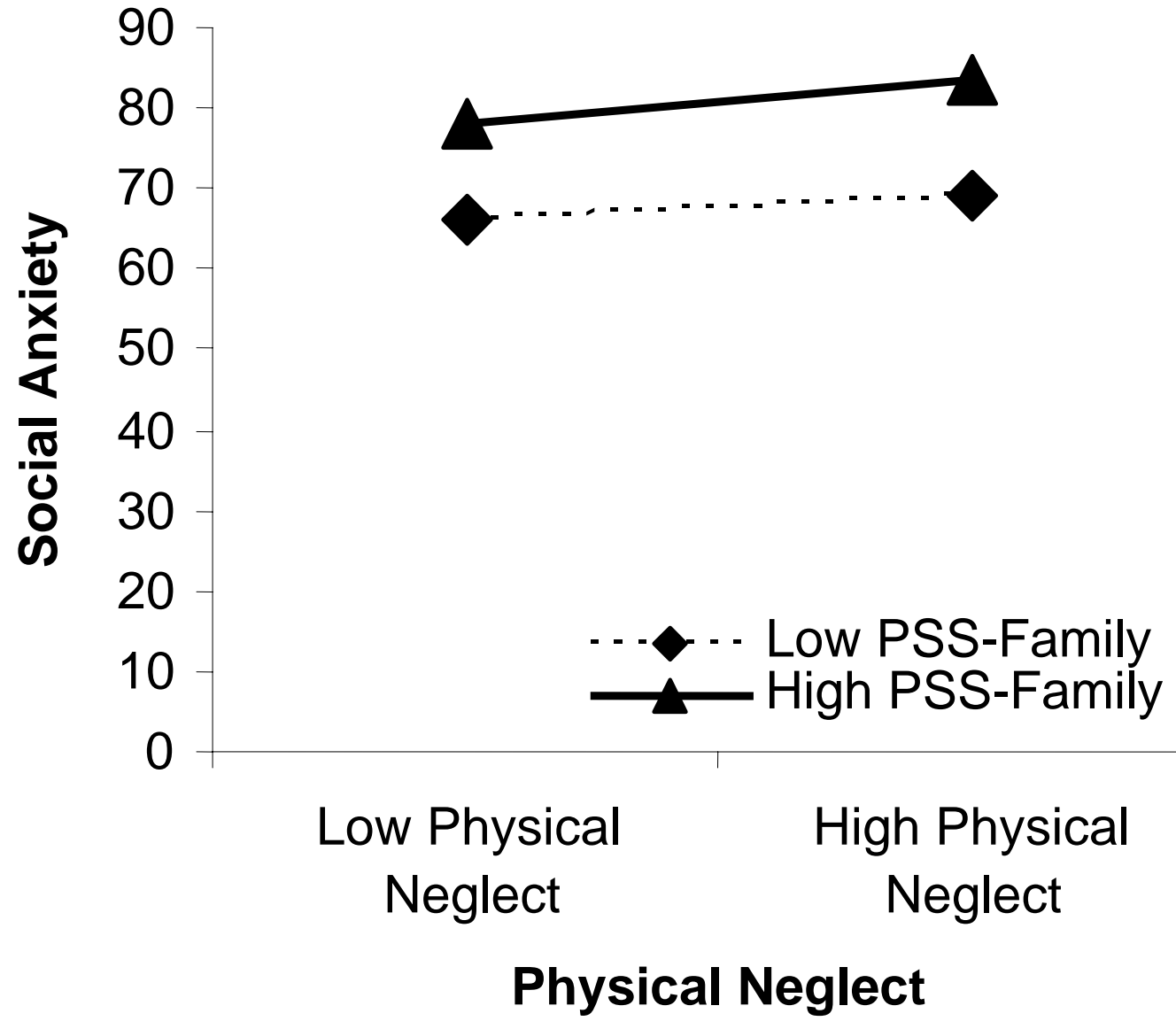

